Maria Margarida da Rocha Fiuza de Mello

Demografia de ârvores em Floresta Pluvial Tropical Atlântica, Ullha do Cardoso, SP, Brasil

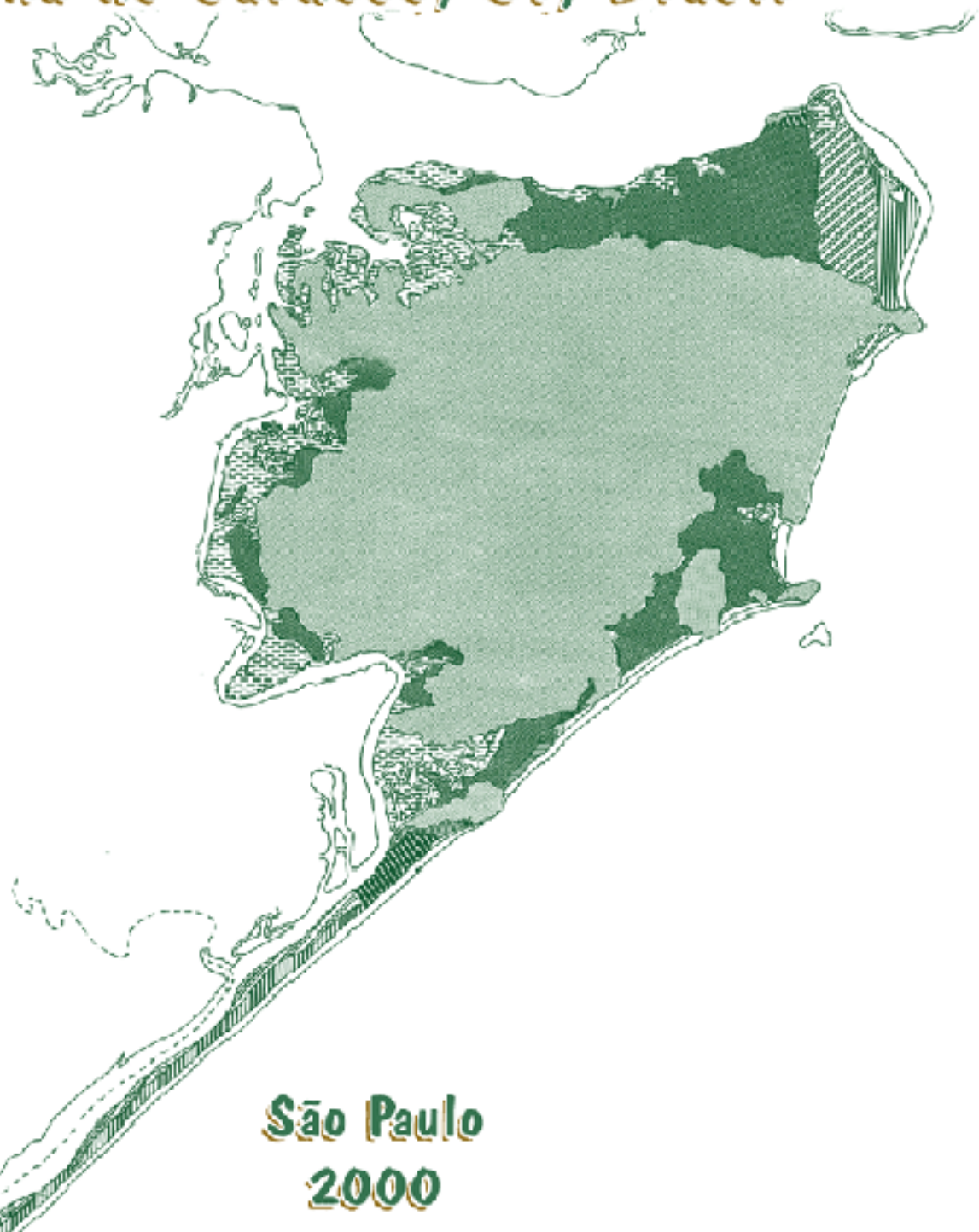


Maria Margarida da Rocha Fiuza de Melo

\section{DEMOGRAFIA DE ÁRVORES EM FLORESTA PLUVIAL TROPICAL ATLÂNTICA, ILHA DO CARDOSO, SP, BRASIL}

Tese apresentada ao Instituto de Biociências da Universidade de São Paulo, para a obtenção de Título de Doutor em Ciências, na Área de Ecologia.

Orientador: Prof. Dr. Waldir Mantovani

São Paulo

2000 
Melo, Maria Margarida da Rocha Fiuza de

Demografia de árvores em Floresta Pluvial Tropical Atlântica, Ilha do Cardoso, SP, Brasil / Maria Margarida da Rocha Fiuza de Melo. São Paulo, SP: [s.n.], 2000. 155p.:ilus.

Orientador: Waldir Mantovani

Tese (doutorado) - Universidade de São Paulo, Instituto de Biociências.

1. Demografia de árvores 2. Estrutura 3. Floresta Pluvial Tropical Atlântica 4. Mata Atlântica I. Universidade de São Paulo. Instituto de Biociências. Departamento de Ecologia Geral.

\section{Comissão Julgadora:}

$\operatorname{Prof}(a) . \operatorname{Dr}(a)$.

$\operatorname{Prof}(\mathrm{a}) . \operatorname{Dr}(\mathrm{a})$.

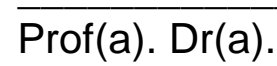

$\operatorname{Prof(a).} \operatorname{Dr}(\mathrm{a})$.

Prof. Dr. Waldir Mantovani

Orientador 


\section{Agradecimentos}

Ao Instituto de Botânica, nas pessoas da equipe diretiva, pelo apoio e incentivo dado à minha formação acadêmica; dos funcionários de apoio à pesquisa, em especial, do SCTC biblioteca, setor da gráfica, da xerox, da biblioteca, da administração, dos motoristas.

A todos os funcionários do Parque Estadual da llha do Cardoso, pela ajuda amiga e atenciosa, durante o ano de 1995, período dos trabalhos de campo do segundo levantamento.

Ao Departamento de Ecologia Geral da Universidade de São Paulo, nas pessoas dos professores e funcionários de apoio, pela recepção e oportunidade de aperfeiçoamento profissional.

Ao Waldir Mantovani, amigo, orientador e responsável por minha pós-graduação, no mestrado e agora no doutorado, sempre paciente e disposto a dar as melhores sugestões, em todas as etapas. Por acreditar e me fazer acreditar que chegar até aqui seria possível, o meu agradecimento especial.

A todos os meus companheiros do dia a dia de trabalho e estagiários da Seção de Curadoria do Herbário do Instituto de Botânica, à Karina Cardoso apoiada por Ana Célia Calado, na assistência da Sociedade Botânica do Brasil, que realizaram tantas atividades, substituindo-me durante as ausências prolongadas; pois, somente assim, pude me dedicar àfinalização deste trabalho, de maneira praticamente exclusiva.

Aos botânicos colaboradores da Flora Fanerogâmica da Ilha do Cardoso, que me ajudaram nas atualizações taxonômicas ou nomenclaturais das espécies amostradas.

Ao Crisógenes Oliveira, pela ajuda amiga nos trabalhos de campo realizados durante o período do segundo levantamento, em 1995.

Ao Eduardo P.C. Gomes, meu co-orientador extra-oficial, pela amizade e pelo encorajamento, sempre contribuindo significativamente para o desenvolvimento de minhas idéias, pelas sugestões tão decisivas para o tratamento e análise dos dados, em especial, do capítulo sobre crescimento, recrutamento e mortalidade de árvores.

À Rosemary J. Oliveira, pela amizade e pelos profícuos momentos de troca de idéias, pela valiosíssima ajuda no tratamento dos dados e no preparo de gráficos; pelos comentários e sugestões para a melhora da redação, em especial, do capítulo sobre a estrutura do componente arbóreo.

À Maria Lucia Kawasaki pela paciente e cuidadosa ajuda no preparo do Abstract.

Ao Fábio de Barros pela revisão da redação dos itens constantes do capítulo sobre estrutura, que contém dados sobre a análise multivariada e pelas valiosas sugestões.

Aos meus familiares, pelo carinho e paciência, em especial, ao Renato e àMaria Arlete, que tanto me pouparam para que eu pudesse, com tranqüilidade, finalizar a tese; pelas cuidadosas apresentações visuais da capa e das figuras 1 e 2, feitas pelo Raul, com a ajuda do Roberto; ao Fernando, pelo auxílio na editoração das tabelas; ao Roberto e ao Renato, pela ajuda na padronização das citações bibliográficas.

Aos amigos que acompanharam o meu trabalho de tese, os momentos difíceis, os momentos de triunfo, os dias de desespero total, os dias de inspiração, os sofrimentos com o computador, os momentos de dúvida e os momentos positivos; e que entenderam que eu não estava empreendendo uma tarefa fácil e, no final, compartilharam com alegria a sua finalização. 


\section{Sumário}

Página

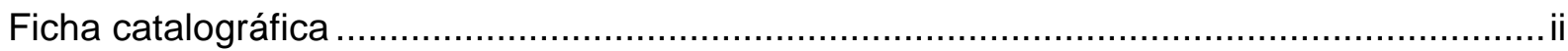

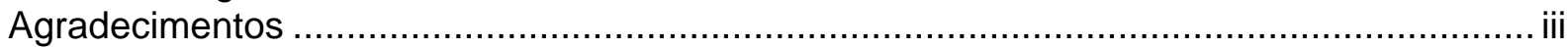

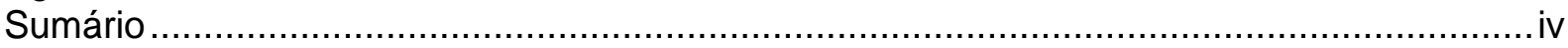

Resumo

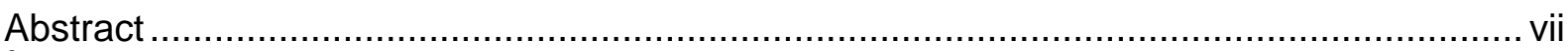

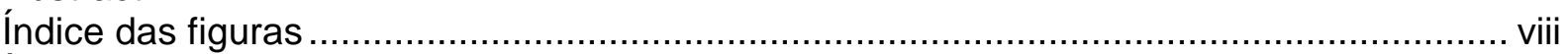

Índice das tabelas

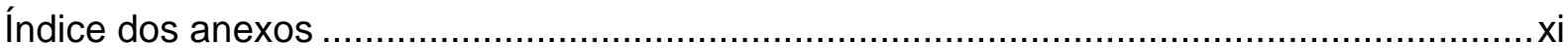

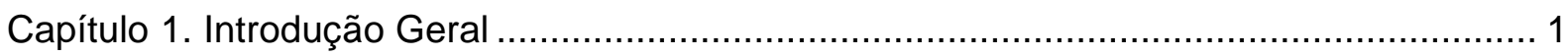

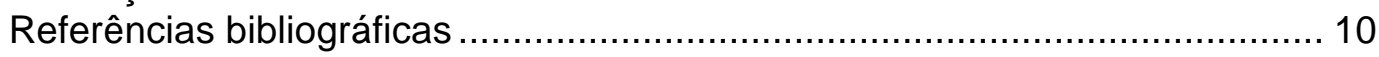

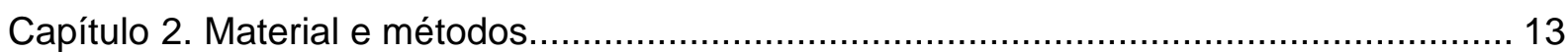

Descrição da área estudada ................................................................. 13

Levantamentos realizados .................................................................... 18

Referências bibliográficas .................................................................... 19

Capítulo 3. Estrutura do componente arbóreo em Floresta Pluvial

Tropical Atlântica, Ilha do Cardoso, SP, Brasil .............................................. 21

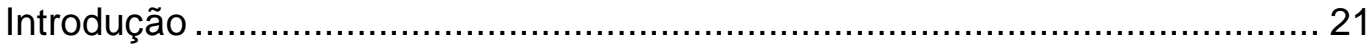

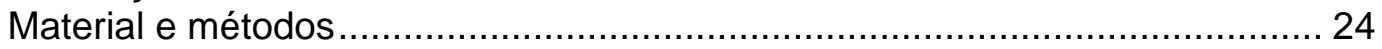

Relação espécie $x$ área................................................................... 25

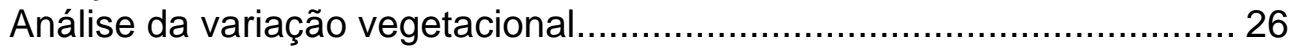

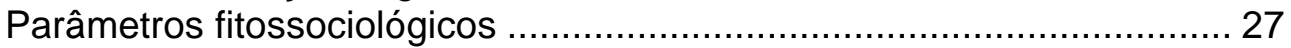

Distribuição do tamanho das árvores.................................................. 28

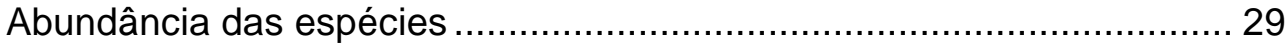

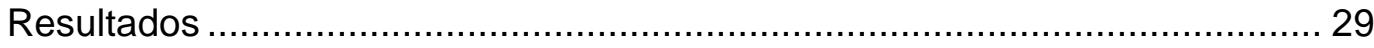

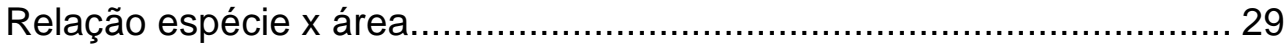

Análise da variação vegetacional........................................................ 30

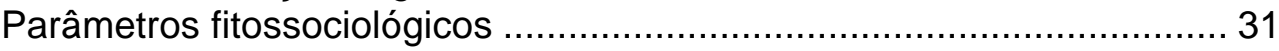

Distribuição do tamanho das árvores.................................................... 32

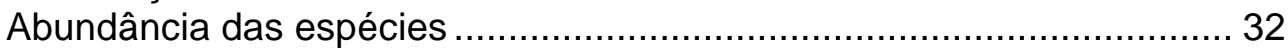

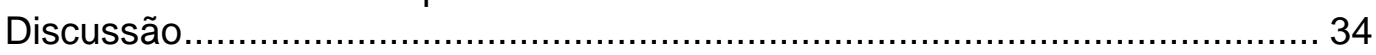

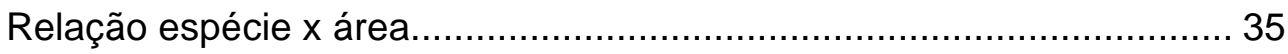

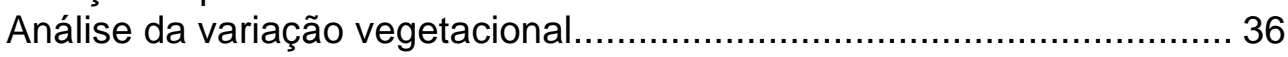

Parâmetros fitossociológicos ........................................................ 37

Distribuição do tamanho das árvores.................................................. 41

Abundância das espécies ..................................................... 43

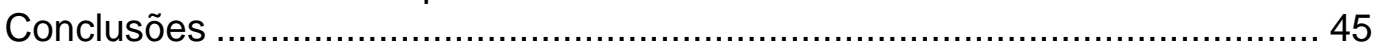

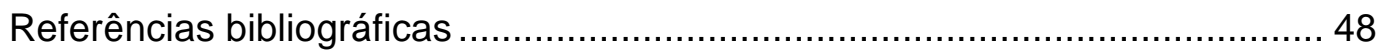


Página

Capítulo 4. Crescimento, recrutamento e mortalidade de árvores em

Floresta Pluvial Tropical Atlântica, Ilha do Cardoso, SP,

Brasil

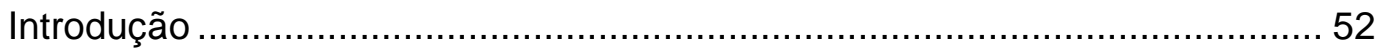

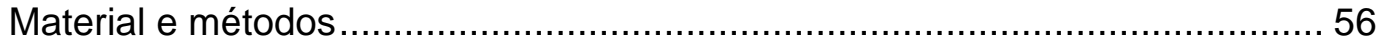

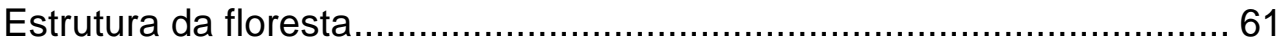

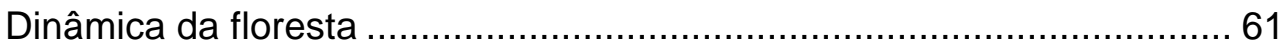

Crescimento ....................................................................... 61

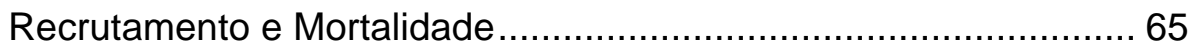

Distribuição espacial das árvores mortas............................. 69

Relação entre o recrutamento e a mortalidade .............................. 70

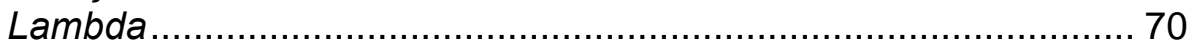

Tempo de meia vida e Tempo para dobrar.................................. 71

Dinâmica e Estabilidade ............................................................... 71

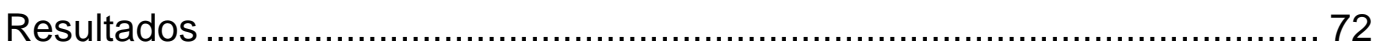

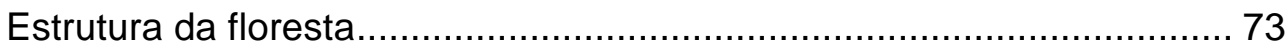

Dinâmica da floresta ......................................................................... 73

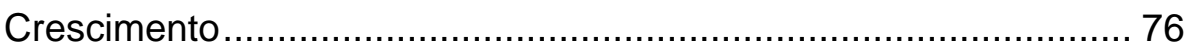

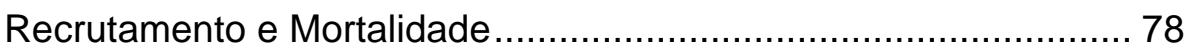

Distribuição espacial das árvores mortas............................. 80

Relação entre o recrutamento e a mortalidade .............................. 83

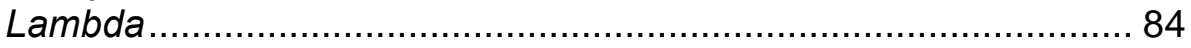

Tempo de meia vida e Tempo para dobrar .................................. 85

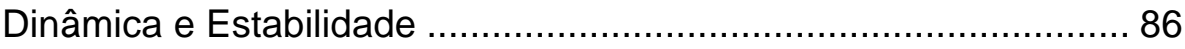

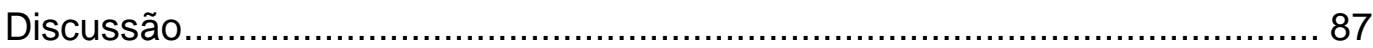

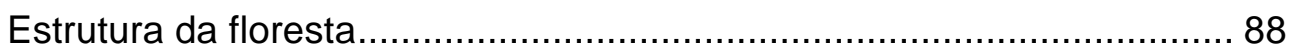

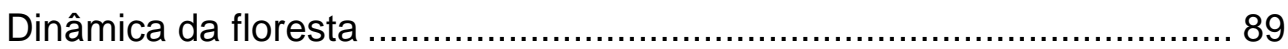

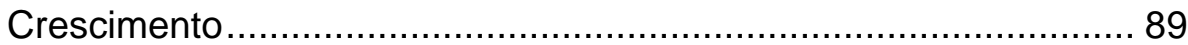

Recrutamento e Mortalidade.................................................... 92

Distribuição espacial das árvores mortas............................ 95

Relação entre o recrutamento e a mortalidade ............................... 96

Lambda................................................................................ 99

Tempo de meia vida e Tempo para dobrar.................................. 98

Dinâmica e Estabilidade .......................................................... 100

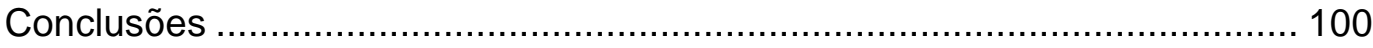

Referências bibliográficas .................................................................. 103

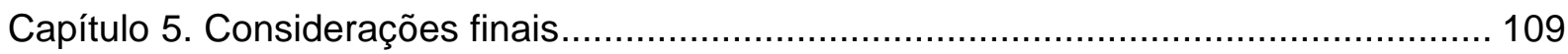

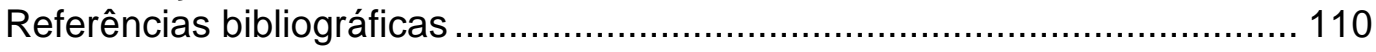




\section{Resumo}

O estudo de demografia de árvores foi realizado em uma parcela permanente de 1 ha, em trecho de Floresta Pluvial Tropical Atlântica na Ilha do Cardoso, São Paulo, Brasil (2503'05"-2518'18"S e 4753'48"-4805'42"W). As árvores foram medidas em dois levantamentos (1987-89 e 1995), num intervalo de tempo médio de 6,8 anos. A análise da estrutura da floresta foi realizada considerando, no primeiro levantamento, 727 árvores de 108 espécies, para o componente dominante (DAP $\geq 9,9 \mathrm{~cm}$ ), e 402 árvores de 64 espécies no sub-bosque $(2,5 \leq \mathrm{DAP}<9,9 \mathrm{~cm})$. No segundo levantamento, de 756 árvores de 109 espécies foram medidas no componente dominante e 377 de 60 espécies no sub-bosque. As mudanças observadas em relação ao número absoluto dos indivíduos e das espécies foram relativamente pequenas. Concomitantemente a estas mudanças, houve aumento na área total dos caules do componente dominante (de 43,48 para $45,57 \mathrm{~m}^{2} / \mathrm{ha}$ ) e redução na do sub-bosque (1,03 para $0,97 \mathrm{~m}^{2} / \mathrm{ha}$ ). Para os cálculos das taxas médias anuais de crescimento, recrutamento e mortalidade, consideraram-se 716 árvores em 1 ha do componente dominante (DAP $\geq 9,9 \mathrm{~cm}$ ), no primeiro levantamento, e 844, no segundo, envolvendo um total de 111 espécies; e 368 árvores em 0,25ha do sub-bosque (2,5 $\leq$ DAP $<9,9 \mathrm{~cm}$ ), no primeiro levantamento, e 430, no segundo, envolvendo 65 espécies. As espécies foram classificadas como raras, ocasionais, ou abundantes de acordo com o número de árvores presentes no primeiro levantamento, classes de diâmetro das árvores, síndromes de dispersão, e características sucessionais. As taxas médias anuais de crescimento, de recrutamento e de mortalidade, incluindo todas as espécies, foram de $0,19 \mathrm{~cm}$, de $2,43 \%$ e de $2,05 \%$, respectivamente, para o componente dominante, e de $0,10 \mathrm{~cm}$, de $2,30 \%$ e de $2,38 \%$, respectivamente, para o sub-bosque. Excluindo as palmeiras, as taxas médias anuais de crescimento, de recrutamento e de mortalidade, para o componente dominante, foram de $0,23 \mathrm{~cm}$, de $1,95 \%$ e de $1,45 \%$, respectivamente, e para o sub-bosque, de $0,08 \mathrm{~cm}$, de $1,68 \%$ e de $2,08 \%$, respectivamente. Estes valores aproximam-se daqueles obtidos em outros estudos de demografia de árvores realizados em parcelas permanentes em trechos preservados de Florestas Pluviais Tropicais. O trecho estudado é de floresta natural, que possui uma dinâmica própria, com mudanças em pequena escala; que está sujeita æ̀s perturbações de origem natural, que ocorrem de maneira esporádica, com impacto de certa forma moderado, e que pode ser considerada como uma floresta climácica, cuja dinâmica interna responde às mudanças observadas. 


\begin{abstract}
Demography of trees studies were carried out in a permanent plot of 1 ha, in the Atlantic rain forest of Cardoso Island, São Paulo, Brazil (2503'05"-2518'18"S and 4753'48"$48^{\circ} 05^{\prime} 42^{\prime \prime W}$ ). The trees were measured in two inventories (1987-89 and 1995), in a 6.8year mean period. The forest structure was analyzed considering, in the first inventory, 727 trees with $\mathrm{DBH} \geq 9.9 \mathrm{~cm}$ (dominant component) of 108 species, and 402 trees with $2.5 \leq$ $\mathrm{DBH}<9.9 \mathrm{~cm}$ ("sub-bosque") of 64 species. In the second inventory, 756 trees of 109 species of the dominant component, and 377 trees of 60 species of the "sub-bosque" were analyzed. The changes observed in relation to absolute number of trees and species were relatively small. Concomitantly to these changes, there was an increase in total basal area of trees with $\mathrm{DBH} \geq 9.9 \mathrm{~cm}$ (from 43.48 to $45.57 \mathrm{~m}^{2} / \mathrm{ha}$ ) and reduction in trees with $2.5 \leq$ $\mathrm{DBH}<9.9 \mathrm{~cm}\left(1.03\right.$ to $\left.0.97 \mathrm{~m}^{2} / \mathrm{ha}\right)$. To calculate the annual growth, recruitment and mortality rates, 716 trees of the dominant component were considered in the first inventory, and 844 trees in the second one, involving 111 species; 368 trees of the "sub-bosque" in the first inventory, and 430 trees in the second one, involving 65 species. The species were classified as rare, occasional, or abundant according to the number of trees present in the first inventory, diameter classes of the trees, dispersal syndromes, and successional characteristics. The annual growth, recruitment and mortality rates for the community, considering all species and all trees with $\mathrm{DBH} \geq 9.9 \mathrm{~cm}$ (dominant component) were 0.19 $\mathrm{cm}^{\mathrm{y}-1}, 2.43 \%$, and $2.05 \%$, respectively; considering all species and all trees with $2.5 \leq \mathrm{DBH}$ $<9.9 \mathrm{~cm}$ ("sub-bosque") were $0.10 \mathrm{~cm}^{\mathrm{y}-1}, 2.30 \%$, and $2.38 \%$, respectively. Excluding the palms, the annual growth, recruitment and mortality rates for the dominant component were $0.23 \mathrm{~cm}^{\mathrm{y}-1}, 1.95 \%$, and $1.45 \%$; for the "sub-bosque", $0.08 \mathrm{~cm}^{\mathrm{y}-1}, 1.68 \%$, and $2.08 \%$, respectively. These values are approximately the same as those obtained in other studies of demography of trees carried out in permanent plots in preserved tropical rain forest. The area studied is a natural forest with its own dynamics, with changes in small scale, under moderate and sporadical natural disturbances; this area could be considered as a climactical forest, whose internal dynamics answer to changes observed.
\end{abstract}




\section{Índice das figuras}

Página

Figura 1: Mapa mostrando a distribuição dos diferentes tipos de vegetação ocorrentes na llha do Cardoso.

Figura 2 . Esquema da distribuição das subparcelas utilizadas na amostragem

Figura 3: Curvas do número acumulado de espécies $x$ área amostrada do subbosque, nos dois levantamentos

Figura 4: Curvas do número acumulado de espécies $x$ área amostrada do componente dominante, nos dois levantamentos

Figura 5: Curvas do número de ocorrência de indivíduos e de espécies $x$ área amostrada do sub-bosque, nos dois levantamentos.

Figura 6: Curvas do número de ocorrência de indivíduos e de espécies $\mathrm{x}$ área amostrada do componente dominante, nos dois levantamentos

Figura 7: Gráfico Biplot resultante da ordenação pela Análise de Correspondência à matriz original das 40 unidades amostrais $x$ número de indivíduos das espécies abundantes do componente dominante.

Figura 8: Gráfico Biplot resultante da ordenação pela Análise de Correspondência à matriz original das 40 unidades amostrais $x$ área dos troncos das árvores das espécies abundantes do componente dominante

Figura 9: Valores dos índices do valor de importância (IVI) das espécies que ocorreram nos dois levantamento do sub-bosque e do componente dominante

Figura 10: Gráfico Biplot resultante da ordenação pela Análise de Correspondência à matriz original das 40 unidades amostrais $x$ classes de diâmetro das árvores das espécies amostradas no subbosque

Figura 11: Gráfico Biplot resultante da ordenação pela Análise de Correspondência à matriz original das 40 unidades amostrais $\mathrm{x}$ classes de diâmetro das árvores das espécies amostradas no componente dominante

Figura 12: Distribuição de freqüência das classes de diâmetro por número de indivíduos e área dos caules das árvores amostradas no subbosque, nos dois levantamentos.

Figura 13: Distribuição de freqüência das classes de diâmetro por número de indivíduos e área dos caules das árvores amostradas no componente dominante, nos dois levantamentos 
Figura 14: Diagramas de dispersão dos dados de abundância das espécies amostradas no primeiro e segundo levantamentos, no sub-bosque e no componente dominante

Figura 15: Distribuição de freqüência das classes de taxas de crescimento absolutas por indivíduos amostrados.

Figura 16: Distribuição das taxas de crescimento absolutas por categorias de abundância das espécies amostradas

Figura 17: Distribuição de freqüência das classes de diâmetro por taxas de crescimento absolutas das espécies amostradas

Figura 18: Distribuição das taxas de crescimento absolutas das espécies por características que apresentam no processo sucessional.....

Figura 19: Distribuição das taxas de crescimento absolutas por síndromes de dispersão das espécies amostradas

Figura 20: Distribuição de freqüência das classes de taxas de crescimento relativas por número de indivíduos amostrados nos dois componentes

Figura 21: Distribuição de freqüência das classes de diâmetro por árvores mortas registradas no segundo levantamento 


\section{Índice das tabelas}

Página

Tabela 1: Autovalores e percentagem da inércia total nos 2 primeiros eixos da Análise de Correspondência aplicada ̀̀ matrizes originais de unidades amostrais $\mathrm{x}$ número de indivíduos e de unidades amostrais $x$ áreas dos troncos de árvores amostradas no componente dominante

Tabela 2: Dados sobre a estrutura, obtidos nos dois levantamentos realizados em trecho de Floresta Pluvial Tropical Atlântica

Tabela 3: Autovalores e percentagem da inércia total nos 2 primeiros eixos da Análise de Correspondência aplicada às matrizes originais do número de indivíduos das espécies abundantes $x$ classes de DAP de árvores amostradas no sub-bosque e no componente dominante.

Tabela 4: Valores de abundância das espécies amostradas em trecho de Floresta Pluvial Tropical Atlântica

Tabela 5: Espécies e dados dos indivíduos que apresentaram decrescimentos

Tabela 6: Dados sobre a estrutura, obtidos nos dois levantamentos realizados

Tabela 7: Valores das taxas médias anuais de crescimento (absolutas e relativas), de mortalidade e de recrutamento; do tempo de meia vida, do tempo para dobrar e do lambda,

Tabela 8: Padrão de distribuição espacial das árvores mortas amostradas no sub-bosque, para $n=10$ parcelas; g.l. $=9$

Tabela 9: Padrão de distribuição espacial das árvores mortas amostradas no componente dominante, para $\mathrm{n}=40$ parcelas; g.I. $=39$.

Tabela 10: Padrão de distribuição espacial das árvores mortas amostradas no componente dominante, para $n=4$ parcelas; g.I. $=3$

Tabela 11: Correlação entre as árvores vivas no primeiro levantamento e as árvores encontradas mortas no segundo levantamento 


\section{Índice dos anexos}

Página

Anexo 1: Listagem das espécies, com respectivas mudanças nas identificações ou correções nomenclaturais.

Anexo 2: Listagem das espécies arbóreas amostradas nos levantamentos fitossociológicos, com respectivas ocorrências nos componentes subbosque e dominante, classificadas quanto à síndrome de dispersão dos propágulos e quanto às características que apresentam no processo sucessional

Anexo 3: Dados sobre o número de espécies, a densidade e a área total dos caules das árvores, obtidos em parcelas permanentes instaladas em Florestas Tropicais.

Anexo 4: Parâmetros fitossociológicos das espécies amostradas no subbosque, no primeiro e segundo levantamentos

Anexo 5: Parâmetros fitossociológicos das espécies amostradas no componente dominante, no primeiro e segundo levantamentos

Anexo 6: Dados sobre crescimento, recrutamento e mortalidade de árvores, obtidos em parcelas permanentes instaladas em Florestas Tropicais. 


\section{Capítulo 1}

\section{INTRODUÇÃO GERAL}

“... as Florestas Pluviais Tropicais - tipo de habitat ou bioma como os ecologistas o chamam - são definidas como aquelas que crescem em regiões com no mínimo duzentos centímetros anuais de chuva espalhados suficientemente ao longo do ano para permitir o crescimento intensivo de árvores perenes de folhas largas. Estas florestas são dispostas em múltiplas camadas ou estratos, desde a abóbada superior com trinta metros ou mais de altura, interrompida por árvores dispersas que ultrapassam quarenta metros, passando por estratos médios entrecortados, até arbustos baixos que chegam à altura do peito humano. Lianas, cipós e trepadeiras enrolam-se nos troncos e pendem dos galhos superiores até o chão. Canteiros de orquídeas e outras epífitas festonam os galhos mais grossos. As palmas são comuns nos estratos médio e inferior de muitas Florestas Tropicais, conferindo luxuriante beleza e um falso senso de benignidade ao visitante a pé. Tão eficazes são as camadas escalonadas da abóbada em interceptar a luz do Sol que a vegetação inferior, sedenta de luz, é tão esparsa quanto numa mata de juníperos... No âmago da Floresta Pluvial, a luz do Sol apenas salpica o chão que, em certos lugares, é coberto por uma fina camada de folhas e húmus e em outros é completamente descoberto."

(Wilson, 1994)

Além da descrição quase poética das Florestas Pluviais Tropicais, Wilson (1994) afirma, ainda, que "a diversidade biológica - 'biodiversidade', como se diz hoje em dia - é a chave da preservação do mundo como o conhecemos. A vida num local assolado por uma tempestade passageira logo se recupera porque ainda existe bastante diversidade. Espécies oportunistas que evoluíram justamente para tais ocasiões correm para preencher os espaços vazios, dando início a uma sucessão que acabará por retornar a algo semelhante ao estado original do meio ambiente. Numa escala maior, as tempestades provocam mudanças em toda a estrutura da floresta. O dinamismo natural aumenta a diversidade da vida por meio de destruição e de regeneração localizadas". 
A origem e a manutenção da grande diversidade de espécies arbóreas das Florestas Tropicais têm sido explicadas por várias teorias que podem ser divididas em duas correntes principais de pensamento: a do equilíbrio e a do não equilíbrio (Primack \& Hall, 1992).

Para a escola do não equilíbrio, as florestas mais ricas em espécies existem em estado de desequilíbrio, onde flutuações climáticas e outras perturbações reduzem as populações antes que o princípio de exclusão competitiva possa ser efetivo (Hubbell, 1979; Hubbell \& Foster 1983, 1986a). Para os defensores desta escola, numa floresta, a abundância das espécies estaria sob constante estado de flutuação, na maior parte do tempo em leve deriva, em analogia com a deriva genética, de mistura de espécies apenas difusamente coevoluídas. A alta diversidade seria uma conseqüência da riqueza regional e da disponibilidade de imigrantes potenciais, que por sua vez seriam determinadas pela interação de diversos fatores, como o clima, a dinâmica da biogeografia histórica de um taxa em particular, a dispersão local, e os processos de especiação numa escala regional e sub-continental (Gomes, 1998).

Os defensores da corrente do equilíbrio acreditam que a Floresta Tropical consiste de um conjunto de espécies coevoluídas e de nichos diferentes coexistindo mesmo em um ambiente estável ou semi-estável, se certas condições são encontradas. De acordo com este pensamento, a estrutura e a composição florística de uma floresta são constantes ao longo de um período e a floresta retornará à condição original se sofrer um distúrbio provocado por um fator externo, como por exemplo um furacão (Connell, 1978).

Distinguir se uma floresta está em equilíbrio ou não requer compreensão dos processos que determinam a abundância relativa das espécies nela presentes. Se a floresta se encontra em uma condição estável, a abundância relativa será aproximadamente constante. Se a floresta for perturbada, a sucessão de espécies, após o distúrbio, será razoavelmente previsível e a composição original de espécies deverá ser, aproximada ou exatamente, a mesma (Hubbell \& Foster, 1986a, b; Hubbell \& Foster, 1987a, b; Gomes, 1998). 
Um assunto discutido por vários pesquisadores, especialmente desde a hipótese de mosaico de Aubreville, proposta em 1938, é que por um lado a Floresta Tropical parece ser, edaficamente, um ambiente homogêneo, porém de outro há um mosaico de estruturas diferentes da comunidade e a composição de espécies muda continuamente no espaço e no tempo (Knight, 1975).

Um marco conceitual útil na análise da variabilidade ambiental que afeta as populações de plantas das Florestas Pluviais é o modelo do ciclo de regeneração natural ou dinâmica de clareiras. A queda de ramos e de árvores provoca aberturas no dossel da floresta, promovendo importantes mudanças ambientais em seu interior. Estas mudanças afetam as probabilidades de germinação, estabelecimento e/ou reprodução das plantas. Com a abertura de uma clareira inicia-se o ciclo de regeneração natural. Nas clareiras grandes $\left(>100 \mathrm{~m}^{2}\right)$ o crescimento rápido da vegetação conduz, depois de várias décadas, ao estabelecimento de novas árvores maduras no dossel. Com o tempo, a queda de outra árvore reinicia o ciclo. O processo de substituição de árvores produz um mosaico de distintas fases regenerativas na comunidade de plantas, que diferem na estrutura, na composição de espécies e nas situações ambientais (Martínez-Ramos \& Álvarez-Buylla, 1995).

Os regimes de distúrbios moderados causados pela queda de árvores e a dinâmica de clareiras são sempre lembrados desempenhando papéis importantes na manutenção do número normalmente grande de espécies arbóreas nas Florestas Tropicais (Denslow, 1987; Ashton, 1992). Por outro lado, um distúrbio em grande escala, como por exemplo a fragmentação de florestas, deve certamente ter um efeito drasticamente negativo sobre a diversidade da comunidade (Oliveira-Filho, 1997).

Atualmente discute-se bastante a exploração racional e o manejo sustentado de Florestas Pluviais Tropicais. Poucas são as áreas no domínio das Florestas Pluviais Tropicais que se encontram preservadas na América do Sul, América Central, África, Indonésia, Malásia e Austrália. A riqueza biológica dessas florestas é reconhecida como uma das maiores existentes na Terra (Sukumar et al., 1992). No Brasil, a Floresta Pluvial Tropical está representada na região amazônica e na costa atlântica, sendo consideradas as duas maiores áreas de Florestas Úmidas do neotrópico (Por, 1992 apud Negrelle, 1995). 
A Floresta Pluvial Tropical Atlântica localiza-se na Região Leste do Brasil e é, genericamente, denominada Mata Atlântica. Originalmente tinha uma distribuição que cobria as serras costeiras do Rio Grande do Norte ao Rio Grande do Sul e hoje está reduzida a pequenas manchas florestais relativamente preservadas, cuja área é estimada em menos de $5 \%$ da cobertura original (Mori et al., 1981).

Desde a época da nossa colonização, tanto a Floresta Pluvial Tropical Atlântica quanto os ecossistemas costeiros a ela associados têm estado sujeitos à degradação, seja pelo adensamento populacional ao longo da costa, pelos ciclos do pau-brasil e da cana-de-açucar, pela extração de ouro e de outros recursos minerais, pela transposição das serras costeiras para atingirem-se os planaltos interiores ou, mais recentemente, pela instalação de complexos industriais. As florestas na encosta Atlântica apresentam variações regionais e locais que as situam entre as florestas mais ricas e diversas no território brasileiro, o que dificulta a exploração racional e o manejo sustentado que envolvam alterações em sua estrutura (Mantovani, 1998).

A outrora vasta área ocupada pela Floresta Pluvial Tropical Atlântica está sendo rapidamente reduzida, antes que tenha sido possível acumular suficiente conhecimento sobre o seu funcionamento. Há necessidade premente que se realizem estudos sobre as mudanças espaciais e temporais que nela ocorrem.

Considera-se, atualmente, como pré-requisito para o manejo sustentável de uma floresta a geração de um conjunto de informações confiáveis sobre o crescimento e a produção para diferentes regimes de manejo e opções silviculturais (Silva et al., 1995).

Existem alguns modelos de manejo de Florestas Tropicais, como o da floresta de Palcazu, na Amazônia peruana, que integra princípios ecológicos, econômicos e sociais no sistema de produção designado por desenvolvimento sustentável dos recursos da Floresta Tropical. Como uma perspectiva ecológica, a oportunidade de utilizar as Florestas Tropicais sem destruí-las é um excitante desafio. Então, a pesquisa básica sobre dinâmica da Floresta Tropical e a teoria sobre clareira pode levar a um manejo de Florestas Tropicais economicamente viável e socialmente atrativo, que contribui significativamente para a conservação da biodiversidade biológica (Hartshorn, 1989). 
Encontra-se disponível uma série de estudos que provêem uma visão da dinâmica de populações em Florestas Tropicais em vários continentes. A maioria deles diz respeito, principalmente, a Florestas Tropicais naturais - florestas que não tenham sido fortemente influenciadas pela atividade humana, nas quais é presumível refletir a seleção pelo ambiente através de longos períodos de tempo. Florestas naturais não perturbadas são auto-mantidas de acordo com processos locais de mortalidade, crescimento e regeneração, as árvores perdidas são continuamente substituídas por novos recrutamentos; a vegetação então continua, em equilíbrio dinâmico ou estado invariável, para ser floresta. Não está implícito que florestas são estáticas ou não mutáveis. De fato, suas mudanças são o maior foco no estudo da dinâmica da vegetação (Swaine et al., 1987).

A maioria dos suprimentos de madeira do mundo é obtido das Florestas Pluviais e tais florestas estão sendo cortadas a taxas muito altas em todos os países. Há necessidade de estudos de longa duração sobre a demografia de plantas para direcionar a regeneração destas florestas e, conseqüentemente, prover a produção sustentada de madeira (Manokaran \& Kochummen, 1987).

A maciça destruição das Florestas Tropicais de todo o mundo chegou num momento crítico, quando nosso conhecimento sobre a organização, a dinâmica funcional e, mesmo, a taxonomia alfa de muitas florestas é ainda rudimentar. Necessita-se, urgentemente, de esforços de conservação e manejo, porém isto é mais difícil por esta ausência de conhecimento básico. A comunidade científica pode ser questionada a melhor responder a esta situação. Porém, parece certo que somente um aumento significativo das pesquisas feitas em Florestas Tropicais poderá ajudar a obter o conhecimento necessário para planejar decisões inteligentes (Hubbell \& Foster, 1983).

O conhecimento da idade e das taxas de crescimento de árvores com potencial madeireiro é essencial para o planejamento de exploração sustentável em Florestas Pluviais Tropicais. No entanto, para realizar uma exploração sustentável, o impacto sobre o ecossistema deve também ser conhecido. Para este propósito são necessários, como referência, dados sobre a idade e as taxas de crescimento de espécies arbóreas obtidos em florestas não perturbadas (Korning \& Balslev, 1994). 
Enquanto que riqueza e diversidade de plantas podem ser igualmente avaliadas por transectos temporários ou outras técnicas de amostragem, estudos sobre a estrutura e a dinâmica da floresta requerem parcelas permanentes. Estas parcelas devem ser suficientemente grandes para cobrir as variações estruturais e funcionais dentro da área e devem ser monitoradas ao longo de um período de tempo que seja suficiente para observar os vários processos florestais e ecológicos. Os dados coletados nestas parcelas grandes podem ser analisados no tempo e no espaço, para entender a estrutura horizontal e vertical da floresta, tanto quanto modelar sua dinâmica (Elouard et al. 1997).

Uma avaliação adequada dos padrões de dispersão, da dependência da densidade e a produção e extração sustentável de espécies arbóreas tropicais somente é possível em estudos de longa duração. A maioria dos trabalhos tem sido feita em um simples hectare ou parcelas pequenas; ou sobre uma ou duas árvores adultas e plântulas ao redor delas; porém a raridade relativa de muitas espécies nas Florestas Tropicais induz ànecessidade de inventários em parcelas de grande escala. O primeiro estudo, iniciado em 1975, foi realizado em Costa Rica em uma parcela de 13ha em floresta seca, que tinha sido invadida pelo fogo e abandonada (Hubbell, 1979).

Como parte de uma rede internacional de estudos de longa duração sobre dinâmica de vegetação tropical, realizados em parcelas permanentes de grande extensão, foram estabelecidas, inicialmente, três parcelas de 50 hectares: a primeira em 1981, na Ilha do Barro Colorado (IBC), no Canal do Panamá, em floresta madura sazonal úmida (Hubbell \& Foster, 1990). Várias publicações recentes sobre a parcela observaram que a composição da floresta da IBC flutua ao acaso, isto é, a maioria das espécies é efetivamente equivalente competidora, cujas abundâncias flutuam estocasticamente (Hubbell \& Foster, 1986a; Welden et al., 1991). Em 1983 foi estabelecida na Península da Malásia uma segunda parcela de 50ha, na Reserva Florestal de Pasoh, floresta madura não sazonal úmida (Manokaran \& Kochummen, 1987). Uma terceira parcela de 50ha foi estabelecida, em 1987, no sudeste da Índia, no Estado de Tamil Nadu, na Reserva de Mudumalai Game, floresta de dossel aberto decídua seca (Sukumar et al., 1992). 
Duas parcelas adicionais de 50ha estão agora completamente mapeadas em florestas sempreverdes úmidas, uma no Parque Nacional de Lambir, em Sarawak, Malásia e outra no Santuário para Vida Selvagem Huai Kha Khaeng, na Tailândia, em floresta sempreverde sazonal úmida e na borda de floresta decídua (Condit, 1995).

Vale ressaltar que um dos primeiros estudos com este enfoque foi realizado na Reserva Florestal Sungei Menyala, na Península da Malásia, em 1947, considerando apenas árvores com diâmetro do tronco a altura do peito igual ou superior a 10,1cm (Manokaran \& Kochummen, 1987).

Encontram-se disponíveis na literatura resultados de alguns estudos sobre a dinâmica florestal, abrangendo áreas de menor extensão. Uma parcela de 16ha foi estabelecida na Floresta Experimental de Luquillo, em Porto Rico, após 1989. Parcelas permanentes de 16ha estão atualmente sendo instaladas no Sri Lanka; nas Filipinas, no Cameron, no Zaire e no Equador (Condit, 1995).

A finalidade da rede de parcelas permanentes para estudos da dinâmica florestal tem extrapolado seu objetivo original, de ecologia da comunidade e a manutenção da diversidade, para incluir análises de manejo orientado, assim como dos recursos econômicos da floresta, sobre a dinâmica da extração sustentável e as mudanças da comunidade de árvores a partir de mudanças climáticas. Governantes e manejadores florestais necessitam de uma base de dados sólida para tomar decisões sensíveis sobre manejo florestal. Os cientistas envolvidos com a rede, que realizaram inventários naquelas parcelas permanentes de grande extensão, têm em mãos uma importante ferramenta para gerar aquela base de dados. Parcelas para dinâmica florestal são então agora vistas como peça central para a pesquisa multidisciplinar e as parcelas em florestas nativas eventualmente servirão como controle para parcelas de grande extensão em florestas plantadas, quando modelos para a extração de bens podem ser cuidadosamente testados (Condit, 1995).

É de suma importância que os resultados das parcelas sejam comparáveis, de tal maneira que hipóteses de amplo alcance sobre a dinâmica de Florestas Tropicais possam ser testadas. Isto requer técnicas de coleta de dados padronizadas, assim como a comunicação e a colaboração entre os trabalhadores de diferentes disciplinas e de diferentes locais. Para estabelecer uma rede coesa e 
para favorecer a comunicação entre investigadores de diferentes parcelas, foi criado o Centro para Ciência Florestal Tropical (CTFS). Este centro facilita a permuta de bancos de dados, pacotes de software, análises, publicações e visitas de cientistas entre locais de pesquisa. Em adição, o CTFS auxilia no desenvolvimento de novas parcelas, com o objetivo de formar uma rede de locais abarcando a faixa de variação das características florísticas, climáticas, geológicas, econômicas e sociais. Os locais da Ásia foram recomendados dentre 10 indicados para a pesquisa de longa duração num Workshop em 1989, em Bangkok, Ásia (locais da Índia, China, Indonésia e Papua Nova Guiné ainda não foram implementados). Em 1994, o Panamá hospedou uma reunião semelhante para identificar locais na América Latina (Condit, 1995).

As informações consistentes sobre a estrutura e a dinâmica das florestas tropicais, obtidas a partir de estudos realizados em parcelas permanentes, podem permitir condições de discernimento sobre os fatores que afetam a estrutura da área estudada, a biodiversidade e as taxas de crescimento das árvores (Primack \& Hall, 1992).

O manejo sustentável de Florestas Tropicais naturais não é possível sem um entendimento holístico de como tal floresta atualmente funciona ecologicamente e como interage com os humanos. Porque o tempo é curto, no entanto, deve-se aprender "no jogo", isto é, conduzindo simultaneamente a pesquisa e implementando planos de manejo (Hubbell \& Foster, 1992).

Para conservar a floresta não necessariamente devemos mante-la intacta. É possível explorar os recursos vegetais sem alterar demasiadamente a estrutura e a dinâmica das populações. Ao manipular os recursos encontrados em algumas das fases do ciclo de vida das plantas, o objetivo será manter ou promover a taxa de crescimento populacional (lambda) em valores iguais ou maiores que 1, ou seja, sem a extinção da população (Martínez-Ramos \& Álvarez-Buylla, 1995).

Alguns aspectos básicos importantes da ética ambiental das culturas e povos tradicionais são analisados por Siqueira (1998). Dos cinco traços ético-ambientais, apresentados pelo autor, é bastante oportuno destacar dois: um que trata do princípio do controle natural do ambiente, ou seja, para manter o equilíbrio entre as coisas é preciso controlar o processo de uso e retirada dos seres da natureza, tanto da flora como da fauna, retirando-se somente o necessário para a sobrevivência 
diária e proporcionalmente ao consumo tribal, e outro que se refere àdimensão de sacralidade da natureza. A dimensão sagrada da natureza conduz a uma postura ética de respeito e admiração por todas as formas de vida e demais expressões abióticas do espaço natural circundante.

Siqueira (1998) concluiu que podemos aprender muito com as posturas éticoambientais desses nossos irmãos mais velhos na trajetória histórico-cultural e mais sábios na relação com a natureza, a partir de mudanças éticas em nossa mentalidade e práticas sociais, assimilando e aprendendo de uma cultura que é mais cosmocêntrica, menos consumista e mais solidária.

Com o objetivo de contribuir para o conhecimento da composição e da estrutura da Floresta Pluvial Tropical Atlântica, realizou-se durante o período de 1987 a 1989 o levantamento fitossociológico de uma parcela permanente de um hectare instalada nesta formação florestal na llha do Cardoso (Melo \& Mantovani, 1994). No ano de 1995, realizou-se um segundo levantamento na mesma parcela, objetivando responder algumas questões, que podem ser agrupadas da seguinte forma:

1) Estrutura da floresta:

- A estrutura da comunidade florestal estudada mudou durante o intervalo de tempo entre os dois levantamentos?

- Quais são os padrões de abundância das árvores do componente dominante e das do sub-bosque?

2) Dinâmica da floresta:

- Quais são os padrões de crescimento, recrutamento e mortalidade das populações?

- As populações estão estáveis ou estão aumentando e diminuindo na área amostrada?

- Em qual direção o processo sucessional na comunidade estudada está caminhando: em direção a um equilíbrio ou está constantemente em estado de desequilíbrio? 
Formularam-se as seguintes hipóteses:

1) As composições florísticas e as estruturas do sub-bosque e do componente dominante variam no tempo.

2) A Floresta Pluvial Tropical Atlântica é estável, apresentando mudanças ao longo do tempo e encontra-se em eqüilíbrio dinâmico.

Os resultados são apresentados em cinco capítulos. No presente capítulo é feita uma abordagem geral sobre o tema da tese e apresentam-se os objetivos. No Capítulo 2 são feitas considerações sobre a área de estudo e apresenta-se a metodologia empregada. O Capítulo 3 analisa a composição florística e a estrutura do trecho estudado. O Capítulo 4 apresenta os dados sobre crescimento, recrutamento e mortalidade de árvores, ocorridos no intervalo de 6,8 anos, em Floresta Pluvial Tropical Atlântica. No Capítulo 5 são feitas Considerações finais sobre a pesquisa.

\section{Referências bibliográficas}

Ashton, P.S. \& Hall, P. 1992. Comparisons of structure among mixed dipterocarp forests of north-western Borneo. Journal of Ecology 80:459-481.

Condit, R. 1995. Research in large, long-term tropical forest plots. Trends in Ecology \& Evolution 10(1):18-22.

Connel, J.H. 1978. Diversity in tropical rain forests and coral reffs. Science 199:1302-1310.

Denslow, J.S. 1987. Tropical rainforest gaps and tree species diversity. Annual Review of Ecology and Systematics 18:431-451.

Elouard, C.; Pascal, J.-P.; Pélissier, R.; Ramesh, B.R.; Houllier, F.; Durand, M.; Aravajy, S.; Moravie, M.-A. \& Carpentier-Gimaret, C. 1997. Monitoring the structure and dynamics of a dense moist evergreen forest in the Western Ghats (Kodagu District, Karnataka, India). Tropical Ecology 38(2):193-214.

Gomes, E.P.C. 1998. Dinâmica do componente arbóreo de um trecho de mata em São Paulo, SP. Tese de Doutorado, Instituto de Biociências, Universidade de São Paulo, São Paulo, 285p.

Hartshorn, G.S. 1989. Application of gap theory to tropical forest management: natural regeneration on strip clear-cuts in the Peruvian Amazon. Ecology 70(3):567-569. 
Hubbell, S.P. \& Foster, R.B. 1983. Diversity of canopy trees in a neotropical forest and implications for conservation. In S.L. Sutton, T.C. Whitmore \& A.C. Chadwick (eds.). Tropical Rain Forest: Ecology and Management. Special Publication n.2 of British Ecological Society. Blackwell Scientific Publications, Oxford. p.25-41.

Hubbell, S.P. \& Foster, R.B. 1986a. Biology, chance, and history and the structure of tropical rain forest tree communities. In J. Diamond \& T.J. Case (eds.). Community ecology. Harper \& Row, New York. p.314-329.

Hubbell, S.P. \& Foster, R.B. 1986b. Commonness and rarity in a neotropical forest: implications for tropical tree conservation. In M. Soulé (ed.). Conservation Biology. Sinauer, Massachusetts. p.205-231.

Hubbell, S.P. \& Foster, R.B. 1987a. La estructura espacial en gran escala de un bosque neotropical. Revista de Biologia Tropical 35(Suplemento 1):7-22.

Hubbell, S.P. \& Foster, R.B. 1987b. The spatial context of regeneration in a neotropical forest. In M.J. Crawley, A.J. Gray \& P.J. Edwards (eds.). Colonization, Sucession, and Stability. Blackwell Scientific Publications, Oxford. p.395-412.

Hubbell, S.P. \& Foster, R.B. 1990. Structure, dynamics, and equilibrium status of old-growth forest on Barro Colorado Island. In A.H. Gentry (ed.). Four neotropical forests. Yale University Press, New Haven. p.522-541.

Hubbell, S.P. \& Foster, R.B. 1992. Short-term dynamics of a neotropical forest: why ecological research matters to tropical conservation and management. Oikos 63(1):4861.

Hubbell, S.P. 1979. Tree dispersion, abundance, and diversity in a tropical dry forest. Science 203:1299-1309.

Knight, D.H.1975. A phytosociological analysis of species-rich tropical forest on Barro Colorado Island, Panama. Ecological Monographs 45:259-284.

Korning, J. \& Balslev, H. 1994. Growth rates and mortality patterns of tropical lowland tree species and the relation to forest structure in Amazonian Ecuador. Journal of Tropical Ecology 10:151-166.

Manokaran, N. \& Kochumen, K.M. 1987. Recruitment, growth and mortality of tree species in a lowland dipterocarp forest in Peninsular Malaysia. Journal of Tropical Ecology (Special Issue) 3:315-330.

Mantovani, W. 1998. Dinâmica da Floresta Pluvial Atlântica. In Anais do IV Simpósio de Ecossistemas Brasileiros, Águas de Lindóia. v. 2. p.1-20.

Martínez-Ramos, M. \& Alvarez-Buylla, E. 1995. Ecología de poblaciones de plantas en una selva húmeda de México. Boletim Sociedad Botánica de México 56:121-153.

Melo, M.M.R.F. \& Mantovani, W. 1994. Composição florística e estrutura de trecho de Mata Atlântica de encosta, na Ilha do Cardoso (Cananéia, SP, Brasil). Boletim do Instituto de Botânica 9:107-158.

Mori, S.A., Boom, B.M. \& Prance, G.T. 1981. Distribution patterns and conservation of eastern Brazilian coastal forest tree species. Brittonia 33(2):233-245.

Negrelle, R.R.B. 1995. Composição florística, estrutura fitossociológica e dinâmica de regeneração da floresta atlântica na Reserva de Volta Velha, Município Itapoá, SC. Tese de Doutorado, Centro de Ciências Biológicas e da Saúde, Universidade Federal de São Carlos, São Carlos, 222p. 
Oliveira Filho, A.T., Mello, J.M. \& Scolforo, J.R.S. 1997. Effects of past disturbance and edges on tree community structure and dynamics within a fragment of tropical semidecidous forest in south-eastern Brazil over a five-year period (1987-1992). Plant Ecology 131:45-66.

Primack, R.B. \& Hall, P. 1992. Biodiversity and forest change in Malaysian Borneo. Bioscience 42(11):829-837.

Silva, F.C., Fonseca, E.P., Soares-Silva, L.H., Müller, C. \& Bianchini, E. 1995. Composição florística e fitossociológica do componente arbóreo das florestas ciliares da Bacia do Rio Tibagi. 3. Fazenda Bom Sucesso, Município de Sapobema, PR. Acta Botanica Brasilica 9(2):289-302.

Siqueira, J.C. 1998. Ética e meio ambiente. Edições Loyola, São Paulo. 85p.

Sukumar, R., Dattaraja, H.S., Suresh, H.S., Radhakrishnan, J., Vasudeva, R., Nirmala, S. \& Joshi, N.V. 1992. Long-term monitoring of vegetation in a tropical deciduous forest in Mudumalai, Southern Índia. Current Science 62(9):608-616.

Swaine, M.D., Lieberman, D. \& Putz, F.E. 1987. The dynamics of tree populations in tropical forest: a review. Journal of Tropical Ecology (Special Issue) 3:359-369.

Welden C.W., Hewett S.W., Hubbell S.P. \& Foster R.B. 1991. Sapling survival, growth, and recruitment: relationship to canopy height in a neotropical forest. Ecology 72(1):35-50.

Wilson, E.O. 1994. Diversidade da vida. Companhia das Letras, São Paulo. 447p. 


\section{Capítulo 2}

\section{MATERIAL E MÉTODOS}

\section{Descrição da área estudada}

O trecho de Floresta Pluvial Tropical Atlântica estudado localiza-se no Parque Estadual da llha do Cardoso, litoral sul do estado de São Paulo, município de Cananéia, dentro do complexo estuarino-lagunar de Iguape-Cananéia-Paranaguá, ao sul das ilhas Comprida e de Cananéia, entre os paralelos 250 03'05" e 2518'18" de

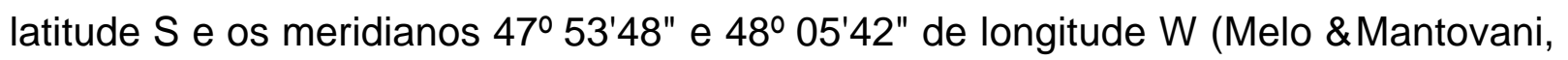
1994). Segundo a classificação de Veloso et al. (1991) trata-se da Floresta Ombrófila Densa Submontana ou Floresta Pluvial Tropical.

Seguindo a classificação de Koeppen, Pfeifer (1981-82) identificou o clima da região como sendo do tipo $\mathrm{Cfa}$, mesotérmico úmido, sem estação seca, com pluviosidade e umidade relativa elevadas. Furari et al. (1987), usando os critérios da segunda classificação climática de Thornthwaite, obtiveram os índices necessários para definir o clima geral na região da llha do Cardoso como super-úmido, megatérmico, com pequena ou nenhuma falta de água e grande excesso de água no verão. Dados climáticos obtidos durante o período de junho de 1989 a abril de 1992, em três estações meteorológicas instaladas na llha do Cardoso (Melo \& Mantovani, 1994), revelaram os seguintes dados: temperatura média das mínimas de 19,41ํㅡ, das máximas de $26,71^{\circ} \mathrm{C}$; temperatura mínima absoluta de $6^{\circ} \mathrm{C}$ e máxima absoluta de $39^{\circ} \mathrm{C}$. A precipitação média mensal foi de $149,4 \mathrm{~mm}$; a precipitação mínima mensal de 14,6mm, observada no mês de julho de 1991 e a máxima mensal de 421,6mm, no mês de janeiro de 1990. O maior valor de precipitação anual foi de $2.098,7 \mathrm{~mm}$, observado em 1990.

A topografia da ilha é predominantemente montanhosa, sendo sua região central ocupada por um maciço montanhoso contínuo, que atinge mais de $800 \mathrm{~m}$ em 
alguns morros, constituído de rochas metamórficas do Pré-Cambriano Inferior, onde ocorrem gnaisses e micaxistos, por entre os quais afloram rochas magmáticas (granitos) (Negreiros et al. 1974).

Nas encostas do maciço montanhoso e nos morros isolados, área de ocorrência da comunidade vegetal estudada, segundo Pfeifer (1981-1982), predominam os solos do tipo Latossolo Vermelho Amarelo-Orto (LV) e, em porções mais acidentadas, o Podzólico Vermelho Amarelo "intergrade" para Latossolo Vermelho-Amarelo (PVL). São solos argilosos, profundos, de coloração alaranjada, ácidos, com baixa saturação de bases, bem drenados, formados a partir de rochas granito-gnáissicas.

A formação estudada no presente trabalho cobre as encostas e topos mais baixos do maciço montanhoso central e os morros isolados, chegando a alcançar o costão rochoso em contato com o oceano, no leste da llha do Cardoso. É a formação que ocupa a maior extensão da ilha, ou cerca de $74 \%$ da área total (Figura 1). Observa-se que não há uniformidade na cobertura florestal do maciço montanhoso central da ilha, existindo dois conjuntos florísticos: o da vegetação nos dois terços inferiores e o da vegetação no terço superior dos morros. Esta variação na composição em espécies e na estrutura da cobertura florestal das encostas é devida ঐ̀ variações de umidade, dos tipos de solo e, em especial, àvariação na temperatura ao longo do gradiente altitudinal (Giulietti et al., 1983).

Visualmente, o aspecto do interior desta floresta não é muito cerrado, com um componente arbustivo-herbáceo que não é denso. $O$ dossel permite a penetração da luz difusa, o que favorece a riqueza em espécies do sub-bosque e em epífitas vasculares, a maioria ocorrendo a grandes alturas. As matas que margeiam os rios que cortam a Floresta Pluvial Tropical na Encosta Atlântica apresentam espécies peculiares, ausentes ou menos freqüentes na floresta adjacente. Sobre as pedras da beira e do leito desses rios, que não chegam a ser cobertas pela água, ocorre uma vegetação rupícola muito característica (Melo \& Mantovani, 1994).

As relações clima-floresta-solo são muito íntimas, tornando-se difícil apontar um único fator de clima ou de solo como a causa de um determinado efeito observado na vegetação, posto que, para cada reação da floresta, corresponde um 
conjunto de interações do ambiente, que deve ser considerado na discussão e explicação do fato observado (Martins, 1991).

Mesmo com a ressalva acima, é possível afirmar, com base nos resultados da pesquisa desenvolvida por Pinto (1998), a importância dos fatores do solo para a manutenção da diversidade e do desenvolvimento da vegetação, mostrando que a recuperação e o manejo de uma floresta dependem da manutenção ou recuperação das condições edáficas.

Analisando o conjunto dos parâmetros de fertilidade do solo apresentados por Pinto (1998) para os trechos sob Florestas Pluviais Tropicais de encosta, estudado na presente pesquisa, e de planície, estudado pelo autor, pode-se afirmar que estes apresentam melhores condições físicas e químicas do que aqueles sob Florestas de Restinga, estudados por Sugiyama (1998), principalmente na profundidade de 0$20 \mathrm{~cm}$. Por se tratarem, nos trechos de encosta, de solos rasos (Litossolos), a dependência da vegetação aos nutrientes disponíveis na camada superficial do solo fica mais acentuada.

Além da pesquisa sobre a influência de fatores edáficos na estrutura da vegetação, desenvolvida por Pinto (1998), alguns estudos ecológicos básicos também foram realizados na parcela permanente do presente trabalho, objetivando dar conhecimento dos processos que regem a Floresta Pluvial Tropical Atlântica: produção de serapilheira e transferência de nutrientes (Moraes, 1993); decomposição de serapilheira (Rebelo, 1994); e importação de nutrientes minerais pela precipitação e transferência para o chão da floresta pela água de gotejamento (Varjabedian, 1994).

A produção de serapilheira foi estimada em $6.283 \mathrm{~kg} / \mathrm{ha} / \mathrm{ano}$, valor situado no limite inferior dos reportados para outras Florestas Tropicais, num processo contínuo ao longo do ano, mas com grandes variações entre os meses. A queda máxima de serapilheira ocorreu no período de maior duração dos dias e início da estação chuvosa (outubro). A concentração de nutrientes minerais na serapilheira produzida não apresenta sazonalidade nítida, sendo altas tanto a concentração de macronutrientes, quanto a de micronutrientes. O retorno anual de nutrientes minerais àsuperfície do solo é superior ao verificado na Floresta sobre Restinga, devido tanto 
à produção de uma maior massa de serapilheira, quanto ̀̀ concentrações de elementos minerais mais elevadas que esta apresenta (Moraes, 1993).

A velocidade da decomposição da serapilheira foi maior no trecho de Floresta Tropical de encosta do que no de Floresta sobre Restinga, em decorrência da existência de condições mais favoráveis. O processo de decomposição apresentou variação sazonal. A fase de maior incremento da velocidade deste processo coincidiu com o período de maior precipitação, quando as condições de temperatura e umidade são mais favoráveis tanto para os processos biológicos, quanto para os físico-químicos. O padrão de ciclagem de nutrientes minerais observado no trecho de Floresta Tropical de encosta, com taxas mais rápidas de ciclagem, sugeriram que 0 êxito desta formação vegetal dependerá mais de sua capacidade de retê-los do que de sua taxa de decomposição (Rebelo, 1994).

A Floresta Pluvial Tropical recebeu grandes volumes de chuva, $2.617 \mathrm{~mm}$ anuais no período registrado por Varjabedian (1994). Os resultados da pesquisa sobre as quantidades de nutrientes minerais importados pela precipitação e transferência para o chão da floresta pela água de gotejamento, desenvolvida pelo autor, revelaram que os fluxos externos e internos dos macronutrientes, do sódio e do cloro ocorreram durante 0 ano todo, mas apresentaram maiores valores no período mais chuvoso do ano. $O$ autor constatou uma participação menor das entradas externas na composição dos fluxos internos de nutrientes através da água, mostrando que esta formação vegetal apresenta uma ciclo de nutrientes mais fechado, onde os fluxos internos estão sob controle relativamente maior dos componentes bióticos e onde há menor dependência externa.

A Floresta Pluvial Tropical Atlântica pode ser considerada um ecossistema mais fechado, pois a maior parte de seus fluxos internos de nutrientes é controlada em maior grau pelos seus componentes bióticos, onde se encontram maiores reservatórios de elementos essenciais, havendo menor dependência de entradas externas (Moraes, 1993, Rebelo, 1994 e Varjabedian, 1994). Supõe-se que as características próprias da Floresta Atlântica, como sua maior complexidade funcional e a ocorrência de ciclos de nutrientes mais fechados e menos dependentes de subsídios nutricionais externos, possam conferir uma maior auto-suficiência a este ambiente e, talvez, criar um quadro nutricional relativamente mais crítico para sua 
recuperação, dependendo do tipo de perturbação ao qual ela for submetida (Varjabedian, 1994).

A história da presença do homem na llha do Cardoso pode ser dividida, a grosso modo, em três fases: uma mais antiga, detectada pela ocorrência de sambaquis; uma intermediária, iniciada com a chegada dos europeus; e outra contemporânea, principiada com a criação do Centro de Pesquisas Aplicadas de Recursos Naturais da llha do Cardoso/CEPARNIC (Barros et al., 1991).

Após a ocupação da llha do Cardoso por uma civilização anterior a dos índios, que mantinha hábitos sedentários e cuja alimentação se baseava na pesca e na coleta de crustáceos, seguiu-se uma outra fase, com a formação dos primeiros núcleos de colonização européia, no início do século XVI. A partir daí, os habitantes utilizavam, em geral, as encostas dos morros para o plantio de culturas de subsistência, evitando apenas as partes mais elevadas. Mais recentemente, com a transformação da llha do Cardoso em Parque Estadual, em 1962, permaneceram umas poucas propriedades particulares, até hoje não desapropriadas pelo Estado, porém a prática do cultivo agrícola intensivo foi abandonada (Barros et al., 1991).

Têm-se registros da invasão das florestas da llha do Cardoso por caçadores e palmiteiros, que agem de maneira ilegal e clandestina. Pouco tempo antes do período em que se realizou o segundo levantamento, foram registrados na parcela permanente da presente pesquisa os cortes de 24 indivíduos adultos de Euterpe edulis, espécie fornecedora de excelente palmito, principalmente nas regiões Sul e Sudeste do Brasil. Além da interferência antrópica, alguns trechos de florestas vêm sofrendo a ação de fatores naturais, tais como deslizamentos das encostas dos morros e queda de árvores após as chuvas torrenciais, acompanhadas de ventos fortes, bastante comuns na região. 


\section{Levantamentos realizados}

Durante o período de agosto de 1987 a novembro de 1989, realizou-se um levantamento em uma parcela permanente de 50x200m, subdividida em 40 parcelas de $10 \times 25 m$, praticamente contíguas não fossem os dois riachos estreitos que cortam a área (Figura 2). Amostraram-se somente os indivíduos arbóreos vivos, que tivessem o perímetro do caule a $1,30 \mathrm{~m}$ de altura do solo (PAP) igual ou superior a $8 \mathrm{~cm}$. Quando as árvores eram ramificadas abaixo de 1,30m de altura do solo, além do tronco principal, tiveram todos os seus troncos medidos igualmente a $1,30 \mathrm{~m}$ do solo, de modo a se calcular a área de cada ramificação. Se a árvore apresentasse raízes tabulares, a medição de seu perímetro era feita acima das suas expansões.

Incluíram-se as palmeiras e os fetos arborescentes com altura do tronco igual ou superior a $2 \mathrm{~m}$, àaltura do ponto de inserção de suas folhas. Para proceder à medição do PAP dos indivíduos de Astrocaryum aculeatissimum, houve necessidade de se retirar os espinhos do pseudo-caule, quando os mesmos encontravam-se exatamente a 1,30m de altura do solo, medindo-se, desse modo, o perímetro um pouco acima. Para as análises, transformaram-se os dados de perímetros em diâmetros. Os indivíduos tiveram mensuradas as alturas máximas das copas, com auxílio de telêmetro.

O segundo levantamento, realizado na mesma área, foi muito mais rápido e completado durante o período de abril a outubro de 1995, quando novamente amostraram-se as 40 parcelas de 10x25m. O intervalo de tempo médio entre os dois levantamentos foi de 6,8 anos, considerando-se todos os indivíduos amostrados. Os indivíduos arbóreos, que receberam placas de alumínio no primeiro levantamento, localizados vivos ou mortos, incluindo as palmeiras e os fetos arborescentes presentes nas 40 unidades amostrais, tiveram seus troncos mensurados, desde que tivessem o PAP igual ou superior a $31 \mathrm{~cm}$ ou DAP $\geq 9,9 \mathrm{~cm}$. Realizou-se um sorteio de 10 unidades amostrais, totalizando 0,25ha, para amostrar os indivíduos arbóreos plaqueados no primeiro levantamento, encontrados vivos ou mortos, que tivessem o PAP igual ou superior a $8 \mathrm{~cm}$ e menor do que $31 \mathrm{~cm}$ ou $2,5 \leq$ DAP $<9,9 \mathrm{~cm}$. Nesta fase decidiu-se não medir as alturas dos indivíduos, tendo em vista que as mesmas haviam sido apenas estimadas com a ajuda de um telêmetro, por ocasião do primeiro 
levantamento. Considerou-se que, para efeito de comparação, após um intervalo de tempo, não se teriam medições precisas, mesmo que as alturas fossem estimadas com o mesmo aparelho.

Para os cálculos das taxas de crescimento, recrutamento e mortalidade, considerou-se apenas o tronco maior, medido no primeiro levantamento. Já para a análise de estrutura, consideraram-se todos os troncos múltiplos.

Para efeito de avaliação do crescimento em DAP de árvores que apresentam raízes tabulares, cuja medição é feita acima das suas expansões, há que se ter cautela, tendo em vista o crescimento ascendente de raízes suportes, o que, freqüentemente, confere pontos de medições diferentes em estudos com longos intervalos. Outra ocorrência que impede medições acuradas é a presença de lianas e hemiepífitas de grande porte, praticamente adnatas ao tronco das árvores, ocorrências já observadas por Clark \& Clark (1996).

Após o primeiro levantamento, incluiu-se pelo menos uma exsicata de cada espécie, mesmo estéril, na coleção do Herbário de Fanerógamas do Instituto de Botânica (SP), como testemunho da presença da espécie na área amostrada, com exceção dos indivíduos de Attalea dubia (Mart.) Burret, Euterpe edulis Mart. e Astrocaryum aculeatissimum (Schott) Burret.

Para o presente trabalho, procedeu-se a uma revisão da listagem florística do primeiro levantamento (Melo \& Mantovani, 1994), objetivando detectar possíveis espécies sinonimizadas ou com identificações imprecisas. Daquela listagem, 32 espécies têm aqui seus nomes modificados, seja nomenclatural ou taxonomicamente (Anexo 1).

\section{Referências bibliográficas}

Barros, F., Melo, M.M.R.F., Chiea, S.A.C., Kirizawa, M., Wanderley, M.G.L., Jung-Mendaçolli, S.L. 1991. In M.M.R.F. Melo, F. Barros, M.G.L. Wanderley, M. Kirizawa, S.L. JungMendaçolli \& S.A.C. Chiea (eds.) Caracterização geral da vegetação e listagem das espécies ocorrentes. Instituto de Botânica, São Paulo. v.1. 184p.

Clark, D.B. \& Clark, D.A. 1996. Abundance, growth and mortality of very large trees in neotropical lowland rain forest. Forest Ecology and Management 80:235-244. 
Funari, F.L., Struffaldi-de Vuono, Y., Salum, S.T. 1987. Balanço hídrico de duas áreas de Mata Atlântica: Reserva Biológica de Paranapiacaba e Parque Estadual da llha do Cardoso (Estado de São Paulo). In Anais do VI Congresso da Sociedade Botânica de São Paulo. Sociedade Botânica de São Paulo, São Paulo. p.95-101.

Giulietti, A.M.; Ribeiro Filho, E.; Bueno, M.S.G. \& Avelar, W.E.P. 1983. Em busca do conhecimento ecológico: Uma introdução à metodologia. Editora Edgard Blücher, São Paulo. 110p.

Martins, F.R. 1991. Estrutura de uma floresta mesófila. Editora da UNICAMP, Campinas. 246p.

Melo, M.M.R.F. \& Mantovani, W. 1994. Composição florística e estrutura de trecho de Mata Atlântica de encosta, na Ilha do Cardoso (Cananéia, SP, Brasil). Boletim do Instituto de Botânica 9:107-158.

Moraes, R.M. 1993. Ciclagem de nutrientes minerais em mata atlântica de encosta e mata sobre restinga, na Ilha do Cardoso, Cananéia, SP: produção de serapilheira e transferência de nutrientes. Dissertação de Mestrado, Instituto de Biociências, Universidade de São Paulo, São

Negreiros, O.C.; Carvalho, C.T.; Cesar, S.F.; Duarte, F.R.; Deshler, W.O.; Thelen, K.D. 1974. Plano de menejo para o Parque Estadual da Ilha do Cardoso. Boletim Técnico do Instituto Florestal 9:1-57.

Pfeifer, R.M. 1981-1982. Levantamento semidetalhado dos solos do Parque Estadual da llha do Cardoso. Revista do Instituto Florestal. 1(1):39-49.

Pinto, M.M. 1998. Fitossociologia e influência de fatores edáficos na estrutura da vegetação em áreas de Mata Atlântica na Ilha do Cardoso - Cananéia, SP. Tese de Doutorado, Instituto de Biologia, Universidade Estadual Paulista, Jaboticabal, 113p.

Rebelo, C.F. 1994. Ciclagem de nutrientes minerais em floresta pluvial tropical de encosta e em floresta sobre restinga na llha do Cardoso, Cananéia, São Paulo: decomposição da serapilheira. Dissertação de Mestrado, Instituto de Biociências, Universidade de São Paulo, São Paulo, 133p.

Sugiyama, M. 1998. Estudo de florestas da restinga da llha do Cardoso, Cananéia, São Paulo, Brasil. Boletim do Instituto de Botânica 11:119-159.

Varjabedian. R. 1994. Aspectos comparativos da ciclagem de nutrientes minerais em mata atlântica de encosta e em mata sobre restinga, no Parque Estadual da llha do Cardoso, SP. Dissertação de Mestrado, Instituto de Biociências, Universidade de São Paulo, São Paulo, 177p.

Veloso, H.P., Rangel Filho, A.L.R., Lima, J.C.A. 1991. Classificação da vegetação Brasileira, adaptada a um sistema universal. IBGE, Rio de Janeiro. 123p. 


\section{Capítulo 3}

\section{ESTRUTURA DO COMPONENTE ARBÓREO EM FLORESTA PLUVIAL TROPICAL ATLÂNTICA, ILHA DO CARDOSO, SP, BRASIL}

\section{Introdução}

As Florestas Pluviais Tropicais compõem os ecossistemas terrestres mais ricos em espécies. Registros botânicos da estrutura da floresta e da diversidade de espécies têm sido feitos em parcelas de 1 ha em várias regiões do mundo. Comparações destas parcelas têm conduzido ao aperfeiçoamento de várias hipóteses que justificam esta diversidade florística (Wright, 1997).

Com o acúmulo das informações ecológicas e taxonômicas, o antigo conceito de Floresta Pluvial Tropical como uma única e vasta formação de composição florística mais ou menos homogênea tem sido revisto. Estudos florísticos detalhados em diferentes Florestas Tropicais do mundo mostram o seu caráter complexo e variável. Estes estudos sugerem que o clima e a história pretérita da distribuição geográfica das espécies seriam os principais fatores responsáveis pela composição florística das Florestas Pluviais. Também há indicações de que dentro de uma determinada província climática, uma série de elementos ecológicos de segunda ordem desempenham um papel importante como determinantes da estrutura e composição das Florestas Pluviais Tropicais. Entre estes elementos, podem ser mencionados: a topografia, que se pode traduzir em um gradiente complexo de outras características do solo; as propriedades físicas e químicas do solo; o padrão de distribuição da precipitação; a nebulosidade; os ventos e o estádio sucessional da vegetação (Lieberman et al., 1985; Peralta et al., 1987).

Conceitos gerais sobre a diversidade de espécies sugerem que a heterogeneidade de habitat é o fator principal que controla a diversidade. Heterogeneidade que pode ser resultado de distúrbios, tais como a queda de 
árvores, ou da ação de propriedades físicas, por exemplo gradientes de umidade, variação de nutrientes do solo ou inclinação do terreno (Wright, 1997).

A maioria dos autores considera as clareiras como o ponto de partida, a origem principal, do processo dinâmico. A floresta seria, então, considerada como um mosaico de eco-unidades em diferentes estádios de ciclos florestais não sincronizados. Por esta razão, as clareiras não deveriam ser consideradas como equivalentes no processo da dinâmica florestal, pois elas agem em diferentes escalas tanto no tempo, quanto no espaço (Pascal \& Pelissier, 1996).

Dados sobre a composição de espécies arbóreas e a estrutura populacional têm sido usados como uma fonte de informações sobre a riqueza em espécies de Florestas Tropicais (Knight, 1975).

A descrição da estrutura de florestas tem servido de base para outros estudos que envolvam a compreensão de processos mais detalhados da biologia de cada população, como a dinâmica, a regeneração e a demografia (Oliveira, 1999).

São encontrados na literatura trabalhos realizados em parcelas permanentes de tamanhos variados e que apresentam dados sobre a estrutura de trechos de Florestas Tropicais comparando áreas diferentes ou componentes diferentes da floresta em uma mesma área. Dentre estes podem-se citar os de Thorington Jr. et al. (1982), na Ilha do Barro Colorado, Panamá; Silva \& Leitão Filho (1982), Mata Atlântica de encosta no Município de Ubatuba, Estado de São Paulo, Brasil); Ho et al. (1987), na Reserva Florestal de Jengka, Península da Malásia; Mantovani et al. (1990), em Floresta Atlântica, no Município de Salesópolis, Estado de São Paulo, Brasil; Ashton \& Hall (1992), em Sarawak e Brunei, Ilha de Bornéo; Felfili \& Silva Jr. (1992) e Felfili (1997a, b), em floresta de galeria do rio Gama, em Brasília, DF, Brasil; Mantovani (1993), em Floresta Atlântica no Município de Iguape, Estado de São Paulo, Brasil; Tabarelli et al. (1994), no Parque Estadual da Serra do Mar Núcleo Santa Virgínia, Estado de São Paulo, Brasil; Sussman \& Rakotozaly (1994), na Floresta Tropical seca, em Madagascar; Negrelle (1995), em Floresta Atlântica, na Reserva Particular do Patrimônio Natural de Volta Velha, Município de Itapoá, Estado de Santa Catarina, Brasil; Knobel (1995), em Floresta de planalto, na capital do Estado de São Paulo, Brasil; Pascal \& Pelissier (1996) e Elouard et al. (1997), nos Western Ghats, Uppangala, India; Guariguata et al. 1997, na província de 
Heredia, Costa Rica; Wright et al. (1997), em Papua, Nova Guiné; Vincent (1997), em mata ripária do município de Cosmópolis, Estado de São Paulo, Brasil; Sampaio (1997), em Floresta Atlântica secundária, na Reserva Biológica da Praia do Sul, Ilha Grande, Estado do Rio de Janeiro, Brasil; Silva et al. (1997), na Reserva Genética Florestal de Caçador, Estado de Santa Catarina, Brasil; Guedes-Bruni (1998), na Mata Atlântica no Estado do Rio de Janeiro, Brasil; e Oliveira (1999), em Floresta Atlântica de encosta no Estado de São Paulo, Brasil.

Porém, poucos são os estudos sobre estrutura de florestas realizados em parcelas permanentes, que apresentaram comparações entre períodos distintos, dentre os quais podem ser citados os de Okali \& Ola-Adams (1987), na Reserva Florestal de Omo, Nigéria, África; Peralta et al. (1987), na Estação Biológica de La Selva, Costa Rica; Manokaran \& Kochummen (1987), em Sungei Menyala, Malásia; Hubbell \& Foster (1990, 1992), na Ilha do Barro Colorado, Panamá; Felfili (1994), em floresta de galeria do rio Gama, em Brasília, DF, Brasil; Oliveira-Filho et al. (1997), na Reserva Florestal da Universidade Federal de Lavras, Estado de Minas Gerais, Brasil; e Gomes (1998), em Floresta de planalto, na capital do Estado de São Paulo, Brasil.

Os resultados obtidos nos trabalhos acima são comparáveis com os da presente pesquisa, fazendo-se restrições quanto aos tamanhos das áreas amostradas, que variaram de 1 a 50ha; aos critérios de inclusão adotados, DAPs de 1,0 a 10,0cm; aos intervalos de tempo médios entre os levantamentos, de 3 a 34 anos; às condições do meio físico onde se localizam as diferentes áreas de amostragem; e às diferentes riquezas florísticas obtidas. No entanto, pode-se observar uma relativa constância dos parâmetros estruturais da floresta, no intervalo de tempo, como o número de espécies, o número de indivíduos amostrados e a área total dos caules das árvores.

No presente estudo, a estrutura do trecho de Floresta Pluvial Tropical Atlântica foi analisada em uma parcela permanente de 1ha, considerando dois componentes da floresta e comparado-se períodos distintos, tendo-se como principais objetivos:

1) analisar a estrutura, a riqueza e a diversidade de um trecho de Floresta Pluvial Tropical Atlântica, em intervalo de tempo; 
2) discutir as implicações das mudanças observadas na dinâmica deste ecossistema;

3) obter subsídios para o estudo da demografia de árvores, objeto do próximo capítulo.

Formulou-se a seguinte hipótese: As composições florísticas e as estruturas do sub-bosque e do componente dominante variam no tempo.

\section{Material e métodos}

A descrição da área e a metodologia empregada nos dois levantamentos realizados em trecho de Floresta Pluvial Tropical Atlântica, na Ilha do Cardoso, encontram-se detalhadas no Capítulo 2.

Considerou-se, da mesma maneira que Tabarelli et al. (1993), que a floresta estudada apresenta dois componentes: 1) o componente dominante ou dossel, constituído pelo conjunto dos indivíduos das espécies arbóreas estabelecidas no teto da floresta, cujas copas compõem um contínuo, acrescido de indivíduos emergentes, quando existirem; e 2) o sub-bosque, composto pelo conjunto de indivíduos pertencentes æ̀s espécies que completam os seus ciclos de vida no interior da floresta, acrescido de indivíduos jovens das espécies arbóreas do dossel e emergentes.

O critério adotado no presente trabalho, para separar as árvores nestes dois componentes, foi: árvores que possuíssem 2,5 $\leq$ DAP $<9,9 \mathrm{~cm}$ seriam incluídas no sub-bosque e aquelas com DAP $\geq 9,9 \mathrm{~cm}$, no componente dominante. Esta divisão foi adotado em alguns estudos em Florestas Tropicais, em especial o critério de inclusão de árvores com DAP $\geq 10,0 \mathrm{~cm}$.

No primeiro levantamento, realizado de 1987-1989, amostrou-se 1ha, considerando-se todas as árvores com DAP $\geq 2,5 \mathrm{~cm}$, em 40 subparcelas de $250 \mathrm{~m}^{2}$ (Melo \& Mantovani, 1994). Para o segundo levantamento, consideram-se as mesmas 40 subparcelas para o estudo do componente dominante e, para o subbosque, somente 10 , sorteadas dentre as 40 , buscando evitar a super amostragem deste componente. 
O número de árvores e de espécies amostradas foi registrado, no primeiro levantamento, levando-se em conta somente as árvores vivas e, no segundo, todas aquelas que, entre os dois levantamentos, cresceram, decresceram, morreram ou foram recrutadas.

Para proceder à análise da estrutura, as populações amostradas em cada componente foram agrupadas de duas maneiras diferentes: quanto à abundância com que foram amostradas no primeiro levantamento e quanto æ̀s classes de diâmetros do caules às quais pertenciam os seus indivíduos.

Quanto às suas abundâncias, em relação ao primeiro levantamento, estas foram divididas em: populações raras - aquelas representadas por 1 e 2 indivíduos arbóreos por hectare; populações ocasionais - representadas por 3 a 9 indivíduos por hectare; populações abundantes - aquelas com pelo menos 10 árvores por hectare.

Com base nas classes de DAP, as árvores foram distribuídas, arbitrariamente, em 3 classes (2,5 a 5,0; 5,0 a 7,5 e 7,5 a 9,9cm) para o sub-bosque e em 7 classes para o componente dominante $(9,9$ a 20,0; 20,0 a 30,0; 30,0 a 40,0; 40,0 a 50,0; $50,0$ a 60,$0 ; 60,0$ a 70,0 e $>70 \mathrm{~cm})$.

As espécies que tiveram seus nomes modificados nomenclatural ou taxonomicamente, a partir da listagem apresentada no primeiro levantamento (Melo \& Mantovani, 1994), são apresentadas no Anexo 1.

\section{Relação espécie x área}

Foram geradas curvas do número acumulado de espécies $\mathrm{x}$ área amostrada, ou curvas do coletor, e de ocorrência de indivíduos e de espécies x área amostrada, para o componente dominante e para o sub-bosque, considerando a seqüência em que as subparcelas foram amostradas.

O exame das curvas do coletor permite avaliar se a área amostrada foi suficiente para dar conhecimento da variação florística do trecho estudado. O exame 
das demais curvas torna possível a avaliação quantitativa da distribuição do número de indivíduos e de espécies por unidades amostrais

\section{Análise da variação vegetacional}

Para observar a variação vegetacional realizou-se uma análise multivariada, do tipo Análise de Correspondência, de ordenação das 40 unidades amostrais, considerando-se parte das espécies amostradas na parcela permanente de um hectare, pois analisou-se, apenas, a variação das populações abundantes amostradas no componente dominante, ou seja, aquelas que tiveram pelo menos 10 indivíduos amostrados no primeiro levantamento.

A AC opera com álgebra matricial, fazendo uma auto-análise a partir de uma matriz de contingências entre as linhas e as colunas. A AC está relacionada a um modelo unimodal, no qual quaisquer espécies ocorrem em um âmbito limitado de valores de cada uma das variáveis ambientais. Aplicando-se esta técnica têm-se condições de avaliar o grau de afinidade florística entre as amostras e de associação entre as espécies (ter Braak, 1987). Vale ressaltar que, no presente trabalho, não será feita correlação com nenhuma variável ambiental.

Esta análise foi aplicada para os dados de abundância e dominância colhidos da vegetação. Para a análise da abundância utilizou-se o número total de indivíduos de cada espécie por unidade amostral como a variável independente da ordenação. Para estimar as relações de dominância das espécies considerou-se a área total dos caules das árvores de cada espécie por unidade amostral como a variável independente. Os cálculos e os gráficos desta ordenação foram obtidos pelo uso dos sub-programas MATRIZ e ORD, do Programa FITOPAC (Shepherd, 1996).

Decidiu-se por incluir somente as espécies abundantes porque, usando-se todas as espécies, a interpretação dos resultados ficaria bastante difícil, tanto pela dificuldade em analisar os dados numéricos obtidos para os autovalores e as percentagens de inércia, quanto para analisar os gráficos com seus emaranhados pontos da dispersão. Por outro lado, a Análise de Correspondência é muito 
influenciada por espécies que estão representadas nas amostras por números baixos de indivíduos.

Apresentam-se os resultados da AC de duas maneiras: sob a forma de gráficos biplot, que mostram a dispersão e sob a forma de tabelas, que trazem os autovalores e as percentagens da inércia total, ambos para os dois primeiros eixos.

Os autovalores nada mais são do que os valores da inércia em números absolutos, representando o quanto da dispersão cada eixo está mostrando. A inércia mede, na Análise de Correspondência, a dispersão ao longo do eixo (seria pois a explicação da dispersão em cada eixo considerado). Já a percentagem de inércia mede o quanto, em percentagem, o autovalor representa em relação ao valor total da inércia. A dispersão, na realidade, é um índice, calculado pela razão entre a variância e a média de um determinado conjunto de dados, como por exemplo, o número de indivíduos de uma determinada espécie, presente em diferentes unidades amostrais (ter Braak, 1987).

\section{Parâmetros fitossociológicos}

Para cada espécie, foram calculados os parâmetros fitossociológicos usuais: freqüências, densidades e dominâncias absolutas e relativas (Mueller-Dombois \& Ellenberg, 1974). Calcularam-se, também, o índice do valor de importância (IVI), os índices de diversidade de Shannon-Wiener e de Simpson e a Equabilidade (Magurran, 1998). Os cálculos foram obtidos pelo uso do Programa FITOPAC (Shepherd, 1996).

Construíram-se gráficos contendo a distribuição das espécies amostradas, no sub-bosque e no componente dominante, pelos respectivos valores de importância, nos dois levantamentos.

Segundo Curtis \& Mclntosh (1950) uma avaliação mais realista da extensão da dominância, do ponto de vista estrutural, poderia ser obtida computando os valores dos índices de importância das espécies. Estes índices incorporam medidas da área total dos caules e a amplitude da distribuição espacial, assim como o 
tamanho da população, expressos em percentagem da soma do total dos valores de importância. Valores de importância foram usados para estabelecer a estrutura das espécies numa área de amostragem, pela primeira vez, por Cain et al. (1956), em Floresta Pluvial Tropical Amazônica.

\section{Distribuição do tamanho das árvores}

Para agrupar as espécies amostradas no componente dominante, nos dois levantamentos, de acordo com os padrões de distribuição dos diâmetros dos caules, realizou-se uma Análise de Correspondência $(A C)$. A matriz de dados foi uma tabela em cujas linhas estavam listadas as espécies abundantes, ou seja, as representadas na amostragem por mais 10 árvores por hectare. Nas colunas foram plotadas as classes de diâmetros dos caules com o intervalo de $4,9 \mathrm{~cm}$, para o componente dominante, e 1,3cm, para o sub-bosque. Estes valores correspondem àmetade do valor dos DAPs mínimos adotados como critério de inclusão em cada componente. Uma análise semelhante foi apresentada para 35 espécies com freqüência maior que 2 árvores por hectare, numa parcela permanente de 3,12ha, na floresta de Uppangala, India (Pascal \& Pelissier, 1996; Elouard et al., 1997).

De modo a avaliar a estrutura de tamanho da floresta, para cada levantamento efetuado, construíram-se gráficos contendo a distribuição de freqüência das classes de diâmetros dos caules por número de árvores e por área dos caules das árvores amostradas no sub-bosque e componente dominante.

Para as análises acima, no primeiro levantamento, foram excluídas 5 árvores da última classe de DAP do sub-bosque, cujos valores de diâmetros dos caules ultrapassaram o critério de inclusão deste componente. Eram árvores com caules múltiplos, que foram incluídas na amostragem do sub-bosque pelos valores de DAP de seus caules maiores. O diâmetro do caule equivalente calculado para o conjunto de caules, no entanto, ultrapassou o valor máximo estabelecido para este componente. No segundo levantamento, foram excluídas 3 árvores. 


\section{Abundância das espécies}

As mudanças ocorridas no trecho da floresta estudada, em relação a abundância das espécies, foram analisadas fazendo-se a correlação entre 0 tamanho das populações no primeiro e no segundo levantamentos, para os dois componentes.

Registraram-se as mudanças em abundância das espécies ocorridas entre os levantamentos realizados, em números absolutos e em percentual, para o conjunto de todas as espécies, com e sem as palmeiras; para o conjunto das raras e das ocasionais; e para as espécies abundantes, amostradas no sub-bosque e no componente dominante. A decisão de registrar as mudanças excluindo as palmeiras, deve-se ao fato de que, em alguns trabalhos sobre estrutura de Florestas Tropicais, esta família botânica não é incluída, com a alegação de dificuldades em realizaremse as medições de seus pseudo-caules com acuidade. Na presente pesquisa esta dificuldade não foi impedimento para incluí-la na análise.

\section{Resultados}

Decorridos 6,8 anos após a realização do primeiro levantamento, observou-se uma mudança acentuada no aspecto geral da parcela permanente amostrada em trecho da Floresta Pluvial Tropical Atlântica na Ilha do Cardoso. Em conseqüência da queda de muitas árvores de grande porte, o padrão de cobertura do dossel foi alterado e, quando estas arrastaram em suas quedas várias árvores de médio e pequeno porte, provocaram a formação de emaranhados de caules e galhos, tornando difícil o trabalho de reconhecimento dos indivíduos amostrados no primeiro levantamento.

\section{Relação espécie $x$ área}

As Figuras 3 e 4 mostram, respectivamente, as curvas do número acumulado de espécies $x$ área amostrada ou curvas do coletor, obtidas, para o sub-bosque e 
componente dominante, em cada um dos levantamentos realizados. As Figuras 5 e 6 mostram, respectivamente, as curvas de ocorrência de indivíduos e de espécies $x$ área amostrada, para os dois componentes, nos dois levantamentos.

\section{Análise da variação vegetacional}

O resultado da ordenação pela Análise de Correspondência $(A C)$ da matriz original das 40 unidades amostrais $\mathrm{x}$ número de indivíduos das espécies abundantes amostradas no componente dominante, no primeiro e segundo levantamentos, é mostrado na Figura 7. O resultado da ordenação pela AC da matriz original das 40 unidades amostrais $x$ valores de área dos caules das árvores das espécies ocasionais e abundantes, amostradas no componente dominante, nos dois levantamentos é mostrado na Figura 8. Em ambos os casos, optou-se pela análise dos dois primeiros eixos da ordenação, devido a percentagem da variação por eles explicada.

Os autovalores e a percentagem da inércia total nos dois primeiros eixos destas duas ordenações estão apresentados na Tabela 1.

Tabela 1: Autovalores e percentagem da inércia total nos 2 primeiros eixos da Análise de Correspondência aplicada æ̀s matrizes originais de unidades amostrais $x$ número de indivíduos (Mat. ind.) e de unidades amostrais $x$ áreas dos caules de árvores (Mat. área) amostradas no componente dominante, em Floresta Pluvial Tropical Atlântica, Ilha do Cardoso, SP, Brasil. Pct. inércia = percentagem da inércia total, em cada eixo.

\begin{tabular}{ccccccccc}
\hline \hline & \multicolumn{3}{c}{ Primeiro Levantamento } & \multicolumn{3}{c}{ Segundo Levantamento } \\
\cline { 2 - 8 } & \multicolumn{2}{c}{ Mat. ind. } & \multicolumn{2}{c}{ Mat. área } & \multicolumn{2}{c}{ Mat. ind. } & \multicolumn{2}{c}{ Mat. área } \\
\cline { 2 - 8 } Eixos & Autovalores & $\begin{array}{c}\text { Pct. } \\
\text { Inércia }\end{array}$ & Autovalores & $\begin{array}{c}\text { Pct. } \\
\text { Inércia }\end{array}$ & Autovalores & $\begin{array}{c}\text { Pct. } \\
\text { Inércia }\end{array}$ & Autovalores & $\begin{array}{c}\text { Pct. } \\
\text { Inércia }\end{array}$ \\
\hline $\mathbf{1}$ & 0,2717 & 22,12 & 0,0570 & 40,98 & 0,2592 & 20,85 & 0,5323 & 21,79 \\
$\mathbf{2}$ & 0,1851 & 15,05 & 0,0245 & 17,61 & 0,1601 & 12,87 & 0,3958 & 16,21 \\
\hline \hline
\end{tabular}




\section{Parâmetros fitossociológicos}

Os parâmetros fitossociológicos das espécies amostradas no sub-bosque e no componente dominante, em cada levantamento, são apresentados, respectivamente, nos Anexos 4 e 5.

A Figura 9 apresenta os valores dos índices de importância (IVIs) obtidos para as 20 espécies comuns aos dois levantamentos, que apresentaram os maiores IVIs no primeiro, amostradas no sub-bosque e no componente dominante.

Uma síntese dos principais dados sobre a estrutura do trecho estudada encontra-se na Tabela 2.

Tabela 2: Dados sobre a estrutura, obtidos nos dois levantamentos realizados em trecho de Floresta Pluvial Tropical Atlântica, Ilha do Cardoso, SP, Brasil. DAP = diâmetro do caule a 1,30m de altura do solo; Nind = número de indivíduos arbóreos amostrados; $\mathrm{Nfa}=$ número de famílias amostradas; $\mathrm{Nsp}=$ número de espécies amostradas; AT = área total dos caules; H' = índice de diversidade de ShannonWiener; $\mathrm{D}$ = índice de diversidade de Simpson; $\mathrm{J}=$ equabilidade.

\begin{tabular}{ccccccccccc}
\hline \hline $\begin{array}{c}\text { Componente } \\
\text { (período do } \\
\text { levantamento) }\end{array}$ & $\begin{array}{c}\text { DAP } \\
(\mathbf{c m})\end{array}$ & Nind & Nfa & Nsp & $\begin{array}{c}\text { Área } \\
(\mathbf{h a})\end{array}$ & $\begin{array}{c}\text { AT } \\
\left(\mathbf{m}^{2} / \mathbf{h a}\right)\end{array}$ & $\begin{array}{c}\mathbf{H}^{\prime} \\
(\text { nat/ind) }\end{array}$ & $\mathbf{D}$ & $\mathbf{J}$ \\
\hline $\begin{array}{c}\text { Dominante } \\
(8 / 87 \text { a } 11 / 89)\end{array}$ & $\geq 9,9$ & 727 & 37 & 108 & 1,00 & 43,48 & 3,529 & 0,102 & 0,754 \\
$\begin{array}{c}\text { Dominante } \\
(4 \text { a } 10 / 95)\end{array}$ & $\geq 9,9$ & 756 & 37 & 109 & 1,00 & 45,57 & 3,531 & 0,100 & 0,753 \\
$\begin{array}{c}\text { Sub-bosque } \\
(8 / 87 \text { a } 11 / 89)\end{array}$ & $\geq 2,5<9,9$ & 402 & 25 & 64 & 0,25 & 1,03 & 3,109 & 0,087 & 0,748 \\
$\begin{array}{c}\text { Sub-bosque } \\
(4 \text { a } 10 / 95)\end{array}$ & $\geq 2,5<9,9$ & 377 & 20 & 60 & 0,25 & 0,97 & 3,042 & 0,093 & 0,743 \\
\hline \hline
\end{tabular}

\section{Distribuição do tamanho das árvores}

Nas Figuras 10 e 11 são mostrados os resultados da ordenação pela Análise de Correspondência $(\mathrm{AC})$ da matriz original das classes de DAP x número de indivíduos das espécies abundantes amostradas, respectivamente no sub-bosque e no componente dominante, no primeiro e no segundo levantamentos. 
Os autovalores e a percentagem da inércia total nos dois primeiros eixos desta ordenação, são apresentados na Tabela 3.

Tabela 3: Autovalores e percentagem da inércia total nos 2 primeiros eixos da Análise de Correspondência aplicada às matrizes originais do número de indivíduos das espécies abundantes $x$ classes de DAP de árvores amostradas no sub-bosque e no componente dominante, em Floresta Pluvial Tropical Atlântica, Ilha do Cardoso, SP, Brasil. Pct. inércia = percentagem da inércia total, em cada eixo.

\begin{tabular}{|c|c|c|c|c|c|c|c|c|}
\hline \multirow[b]{3}{*}{ Eixos } & \multicolumn{4}{|c|}{ Primeiro Levantamento } & \multicolumn{4}{|c|}{ Segundo Levantamento } \\
\hline & \multicolumn{2}{|c|}{ Sub-bosque } & \multicolumn{2}{|c|}{ Dominante } & \multicolumn{2}{|c|}{ Sub-bosque } & \multicolumn{2}{|c|}{ Dominante } \\
\hline & Autovalores & $\begin{array}{l}\text { Pct. } \\
\text { Inércia }\end{array}$ & Autovalores & $\begin{array}{l}\text { Pct. } \\
\text { Inércia }\end{array}$ & Autovalores & $\begin{array}{l}\text { Pct. } \\
\text { Inércia }\end{array}$ & Autovalores & $\begin{array}{l}\text { Pct. } \\
\text { Inércia }\end{array}$ \\
\hline 1 & 0,0969 & 55,70 & 0,6673 & 48,88 & 0,1925 & 61,37 & 0,6415 & 53,09 \\
\hline 2 & 0,0447 & 25,73 & 0,2341 & 17,15 & 0,0626 & 19,98 & 0,2744 & 22,71 \\
\hline
\end{tabular}

As Figuras 12 e 13 mostram, respectivamente, a distribuição de freqüência das classes de diâmetros dos caules das árvores por número de indivíduos e por área total dos caules amostrados no sub-bosque e no componente dominante, nos dois levantamentos.

\section{Abundância das espécies}

A correlação entre o tamanho das populações no primeiro e no segundo levantamentos corresponderam a $99,57 \%$ para o sub-bosque e $99,82 \%$ para o componente dominante. A dispersão dos valores para cada componente da floresta, sub-bosque e componente dominante, pode ser observada na Figura 14.

A Tabela 4 traz os valores de abundância das espécies amostradas no primeiro e no segundo levantamentos, nos dois componentes. Apresenta-se a compilação dos dados para as espécies em conjunto, incluindo e excluindo as palmeiras, para os conjuntos das raras e das ocasionais e para as espécies abundantes, individualmente. 
Tabela 4: Valores de abundância das espécies amostradas em trecho de Floresta Pluvial Tropical Atlântica, Ilha do Cardoso, SP, Brasil.

\begin{tabular}{|c|c|c|c|c|c|}
\hline Espécies & Famílias & $\begin{array}{l}\text { Componente } \\
\text { amostrado }\end{array}$ & $\begin{array}{l}N^{\circ} \text { de ind } \\
1987-89\end{array}$ & $\begin{array}{r}\text { ríduos } \\
1995\end{array}$ & $\begin{array}{c}\text { Mudanças } \\
(\%)\end{array}$ \\
\hline \multirow{2}{*}{$\begin{array}{l}\text { Conjunto de todas } \\
\text { as espécies }\end{array}$} & \multirow[t]{2}{*}{ Diversas } & Dominante & 727 & 756 & \multirow{2}{*}{$\begin{array}{l}3,99 \\
-6,22\end{array}$} \\
\hline & & Sub-bosque & 402 & 377 & \\
\hline \multirow{2}{*}{$\begin{array}{l}\text { Conjunto das espécies, } \\
\text { excluindo as palmeiras }\end{array}$} & \multirow[t]{2}{*}{ Diversas } & Dominante & 497 & 516 & 3,82 \\
\hline & & Sub-bosque & 317 & 296 & $-6,62$ \\
\hline \multirow[t]{2}{*}{ Espécies raras } & \multirow{2}{*}{ Diversas } & Dominante & 72 & 65 & $-9,72$ \\
\hline & & Sub-bosque & 45 & 40 & $-11,11$ \\
\hline \multirow[t]{2}{*}{ Espécies ocasionais } & \multirow[t]{2}{*}{ Diversas } & Dominante & 209 & 212 & 1,43 \\
\hline & & Sub-bosque & 104 & 91 & $-12,50$ \\
\hline \multirow[t]{2}{*}{ Astrocaryum aculeatissimum } & \multirow[t]{2}{*}{ Palmae } & Dominante & $\mathrm{b}$ & 13 & --- \\
\hline & & Sub-bosque & $b$ & $\mathrm{~b}$ & --- \\
\hline \multirow[t]{2}{*}{ Calyptranthes lanceolata } & \multirow[t]{2}{*}{ Myrtaceae } & Dominante & a & $\mathrm{a}$ & --- \\
\hline & & Sub-bosque & 12 & 12 & 0,0 \\
\hline \multirow[t]{2}{*}{ Calyptranthes lucida } & \multirow[t]{2}{*}{ Myrtaceae } & Dominante & 16 & 16 & 0,0 \\
\hline & & Sub-bosque & $\mathrm{b}$ & $\mathrm{b}$ & --- \\
\hline \multirow[t]{2}{*}{ Chrysophyllum flexuosum } & \multirow[t]{2}{*}{ Sapotaceae } & Dominante & 32 & 33 & 3,13 \\
\hline & & Sub-bosque & $\mathrm{b}$ & $\mathrm{b}$ & --- \\
\hline \multirow[t]{2}{*}{ Cryptocaria moschata } & \multirow[t]{2}{*}{ Lauraceae } & Dominante & 20 & 20 & 0,0 \\
\hline & & Sub-bosque & $\mathrm{C}$ & a & -- \\
\hline \multirow[t]{2}{*}{ Eugenia cuprea } & \multirow[t]{2}{*}{ Myrtaceae } & Dominante & $b$ & $\mathrm{~b}$ & --- \\
\hline & & Sub-bosque & 14 & 15 & 7,14 \\
\hline \multirow[t]{2}{*}{ Eugenia mosenii } & \multirow[t]{2}{*}{ Myrtaceae } & Dominante & 17 & 20 & 17,64 \\
\hline & & Sub-bosque & $\mathrm{b}$ & $\mathrm{b}$ & --- \\
\hline \multirow[t]{2}{*}{ Euterpe edulis } & Palmae & Dominante & 221 & 227 & 2,71 \\
\hline & & Sub-bosque & 71 & 69 & $-2,81$ \\
\hline Garcinia gardneriana & Clusiaceae & Dominante & 23 & 28 & 21,73 \\
\hline & & Sub-bosque & 16 & 16 & 0,0 \\
\hline Malouetia arborea & Apocynaceae & Dominante & 22 & 18 & $-18,18$ \\
\hline & & Sub-bosque & 14 & 12 & $-14,28$ \\
\hline Marlierea obscura & Myrtaceae & Dominante & $\mathrm{b}$ & 12 & --- \\
\hline & & Sub-bosque & $\mathrm{b}$ & $\mathrm{b}$ & --- \\
\hline Marlierea tomentosa & Myrtaceae & Dominante & 15 & 14 & $-6,66$ \\
\hline & & Sub-bosque & $\mathrm{b}$ & $\mathrm{b}$ & -- \\
\hline Myrcia pubipetala & Myrtaceae & Dominante & 11 & $\mathrm{~b}$ & --- \\
\hline & & Sub-bosque & $\mathrm{a}$ & $\mathrm{a}$ & --- \\
\hline Psychotria nuda & Rubiaceae & Dominante & 13 & 18 & 38,46 \\
\hline & & Sub-bosque & 62 & 56 & $-9,67$ \\
\hline Rudgea jasminoides & Rubiaceae & Dominante & 11 & 12 & 9,09 \\
\hline & & Sub-bosque & 64 & 66 & 3,13 \\
\hline Sorocea bonplandii & Moraceae & Dominante & 11 & 11 & 0,0 \\
\hline & & Sub-bosque & $b$ & $\mathrm{~b}$ & --- \\
\hline Tetrastilydium grandifolium & Olacaceae & Dominante & 15 & 18 & 20,0 \\
\hline & & Sub-bosque & $\mathrm{c}$ & $\mathrm{a}$ & --- \\
\hline Virola oleifera & Myristicaceae & Dominante & 19 & 19 & 0,0 \\
\hline & & Sub-bosque & $a$ & $\mathrm{a}$ & -- \\
\hline
\end{tabular}

a: espécie não amostrada no componente.

b: espécie não ocorreu como abundante e sim como ocasional.

c: espécie não ocorreu como abundante e sim como rara. 


\section{Discussão}

Uma análise dos estudos realizados em parcelas permanentes de 110 locais situados no continente americano, na Ásia, na África e na Oceania, para acompanhamento de mudanças demográficas, foi apresentada por Gomes (1998).

Quanto às características físic as, a parcela permanente utilizada na presente pesquisa enquadrou-se junto à maioria das parcelas quantificadas pelo autor, pois: situa-se abaixo dos $500 \mathrm{~m}$ de altitude (100-250m.s.m.); sob temperatura média anual de $21,2^{\circ} \mathrm{C}$ e média do total pluviométrico anual de $1.948 \mathrm{~mm}$.

Das características amostrais, o critério de inclusão de árvores adotado, com DAP $\geq 9,9 \mathrm{~cm}$ (aproximadamente $10,0 \mathrm{~cm}$ ), foi o mais utilizado na maioria dos estudos quantificados pelo autor. Os tamanhos das parcelas utilizadas no presente estudo enquadram-se dentre os mais freqüentes em diversos trabalhos: 0,25ha, aqui adotado para o estudo do sub-bosque e 1 ha, para o do componente dominante. $O$ intervalo entre os levantamentos realizados ( 6,8 anos) aproximou-se de valores em que se enquadra o maior número de estudos analisados pelo autor.

Nos estudos de parcelas permanentes com árvores de DAP $\geq 10 \mathrm{~cm}$, quantificadas por Gomes (1998), foram registradas de 60 a 283 espécies, com mediana de 165 espécies. No presente estudo, registraram-se 108 espécies no primeiro levantamento, valor abaixo da mediana dos valores das parcelas analisadas.

Dentre as parcelas que utilizaram como critério de inclusão DAP $\geq 10 \mathrm{~cm}$, a densidade variou de 280 a 935 indivíduos por hectare, com mediana de 583,5 ind./ha (Gomes, 1998). A da parcela permanente do presente trabalho foi de 727 árvores vivas/ha consideradas para o estudo da estrutura da floresta, no primeiro levantamento, valor mais alto que a mediana dos valores levantados na revisão do autor.

A distribuição dos valores de área basal apresentou moda entre 25,01 e $35,00 \mathrm{~m}^{2} / \mathrm{ha}$, com mediana de $30,60 \mathrm{~m}^{2} /$ ha (Gomes, 1998). A área total encontrada no presente trabalho foi de $43,48 \mathrm{~m}^{2} / \mathrm{ha}$, no primeiro levantamento. Este valor é considerado alto e se aproxima daqueles obtidos nas parcelas permanentes que 
adotaram o citado critério de inclusão na Austrália, no sudeste asiático e em duas parcelas do continente americano.

A parcela permanente da presente pesquisa apresentou um número maior de indivíduos, maior de área basal e um número menor de espécies, provavelmente devido à ocorrência de Euterpe edulis, com uma abundância bem maior do que a das demais. Cinco espécies, Chrysophyllum flexuosum, Cryptocharia moschata, Virola oleifera, Garcinia gardneriana e Malouetia arborea ocorreram com números altos de indivíduos, inferiores ao de E. edulis, porém com uma dominância maior. Três espécies também contribuíram para o aumento da área total dos caules, $C$. flexuosum, C. moschata e V. oleifera.

\section{Relação espécie $x$ área}

A análise das curvas do coletor para o sub-bosque (Figura 3), indica que seria necessário aumentar o número de subparcelas, para se alcançar a estabilização das curvas, nos dois levantamentos. Com base nos dados do primeiro levantamento (Melo \& Mantovani, 1994), considerando as 40 subparcelas, obteve-se para o subbosque um total de 1.768 indivíduos, pertencentes a 128 espécies. O número ideal de subparcelas para o estudo deste componente, no trecho de floresta considerada, provavelmente seria bem maior do que 10 e menor do que 40.

Para o componente dominante, as curvas atingiram a estabilização nos dois levantamentos (Figura 4), podendo-se concluir que o tamanho da área amostrada foi suficiente para dar conhecimento da representatividade florística do trecho de floresta estudado (Mueller-Dombois \& Ellenberg, 1974).

O uso da curva do coletor para a análise da representatividade florística de uma amostragem não foi feito por todos os autores dos trabalhos que realizaram comparações da estrutura da floresta em intervalo de tempo (Anexo 3). Não foi possível, portanto, realizar-se comparações entre os resultados com aqueles que a usaram, porque ou as áreas são muito maiores (Felfili, 1994; Hubbell \& Foster, 1992), ou a construção da curva foi diferente (Gomes, 1998).

Analisando-se a variação do número de indivíduos e de espécies nas 
subparcelas, entre os dois levantamentos, observou-se que no sub-bosque esta variação foi mais pronunciada em 3 subparcelas $^{1}$, de números 1, 3 e 9 da Figura 5.

No componente dominante, as parcelas apresentaram pouca variação, destacando-se as de números 3, 13, 2035 e 40 da Figura 6.

Variações mais pronunciadas indicam trechos da floresta que apresentam maior dinâmica, ou seja, o aumento do número de indivíduos correspondeu àmaior recrutamento, assim como uma diminuição correspondeu à maior mortalidade. As parcelas 13 e 15, que apresentaram variações maiores no componente dominante e no sub-bosque, respectivamente, ficam muito próximas à parcela 11, onde foi observado em campo, já no primeiro levantamento, uma clareira em processo de recuperação, com a presença de um agrupamento de indivíduos de Cecropia glazioui, Miconia pyrifolia, Leandra mosenii, Miconia dodecandra, espécies pioneiras que comumente participam da cicatrização de clareiras em Florestas Pluviais Atlânticas.

\section{Análise da variação vegetacional}

A análise dos autovalores e da percentagem de inércia total (Tabela 1) mostram que o primeiro eixo está explicando somente uma parte da variação da ordenação, quando se considerou o número de indivíduos como a variável estrutural independente, nos dois levantamentos. Os dois primeiros eixos explicam $37,19 \%$ da inércia total no primeiro levantamento e 33,72\%, no segundo. A Figura 7 mostra, nos dois levantamentos, o isolamento de algumas espécies, em relação æ̀s demais, quando se consideram o número de indivíduos representados nas parcelas. Estas espécies encontravam-se bem representadas em algumas parcelas, Garcinia gardneriana (parcela 39, no segundo levantamento), Calyptranthes lucida e Eugenia mosenii (34) e Sorocea bomplandii (29 e 32). No primeiro levantamento Myrcia pubipetala também contribuiu para a parcela 34, porém esta espécie não foi considerada no segundo levantamento por ter deixado de ser uma população abundante.

1. Estas parcelas correspondem àquelas de números 4, 15 e 32 da Figura 6. 
Os valores dos autovalores e da percentagem de inércia (Tabela 1) mostram que o primeiro eixo está explicando a maior parte da variação da ordenação, no primeiro levantamento, quando se considera a área dos caules das árvores como a variável estrutural independente. Os dois primeiros eixos explicam $58,59 \%$ da inércia total, no primeiro levantamento, e somente $38,00 \%$, no segundo. A análise da Figura 8 mostra, nos dois levantamentos, o isolamento de Virola oleifera, quando se considera a área total dos caules dos indivíduos, espécie representada em 4 subparcelas $(6,18,33$ e 35), por 6 indivíduos de grande porte.

Considerando-se a área dos caules das árvores das populações abundantes, verificou-se uma variação menor na estrutura da vegetação do trecho de floresta estudado, ao contrário do observado quando se considerou o número de indivíduos. Provavelmente isto se deve à mortalidade maior de indivíduos com diâmetros dos caules menores.

O uso de método numérico de ordenação para realizar a análise florística em parcelas permanentes vem sendo adotado por vários autores, como Knight (1975), Ho et al. (1987), Peralta et al. (1987), Pascal \& Pelissier (1996), Elouard et al. (1997), Oliveira-Filho et al. (1997), Gomes (1998) e Oliveira (1999). Destes estudos apenas o de Oliveira-Filho et al. (1997) compara períodos diferentes, porém não foi possível confrontar os resultados por eles obtidos com os da presente pesquisa, pois a técnica de ordenação adotada foi diferente e a variável estrutural considerada foi o índice do valor de cobertura (IVC) e não a área dos caules. Os autores relacionam variáveis estruturais e dinâmicas, o que não foi feito no presente estudo.

\section{Parâmetros fitossociológicos}

No sub-bosque, Euterpe edulis, Rudgea jasminoides, Psychotria nuda, Eugenia cuprea e Garcinia gardneriana tiveram os valores mais altos de importância, nos dois levantamentos (Anexo 4). Em seqüência estiveram Malouetia arborea, Astrocaryum aculeatissimum e Calyptranthes lucida, ocupando, porém, posições diferentes nos dois períodos, na ordenação por IVI, relativa ao primeiro levantamento deste componente. Estas 8 espécies podem ser consideradas as mais bem sucedidas na exploração dos recursos do habitat (Felfili, 1994). Em seqüência, teve- 
se: Mollinedia schottiana, Eugenia oblongata, Eugenia mosenii, Marlierea tomentosa, Dahlstedtia pinnata, Marlierea obscura, Calyptranthes lucida, Gomidesia spectabilis, Eugenia mosenii, Eugenia sp1, Sorocea bonplandii, Chrysophyllum flexuosum e Myrcia richardiana. Dentre as espécies citadas merecem destaque: E. oblongata, que ocupava a 10 $0^{\underline{a}}$ posição no primeiro levantamento e passou a 19 ${ }^{\underline{a}}$ no segundo, pela perda de 3 indivíduos; S. bonplandii, 18 segundo, pela perda de 2 indivíduos; e $M$. richardiana, que ocupava a 20aㅡ no primeiro tendo passado para $27^{\text {a }}$ no segundo, pela perda de um indivíduo de grande porte. As mudanças observadas para posições mais elevadas foram ocasionadas pelo crescimento em DAP ou pelo aumento do número de indivíduos. As mudanças para posições inferiores, como as observadas para E. oblongata, S. bonplandii e $M$. richardiana, foram ocasionadas ou pela morte ou pelo maior crescimento das árvores que passaram, como recrutadas, para o componente dominante.

Para o componente dominante, Euterpe edulis, Cryptocarya moschata, Virola oleifera e Chrysophyllum flexuosum tiveram os valores mais altos de importância, nos dois levantamentos (Anexo 5). Malouetia arborea, Hyeronima alchorneoides, Calyptranthes Iucida, Garcinia gardneriana, Pseudopiptadenia warmingii, Eugenia mosenii e Tetrastylidium grandifolium, ocuparam as posições seguintes. Neste grupo de espécies, merecem destaque as trocas de posições de: C. lucida, da $7^{\mathfrak{a}}$ posição no primeiro levantamento para a $11^{\text {a }}$ posição, mantendo o mesmo número de indivíduos, ocorrência devida à morte de um indivíduo com DAP $=24,8 \mathrm{~cm}$ e 0 recrutamento de uma árvore do sub-bosque; G. gardneriana, da $8^{\text {a }}$ posição para a $5^{\text {a }}$, população que teve a ocorrência de morte de 3 indivíduos, compensada numericamente pelo recrutamento de 7 árvores e 0 acréscimo em diâmetros dos caules registrados para as demais árvores. Outras mudanças que se destacaram foram para $M$. tomentosa, da $13^{\text {a }}$ posição para a $18^{\underline{a}}$,C. decandra, da 16 a posição

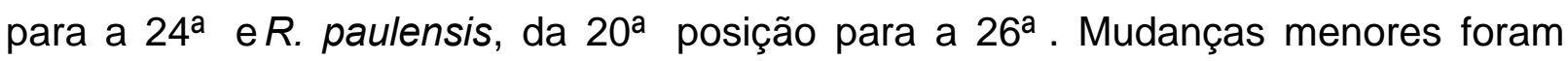
observadas para Myrcia pubipetala, Marlierea tomentosa, Pterocarpus rohrii, Psychotria nuda, Casearia decandra, Sloanea guianensis, Sorocea bonplandii, Rudgea jasminoides e Roupala paulensis.

O que foi exposto acima, pode ser visualizado na Figura 9, que apresenta as espécies comuns aos dois levantamentos, cujos valores de IVI, ordenados pelo 
primeiro levantamento, foram maiores que 3,94, para o componente dominante e, 3,64 para o sub-bosque.

A espécie Euterpe edulis apresenta-se como a mais importante na ordenação por IVI, principalmente, em função de seus altos valores de densidade relativa. A estratégia desta espécie para ocupar as áreas de Florestas Pluviais Tropicais é por meio de numerosos indivíduos de pequeno a médio portes, fato que tem sido observado e relatado em trabalhos disponíveis na literatura. Esta mesma estratégia é apresentada também por Rudgea jasminoides e Psychotria nuda, todas típicas do sub-bosque.

Outra estratégia de ocupação das áreas florestais tropicais é aquela por meio de indivíduos de grande porte, presentes na amostragem com números baixos de indivíduos. Na amostragem do componente dominante, podem-se citar Hyeronima alchorneoides e Pseudopiptadenia warmingii, em posição de destaque.

Ainda uma outra estratégia é observada em espécies que estão presentes nas áreas florestais com indivíduos de grande porte e em números relativamente altos. No componente dominante encontram-se Cryptocarya moschata, Virola oleifera, Chrysophyllum flexuosum, Malouetia arborea e Garcinia gardneriana.

De maneira geral, a estrutura e a composição de espécies do trecho de floresta estudado mantiveram-se, durante o período de 6,8 anos. Esta situação ocorreu àdespeito da mortalidade e do recrutamento registrados para as espécies. Como pode ser observado na Tabela 2, houve um aumento relativamente pequeno no número absoluto dos indivíduos do componente dominante e uma diminuição no dos indivíduos do sub-bosque. Ocorreu o aumento de 1 espécie para o componente dominante e a redução de 4 , no sub-bosque. Concomitantemente a esta mudança, houve aumento maior na área total dos caules do componente dominante e pouca redução na do sub-bosque.

Constância em riqueza de espécies não é surpresa, porque pouco menos de uma década é um período muito curto para medir a dinâmica em espécies de uma comunidade de organismos de vida longa, como as árvores. Seria interessante saber se o número de espécies permanece constante ao longo de períodos maiores (Condit et al., 1992). 
Com a ressalva de que realizar comparações da riqueza específica de diferentes florestas ou diferentes tipos florestais é freqüentemente difícil, devido à grande dissimilitude dos dados disponíveis, ao tamanho da área de amostragem e aos critérios de inclusão adotados que influenciam grandemente o valor de diversidade obtido, uma análise ampla da diversidade de sítios neotropicais, atlânticos e extra-atlânticos, foi apresentada por Negrelle (1995).

A autora afirmou ser previsível, frente à variabilidade latitudinal, altitudinal, pluviométrica e edáfica que ocorre ao longo da faixa de distribuição da Floresta Atlântica, encontrar valores bastante diferenciados, em diferentes pontos. Apesar do número relativamente expressivo de locais que analisou, os dados obtidos não permitiram a elaboração de análises muito aprofundadas sobre a questão da diversidade, principalmente pela variedade de métodos e de critérios de inclusão adotados. A maioria absoluta dos trabalhos extra-atlânticos consultados pela autora não apresentaram informações sobre o número de indivíduos amostrados e nem os valores dos índices de diversidade.

Na presente pesquisa, os índices de diversidade obtidos para o componente dominante foram $H^{\prime}=3,529$ e $H^{\prime}=3,531$, respectivamente para o primeiro e segundo levantamentos, valores abaixo da maioria dos trabalhos analisados por Negrelle (1995). Os valores de $H^{\prime}$ para o sub-bosque, 3,109 e 3,042, respectivamente para cada um dos dois levantamentos, são valores igualmente muito inferiores. As numerosas espécies amostradas com 1 e 2 indivíduos contribuíram de maneira decisiva para todos os valores acima.

Os valores de equabilidade não são comumente fornecidos nos trabalhos sobre estrutura de florestas tropicais. Os valores obtidos na presente pesquisa são considerados baixos, para os dois componentes, nos dois levantamentos, indicando que algumas populações são mais abundantes do que as demais. De fato, na área parcial utilizada para a análise da estrutura do sub-bosque, três espécies ocorreram com números altos de indivíduos em relação æ̀s demais espécies, Euterpe edulis (71 e 69 indivíduos, em cada levantamento realizado), Rudgea jasminoides (64 e 66) e Psychotria nuda (62 e 56). No componente dominante, uma única espécie, Euterpe edulis, contribuiu com 221 indivíduos no primeiro levantamento e 227 no segundo, de um total de 727 e 756 indivíduos, respectivamente. 
A floresta sofreu perturbações naturais, provavelmente causadas por chuvas torrenciais, acompanhadas de ventos fortes, ocorrências comuns na região. Como não se observaram mudanças marcantes na estrutura da floresta no intervalo de tempo, estes eventos naturais devem ter sido de pequeno impacto, causando pouca perturbação na floresta.

\section{Distribuição do tamanho das árvores}

Em geral, podem-se distinguir três modelos de estruturas de tamanho nas populações de plantas de Florestas Úmidas (Bongers et al., 1988 apud MartínezRamos \& Álvarez-Buylla, 1995): a) Tipo I, onde há uma diminuição da freqüência de indivíduos com o aumento no tamanho; b) Tipo II, onde há maior freqüência de indivíduos grandes que pequenos; c) Tipo III: onde se encontra maior freqüência de indivíduos de tamanhos pequenos e grandes que intermediários. Vários autores têm analisado a distribuição dos diâmetros dos caules das árvores em Florestas Tropicais e encontrado a tendência de $\mathrm{J}$ invertido quando todos os indivíduos de todas as espécies são analisados (Hubbell \& Foster, 1987). Estas análises somente podem ser realizadas quando se leva em conta todas as classes de tamanho de uma determinada população, se possível das plântulas até as árvores adultas.

Se a comunidade está em eqüilíbrio, o número de indivíduos jovens deve ser maior do que o de adultos. Há, então, uma contínua afluência de árvores desenvolvendo-se passando gradualmente de uma classe de diâmetro do caule para a imediatamente superior, mas, devido à mortalidade, aquela afluência vai decrescendo cada vez mais, até tornar-se muito pequena na maior classe (Martins, 1996).

A distribuição das classes de tamanho dos caules das árvores amostradas na presente pesquisa é típica de floresta natural regenerando por sementes, com números altos nas classes de tamanhos pequenos e um declínio mais ou menos geométrico com o aumento do tamanho, sugerindo uma distribuição estável das classes de tamanho e de idade (Swaine et al., 1987).

Os valores dos autovalores e da percentagem de inércia (Tabela 3) mostram 
que o primeiro eixo está explicando a maior parte da variação da ordenação, quando se consideram as classes de DAP como a variável estrutural independente, para os dois componentes da floresta, nos dois levantamentos.

Para o sub-bosque, no primeiro levantamento, os dois primeiros eixos explicaram $81,44 \%$ da variação da distribuição dos pontos, e, no segundo, $81,35 \%$ da variação (Tabela 3). Pelo exame da Figura 10, comparando-se os dois levantamentos deste componente, pode-se observar que 3 espécies contribuíram para a classe 1 (DAPs 2,55-3,83cm), Calyptranthes lanceolata, Rudgea jasminoides e Malouetia arborea, sendo que estas últimas também contribuíram para a classe 3 (5,11-6,39cm); Euterpe edulis contribuiu para a classe 2 (3,83-5,11cm); Psychotria nuda contribuiu tanto para as classes $4(6,39-7,67 \mathrm{~cm})$ e $6(8,95-10,23 \mathrm{~cm})$, quanto, um pouco, para a classe 3; Garcinia gardneriana contribuiu para a classe $5(7,67$ $8,95 \mathrm{~cm})$.

Para o componente dominante, no primeiro levantamento, os dois primeiros eixos explicaram $66,02 \%$ da variação da distribuição dos pontos, e no segundo, $75,81 \%$. Comparando-se os dois levantamentos deste componente, pode-se observar na Figura 11 que ocorreram três situações: 1) um acúmulo de espécies contribuindo para as classes 1 e 2, de DAPs menores (9,9-14,8 e 14,8-19,7cm), Euterpe edulis, Garcinia gardneriana, Marlierea tomentosa, Psychotria nuda, Rudgea jasminoides, Eugenia mosenii, Sorocea bonplandii e Myrcia pubipetala, que são espécies típicas de sub-bosque, que atingiram seu limite máximo de crescimento, exceto S. bonplandii, espécie do dossel da floresta, que pode atingir diâmetros dos caules maiores do que estes; 2) para as classes intermediárias de DAPs (de números 3 a 9, com DAPs entre 19,8 a 64,3cm) têm-se Chrysophyllum flexuosum, Malouetia arborea, Calyptranthes lucida e Tetrastylidium gradifolium, espécies do dossel da floresta; 3) contribuindo para as classes de DAPs acima de 64,4cm (de números 10 a 23, com DAPs entre 64,3 a 143,2cm), encontram-se Cryptocarya moschata e Virola oleifera, espécies de grande porte na floresta estudada, que ocuparam posições no dossel superior e tiveram indivíduos emergentes.

No primeiro levantamento Myrcia pubipetala contribuiu para o primeiro agrupamento de classes de DAP; porém, esta espécie não foi considerada no segundo levantamento, por ter deixado de ser uma população abundante. No 
segundo levantamento, duas novas espécies contribuíram para o primeiro agrupamento de classes de DAP: Astrocaryum aculeatissimum e Marlierea obscura.

Os resultados obtidos em análises semelhantes, realizadas por Pascal \& Pelissier (1996) e Elouard et al. (1997), no mesmo trecho de Floresta Tropical Perenifólia de Uppangala, em Western Ghats, Índia, permitiram a identificação de 4 grupos bastante distintos. Segundo os autores, trata-se de uma floresta natural, não sujeita a grandes distúrbios, caracterizada pela alta densidade (635 árvores/ha com $\geq 30 \mathrm{~cm}$ de perímetro), alto valor de área total dos caules das árvores $\left(39,7 \mathrm{~m}^{2} / \mathrm{ha}\right) \mathrm{e}$ riqueza florística não muito alta (91 espécies, em 3,12ha).

Para a comunidade como um todo, a análise das Figuras 12 e 13, considerando a distribuição do número de indivíduos pelas classes de DAP, permite afirmar que o trecho de floresta estudado na presente pesquisa apresenta uma distribuição em $\mathrm{J}$ invertido, tanto no sub-bosque quanto no componente dominante, como já observado para outras Florestas Tropicais naturais regenerando por sementes.

Em relação a distribuição da área dos caules das árvores do sub-bosque, existe uma compensação entre a diminuição do número e o aumento do tamanho dos indivíduos (Figura 12).

Para o componente dominante, esta relação não é observada, pois os valores das áreas dos caules se mantém praticamente semelhantes nos dois levantamentos, independente da diminuição do número de indivíduos (Figura 13).

\section{Abundância das espécies}

Pela amostragem realizada, esta floresta caracteriza-se por conter um número grande de espécies ocorrendo com baixas densidades, assim é que, no componente dominante, somente 14 espécies foram abundantes, com pelo menos 10 árvores/ha, no primeiro levantamento e 15, no segundo; 41 foram ocasionais, com 3 a 9 indivíduos no primeiro levantamento e 43, no segundo; e 53 espécies foram raras, com 1 e 2 indivíduos no primeiro levantamento e 51, no segundo. Já no 
sub-bosque, somente 7 foram abundantes e 20 foram ocasionais, tanto no primeiro quanto no segundo levantamentos; e 37 foram raras no primeiro e 33 , no segundo.

A heterogeneidade ambiental pode afetar a densidade e a distribuição espacial das populações (Hubbell \& Foster, 1983). Determinadas plantas são abundantes nas clareiras e quase não se encontram nas áreas sombreadas na floresta. Já outras podem desenvolver-se de maneira abundante também na sombra. No primeiro levantamento, a palmeira Euterpe edulis chegou a possuir 501 indivíduos com DAP $\geq 2,5 \mathrm{~cm}$, distribuídos amplamente ao longo de toda a parcela, com alturas que variaram de 2,0 a 22,0m (Melo \& Mantovani, 1994). Outras populações, com elevada densidade populacional, não se distribuem de maneira ampla e apresentam um padrão espacial agregado. Esta agregação pode responder a uma dispersão a curta distância e baixos níveis de predação de sementes (Martínez-Ramos \& Álvarez-Buylla, 1995).

A maioria das espécies arbóreas das Florestas Úmidas apresenta densidades populacionais baixas, com freqüência de menos de um indivíduo adulto por hectare (Hubbell \& Foster, 1983). Com freqüência, as populações de baixa densidade são especialistas em habitat, de modo que ocorrem associadas com fases regenerativas da floresta, pouco freqüentes, tais como as clareiras, ou ainda com situações topográficas e solos muito particulares (Hubbell \& Foster, 1986, 1987, 1990). Um processo de extinção local ou o início de um processo de colonização e crescimento, podem explicar a raridade populacional de outras espécies (Hubbell \& Foster, 1986).

Analisando-se a Figura 14, observa-se que houve uma alta correlação tanto para o sub-bosque $(0,9957)$ quanto para o componente dominante $(0,9982)$, apesar das mudanças que ocorreram com a morte e o recrutamento de indivíduos, no intervalo de tempo.

Pela análise da Tabela 4, considerando-se a comunidade como um todo, incluindo todas as espécies amostradas, ocorreu uma maior variação no subbosque, com um aumento do número de indivíduos, em relação ao componente dominante; e, excluindo-se as palmeiras, a variação maior também ocorreu no subbosque, porém com uma diminuição do número de indivíduos. Para o conjunto das espécies ocasionais observa-se variação maior para o sub-bosque, porém com uma diminuição do número de indivíduos. Já para o conjunto das espécies raras, 
consideradas em conjunto, a variação foi praticamente a mesma, com diminuição do número de indivíduos nos dois componentes. Para as populações abundantes, consideradas individualmente, verificou-se que algumas mudaram bastante, enquanto que outras mantiveram sua abundância. Vale destacar as mudanças de tamanho das populações de Psychotria nuda (38,46\%), Tetrastylidium grandifolium (20,0\%), Garcinia gardneriana (21,73\%), Eugenia mosenii $(17,64 \%)$ e Rudgea jasminoides $(9,09 \%)$, com aumento do número de indivíduos no componente dominante; e de Malouetia arborea (-18,18\%, no componente dominante e -14,28\%, no sub-bosque), Psychotria nuda (-9,67, no sub-bosque) e Marlierea tomentosa ($6,66 \%$, no componente dominante), com diminuição do número de indivíduos, no intervalo de tempo.

\section{Conclusões}

- A metodologia utilizada na presente pesquisa permitiu que se realizasse a análise do componente dominante, com o critério de inclusão adotado, sem a participação predominante das populações típicas do sub-bosque, que são constituídas de numerosos indivíduos de tamanhos bastante diferentes. A análise do sub-bosque, embora parcial, foi igualmente eficiente, tendo permitido a análise das populações típicas deste componente nas diversas abordagens da presente pesquisa.

- O tamanho da área utilizada para o estudo do componente dominante foi suficiente para dar conhecimento da representatividade florística, conforme a tendência à estabilização observada nas curvas do coletor. A análise das curvas para o sub-bosque indicou que seria necessário aumentar o número de subparcelas, para se ter alcançado a estabilização. O ideal teria sido aumentar o número de subparcelas para o estudo deste componente.

- A distribuição do número de espécies e de indivíduos amostrados nas subparcelas do componente dominante foi praticamente uniforme, com poucas variações merecendo destaque. 
- A análise da distribuição das espécies nas parcelas utilizadas para a amostragem dos dois componentes, nos dois levantamentos, com base na área total dos caules das árvores, revelou uma variação menor na estrutura da vegetação do trecho de floresta estudado, ao contrário do observado quando se considerou o número de indivíduos. Provavelmente isto se deve à mortalidade maior de indivíduos com diâmetros dos caules menores.

- Observaram-se discretos padrões de distribuição de DAP entre as diferentes populações analisadas, em especial no componente dominante. Basicamente, três situações podem ser descritas: 1) um acúmulo de espécies contribuindo para as classes 1 e 2, de DAPs menores (9,9-14,8 e 14,8-19,7cm), Euterpe edulis, Garcinia gardneriana, Marlierea tomentosa, Psychotria nuda, Rudgea jasminoides, Eugenia mosenii, Sorocea bonplandii e Myrcia pubipetala, que são espécies típicas de subbosque, que atingiram seu limite máximo de crescimento, exceto $S$. bonplandii, espécie do dossel da floresta, que pode atingir diâmetros dos caules maiores do que estes; 2) para as classes intermediárias de DAPs (de números 3 a 9, com DAPs entre 19,8 a 64,3cm) têm-se Chrysophyllum flexuosum, Malouetia arborea, Calyptranthes lucida e Tetrastylidium gradifolium, espécies do dossel da floresta; 3 ) contribuindo para as classes de DAPs acima de $64,4 \mathrm{~cm}$ (de números 10 a 23, com DAPs entre 64,3 a 143,2cm), encontram-se Cryptocarya moschata e Virola oleifera, espécies de grande porte na floresta estudada, que ocuparam posições no dossel e tiveram indivíduos emergentes.

- A distribuição das classes de tamanho dos caules das árvores amostradas na presente pesquisa é típica de floresta natural regenerando por sementes, com números altos nas classes de tamanhos pequenos e um declínio mais ou menos geométrico com o aumento do tamanho, sugerindo uma distribuição estável das classes de tamanho e de idade.

- As espécies que se destacaram pelos valores de importância no sub-bosque, nos dois levantamentos, foram: Euterpe edulis, Rudgea jasminoides, Psychotria nuda, Eugenia cuprea e Garcinia gardneriana, seguidas de Malouetia arborea, Astrocaryum aculeatissimum e Calyptranthes lucida, com os 3 valores maiores seguintes, porém ocupando posições diferentes nos dois períodos. 
- Euterpe edulis, Rudgea jasminoides e Psychotria nuda, espécies típicas do subbosque, apresentam uma estratégia característica para ocupar as áreas de Florestas Pluviais Tropicais: numerosos indivíduos de pequeno a médio portes.

- As espécies que se destacaram pelos valores de importância no componente dominante, nos dois levantamentos, foram: Euterpe edulis, Cryptocarya moschata, Virola oleifera e Chrysophyllum flexuosum, seguidas de Malouetia arborea, Hyeronima alchorneoides, Calyptranthes lucida, Garcinia gardneriana, Pseudopiptadenia warmingii, Eugenia mosenii e Tetrastylidium grandifolium, com troca de posições de um período de amostragem para o outro.

- Outra estratégia de ocupação das áreas de Florestas Tropicais é aquela por meio de indivíduos de grande porte e em números relativamente altos de indivíduos, como Cryptocarya moschata, Virola oleifera, Chrysophyllum flexuosum, Malouetia arborea e Garcinia gardneriana. Ainda no componente dominante, encontram-se Hyeronima alchorneoides e Pseudopiptadenia warmingii, com uma outra estratégia: indivíduos de grande porte, presentes na amostragem com números baixos de indivíduos.

- Com base na ordenação das espécies, pela importância que ocupam na comunidade como um todo, pode-se afirmar que o trecho de Floresta Pluvial Tropical estudado é estruturalmente dinâmico.

- Os valores de diversidade obtidos, respectivamente para cada levantamento efetuado, foram: para o sub-bosque, 3,109 e 3,042, mais baixos que os obtidos para o componente dominante, 3,529 e 3,531. Estes valores, quando comparados com outros, obtidos em estudos de Florestas Pluviais Tropicais Atlânticas, são considerados muito baixos. A presença de espécies representadas na área com muitos indivíduos contribuiu para esta ocorrência. De 108 e 109 espécies amostradas no componente dominante, no primeiro e segundo levantamentos, $53 \mathrm{e}$ 51 espécies, respectivamente, estavam representadas por 1 e 2 indivíduos por hectare.

- Os valores de equabilidade obtidos, respectivamente para os dois levantamentos, foram: para o sub-bosque, 0,748 e 0,743 , mais baixos que aqueles encontrados para o componente dominante, 0,754 e 0,753. Para o sub-bosque, contribuiu a abundância com que foram amostradas 3 espécies, Euterpe edulis (71 e 69 
indivíduos, em cada levantamento realizado), Rudgea jasminoides (64 e 66) e Psychotria nuda (62 e 56), populações típicas deste componente. Para o componente dominante, uma única espécie contribuiu para a diminuição deste índice, Euterpe edulis, amostrada por 221 indivíduos no primeiro levantamento e 227 no segundo, de um total de 727 e 756 indivíduos, respectivamente.

- Deve-se ressaltar a dificuldade em interpretar os dados obtidos no presente estudo, pelas incertezas sobre os eventos ocorridos durante os anos que se sucederam após o primeiro levantamento. Muito provavelmente foram as tempestades e a interferência antrópica que provocaram a morte de 13,3\% do total de árvores consideradas para análise demográfica, a ser apresentada no próximo capítulo.

- De maneira geral, a composição de espécies e a estrutura do trecho de floresta estudado mantiveram-se, durante o período de 6,8 anos. Esta situação ocorreu à despeito da mortalidade e do recrutamento registrados para as espécies.

- Pode-se concluir que a Floresta Pluvial Tropical Atlântica na llha do Cardoso é uma floresta natural, que não está sujeita àgrandes distúrbios naturais, podendo ser considerada uma floresta climácica, cuja dinâmica interna responde às mudanças observadas.

\section{Referências bibliográficas}

Ashton, P.S. \& Hall, P. 1992. Comparisons of structure among mixed dipterocarp forests of north-western Borneo. Journal of Ecology 80:459-481.

ter Braak, C.J.F. 1987. Ordination. In Jongman, R.H.G., Braak, C.J.F. \& van Tongeren, O.F.R. Data analysis in community and landscape ecology. Pudoc, Wageningen. p.91-173.

Cain, S.A.; Castro, G.M.O.; Pires, J.M. \& Silva, N.T. 1956. Application of some phytosociological techniques to Brazilian rain forest. American Journal of Botany 43:911-941.

Condit, R., Hubbell, S.P. \& Foster, R.B. 1992. Short-term dynamics of a neotropical forest. BioScience 42(11):822-828.

Curtis, J.T.\& Mclntosh, R.P. 1950. The interrelationsl of certain analytic and synthetic phytosociological characters. Ecology 31:434-455. 
Elouard, C.; Pascal, J.-P.; Pélissier, R.; Ramesh, B.R.; Houllier, F.; Durand, M.; Aravajy, S.; Moravie, M.-A. \& Carpentier-Gimaret, C. 1997. Monitoring the structure and dynamics of a dense moist evergreen forest in the Western Ghats (Kodagu District, Karnataka, India). Tropical Ecology 38(2):193-214.

Felfili, J.M. \& Silva Junior, M.C. 1992. Floristic composition, phytosociology and comparison of cerrado and gallery forests at Fazenda Água Limpa, Federal District, Brazil. In P.A. Furley, J.A. Proctor \& J.A. Ratter. Nature and dynamics of forest-savanna boundaries. Champman \& Hall, London. p.393-416.

Felfili, J.M. 1994. Floristic composition and phytosociology of the gallery forest alongside the Gama stream in Brasília, DF, Brazil. Revista Brasileira de Botânica 17(1):1-11.

Felfili, J.M. 1997a. Diameter and hight distributions in a gallery forest tree community and some of its main species in central Brazil over a six-year period (1985-1991). Revista Brasileira de Botânica 20(2):155-162.

Felfili, J.M. 1997b. Dinamics of the natural regeneration in the Gama gallery forest in central Brazil. Forest Ecology and Management 91:235-245.

Gomes, E.P.C. 1998. Dinâmica do componente arbóreo de um trecho de mata em São Paulo, SP. Tese de Doutorado, Instituto de Biociências, Universidade de São Paulo, São Paulo, 285p.

Guariguata, M.R., Chazdon, R.L., Denslow, J.S., Dupuy, J.M. \& Anderson, L. 1997. Structure and floristics of secondary and old-growth forest stands in lowland Costa Rica. Plant Ecology 132:107-120.

Guedes-Bruni, R.R. 1998. Composição, estrutura e similaridade florística de dossel de seis unidades de Mata Atlântica no Rio de Janeiro. Tese de Doutorado, Instituto de Biociências, Universidade de São Paulo, São Paulo, 231p.

Ho, C.C., Newbery, D. McC. \& Poore, M.E. 1987. Forest composition and inferred dynamics in Jengka Forest Reserve, Malaysia. Journal of Tropical Ecology (Special Issue) 3(1):25-56.

Hubbell, S.P. \& Foster, R.B. 1983. Diversity of canopy trees in a neotropical forest and implications for conservation. In S.L. Sutton, T.C. Whitmore \& A.C. Chadwick (eds.). Tropical Rain Forest: Ecology and Management. Special Publication n.2 of British Ecological Society. Blackwell Scientific Publications, Oxford. p.25-41.

Hubbell, S.P. \& Foster, R.B. 1986. Commonness and rarity in a neotropical forest: implications for tropical tree conservation. In M. Soulé (ed.). Conservation Biology. Sinauer, Massachusetts. p.205-231.

Hubbell, S.P. \& Foster, R.B. 1987. La estructura espacial en gran escala de un bosque neotropical. Revista de Biologia Tropical 35(Suplemento 1):7-22.

Hubbell, S.P. \& Foster, R.B. 1990. Structure, dynamics, and equilibrium status of old-growth forest on Barro Colorado Island. In A.H. Gentry (ed.). Four neotropical forests. Yale University Press, New Haven. p.522-541.

Hubbell, S.P. \& Foster, R.B. 1992. Short-term dynamics of a neotropical forest: why ecological research matters to tropical conservation and management. Oikos 63(1):4861.

Knight, D.H.1975. A phytosociological analysis of species-rich tropical forest on Barro Colorado Island, Panama. Ecological Monographs 45:259-284.

Knobel, M.G. 1995. Aspectos da regeneração natural do componente arbóreo-arbustivo de trecho da floresta da Reserva Biológica do Instituto de Botânica de São Paulo, 
SP. Dissertação de Mestrado, Instituto de Biociências, Universidade de São Paulo, São Paulo, 128p.

Lieberman, D., Lieberman, M., Hartshorn, G.S. \& Peralta, R. 1985. Small-scale altitudinal variation in lowland wet tropical forest vegetation. Journal of Ecology 73:505-516.

Magurran, A.E. 1988. Ecological diversity and its measurement. Cambridge University Press, Cambridge. 179p.

Manokaran, N. \& Kochumen, K.M. 1987. Recruitment, growth and mortality of tree species in a lowland dipterocarp forest in Peninsular Malaysia. Journal of Tropical Ecology (Special Issue) 3:315-330.

Mantovani, W., Rodrigues, R.R., Rossi, L., Romaniuc Neto, S., Catharino, E.L.M., Cordeiro, I. 1990. A vegetação na Serra do Mar em Salesópolis, SP. In Anais do II Simpósio de Ecossistemas da Costa Sul e Sudeste Brasileira - Estrutura, função e manejo, Águas de Lindóia. v. 1. p.348-384.

Mantovani, W. 1993. Estrutura e dinâmica da floresta atlântica na Juréia, Iguape - SP. Tese de Livre Docência, Instituto de Biociências, Universidade de São Paulo, São Paulo, 126p.

Martínez-Ramos, M. \& Alvarez-Buylla, E. 1995. Ecología de poblaciones de plantas en una selva húmeda de México. Boletim Sociedad Botánica de México 56:121-153.

Martins, F.R. 1996. Aspectos da organização de uma comunidade arbórea florestal: um estudo prático. Apostilha do Curso Ecologia Vegetal BT-682. 18p.

Melo, M.M.R.F. \& Mantovani, W. 1994. Composição florística e estrutura de trecho de Mata Atlântica de encosta, na Ilha do Cardoso (Cananéia, SP, Brasil). Boletim do Instituto de Botânica 9:107-158.

Mueller-Dombois, D. \& Ellenberg, H. 1974. Aims and methods of vegetation ecology. John Wiley, New York. 547p.

Negrelle, R.R.B. 1995. Composição florística, estrutura fitossociológica e dinâmica de regeneração da floresta atlântica na Reserva de Volta Velha, Município Itapoá, SC. Tese de Doutorado, Centro de Ciências Biológicas e da Saúde, Universidade Federal de São Carlos, São Carlos, 222p.

Okali, D.U.U. \& Ola-Adams, B.A. 1987. Tree population changes in treated rain forest at Omo Forest Reserve, south-western Nigeria. Journal of Tropical Ecology (Special Issue) 3:291-313.

Oliveira Filho, A.T., Mello, J.M. \& Scolforo, J.R.S. 1997. Effects of past disturbance and edges on tree community structure and dynamics within a fragment of tropical semidecidous forest in south-eastern Brazil over a five-year period (1987-1992). Plant Ecology 131:45-66.

Oliveira, R.J. 1999. Dinâmica de plântulas e estrutura da Mata Atlântica Secundária de encosta, Peruíbe, SP. Dissertação de Mestrado, Instituto de Biociências, Universidade de São Paulo, São Paulo, 125p.

Pascal, J. \& Pelissier, R. 1996. Structure and floristic composition of a tropical evergreen forest in South-west Índia. Journal of Tropical Ecology 12:191-214.

Peralta, R., Hartshorn, G.S., Lieberman,D. \& Lieberman, M. 1987. Reseña de estudios a largo plazo sobre composición florística y dinámica del bosque tropical en La Selva, Costa Rica. Revista de Biologia Tropical 35(Supl. 1):23-39. 
Sampaio, P.D. 1997. Estrutura e floristica de floresta atlântica secundária - Reserva Biológica Estadual da Praia do Sul, Ilha Grande, RJ. Dissertação de Mestrado, Instituto de Biociências, Universidade de São Paulo, São Paulo, 117p.

Shepherd, G.J. 1996. FITOPAC I. Manual do usuário. Instituto de Biologia, Universidade Estadual de Campinas, Campinas.

Silva, A.F. \& Leitão Filho, H.F. 1982. Composição florística e estrutura de um trecho de mata atlântica de encosta no município de Ubatuba (São Paulo, Brasil). Revista Brasileira de Botânica 5(1-2):43-52.

Silva, J.A., Salomão, A.N., Gripp, A. \& Leite, E.J. 1997. Phytosociological survey in brazilian forest genetic reserve of Caçador. Plant Ecology 133:1-11.

Sussman, R.W. \& Rakotozafy, A. 1994. Plant diversity and structural analysis of a tropical dry forest in southwestern Madagascar. Biotropica 26(3):241-254.

Swaine, M.D., Hall, J.B. \& Alexander, I.J. 1987. Tree populations dynamics at Kade, Ghana (1968-1982). Journal of Tropical Ecology (Special Issue) 3:331-345.

Tabarelli, M., Villani, J.P. \& Mantovani, W. 1993. Aspectos da sucessão secundária em trecho da floresta atlântica no Parque Estadual da Serra do Mar, SP. Revista do Instituto Florestal 5(1):99-112.

Tabarelli, M., Villani, J.P. \& Mantovani, W. 1994. Estudo comparativo da vegetação de dois trechos de floresta secundária no Núcleo Santa Virgínia, Parque Estadual da Serra do Mar, SP. Revista do Instituto Florestal 6:1-11.

Thorington Junior, R.W., Tannenbaum, B., Tarak, A. \& Rudran, R. 1982. Distribution of trees on Barro Colorado Island: a five hectare sample. In E.G. Leigh Junior, A.S. Rand \& D.M. Windsor (eds.). The ecology of a tropical forest: seasonal rhytms and long-term changes. Smithsonian Institution Press, Washington, D.C., p.83-94.

Vincent, R.C. 1997. Florística, estrutura e sucessão de matas ripárias em Cosmópolis (SP). Dissertação de Mestrado, Instituto de Biociências, Universidade de São Paulo, São Paulo, 146p.

Wright, D.D., Jessen, J.H., Burke, P. \& Garza, H.G.S. 1997. Tree and liana enumeration diversity on a one-hectare plot in Papua New Guinea. Biotropica 29(3):250-260. 


\section{Capítulo 4}

\section{CRESCIMENTO, RECRUTAMENTO E MORTALIDADE DE ÁRVORES EM FLORESTA PLUVIAL TROPICAL ATLÂNTICA, ILHA DO CARDOSO, SP, BRASIL}

\section{Introdução}

A Ecologia compartilha com os economistas um interesse especial. As características demográficas das árvores tropicais limitam a taxa potencial de extração e, conseqüentemente, a rentabilidade. Quando um ecologista descreve a abundância e a distribuição de plantas úteis, os resultados também poderão informar os cálculos dos recursos econômicos (LaFrankie, 1994). Informações sobre as árvores de Florestas Pluviais são particularmente relevantes do ponto de vista ecológico, porque estas árvores constituem um componente importante da maioria dos biomas mais ricos em espécies no mundo. As informações sobre as taxas de crescimento, recrutamento e mortalidade das espécies arbóreas são necessárias para o entendimento da ecologia da Floresta Tropical, podendo ser utilizadas para avaliar se estas populações estão sendo substituídas por outras. No entanto, as Florestas Pluviais Tropicais estão sendo cortadas a taxas rápidas em todo o mundo (Nicholson, 1965; Primack et al., 1985; Primack. \& Lee, 1991; LaFrankie, 1994).

Estudos sobre as mudanças espaciais e temporais em Florestas Pluviais Tropicais naturais são necessários para que se possa estabelecer diferenças entre o impacto causado pelo homem e os processos dinâmicos naturais. Porém, diferentemente das Florestas Temperadas, onde é possível se realizar estudos das mudanças temporais a partir das medições de crescimento dos anéis que se formam nos troncos das árvores, nas Florestas Pluviais Tropicais estes estudos necessitam ser monitorados ao longo de determinados períodos de tempo (Korning \& Balslev, 1994a, b). 
Em todas as florestas há um ciclo sucessional iniciado por distúrbio, tenha este ocorrido pela ação do homem ou naturalmente. Em cada ciclo, arbitrariamente, reconhecem-se numa floresta três fases: a de clareira, seguida de uma fase de construção, e, finalmente, a madura. Pode-se, deste modo, considerar uma floresta como um mosaico espacial de fases estruturais, sujeita a mudanças através do tempo, como resultado de processos dinâmicos (Whitmore, 1989a). Portanto, as comunidades florestais são dinâmicas e as mudanças ocorrem continuamente ao longo do tempo, tanto no nível dos indivíduos, quanto no das populações, mesmo que a comunidade como um todo permaneça estável, devido à compensação entre crescimento, recrutamento e mortalidade (Felfili, 1995).

Encontram-se na literatura vários estudos sobre a dinâmica das Florestas Tropicais, a maioria realizada em parcelas permanentes, com censos feitos em intervalos de tempo variados, dentre os quais podem citar-se: Crow \& Weaver (1977), Crow (1980) e Parresol (1995), em Luquillo Experimental Forest, El Verde, Porto Rico; Uhl (1982) e Uhl et al. (1988), em San Carlos de Río Negro, Venezuela; Putz \& Milton (1982), Lang \& Knight (1983), Hubbell \& Foster (1990a), Condit et al. (1992a, b, 1993, 1995), Milton et al. (1994) e Gilbert et al. (1994), na llha do Barro Colorado, Panamá; Primack et al. (1985) e Ashton \& Hall (1992), em Sarawak e Brunei, Ilha de Bornéo, Malásia; Lieberman et al. (1985a, b, 1990), Peralta et al. (1987), Clark \& Clark (1987, 1991, 1992, 1996) e Lieberman \& Lieberman (1987, 1994), na Estação Biológica de La Selva, Costa Rica; Okali \& Ola-Adams (1987), na Reserva Florestal de Omo, Nigéria, África; Swaine et al. (1987, 1990), em Kade e Shai Hills, Gana, África; Manokaran \& Kochummen (1987, 1994), em Sungei Menyala, Malásia; Whitmore (1989b), em floresta pluvial na llha de Kolombangara, no sudeste do Pacífico; Gentry \& Terborgh (1990), Phillips \& Gentry (1994), Phillips et al. (1994) e Terborgh et al. (1997), em Cocha Cashu, rio Manu, Peru; Jardim (1990); Rankin-de-Merona et al. (1990, 1992) e Laurance et al. (1998), no Distrito Agropecuário da SUFRAMA, Estado do Amazonas, Brasil; Álvarez Buylla \& Martínez-Ramos (1992), em Los Tuxtlas, Veracruz, México; Sukumar et al. (1992), em Mudalamai Game Reserve, Tamil Nadu, Índia; Batista (1994) e Rolim (1997), na Reserva Florestal de Linhares, Estado do Espírito Santo, Brasil; Carey et al. (1994), em Merida, Venezuela; Herwitz \& Young (1994), em Bellenden-Ker, Queensland, Austrália; Korning \& Balslev (1994a, b), em Añangu, Equador; Felfili (1995, 1997), 
em floresta de galeria do rio Gama, em Brasília, Distrito Federal, Brasil; Silva et al. (1995), na Floresta Nacional do Tapajós, Santarém, Estado do Pará, Brasil; van der Meer \& Bongers (1996), em Nouragues, Guiana Francesa; Elouard et al. (1997), nos Western Ghats, Uppangala, Índia; Oliveira-Filho et al. (1997), na Reserva Florestal da Universidade Federal de Lavras, Estado de Minas Gerais, Brasil; Gomes (1998), em floresta de planalto na capital do Estado de São Paulo, Brasil.

A maioria buscou, como um dos principais objetivos, o entendimento da regeneração das árvores tropicais, através do estudo de seu ciclo de vida. Em suas conclusões, estes autores afirmaram que estes estudos ainda são insuficientes para um bom entendimento da dinâmica da Floresta Tropical.

Uma análise ampla das características das parcelas permanentes utilizadas no acompanhamento de mudanças demográficas de 110 locais situados no continente americano, na Ásia, na África e na Oceania, dos resultados obtidos e das hipóteses envolvidas nessas pesquisas, foi apresentada por Gomes (1998). As principais hipóteses envolvidas nas explicações sobre a dinâmica das florestas foram assim resumidas:

Numa análise sobre a dinâmica e a riqueza de espécies em 25 florestas pluviais tropicais, Phillips et al. (1994) chegaram à conclusão de que quanto mais desenvolvida a floresta, isto é, maior altura do dossel e área total dos caules das árvores que a compõem, maior a riqueza e maior a dinâmica local, isto é, ocorrerão mortalidade e recrutamento a taxas mais altas.

Após analisarem as taxas de mortalidade e recrutamento de 40 sítios de florestas tropicais, Phillips \& Gentry (1994) sugeriram que, a partir de 1950, a dinâmica vem aumentando, provavelmente, devido ao aumento de gases que contribuem para o efeito estufa na atmosfera. Sheil (1995), Sheil et al. (1995) e Sheil \& May (1996), rebatendo as conclusões a que chegaram Phillips et al. (1994), afirmaram que somente o acompanhamento de um número elevado de parcelas permanentes, que utilizassem procedimentos de coleta e análise de dados padronizados, poderia responder se a dinâmica difere significativamente entre regiões fitogeográficas distintas. O erro na revisão de Phillips et al. (1994) apontado pelos autores era de que a tendência encontrada poderia ser motivada por um artefato matemático no cálculo das taxas, pois quanto menor o intervalo entre 
censos, maior tende a ser a taxa obtida, acrescido do emprego de parcelas tendenciosas. Phillips (1996) ampliou a análise de 40 para 67 parcelas, procurando provar que mesmo com o artefato apontado pelos críticos havia uma tendência no aumento da dinâmica das florestas, significativa a partir de 1950.

Foram registradas diferenças as taxas de mortalidade obtidas em trechos situados no fundo de um vale e mais próximo ao topo da colina por Herwitz \& Young (1994). Estes autores chegaram àconclusão de que a riqueza de espécies pode não ser o fator que causa uma maior dinâmica local, mas sim, conseqüência de variações topográficas do terreno o que, por sua vez, também estaria favorecendo a morte das árvores por queda ou variações na disponibilidade de água.

Foram detectadas variações na presença e na abundância relativas de espécies em escala local, no estudo realizado por Lieberman et al. (1985a), em La Selva, onde terrenos um pouco mais inclinados e acidentados tenderam a apresentar uma maior riqueza de espécies.

Uma hipótese apresentada por Gomes (1998) diz que na verdade uma causa comum é que estaria agindo, simultaneamente, sobre a alta biodiversidade e a dinâmica. Por exemplo, a declividade do terreno proporcionaria variações das propriedades do solo, que por sua vez é que estariam agindo como fatores reguladores da biodiversidade e dinâmica da floresta.

Neste contexto, procurando contribuir para o conhecimento da dinâmica da Floresta Pluvial Tropical Atlântica, o presente trabalho objetivou, principalmente:

1) Determinar as taxas de crescimento, de recrutamento e de mortalidade de indivíduos jovens e adultos de diferentes populações arbóreas, considerando aquelas do sub-bosque e do componente dominante.

2) Analisar o crescimento, o recrutamento e a mortalidade em populações arbóreas agrupadas por categorias sucessionais, por classes de diâmetro do caule, pelas síndromes de dispersão e pela abundância.

3) Comparar os resultados obtidos com os de outros trabalhos que usaram parcelas permanentes em Florestas Pluviais Tropicais, discutindo aspectos de sua dinâmica. 
Esperava-se com o desenvolvimento da presente pesquisa, responder às seguintes perguntas:

1) As taxas médias anuais de crescimento absolutas variaram em função das síndromes de dispersão, características sucessionais, classes de DAP das árvores ou abundância apresentadas pelas espécies amostradas nos dois componentes?

2) As taxas médias anuais de recrutamento e mortalidade relativas variaram em função das classes de DAP das árvores?

3) Existiu um padrão de distribuição das árvores que morreram no intervalo de tempo entre os dois levantamentos?

4) As mortes estão sendo compensadas pelo recrutamento de árvores no trecho de floresta estudado?

Formulou-se a seguinte hipótese: A Floresta Pluvial Tropical é estável, apresentando mudanças ao longo do tempo e encontra-se em eqüilíbrio dinâmico.

\section{Material e métodos}

A descrição da área e dos levantamentos realizados encontram-se detalhados no Capítulo 2.

Para proceder à análise do crescimento, do recrutamento e da mortalidade das árvores, dividiu-se a comunidade amostrada no primeiro levantamento, realizado no período de agosto de 1987 a novembro de 1990, em dois componentes, dominante e sub-bosque, analisando-os separadamente. O componente dominante compreendeu as árvores com DAP $\geq 9,9 \mathrm{~cm}$, amostradas em 40 unidades amostrais de $250 \mathrm{~m}^{2}$, praticamente contíguas não fossem os dois riachos estreitos que cortam a parcela permanente de 1 ha. $O$ sub-bosque compreendeu as árvores com 2,5 $\leq$ DAP $<9,9 \mathrm{~cm}$, amostradas em 10 unidades amostrais, sorteadas entre as 40 , totalizando 1/4ha. Alguns estudos compararam, também, crescimento e mortalidade de árvores 
muito grandes com aquelas árvores menores, como o realizado por Clark \& Clark (1996) na Floresta Pluvial Tropical de planície em La Selva, dentre outros.

Para cada indivíduo arbóreo foram anotadas as seguintes informações: número da placa de identificação, nome da espécie e perímetros do caule a 1,30m de altura do solo, medidos no primeiro e no segundo levantamentos $(\mathrm{cm})$, posteriormente convertidos em diâmetros $(\mathrm{cm})$. Foram registradas as datas de todas as medições, para o cálculo do $\Delta_{t}$ (intervalo de tempo), que é dado em anos e, se necessário, em fração do ano.

$\mathrm{Na}$ análise de demografia foram excluídos três indivíduos: um representante de Talauma ovata (placa 2547), um de Tetrastylidium grandifolium (placa 592) e um de Astrocaryum aculeatissimum (placa 623). O primeiro deixou de ser medido no levantamento de 1987-89, por erro amostral, e os outros dois, igualmente no segundo. No entanto, foram incluídos na análise de estrutura (Capítulo 2).

As populações amostradas em cada componente foram agrupadas de quatro maneiras diferentes: quanto à abundância com que foram amostradas no primeiro levantamento; quanto æ̀s classes de diâmetro do caule æ̀s quais pertenciam os seus indivíduos; quanto às síndromes de dispersão; e quanto às características sucessionais que apresentam. Knight (1975), analisando os resultados dos primeiros trabalhos realizados na llha do Barro Colorado, usando métodos quantitativos na análise de dados florísticos, concluiu que a análise dos dados de certos agrupamentos de espécies, permitem extrair muito mais informações ecológicas do que a dos dados de todas as espécies em conjunto.

Para proceder à análise de crescimento, de recrutamento e de mortalidade das populações quanto às suas abundâncias, em relação ao primeiro levantamento, estas foram divididas em: populações raras - aquelas representadas por 1 e 2 indivíduos na área amostrada (1ha); populações ocasionais - representadas por 3 a 9 indivíduos por hectare; populações abundantes - aquelas que tiveram ao menos 10 sobreviventes por hectare do primeiro levantamento.

Em outros estudos, a abundância também foi considerada em relação ao primeiro levantamento (Primack \& Hall, 1992; Gomes, 1998). Até o trabalho de Welden et al. (1991), as espécies amostradas na parcela permanente instalada na 
Floresta Tropical da llha do Barro Colorado, eram classificadas, em relação æ̀ abundâncias, como raras e comuns - as raras representadas por um indivíduo por hectare e as demais, comuns. Foi a partir deste trabalho que as espécies passaram a ser classificadas em três grupos: raras, com densidade de 1 indivíduo por hectare; ocasionais, quando a densidade variava de 1 a 10 indivíduos por hectare e, comuns, - com mais de 10 indivíduos por hectare. No presente trabalho, adotou-se a classificação das populações em três grupos, porém, considerou-se como rara, a espécie que apresentou densidade de 1 e 2 indivíduos por hectare.

Lieberman \& Lieberman (1994) afirmaram ser duvidoso o tratamento das espécies raras agrupadas como uma única guilda. Não obstante, trataram-se no presente trabalho não somente as espécies raras como uma população única, mas também as espécies consideradas como ocasionais.

Segundo Lieberman \& Lieberman (1994), muitas espécies das Florestas Tropicais são, necessariamente, relativamente raras por causa da diversidade local, que é alta. Os autores citaram Rabinowitz (1981) como um dos biologistas tropicais que tem procurado investigar as implicações desta raridade. Este autor notou que a raridade em uma determinada área pode aumentar por muitas razões, envolvendo a combinação da faixa de variação geográfica, da especificidade de habitat e do tamanho da população local, e, mais importante, raridade em uma área necessariamente não implica raridade em outra.

Para analisar o crescimento, o recrutamento e a mortalidade das populações, com base na distribuição das classes de diâmetros dos caules dos indivíduos, elaboraram-se gráficos com uma amplitude de classe igual a $10 \mathrm{~cm}$ para 0 componente dominante e de $2,5 \mathrm{~cm}$ para o sub-bosque, em progressão aritmética. Adotou-se a amplitude de $10 \mathrm{~cm}$ para o componente dominante, de modo a não se obter um número excessivo de classes diamétricas.

Condit et al. (1993) examinaram a relação entre a mortalidade e o crescimento e os valores de diâmetros dos caules. Analisaram, também, a variação das taxas de crescimento pelo tamanho das árvores. Estas análises são particularmente importantes do ponto de vista do manejo, porque o entendimento da variação em crescimento pode ajudar a desvendar o mistério que é o aumento em crescimento de uma floresta manejada ou plantada. 
As análises do crescimento, do recrutamento e da mortalidade, foram realizadas ainda com base na síndrome de dispersão apresentada pelas diferentes populações As espécies foram agrupadas em três categorias, baseadas nas características das unidades de dispersão ou diásporos, segundo Pijl (1972): a) anemocóricas: existência de mecanismos que facilitam a sua dispersão pelo vento; b) zoocóricas: existência de atrativos que permitam a dispersão por animais; c) autocóricas: existência de mecanismos de auto-dispersão, como a deiscência explosiva dos frutos.

$\mathrm{Na}$ falta de dados sobre os requisitos de luz para as árvores tropicais, é possível usar-se a distribuição diamétrica dos troncos para classificar as espécies nas categorias de tolerantes ou intolerantes à sombra (Hubbell \& Foster, 1987). A suposição dos autores era a de que as espécies intolerantes à sombra teriam distribuições "senis", termo usado para uma espécie com, relativamente, pouca regeneração durante muito tempo, ou seja, com poucas árvores jovens por adulto, porque clareiras grandes aparecem com muito menos freqüência do que clareiras pequenas. Ao contrário, esperavam que as espécies tolerantes à sombra tivessem distribuições "jovens", em uma forma mais ou menos exponencial. Num gráfico, esta distribuição tem a forma de $\mathrm{J}$ invertido, por causa da existência de muitos troncos pequenos por adultos. Estas espécies têm capacidade de regenerar em clareiras pequenas e sobreviver por muito tempo como jovens suprimidos no sub-bosque, e, conseqüentemente, devem demonstrar uma regeneração contínua. Os autores alertam, no entanto, que é possível se incorrer em erro quando se classifica uma espécie como intolerante ou tolerante à sombra usando, como único critério, a distribuição diamétrica de população local.

Partindo da premissa que a riqueza em espécies de uma Floresta Pluvial Tropical cria dificuldades para as análises ecológicas, e considerando que estas dificuldades podem ser minimizadas pela classificação das espécies em grupos ecológicos, Swaine \& Whitmore (1988), propuseram a divisão das espécies arbóreas em apenas dois grupos ou guildas - pioneiras e não pioneiras ou clímax, baseados nos requerimentos para germinação das sementes e estabelecimento das plântulas. Para estes autores, é mais importante estabelecer o grupo ao qual a espécie pertence, do que sua identificação botânica. 
O agrupamento das espécies quanto æ̀s características que apresentam no processo sucessional, permite contornar o problema da maioria das espécies ser representada somente por poucos indivíduos na área amostrada (Manokaran \& Kochummen, 1994).

Assim como Oliveira-Filho et al. (1997), que adotaram o sistema de classificação baseado nos grupos ecológicos de Swaine \& Whitmore (1988), para Florestas Pluviais Tropicais, as populações arbóreas amostradas no presente trabalho foram consideradas em dois grupos principais, quanto à características que apresentam no processo sucessional - grupo 1, das espécies iniciais e 2, das tardias. O grupo das iniciais é constituído por espécies arbóreas de vida curta; que requerem aberturas no dossel para germinação e estabelecimento; mostram crescimento rápido; são extremamente demandantes de luz, desenvolvendo-se sob luz intensa a não muito intensa, intolerantes à sombra. $O$ grupo das tardias desenvolve-se em condições de sombra nas fases iniciais de crescimento, ou de luminosidade moderada, porém são relativamente tolerantes à sombra durante os estádios tardios da sucessão, podendo persistir para formar parte da floresta madura. Pertencem a este grupo as espécies de dossel e as emergentes, que necessitam de elevada luminosidade para a conclusão do seu desenvolvimento em altura, floração e frutificação. No presente trabalho, as espécies típicas de subbosque, tolerantes àsombra, foram incluídas no grupo das tardias.

A listagem das espécies arbóreas, com suas respectivas classificações nos dois grupos, é apresentada no Anexo 2. Esta listagem é fruto da compilação de classificações disponíveis em trabalhos realizados em outras Florestas Tropicais, indicada em: Catharino (1990), Lorenzi (1992), Leitão Filho (1993), Mantovani (1993), Roizman (1993), Tabarelli et al. (1993), Rossi (1994), Tabarelli (1994), Gandolfi et al. (1995), Knobel (1995), Aragaki (1997), Sampaio (1997), Gomes (1998) e Oliveira (1999), acrescida das observações de campo realizadas pela autora. Também apresenta-se nesta listagem, a classificação das espécies quanto à síndrome de dispersão. 


\section{Estrutura da floresta}

O Capítulo 3 apresenta a estrutura do trecho estudado de Floresta Pluvial Tropical Atlântica, na llha do Cardoso, comparando os dois componentes da floresta, sub-bosque e componente dominante, num intervalo de tempo médio de 6,8 anos.

\section{Dinâmica da floresta}

Para a discussão sobre a dinâmica do trecho de Floresta Tropical estudado foram efetuados os cálculos das taxas médias anuais de crescimento (absolutas e relativas), de recrutamento e de mortalidade (relativas). Calcularam-se, também, os valores de lambda, dos tempos de meia vida e do tempo para dobrar. Estes valores foram calculados para todas as espécies, para o conjunto das espécies excluindo as palmeiras, para os conjuntos das espécies raras e das espécies ocasionais e para todas as espécies abundantes, de cada componente estudado.

\section{Crescimento}

A ausência generalizada de anéis de crescimento anuais em árvores tropicais impede o uso de abordagens indiretas, convenientes ao estudo dos processos dependentes do tempo, tais como crescimento e mortalidade. Repetição de inventários de indivíduos etiquetados são geralmente necessários para se obter, com segurança, a maioria dos dados básicos, e a utilidade deles depende fortemente, tanto do intervalo de tempo entre inventários, quanto do tamanho da amostra (Lieberman et al., 1985b). Taxas de crescimento obtidas dessa maneira, podem fornecer alguns indícios sobre a longevidade de árvores em Florestas Tropicais (Swaine et al. 1987).

Com base nas informações anotadas para cada indivíduo, foi calculada, para 
cada população, a taxa média de incremento anual $\left({ }^{*}\right)$, aqui denominada taxa de crescimento, da mesma maneira que Crow \& Weaver (1997). Foi considerada a média dos intervalos de tempo $\left(t_{2}-t_{1}\right)$ para cada população.

Para as árvores com troncos múltiplos, foi considerado o tronco maior do primeiro levantamento. Se este tivesse morrido, a árvore era considerada morta, sendo portanto retirada da análise de crescimento. Um único caso foi registrado - a árvore de número 71 (Chrysophyllum flexuosum) cujo tronco maior, que mediu no primeiro levantamento $91,5 \mathrm{~cm}$ de perímetro a $1,30 \mathrm{~m}$ de altura do solo, morreu no período entre os dois levantamentos, passando então a ser considerada uma árvore morta para o componente dominante. Gomes (1998) registou alguns casos semelhantes a este, aos quais denominou de falsos mortos.

A fórmula utilizada para o cálculo da taxa média de crescimento absoluta do diâmetro do caule, em centímetros, foi a seguinte:

$$
\mathrm{T}_{\mathrm{CA}}=\underline{\mathrm{DAP}} \underline{\mathrm{t}}_{2} \frac{-\mathrm{DAP}_{\mathrm{t}}}{\Delta_{\mathrm{t}}}
$$

onde: $\mathrm{DAP} \mathrm{t}_{1}=$ medida do diâmetro do caule a $1,30 \mathrm{~m}$ de altura do solo, em $\mathrm{cm}$, no primeiro levantamento

DAP $t_{2}=$ medida do diâmetro do caule, em cm, no segundo levantamento $\Delta_{\mathrm{t}}=\mathrm{t}_{2}-\mathrm{t}_{1}=$ intervalo de tempo, em anos, entre os dois levantamentos

Calculou-se a taxa média de crescimento relativa do diâmetro do caule $\left(T_{C R}\right)$, em percentagem, a partir da seguinte fórmula:

$$
\mathrm{T}_{\mathrm{CR}}=\frac{\left(\mathrm{DAP}_{2}\right.}{2} \frac{\left./ \mathrm{DAP}_{\mathrm{t}}\right)-1 \times 100}{\Delta_{\mathrm{t}}}
$$

\footnotetext{
* Crow \& Weaver (1977) empregaram o termo taxa de incremento, e não taxa de crescimento, porque o cálculo das taxas médias é baseado em um segmento temporal da vida da árvore e não em toda a sua vida, como implica o termo Tc / ano.
} 
Justifica-se o cálculo da taxa de crescimento relativa, para avaliar o crescimento real dos indivíduos amostrados. Duas árvores podem ter o mesmo valor de crescimento absoluto, porém, como o incremento baseia-se no diâmetro inicial de cada árvore, o valor relativo mostra qual das duas cresceu mais, proporcionalmente.

Gomes (1998) calculou também a taxa média de crescimento relativa para a área do caule a $1,30 \mathrm{~m}$ de altura do solo $\left(\mathrm{T}_{\mathrm{CAB}}\right)$. No entanto, este autor não encontrou diferenças significativas que justificassem a necessidade de se calcular, no presente estudo, a taxa de crescimento relativa utilizando, simultaneamente, o diâmetro e a área do caule. A maioria dos trabalhos que analisou crescimento de árvores tropicais baseou-se nos valores dos incrementos dos diâmetros para 0 cálculo das taxas.

As taxas de crescimento relativas foram calculadas aritmeticamente, e não pela forma logarítmica, por dois motivos: primeiro, porque os indivíduos não estão em fase exponencial de crescimento e, segundo, porque o cálculo aritmético padroniza as taxas de crescimento de árvores com diâmetros iniciais diferentes (Del Amo \& Pascual, 1989; Welden et al., 1991; Gomes, 1998).

Foram observados três tipos de crescimento: decrescimento ou diminuição do valor do diâmetro, crescimento nulo e aumento de crescimento. Para a análise das árvores que tiveram registro de decrescimento, foram adotados alguns procedimentos:

a) decrescimentos $\leq 0,32 \mathrm{~cm}$ de DAP foram transformados em crescimento nulo;

b) decrescimentos $>0,32 \mathrm{~cm}$ de DAP foram retirados do cálculo da taxa de crescimento.

O registro de valores superiores a $0,32 \mathrm{~cm}$ de DAP, provavelmente, se referem a erros nas medições dos perímetros ou a variações do estado de turgor das cascas nos momentos das medições. É possível que as medições dos diâmetros dos caules dos indivíduos de Mollinedia schottiana e Brosimum glazioui tenham sido tomadas de maneira incorreta, no primeiro levantamento. Já aquelas dos indivíduos das demais espécies, podem ter sido num estádio de turgor das cascas (Tabela 5). 
Tabela 5: Espécies e dados dos indivíduos que apresentaram decrescimentos, amostrados na Floresta Pluvial Tropical Atlântica, Ilha do Cardoso, SP, Brasil. COMP = componente onde foi amostrado o indivíduo ( $D=$ dominante e $S=$ sub-bosque); DAP1 = diâmetro do caule a 1,30m de altura do solo medido no primeiro levantamento; DAP2 = diâmetro medido no segundo levantamento; Cre DAP = decrescimento em diâmetro; $\Delta_{t}=$ intervalo de tempo entre as duas medições.

\begin{tabular}{lccccc}
\hline \hline \multicolumn{1}{c}{ Espécies (n' ${ }^{\circ}$ indivíduos) } & COMP & $\begin{array}{c}\text { DAP1 } \\
\text { (cm) }\end{array}$ & $\begin{array}{c}\text { DAP2 } \\
\text { (cm) }\end{array}$ & $\begin{array}{c}\text { Cre DAP } \\
\text { (cm) }\end{array}$ & $\Delta_{\mathbf{t}}$ (ano) \\
\hline Alchornea glandulosa (1058) & D & 29,3 & 28,5 & $-0,8$ & 7,0 \\
Brosimum glazioui (78) & $\mathrm{D}$ & 30,7 & 22,4 & $-8,3$ & 7,7 \\
Chrysophyllum inornatum (677) & $\mathrm{D}$ & 19,7 & 17,8 & $-1,9$ & 7,3 \\
Euterpe edulis (356) & $\mathrm{D}$ & 14,6 & 12,7 & $-1,9$ & 7,7 \\
Marlierea tomentosa (342) & $\mathrm{D}$ & 10,2 & 9,7 & $-0,5$ & 7,7 \\
Marlierea tomentosa (544) & $\mathrm{D}$ & 12,7 & 12,3 & $-0,5$ & 7,8 \\
Marlierea tomentosa (707) & $\mathrm{D}$ & 9,9 & 8,0 & $-1,9$ & 7,2 \\
Meliosma selloui (177) & $\mathrm{D}$ & 20,2 & 19,6 & $-0,6$ & 7,7 \\
Psychotria nuda (501) & $\mathrm{D}$ & 10,8 & 9,6 & $-1,2$ & 7,8 \\
Mollinedia schottiana (2095) & $\mathrm{S}$ & 8,0 & 2,9 & $-5,1$ & 6,0 \\
Psychotria nuda (1542) & $\mathrm{S}$ & 4,5 & 2,7 & $-1,8$ & 6,6 \\
Psychotria nuda (1830) & $\mathrm{S}$ & 3,8 & 3,3 & $-0,5$ & 6,0 \\
& & & & & \\
\hline \hline
\end{tabular}

A variação sazonal de fatores climáticos, tais como comprimento do dia, temperatura e pluviosidade, é conhecida por afetar padrões de crescimento em árvores. Isto é verdade tanto para regiões temperadas, onde existem diferenças marcantes entre as condições durante o verão e o inverno, como nas regiões tropicais, onde ocorrem estações distintas de umidade e seca. Existem na literatura estudos sobre variações diurnas e sazonais no crescimento em diâmetro do caule, alguns deles realizados por Kozlowski \& Winget (1964), Rogers, (1981) e Lieberman (1982). Felfili (1995) registrou crescimento negativo para 46 árvores, entre $-0,01 \mathrm{~cm}$ a $-0,14 \mathrm{~cm}$ no período de 1985-1991, tendo-os considerado como incremento nulo no computo geral para a análise de crescimento. Welden et al. (1991) também não consideraram em suas análises os registros de decrescimentos. Gomes (1998) adotou critério semelhante ao do presente trabalho. Swaine et al. (1987) consideraram em suas análises sobre mortalidade as árvores que mostraram decrescimento em diâmetro. 
Para a determinação do $\Delta_{\mathrm{t}}$, usado nos cálculos das taxas de crescimento, recrutamento e mortalidade, os decrescimentos $>0,32 \mathrm{~cm}$ de DAP foram considerados, tanto para o componente dominante quanto para o sub-bosque, exceto 3 indivíduos amostrados no primeiro levantamento no componente dominante, que foram retirados porque não mais preenchiam o requerimento do critério de inclusão no segundo levantamento.

Aplicou-se o teste não paramétrico de Kruskal-Wallis (Noether, 1983), para verificar a significância estatística entre as diferenças observadas nas medianas das taxas de crescimento em cada modo de agrupamento das espécies amostradas pela abundância, pelas classes de diâmetro, pelas características que apresentam no processo sucessional e pela síndrome de dispersão.

\section{Recrutamento e Mortalidade}

A repetição de censos em parcelas permanentes em florestas pode ser usada para determinar as taxas de recrutamento e mortalidade e, conseqüentemente, para descrever a dinâmica de populações de árvores. Há, no entanto, problemas na estimativa destas taxas (Sheil et al., 1995; Sheil \& May, 1996), os quais aumentam o debate sobre se a dinâmica das florestas aumenta ou não com o tempo (Phillips \& Gentry, 1994; Sheil, 1995). Estes problemas crescem parcialmente porque, de modo a se obterem estimativas demográficas, com base na densidade das populações, consideram-se árvores de ambientes diferentes e em fases diferentes do ciclo de vida.

Uma forma de contornar estes problemas é incorporar a distribuição do tamanho das árvores na análise demográfica, porque o que acontecerá com as árvores dependerá tanto do seu tamanho, quanto de sua posição na estrutura da comunidade, em um determinado censo (Kohyama \& Takada, 1998).

Segundo estes autores, a taxa de crescimento, geralmente calculada com base no aumento do perímetro ou do diâmetro do tronco, medido numa posição previamente marcada, poderá ser facilmente determinada por censos repetidos e analisada com base na distribuição do tamanho dos troncos das árvores. A 
estimativa de recrutamento para um determinado tamanho mínimo é sempre mais difícil, porque o número de recrutados variará amplamente, dependendo do intervalo de tempo entre os censos e do tamanho da parcela. Já a estimativa da mortalidade em uma determinada classe de tamanho é menos precisa porque poderá ser afetada pelo tamanho da amostra.

Como o intervalo de tempo entre as medições é curto, comparado com o ciclo florestal natural, assume-se que o recrutamento das árvores, assim como a mortalidade, constituem uma proporção constante da população inicial de árvores por intervalo de tempo.

A fórmula utilizada para o cálculo da taxa de recrutamento anual relativa, em percentagem, foi a seguinte:

$$
T_{R}=\left\{\left[\left(n_{0}+n_{r}\right) / n_{0}\right]^{1 / \Delta t}-1\right\} \times 100
$$

onde: $\mathrm{T}_{\mathrm{R}}=$ taxa média anual de recrutamento

$\mathrm{n}_{\mathrm{r}}=$ número de indivíduos recrutados

$\mathrm{n}_{\mathrm{o}}=$ número de indivíduos no primeiro levantamento

$\Delta_{\mathrm{t}}=$ média dos intervalos de tempo, em anos, entre os dois levantamentos,

para todos os indivíduos presentes do primeiro levantamento. Foram

excluídos deste valor 3 indivíduos do componente dominante, que tiverem decrescimento (números 342, 501 e 701), deixando assim de preencher o critério de inclusão, ou seja, perímetro do tronco a 1,30m de altura do solo igual ou superior a $31 \mathrm{~cm}$.

Dois problemas são apontados na estimativa da taxa de recrutamento dessa maneira: 1) se a área de repetição dos censos é pequena, o número de eventos de recrutamento será limitado e sofrerá variação estocástica muito grande, particularmente em curtos intervalos de tempo entre censos; 2) a dificuldade, no entanto, aumenta se o intervalo entre censos é longo, pois a contagem de recrutamento no censo é, inevitavelmente, subestimada devido ao aumento da 
fração que foi recrutada e, então, morreu durante o período entre censos (Kohyama \& Takada,(1998).

Vale ressaltar que na presente pesquisa, trabalhou-se com uma área pequena (1ha), com um intervalo entre censos relativamente longo (6,8 anos) e, pelo fato de não se terem registrado as árvores mortas no primeiro levantamento, não foi possível se distinguir entre as encontradas mortas no segundo, quais foram as recrutadas que morreram.

A morte de árvores e, em particular, o padrão de mortalidade no tempo e no espaço, estão estreitamente ligados à máxima longevidade das árvores, à distribuição das classes de tamanho, à abundância relativa das espécies e ao tamanho e número das clareiras formadas na área. A morte de árvores é, provavelmente, o principal mecanismo através do qual opera a seleção natural. A perda de árvores influencia as condições microambientais, propiciando o aumento das taxas de crescimento de árvores vizinhas; a morte de uma árvore pode aumentar ou decrescer a chance de morte de outras (Swaine et al., 1987). Em florestas onde o regime de distúrbio é dirigido principalmente por queda de árvores, a morte de árvores emergentes pode causar grandes distúrbios (Clark \& Clark (1996).

As clareiras formadas no dossel de uma floresta mais jovem, pela queda de árvores, tendem a ser menores do que na floresta mais antiga, de maneira que a estrutura e a aparência da floresta jovem tende a ser mais homogênea (Foster \& Brokaw, 1992).

A etapa adulta do ciclo de vida corresponde àfase de menor risco de morte para as plantas das Florestas Úmidas. Ainda não existem informações suficientes para detectar as fontes de mortalidade mais importantes nas populações de plantas adultas (Martínez-Ramos \& Álvarez Buylla, 1995). Em regiões centro-americanas, africanas e asiáticas, registraram-se de $1 \%$ a $4 \%$ de morte de adultos em populações de árvores a cada ano (Lieberman et al., 1985; Gomes, 1998). Estes estudos indicam que a morte das árvores adultas pode ocorrer pela ação conjunta ou única de: 1) descargas elétricas; 2) queda das árvores ocasionada por ventos e cargas de peso excessivas, devidas, por exemplo, a chuva e/ou a presença de plantas epífitas e lianas; 3) danos severos causados por herbívoros, tanto 
vertebrados como invertebrados, estes últimos principalmente insetos e parasitas, como, por exemplo, nematódios fitófagos das raízes (Lieberman et al., 1985b).

$\mathrm{Na}$ população de árvores fortemente demandantes de luz, a taxa de mortalidade é muito elevada nos indivíduos de diâmetros pequenos e diminui à medida que as árvores alcançam diâmetros maiores. Em relação às espécies demandantes de luz, aquelas que podem se desenvolver àsombra mostram maiores taxas de sobrevivência, em toda sua amplitude de tamanhos (Martínez-Ramos \& Álvarez-Buylla, 1995).

A taxa média anual de mortalidade pode ser calculada usando-se dois modelos: o logarítmico e o algébrico (Sheil et al., 1995). É possível calcular-se a taxa de mortalidade tanto para a densidade de árvores quanto para o total de biomassa viva, sendo mais comumente calculada para a densidade.

O modelo logarítmico tem sido o mais utilizado para o cálculo das taxas, tanto de mortalidade quanto de recrutamento (Swaine, 1989; Lieberman et al., 1990; Clark \& Clark, 1992; Condit et al., 1993 e Milton et al., 1994). O modelo algébrico foi recomendado por Sheil (1995), Sheil et al. (1995) e Sheil \& May (1996). O modelo algébrico é considerado como o que estima verdadeiramente a taxa anual de mortalidade e o modelo logarítmico como aquele que, simplesmente, calcula o coeficiente exponencial das taxas, superestimando a mortalidade e subestimando 0 recrutamento (Sheil et al., 1995). Na presente pesquisa utilizou-se o modelo algébrico.

Para o cálculo da taxa de mortalidade foram identificadas as árvores que haviam morrido no intervalo de tempo, entre os dois levantamentos, e registrada a maneira como foram encontradas: se em pé, caídas ou se cortadas. As árvores que foram encontradas mortas no segundo censo não foram medidas, tendo-se registrado a maneira como se mantinham e anotado os números das placas, através dos quais foi possível obter suas identificações botânicas.

A fórmula utilizada para o cálculo da taxa de mortalidade anual relativa, em percentagem, foi a seguinte:

$$
T_{M}=\left\{1-\left[\left(n_{0}-n_{m}\right) / n_{0}\right]^{1 / \Delta t}\right\} \times 100
$$


onde: $\mathrm{T}_{\mathrm{M}}=$ taxa média anual de mortalidade

$\mathrm{n}_{\mathrm{o}}=$ número de indivíduos no primeiro levantamento

$\mathrm{n}_{\mathrm{m}}=$ número de mortos da população inicial, após o período entre

levantamentos

$\Delta_{\mathrm{t}}=$ média dos intervalos de tempo, em anos, entre os dois levantamentos, para todos os indivíduos presentes do primeiro levantamento, exceto 3 indivíduos do componente dominante que tiveram decrescimento (números 342, 501 e 701), deixando, assim, de preencher o critério de inclusão, ou seja, perímetro do tronco a $1,30 \mathrm{~m}$ de altura do solo igual ou superior a $31 \mathrm{~cm}$.

Para analisar as relações entre os diferentes registros de árvores mortas (cortadas, caídas ou em pé) e o tamanho das árvores, construíram-se histogramas a partir dos quais é possível observar-se a distribuição das árvores mortas por classes de diâmetros das árvores, 3 classes para 0 sub-bosque e 7 para 0 componente dominante.

\section{Distribuição espacial das árvores mortas}

Foi verificado se a distribuição do número de árvores mortas por parcelas ocorreu ao acaso, não diferindo da distribuição de Poisson. Para tanto, calcularamse o índice de dispersão (ID), pela fórmula ID = V/M, onde $V$ é a variância observada e $M$ é a média observada; e o respectivo $X^{2}$ da distribuição de Poisson, pela fórmula $X^{2}=\mathrm{ID}(\mathrm{n}-1)$, onde $\mathrm{n}$ é igual ao número de parcelas (Krebs, 1989).

Para a análise da distribuição das árvores mortas no componente subbosque, consideraram-se as 10 unidades amostrais dispostas de maneira disjunta, tendo em vista o sorteio realizado dentre as 40 originais. Para o componente dominante, realizaram-se duas análises: uma considerando as 40 unidades amostrais e suas respectivas ocorrências de mortes; e a outra, na qual agruparamse as 40 unidades amostrais em 4 blocos de $2.500 \mathrm{~m}^{2}$ cada. Decidiu-se por realizar 
estes dois tipos de análise para verificar o padrão de distribuição espacial das árvores mortas entre as parcelas em distintas escalas.

Analisou-se também a relação entre o número de árvores vivas, amostradas no primeiro levantamento, e o de árvores encontradas mortas, no segundo. Para tanto, calcularam-se as correlações entre esses valores.

\section{Relação entre o recrutamento e a mortalidade}

A análise da relação entre a mortalidade e o recrutamento foi feita a partir dos valores das taxas médias anuais de recrutamento e mortalidade relativas, constantes da Tabela 7. Procurou-se destacar as espécies que apresentaram as maiores mudanças na entrada e saída de árvores, nos dois componentes estudados.

\section{$\operatorname{Lambda}(\lambda)$}

Calculou-se a taxa finita de crescimento natural-lambda, que está diretamente relacionada com a taxa intrínseca de crescimento natural. Assim sendo, os valores de lambda $(<1,=1,>1)$ podem expressar a estabilidade numérica da população. Esta taxa foi calculada pela fórmula:

$$
\lambda=\left(n_{t} / n_{0}\right)^{1 / \Delta t}
$$

onde: $\lambda=$ taxa finita de crescimento natural (lambda)

$\mathrm{n}_{\mathrm{o}}=$ número de indivíduos no primeiro levantamento

$\mathrm{n}_{\mathrm{t}}=$ número de indivíduos no segundo levantamento

$\Delta_{\mathrm{t}}=$ média dos intervalos de tempo, em anos, entre os dois levantamentos, para todos os indivíduos presentes do primeiro levantamento 


\section{Tempo de meia vida e Tempo para dobrar}

A partir das taxas de mortalidade e de recrutamento, calculou-se o tempo de meia-vida $(T 0,5)$, em anos, que é o tempo para uma população ou um conjunto de populações decrescerem em tamanho até a metade, considerando-se a taxa de mortalidade constante. Utilizou-se a seguinte fórmula:

$$
\left.\mathrm{T}_{0,5}=\left(\mathrm{I}_{\mathrm{n}} 0,5\right) / \ln \left[\left(\mathrm{n}_{0}-\mathrm{n}_{\mathrm{m}}\right) / \mathrm{n}_{\mathrm{o}}\right)\right]^{1 / \Delta \mathrm{t}}
$$

A partir das taxas de recrutamento, calculou-se o dobro do tempo $\left(T_{2}\right)$, que é o tempo necessário para uma população ou um conjunto de populações dobrar o número inicial de indivíduos, em anos, considerando-se a taxa de recrutamento constante. A fórmula usada foi:

$$
T_{2}=\left(I_{n} 2\right) / I_{n}\left[\left(n_{o}+n_{r}\right) / n_{0}\right]^{1 / \Delta t}
$$

\section{Dinâmica e Estabilidade}

Para o cálculo da dinâmica, em anos, utilizou-se a fórmula proposta por Korning \& Balslev (1994b):

$$
D=\left(T_{2}+T_{0,5}\right) / 2
$$

Existe uma fórmula, por meio da qual também se pode calcular a dinâmica, $D=\left[\left(n_{r}+n_{m}+d\right) / n_{o}\right] \times 100$, onde $d=$ número de indivíduos recrutados mortos entre censos, usada por Gomes (1998). Esta fórmula não pode ser usada no presente estudo, porque não foi possível se determinar se houve morte de recrutado entre os levantamentos. Somente é possível ter-se esta informação se registram-se as árvores que são encontradas mortas num primeiro levantamento e, num segundo, 
tomam-se as medidas de diâmetro dos troncos daquelas que morreram no intervalo de tempo.

Calculou-se, também, a medida de estabilidade (E), em percentagem, para a comunidade, seguindo a fórmula proposta por Gomes (1998):

$$
E=\left[\left(n_{m}+n_{r}\right) / n_{0}\right] \times 100
$$

A estabilidade indica o estado da floresta ao longo do tempo, isto é, mudanças no número absoluto dos indivíduos ou na área basal. Pode também ser calculada, em anos, pela diferença numérica entre o tempo de meia-vida e o dobro do tempo (Korning \& Balslev, 1994b). Segundo estes autores e Sheil \& May (1996), as medidas de dinâmica e de estabilidade dependem tanto do intervalo de tempo entre os censos quanto do tamanho da amostra.

\section{Resultados}

No intervalo de tempo entre os dois levantamentos, realizados nos anos de 1987-89 e 1995, respectivamente, houve uma mudança acentuada na aparência da parcela permanente amostrada. O padrão de cobertura do dossel foi alterado, pela queda de muitas árvores deste estrato ou de emergentes, que arrastaram consigo várias árvores de médio e pequeno portes, promovendo um emaranhado de troncos e caules. As causas destas mudanças não foram registradas durante este intervalo de tempo, sendo, muito provavelmente, as fortes chuvas, comuns na região, as causadoras da queda das árvores. Contudo, foi possível localizar todos os indivíduos amostrados em 1987-89. 


\section{Estrutura da floresta}

Os principais dados sobre a estrutura do trecho de Floresta Pluvial estudada encontram-se sumarizados na Tabela 6.

Tabela 6: Dados sobre a estrutura, obtidos nos dois levantamentos realizados em trecho de Floresta Pluvial Tropical Atlântica, Ilha do Cardoso, SP, Brasil. DAP = diâmetro do caule a 1,30m de altura do solo; Nind = número de indivíduos arbóreos amostrados; $\mathrm{Nfa}=$ número de famílias amostradas; $\mathrm{Nsp}=$ número de espécies amostradas; $A T$ = área total dos caules; $H^{\prime}$ = índice de diversidade de ShannonWiener; $\mathrm{D}$ = índice de diversidade de Simpson; $\mathrm{J}=$ equabilidade.

\begin{tabular}{ccccccccccc}
\hline \hline $\begin{array}{c}\text { Componente } \\
\text { (período do } \\
\text { levantamento) }\end{array}$ & $\begin{array}{c}\text { DAP } \\
\mathbf{( c m})\end{array}$ & Nind & Nfa & Nsp & $\begin{array}{c}\text { Área } \\
(\mathbf{h a})\end{array}$ & $\begin{array}{c}\text { AT } \\
\left(\mathbf{m}^{2} / \mathbf{h a}\right)\end{array}$ & $\begin{array}{c}\mathbf{H}^{\prime} \\
(\mathbf{n a t} / \mathbf{i n d})\end{array}$ & $\mathbf{D}$ & $\mathbf{J}$ \\
\hline $\begin{array}{c}\text { Dominante } \\
(8 / 87 \text { a } 11 / 89)\end{array}$ & $\geq 9,9$ & 727 & 37 & 108 & 1,00 & 43,48 & 3,529 & 0,102 & 0,754 \\
$\begin{array}{c}\text { Dominante } \\
(4 \text { a 10/95) }\end{array}$ & $\geq 9,9$ & 756 & 37 & 109 & 1,00 & 45,57 & 3,531 & 0,100 & 0,753 \\
$\begin{array}{c}\text { Sub-bosque } \\
(8 / 87 \text { a } 11 / 89)\end{array}$ & $\geq 2,5<9,9$ & 402 & 25 & 64 & 0,25 & 1,03 & 3,109 & 0,087 & 0,748 \\
$\begin{array}{c}\text { Sub-bosque } \\
(4 \text { a 10/95) }\end{array}$ & $\geq 2,5<9,9$ & 377 & 20 & 60 & 0,25 & 0,97 & 3,042 & 0,093 & 0,743 \\
\hline \hline
\end{tabular}

\section{Dinâmica da floresta}

Os cálculos das taxas médias anuais de crescimento, recrutamento e mortalidade envolveram 716 árvores vivas do componente dominante, no primeiro levantamento, e 844 vivas e mortas, no segundo; e 368 árvores vivas do subbosque, no primeiro levantamento, e 430 vivas e mortas, no segundo.

Os números de árvores considerados para a análise da estrutura (Tabela 6), nos dois componentes e nos dois levantamentos, diferem dos números considerados para a análise de demografia, pelos seguintes motivos:

1) das 727 árvores do componente dominante, no primeiro levantamento, foram subtraídas 9, que apresentaram decrescimento, e 2, que deixaram de ser medidas no segundo. 
2) das 756 árvores vivas do componente dominante, no segundo levantamento, foram subtraídas somente 6 das 9 árvores, que decresceram, (3 delas não preencheram mais o critério de inclusão) e 1, que não foi medida no primeiro levantamento; e foram somadas 95 árvores encontradas mortas.

3) das 402 árvores do sub-bosque, no primeiro levantamento, foram subtraídas 31 árvores, que foram recrutadas para o dominante, e 3, que apresentaram decrescimento.

4) das 377 vivas árvores do sub-bosque, no segundo levantamento, foram subtraídas 3 árvores que decresceram; e foram somadas 56 árvores encontradas mortas.

Os valores das taxas médias anuais de crescimento (absolutas e relativas), de mortalidade e de recrutamento; do tempo de meia vida, do tempo para dobrar e do lambda são apresentadas na Tabela 7. 
Tabela 7: Valores das taxas médias anuais de crescimento ( $T_{C A}$ - absolutas e $T_{C R}$ relativas), de mortalidade $\left(T_{M}\right)$ e de recrutamento $\left(T_{R}\right)$; do tempo de meia vida $\left(T_{0,5}\right)$, do tempo para dobrar $\left(T_{2}\right)$ e do $\lambda$ (lambda), obtidos no estudo sobre demografia de árvores em Floresta Pluvial Tropical Atlântica, Ilha do Cardoso, SP, Brasil.

\begin{tabular}{|c|c|c|c|c|c|c|c|c|}
\hline Espécies & $\begin{array}{c}\text { Componente } \\
\text { amostrado }\end{array}$ & $\begin{array}{c}\text { TCA } \\
\text { (cm/ano) }\end{array}$ & $\begin{array}{c}\mathrm{T}_{\mathrm{CR}} \\
\text { (\%/ano) }\end{array}$ & $\begin{array}{c}\mathrm{T}_{\mathrm{M}} \\
\text { (\%/ano) }\end{array}$ & $\begin{array}{c}\mathrm{T}_{\mathrm{R}} \\
\text { (\%/ano) }\end{array}$ & $\begin{array}{c}\mathrm{T}_{0,5} \\
\text { (anos) }\end{array}$ & $\begin{array}{c}\mathrm{T}_{2} \\
\text { (anos) }\end{array}$ & $\lambda$ \\
\hline $\begin{array}{l}\text { Conjunto de todas } \\
\text { as espécies }\end{array}$ & $\begin{array}{l}\text { Dominante } \\
\text { Sub-bosque }\end{array}$ & $\begin{array}{l}0,19 \\
0,10\end{array}$ & $\begin{array}{l}0,89 \\
2,26\end{array}$ & $\begin{array}{l}2,05 \\
2,38\end{array}$ & $\begin{array}{l}2,43 \\
2,30\end{array}$ & $\begin{array}{l}33,4 \\
28,8\end{array}$ & $\begin{array}{l}28,9 \\
30,5\end{array}$ & $\begin{array}{l}1,0066 \\
1,0024\end{array}$ \\
\hline \multirow{2}{*}{$\begin{array}{l}\text { Conjunto das espécies, } \\
\text { excluindo as palmeiras }\end{array}$} & Dominante & 0,23 & 0,97 & 1,45 & 1,95 & 47,4 & 35,9 & 1,0065 \\
\hline & Sub-bosque & 0,08 & 1,97 & 2,08 & 1,68 & 32,9 & 41,6 & 0,9980 \\
\hline \multirow[t]{2}{*}{ Espécies raras } & Dominante & 0,26 & 0,94 & 1,49 & 2,11 & 46,1 & 33,2 & 1,0080 \\
\hline & Sub-bosque & 0,11 & 2,37 & 3,23 & 3,03 & 21,1 & 23,2 & 1,0036 \\
\hline \multirow[t]{2}{*}{ Espécies ocasionais } & Dominante & 0,22 & 0,97 & 1,34 & 1,77 & 51,3 & 39,4 & 1,0056 \\
\hline & Sub-bosque & 0,07 & 1,61 & 2,91 & 1,29 & 23,5 & 54,2 & 0,9861 \\
\hline \multirow{2}{*}{ Calyptranthes lanceolata $^{a}$} & Dominante & - & - & - & - & - & - & - \\
\hline & Sub-bosque & 0,03 & 0,97 & 1,27 & 1,18 & 54,2 & 58,9 & 1,0000 \\
\hline \multirow[t]{2}{*}{ Calyptranthes lucida ${ }^{\mathrm{b}}$} & Dominante & 0,15 & 0,59 & 1,02 & 0,97 & 67,7 & 72,0 & 1,0000 \\
\hline & Sub-bosque & - & - & - & - & - & - & - \\
\hline \multirow[t]{2}{*}{ Chrysophyllum flexuosum ${ }^{\text {b }}$} & Dominante & 0,21 & 0,99 & 0,93 & 1,31 & 74,1 & 53,4 & 1,0045 \\
\hline & Sub-bosque & - & - & - & - & - & - & - \\
\hline \multirow{2}{*}{ Cryptocaria moschata $^{\mathrm{c}}$} & Dominante & 0,38 & 0,99 & 0,77 & 0,74 & 89,2 & 93,8 & 1,0000 \\
\hline & Sub-bosque & - & - & - & - & - & - & - \\
\hline \multirow[t]{2}{*}{ Eugenia cuprea $^{\mathrm{b}}$} & Dominante & - & - & - & - & - & - & - \\
\hline & Sub-bosque & 0,05 & 1,62 & 1,07 & 1,95 & 64,5 & 35,8 & 1,0100 \\
\hline \multirow[t]{2}{*}{ Eugenia mosenii $^{\mathrm{b}}$} & Dominante & 0,13 & 0,68 & 0,00 & 2,57 & d & 27,3 & 1,0257 \\
\hline & Sub-bosque & - & - & - & - & - & - & - \\
\hline \multirow[t]{2}{*}{ Euterpe edulis } & Dominante & 0,08 & 0,70 & 3,57 & 3,27 & 19,1 & 21,5 & 1,0039 \\
\hline & Sub-bosque & 0,21 & 4,33 & 3,42 & 5,30 & 19,9 & 13,4 & 1,0285 \\
\hline \multirow[t]{2}{*}{ Garcinia gardneriana } & Dominante & 0,16 & 1,28 & 1,41 & 4,24 & 48,8 & 16,7 & 1,0312 \\
\hline & Sub-bosque & 0,10 & 2,13 & 0,00 & 2,11 & d & 33,2 & 1,0211 \\
\hline \multirow[t]{2}{*}{ Malouetia arborea } & Dominante & 0,18 & 0,79 & 4,64 & 1,31 & 14,6 & 53,4 & 0,9705 \\
\hline & Sub-bosque & 0,05 & 1,35 & 3,48 & 1,02 & 19,5 & 68,3 & 0,9776 \\
\hline \multirow[t]{2}{*}{ Marlierea tomentosa ${ }^{\mathrm{b}}$} & Dominante & 0,06 & 0,52 & 0,00 & 1,06 & d & 65,5 & 1,0106 \\
\hline & Sub-bosque & - & - & - & - & - & - & - \\
\hline \multirow[t]{2}{*}{ Myrcia pubipetala ${ }^{a}$} & Dominante & 0,35 & 1,28 & 3,09 & 0,00 & 22,1 & e & 0,9691 \\
\hline & Sub-bosque & - & - & - & - & - & - & - \\
\hline \multirow[t]{2}{*}{ Psychotria nuda } & Dominante & 0,09 & 0,83 & 4,03 & 8,32 & 16,9 & 8,7 & 1,0596 \\
\hline & Sub-bosque & 0,11 & 2,85 & 1,85 & 1,21 & 37,2 & 57,8 & 0,9949 \\
\hline \multirow[t]{2}{*}{ Rudgea jasminoides } & Dominante & 0,08 & 0,76 & 2,95 & 3,66 & 23,1 & 19,3 & 1,0131 \\
\hline & Sub-bosque & 0,07 & 1,59 & 1,53 & 2,08 & 45,0 & 33,7 & 1,0072 \\
\hline \multirow[t]{2}{*}{ Sorocea bonplandii ${ }^{\text {b }}$} & Dominante & 0,06 & 0,50 & 1,50 & 1,39 & 45,8 & 50,2 & 1,0000 \\
\hline & Sub-bosque & - & - & - & - & - & - & - \\
\hline \multirow[t]{2}{*}{ Tetrastilydium grandifolium ${ }^{\mathrm{c}}$} & Dominante & 0,24 & 0,99 & 1,05 & 4,46 & 65,5 & 15,9 & 1,0366 \\
\hline & Sub-bosque & - & - & - & - & - & - & - \\
\hline \multirow[t]{2}{*}{ Virola oleifera $^{a}$} & Dominante & 0,59 & 1,62 & 0,00 & 0,00 & $d$ & e & 1,0000 \\
\hline & Sub-bosque & - & - & - & - & - & - & - \\
\hline
\end{tabular}

a: espécie não amostrada no componente.

b: espécie não ocorreu como abundante e sim como ocasional.

c: espécie não ocorreu como abundante e sim como rara.

d: não houve registro de morte para a espécie, portanto, não foi calculado o tempo de meia vida.

e: não houve registro de recrutamento para a espécie, logo, não foi calculado o tempo para dobrar. 


\section{Crescimento}

Calcularam-se as taxas médias anuais de crescimento, absolutas e relativas, de 104 espécies do componente dominante e 55 espécies do sub-bosque.

A taxa média anual de crescimento absoluta $\left(T_{C A}\right)$ das espécies do subbosque foi de $0,10 \mathrm{~cm} /$ ano e, excluindo-se as palmeiras, de $0,08 \mathrm{~cm} / \mathrm{ano}$. As taxas das 7 espécies abundantes, no primeiro levantamento, variaram de 0,03 a $0,21 \mathrm{~cm} / \mathrm{ano}$, na seguinte ordem decrescente: Euterpe edulis $(0,21)$, Psychotria nuda $(0,11)$, Garcinia gardneriana $(0,10)$, Rudgea jasminoides $(0,07)$, Eugenia cuprea $(0,05)$, Malouetia arborea $(0,05)$ e Calyptranthes lanceolata $(0,03)$. Para as 20 espécies ocasionais, foi de $0,07 \mathrm{~cm} /$ ano e para as 28 espécies raras, de $0,11 \mathrm{~cm} /$ ano.

Para as espécies do componente dominante foi de $0,19 \mathrm{~cm} /$ ano e, excluindose as palmeiras, de 0,23cm/ano. Do total de espécies amostradas, 14 foram consideradas abundantes no primeiro levantamento, com taxas que variaram de 0,06 a $0,59 \mathrm{~cm} / a n o$ na seguinte ordem, da mais alta para a mais baixa: Virola oleifera (0,59), Cryptocarya moschata $(0,38)$, Myrcia pubipetala $(0,35)$, Tetrastylidium grandifolium $(0,24)$, Chrysophyllum flexuosum $(0,21)$, Malouetia arborea $(0,18)$, Garcinia gardneriana $(0,16)$, Calyptranthes lucida $(0,15)$, Eugenia mosenii $(0,13)$, Psychotria nuda $(0,09)$, Rudgea jasminoides $(0,08)$, Euterpe edulis $(0,08)$, Marlierea tomentosa $(0,06)$ e Sorocea bonplandii $(0,06)$. Para as 41 espécies ocasionais, no primeiro levantamento, foi de $0,22 \mathrm{~cm} /$ ano e para as 49 espécies raras, de $0,26 \mathrm{~cm} /$ ano.

A Figura 15 mostra a distribuição de freqüência das classes de taxas de crescimento absolutas pelos indivíduos amostrados no sub-bosque e no componente dominante, considerando todas as espécies. Analisando-se esta figura, observa-se que, tanto no sub-bosque quanto no componente dominante, a distribuição apresenta curva deslocada para a esquerda, com moda na primeira classe.

A Figura 16 mostra a distribuição das taxas de crescimento absolutas por categorias de abundância das espécies amostradas no sub-bosque e no componente dominante, considerando todas as espécies. Analisando-se esta figura, 
observa-se que, no sub-bosque, as taxas das espécies raras foram maiores do que as das ocasionais, porém menores do que as das abundantes, sendo significativas as diferenças apresentadas, segundo o teste de Kruskal-Wallis (2 g.l., p = 0,0343). No componente dominante, observa-se uma diminuição das taxas das espécies raras para as das abundantes, significativamente diferentes (Kruskal-Wallis, 2 g.l., $p=0,0001)$.

A Figura 17 mostra a distribuição das taxas de crescimento absolutas pelas classes de diâmetro das espécies amostradas. No sub-bosque as taxas aumentaram da primeira para a segunda classe de diâmetro, havendo uma diminuição acentuada na classe de maior tamanho, cujo valor mediano foi praticamente igual ao da primeira classe, não havendo diferenças significativas (Kruskal-Wallis, g.l. 2, $p=0,1150)$. No componente dominante as taxas das três primeiras classes aumentaram, porém esse aumento foi interrompido, observando-se um declínio do valor da taxa na quarta classe, seguido de aumento nas três classes seguintes e apresentando nova diminuição na sétima classe, a de maiores DAPs, sendo estas diferenças estatisticamente significantes (Kruskal-Wallis, g.I. 6, p < 0,0001).

A Figura 18 mostra a distribuição das taxas de crescimento absolutas das espécies com diferentes características sucessionais. Tanto no sub-bosque quanto no componente dominante, as medianas das taxas das espécies consideradas iniciais foram maiores do que as das tardias, sem diferença significativa para o subbosque (Kruskal-Wallis, g.I. 2, $p=0,0961$ ), porém estatisticamente significante para o componente dominante (Kruskal-Wallis, g.I. 2, p =0,0017).

A Figura 19 mostra a distribuição das taxas de crescimento absolutas pelas síndromes de dispersão das espécies amostradas. No sub-bosque as taxas das espécies zoocóricas foram menores do que as das anemocóricas e autocóricas, não sendo significativas estas diferenças (Kruskal-Wallis, g.l. 2, $p=0,9313$ ). No componente dominante, ocorreu o inverso, com as anemocóricas apresentando taxas maiores que as das demais categorias, porém sem diferença significativa (Kruskall-Wallis, g.I. 2, $p=0,1316$ ).

A taxa média anual de crescimento relativas $\left(T_{C R}\right)$ das espécies do subbosque foi de 2,26\%/ano e, excluindo-se as palmeiras, de 1,97\%/ano. As taxas das 7 espécies abundantes variaram de 0,97 a 4,33\%/ano, na seguinte ordem 
decrescente: Euterpe edulis (4,33), Psychotria nuda (2,85), Garcinia gardneriana $(2,13)$, Eugenia cuprea $(1,62)$, Rudgea jasminoides $(1,59)$, Malouetia arborea $(1,35)$, e Calyptranthes lanceolata $(0,97)$. Para as 20 espécies ocasionais do sub-bosque foi de $1,61 \% / a n o$, e para as 28 espécies raras, de 2,37\%/ano.

Para as espécies do componente dominante foi de 0,89\%/ano e, excluindo-se as palmeiras, de 0,97\%/ano. As taxas das 14 espécies abundantes variaram de 0,50 a 1,62\%/ano, na seguinte ordem, do mais alto valor para o mais baixo: Virola oleifera $(1,62)$, Myrcia pubipetala (1,28), Garcinia gardneriana (1,28), Chrysophyllum flexuosum $(0,99)$, Tetrastylidium grandifolium $(0,99)$, Cryptocarya moschata $(0,99)$, Psychotria nuda $(0,83)$, Malouetia arborea $(0,79)$, Rudgea jasminoides $(0,76)$, Euterpe edulis $(0,70)$, Eugenia mosenii $(0,68)$, Calyptranthes lucida $(0,59)$, Marlierea tomentosa $(0,52)$ e Sorocea bonplandii $(0,50)$. Para as 41 espécies ocasionais do componente dominante, no primeiro levantamento, foi de $0,97 \% /$ ano, e para as 49 espécies raras, de 0,94\%/ano.

A Figura 20 mostra a distribuição da freqüência de classes de taxas de crescimento relativas pelo número de indivíduos amostrados no sub-bosque e no componente dominante, considerando todas as espécies. Analisando-se esta figura, observa-se que, tanto no sub-bosque quanto no componente dominante, a distribuição apresenta curva deslocada para a esquerda, com moda na primeira classe.

\section{Recrutamento e Mortalidade}

Calcularam-se as taxas médias anuais de recrutamento de 31 espécies do componente dominante e 21 espécies do sub-bosque.

A taxa média anual de recrutamento das espécies do sub-bosque foi de 2,30\%/ano e, excluindo-se as palmeiras, de 1,68\%/ano. As taxas das 7 espécies abundantes no primeiro levantamento, com árvores recrutadas, variaram de 1,02 a 5,30\%/ano, na seguinte ordem decrescente: Euterpe edulis (5,30), Garcinia gardneriana (2,11), Rudgea jasminoides (2,08), Eugenia cuprea (1,95), Psychotria 
nuda $(1,21)$, Calyptranthes lanceolata $(1,18)$ e Malouetia arborea $(1,02)$. Para as 6 espécies ocasionais, foi de 1,29\%/ano e para as 8 espécies raras, de 3,03\%/ano.

Para as espécies do componente dominante foi de 2,43\%/ano e, excluindo-se as palmeiras, de 1,95\%/ano. Do total de espécies com árvores recrutadas, 12 foram consideradas abundantes no primeiro levantamento, com taxas que variaram de 0,74 a $8,32 \% / a n o$ na seguinte ordem, da mais alta para a mais baixa: $P$. nuda $(8,32)$, Tetrastilydium grandifolium (4,46), G. gardneriana $(4,24), R$. jasminoides $(3,66)$, E. edulis $(3,27)$, Eugenia mosenii $(2,57)$, Sorocea bonplandii $(1,39)$, Chrysophyllum flexuosum (1,31), M. arborea (1,31), Marlierea tomentosa (1,06), Calyptranthes lucida $(0,97)$ e Cryptocaria moschata $(0,74)$. Para as 12 espécies ocasionais no primeiro levantamento, foi de 1,77\%/ano, e para as 7 espécies raras, de 2,11\%/ano.

Calcularam-se as taxas médias anuais de mortalidade de 29 espécies do componente dominante e 26 espécies do sub-bosque.

A taxa média anual de mortalidade das espécies do sub-bosque foi de 2,38\%/ano e, excluindo-se as palmeiras, de 2,08\%/ano. As taxas das 6 espécies abundantes no primeiro levantamento, com árvores mortas, variaram de 1,07 a 3,48\%/ano, na seguinte ordem decrescente: Malouetia arborea $(3,48)$, Euterpe edulis (3,42), Psychotria nuda (1,85), Rudgea jasminoides $(1,53)$, Calyptranthes lanceolata $(1,27)$ e Eugenia cuprea $(1,07)$. Para as 12 espécies ocasionais, foi de 2,91\%/ano e para as 8 espécies raras, de 3,23\%/ano.

Para as espécies do componente dominante foi de 2,05\%/ano e, excluindo-se as palmeiras, de 1,45\%/ano. Do total de espécies com árvores mortas, as 11 abundantes tiveram taxas que variaram de 0,77 a 4,64\%/ano, na seguinte ordem, da mais alta para a mais baixa: $M$. arborea $(4,64)$, $P$. nuda $(4,03)$, E. edulis $(3,57)$, Myrcia pubipetala $(3,09)$, R. jasminoides $(2,95)$, Sorocea bonplandii $(1,50)$, Garcinia gardneriana $(1,41)$, Tetrastylidium grandifolium $(1,05)$, Calyptranthes lucida $(1,02)$, Chrysophyllum flexuosum (0,93) e Cryptocarya moschata $(0,77)$. Para as 12 espécies ocasionais, foi de 1,34\%/ano e para as 6 espécies raras, de 1,49\%/ano.

A falta de monitoramento das unidades amostrais da parcela permanente, durante o longo intervalo de tempo entre os dois levantamentos (6,8 anos), impossibilitou a avaliação das múltiplas mortes nas unidades amostrais, para 
verificar se estas ocorreram simultânea ou seqüencialmente. O mesmo foi referido nos resultados apresentados por Lieberman et al. (1985b) para La Selva, Costa Rica. A causa da morte de indivíduos adultos encontrados em pé foi, aparentemente, a senescência, e, talvez, uma ou duas árvores por terem sido atingidas por raios.

Durante o intervalo de tempo entre os dois levantamentos, ocorreu a morte de $13,3 \%$ das 716 árvores vivas do componente dominante consideradas para o estudo de demografia. Do total de 95 árvores mortas, 38,9\% encontravam-se em pé, 35,8\% caídas e $25,3 \%$ cortadas. No sub-bosque, morreram $13,0 \%$ das 430 árvores vivas consideradas para o estudo demográfico. Das 56 árvores mortas, 30,4\% estavam em pé, $64,3 \%$ caídas e $5,4 \%$ cortadas.

A distribuição dos registros de morte por classes de diâmetros das árvores, medidos no primeiro levantamento, é mostrada na Figura 21. No sub-bosque e no componente dominante, a perda maior, tanto de árvores que foram encontradas caídas quanto daquelas em pé, deu-se nas classes de diâmetros menores. Nas Florestas Pluviais Tropicais é bastante comum a ocorrência de chuvas torrenciais, acompanhadas de ventos fortes e raios, que freqüentemente ocasionam a queda de umas poucas árvores de porte grande, que arrastam junto consigo árvores de pequeno e médio portes. No componente dominante teve-se a ocorrência da queda de 5 árvores enquadradas nas classes de DAP $30-40 \mathrm{~cm}$ (2 árvores) e de $50-60 \mathrm{~cm}$ (3). Foram localizados 24 indivíduos de Euterpe edulis cortados, todos pertencentes à classe de DAP 9,9-20 cm, tamanho considerado ideal para o corte das palmeiras adultas para a extração do palmito comercial (Fisch, 1999).

\section{Distribuição espacial das árvores mortas}

As Tabelas 8, 9 e 10 trazem os dados numéricos que permitiram a caracterização dos padrões de distribuição espacial das árvores encontradas mortas no segundo levantamento, nos dois componentes. 
Tabela 8: Padrão de distribuição espacial das árvores mortas amostradas no sub-bosque, em Floresta Pluvial Tropical Atlântica, Ilha do Cardoso, SP, Brasil. Nind = número de árvores mortas; ID = índice de dispersão (variância/média); $X^{2}$ da distribuição de Poisson $=[\mathrm{ID}(\mathrm{n}-1)] ; \mathrm{n}=10$ parcelas; g.I. $=9$.

\begin{tabular}{ccccc}
\hline \hline & Mortas caídas & Mortas em pé & Mortas cortadas & Todas as mortas \\
\cline { 2 - 5 } Nind & 36 & 17 & 3 & 56 \\
Média & 3,60 & 1,70 & 0,30 & 5,60 \\
Variância & 11,38 & 1,57 & 0,46 & 17,60 \\
ID & 3,16 & 0,92 & 1,52 & 3,14 \\
$X^{2}$ & $28,44\left(^{*}\right)$ & 8,29 & 13,67 & $28,29\left(^{*}\right)$ \\
\hline \hline
\end{tabular}

$\left({ }^{*}\right)$ Distribuição agregada $(p=0,05)$

Para 9 graus de liberdade (g.I.), se o $X^{2}$ calculado for maior do que 19,0, a distribuição é considerada agregada, se menor do que 2,7, é uniforme e, se for um valor situado entre estes dois números, a distribuição é aleatória. Assim sendo, o padrão de distribuição espacial das árvores mortas no sub-bosque foi agregado para o conjunto das árvores mortas encontradas caídas e o conjunto de todas as árvores mortas, independente da maneira como foram encontradas; e aleatório para o conjunto das árvores encontradas mortas em pé e cortadas.

Tabela 9: Padrão de distribuição espacial das árvores mortas amostradas no componente dominante, em Floresta Pluvial Tropical Atlântica, Ilha do Cardoso, SP, Brasil. Nind = número de árvores mortas; ID = índice de dispersão (variância/média); $X^{2}$ da distribuição de Poisson $=[\mathrm{ID}(\mathrm{n}-1)] ; \mathrm{n}=40$ parcelas; g.I. $=39$.

\begin{tabular}{ccccc}
\hline & Mortas caídas & Mortas em pé & Mortas cortadas & Todas as mortas \\
\cline { 2 - 5 } Nind & 34 & 37 & 24 & 95 \\
Média & 0,85 & 0,93 & 0,60 & 2,38 \\
Variância & 1,26 & 1,20 & 1,22 & 2,80 \\
ID & 1,48 & 1,30 & 2,03 & 1,18 \\
$X^{2}$ & 57,76 & 50,57 & $79,33\left(^{*}\right)$ & 46,05 \\
\hline \hline
\end{tabular}

$\left(^{*}\right)$ Distribuição agregada $(p=0,05)$ 
Para 39 g.l., se o $X^{2}$ calculado for maior do que 58,1, a distribuição é considerada agregada, se menor do que 23,6, uniforme e se for um valor situado entre estes dois limites é aleatório. Por conseguinte, para o componente dominante, o valor do $X^{2}$ calculado para o conjunto de árvores mortas cortadas indicou o padrão de distribuição agregado; para o conjunto das árvores encontradas mortas em pé e para o conjunto de todas as mortas, o padrão de distribuição foi aleatório. Poder-seia considerar um padrão de distribuição agregado para as árvores mortas encontradas caídas, pois o valor do $X^{2}$ calculado $(57,76)$ ficou pouco abaixo do $X^{2}$ tabelado $(58,1)$.

Tabela 10: Padrão de distribuição espacial das árvores mortas amostradas no componente dominante, em Floresta Pluvial Tropical Atlântica, llha do Cardoso, SP, Brasil. Nind = número de árvores mortas; ID = índice de dispersão (variância/média); $X^{2}$ da distribuição de Poisson $=[\operatorname{ID}(\mathrm{n}-1)] ; n=4$ parcelas; g.l. $=3$.

\begin{tabular}{ccccc}
\hline \hline & Mortas caídas & Mortas em pé & Mortas cortadas & Todas as mortas \\
\cline { 2 - 5 } Nind & 34 & 37 & 24 & 95 \\
Média & 8,50 & 9,25 & 6,00 & 23,75 \\
Variância & 3,00 & 6,92 & 42,00 & 53,58 \\
ID & 0,35 & 0,75 & 7,00 & 2,26 \\
$X^{2}$ & 1,06 & 2,24 & $21,00\left(^{*}\right)$ & 6,77 \\
\hline \hline
\end{tabular}

$\left(^{*}\right)$ Distribuição agregada $(p=0,05)$

Para 3 g.l., se o $X^{2}$ calculado for maior do que 9,3, a distribuição é considerada agregada, se menor do que 0,2, uniforme e se for um valor situado entre estes dois limites é aleatório. Por conseguinte, para o componente dominante, o valor do $X^{2}$ calculado, para o conjunto de árvores mortas cortadas, indicou 0 padrão de distribuição agregado; para o conjunto das árvores encontradas mortas caídas, mortas em pé e para o conjunto de todas as mortas, o padrão de distribuição foi aleatório.

No sub-bosque, o registro de mortalidade variou de zero a 14 árvores por unidade amostral, nas 10 unidades amostrais sorteadas para o segundo 
levantamento, sem registro de morte em uma. O número de árvores vivas, no primeiro levantamento, variou 31 a 48 por subparcela.

O número de árvores mortas do componente dominante nas 40 subparcelas variou de zero a 5 árvores por unidade amostral, não havendo registro de morte em 7 subparcelas. O número de árvores vivas, no primeiro levantamento, variou de 11 a 31 por subparcela.

A correlação entre as árvores vivas e as mortas é mostrada na Tabela 11.

Tabela 11: Correlação entre as árvores vivas no primeiro levantamento e as árvores encontradas mortas no segundo levantamento, em Floresta Pluvial Tropical Atlântica, Ilha do Cardoso, SP, Brasil.

\begin{tabular}{ccccc}
\hline \hline & \multicolumn{4}{c}{ Correlação } \\
\cline { 2 - 5 } Componente estudado & $\begin{array}{c}\text { Árvores vivas x } \\
\text { Mortas caídas }\end{array}$ & $\begin{array}{c}\text { Árvores vivas x } \\
\text { Mortas em pé }\end{array}$ & $\begin{array}{c}\text { Árvores vivas x } \\
\text { Mortas cortadas }\end{array}$ & $\begin{array}{c}\text { Árvores vivas x } \\
\text { Todas as mortas }\end{array}$ \\
\hline Sub-bosque & 0,14 & $-0,29$ & 0,21 & 0,06 \\
Componente dominante & 0,13 & $-0,15$ & $-0,31\left(^{*}\right)$ & $-0,22$ \\
\hline \hline
\end{tabular}

(*) Correlação significativa para $p<0,05$

No sub-bosque, as correlações foram positivas ou diretas entre as árvores vivas e os diferentes registros de mortas, exceto para as mortas em pé, porém significativas. No componente dominante, as correlações foram negativas ou inversas, exceto para as mortas caídas. Houve significância apenas para a correlação entre as árvores vivas e as mortas cortadas, 24 indivíduos de Euterpe edulis, no componente dominante.

\section{Relação entre o recrutamento e a mortalidade}

Durante o período entre os dois censos, indivíduos pertencentes a 29 espécies, amostradas no componente dominante, morreram de maneiras diferentes e 31 espécies apresentaram incremento de árvores para este componente. Dentre 
as espécies que apresentaram maiores mudanças na entrada e saída de árvores, neste componente, destacaram-se: Euterpe edulis, que apresentou incremento de 55 árvores durante o intervalo de tempo de 6,8 anos, tendo perdido 49 árvores, 24 das quais cortadas; Psychotria nuda, incremento de 9 árvores e perda de 3; e Garcinia gardneriana, recrutamento de 7 árvores e morte de apenas 2.

No sub-bosque, no período entre os dois levantamentos, árvores de 26 espécies foram encontradas mortas e 21 espécies apresentaram incremento de árvores. As maiores mudanças na entrada e saída de árvores foram observadas para espécies amostradas neste componente. Euterpe edulis, que recrutou, entre os censos, 24 árvores, e perdeu 12 por morte; Rudgea jasminoides, recrutando 9 e perdendo 6 árvores; e Psychotria nuda, que recrutou 5 árvores e perdeu 7.

\section{$\operatorname{Lambda}(\lambda)$}

O valor de lambda para as espécies do sub-bosque foi de 1,0024 e, excluindo-se as palmeiras, de 0,9980. Os valores para as 7 espécies abundantes variaram de 0,9776 a 1,0285, na seguinte ordem decrescente: Euterpe edulis $(1,0285)$, Garcinia gardneriana (1,0211), Eugenia cuprea (1,0100), Rudgea jasminoides (1,0072) Calyptranthes lanceolata (1,0000) Psychotria nuda $(0,9949) \mathrm{e}$ Malouetia arborea $(0,9776)$. Para as 20 espécies ocasionais do sub-bosque foi de 0,9861 e para as 28 espécies raras, de 1,0036.

Para as espécies do componente dominante foi de 1,0066 e, excluindo-se as palmeiras, de 1,0065. As taxas das 14 espécies abundantes variaram de 0,9691 a 1,0596, na seguinte ordem, do mais alto valor para o mais baixo: Psychotria nuda (1,0596), Tetrastylidium grandifolium (1,0366), Garcinia gardneriana (1,0312), Eugenia mosenii (1,0257), Rudgea jasminoides (1,0131), Marlierea tomentosa $(1,0106)$, Chrysophyllum flexuosum $(1,0045)$, Euterpe edulis $(1,0039)$, Calyptranthes lucida (1,0000), Cryptocarya moschata $(1,0000)$, Sorocea bonplandii $(1,0000)$, Virola oleifera (1,0000), Malouetia arborea $(0,9705)$ e Myrcia pubipetala $(0,9691)$. Para as 41 espécies ocasionais do componente dominante, no primeiro levantamento, foi de 1,0056 e, para as 49 espécies raras, de 1,0080. 


\section{Tempo de meia vida e Tempo para dobrar}

O tempo de meia vida $(T 0,5)$ para o sub-bosque foi de 28,8 anos e, excluindose as palmeiras, de 32,9 anos. Para 6 das 7 espécies abundantes no primeiro levantamento, variou de 19,5 a 64,5 anos, na seguinte ordem decrescente: Eugenia cuprea necessitaria do maior período de tempo para reduzir à metade sua população inicial (64,5 anos), seguida de Calyptranthes lanceolata $(54,2)$, Rudgea jasminoides (45,0), Psychotria nuda $(37,2)$, Euterpe edulis $(19,9)$ e Malouetia arborea $(19,5)$. Não foi possível calcular o T0,5 para Garcinia gardneriana, porque não houve registro de morte entre os levantamentos. Para as 20 espécies ocasionais, foi de 23,5 anos e para as 28 espécies raras, de 21,1 anos.

Para o componente dominante foi de 33,4 anos e, excluindo-se as palmeiras, de 47,4 anos. Para 11 das 14 espécies abundantes, a variação foi de 14,6 a 89,2 anos, na seguinte ordem, do mais alto para o mais baixo valor de T0,5: Cryptocarya moschata necessitaria do maior período de tempo para reduzir à metade sua população inicial (89,2 anos), seguida de Chrysophyllum flexuosum $(74,1)$, Calyptranthes lucida $(67,7)$, Tetrastylidium grandifolium $(65,5)$, Garcinia gardneriana $(48,8)$, Sorocea bonplandii $(45,8)$, Rudgea jasminoides $(23,1)$, Myrcia pubipetala $(22,1)$, Euterpe edulis $(19,1)$, Psychotria nuda $(16,9)$ e Malouetia arborea (14,6). Não foram calculados os T0,5 para as espécies Eugenia mosenii, Marlierea tomentosa e Virola oleifera, porque não houve registros de morte entre os levantamentos. Para as 41 espécies ocasionais no primeiro levantamento, foi de 51,3 anos, e para as 49 espécies raras, de 46,1 anos.

O tempo para dobrar $\left(\mathrm{T}_{2}\right)$ o número inicial de indivíduos do sub-bosque foi de 30,5 anos e, excluindo-se as palmeiras, de 41,6 anos. Os $T_{2}$ das 7 espécies abundantes no primeiro levantamento, com árvores recrutadas, variaram de 13,4 a 68,3 anos, na seguinte ordem decrescente: Malouetia arborea, uma espécie típica do sub-bosque, que pode alcançar o dossel da floresta, necessitaria do maior período para dobrar o número inicial de sua população (68,3 anos), seguida por Calyptranthes lanceolata $(58,9)$, Psychotria nuda $(57,8)$, Eugenia cuprea $(35,8)$, Rudgea jasminoides (33,7), Garcinia gardneriana $(33,2)$ e Euterpe edulis $(13,4)$. Para as 6 espécies ocasionais, foi de 54,2 anos, e para as 8 espécies raras, de 23,2 anos. 
Para as espécies do componente dominante foi de 28,9 anos e, excluindo-se as palmeiras, de 35,9 anos. Para 12 das 14 espécies abundantes, com árvores recrutadas, a variação foi de 8,7 a 93,8 anos, na seguinte ordem, do mais alto para o mais baixo valor de $\mathrm{T}_{2}$ : Cryptocaria moschata necessitaria do maior período para dobrar o número inicial de sua população (93,8 anos), seguida por Calyptranthes Iucida (72,0), Marlierea tomentosa $(65,5)$, Malouetia arborea $(53,4)$, Chrysophyllum flexuosum $(53,4)$, Sorocea bonplandii $(50,2)$, Eugenia mosenii $(27,3)$, Euterpe edulis (21,5), Rudgea jasminoides (19,3), Garcinia gardneriana (16,7), Tetrastilydium grandifolium (15,9), Psychotria nuda $(8,7)$. Não foram calculados os $T_{2}$ para as espécies Myrcia pubipetala e Virola oleifera, porque não houve registros de recrutamento entre os levantamentos. Para as 12 espécies ocasionais no primeiro levantamento, foi de 39,4 anos, e para as 7 espécies raras, de 33,2 anos.

\section{Dinâmica e Estabilidade}

Utilizando a fórmula proposta por Korning \& Balslev (1994b), os maiores tempos de dinâmica encontrados foram, para o componente dominante e subbosque, 41,7 e 37,3 anos, respectivamente, excluindo as palmeiras, e os menores foram, para o componente dominante e sub-bosque, 31,1 e 29,7 anos, respectivamente, incluindo todas as espécies.

Aplicando a fórmula utilizada por Gomes (1998), as maiores taxas de estabilidade encontradas para o sub-bosque e para o componente dominante foram de 31,8 e 30,9\%, respectivamente, considerando todas as espécies amostradas, e as menores, para o sub-bosque e para o componente dominante, 25,3 e 23,1\%, respectivamente, excluindo as palmeiras amostradas.

Pela fórmula proposta por Korning \& Balslev (1994b), os maiores tempos de estabilidade encontrados foram, para o componente dominante, sem as palmeiras, de 11,5 anos, e incluindo todas as espécies, de 4,5 anos, e os menores, para o subbosque, incluindo todas as espécies, de $-8,7$ anos e excluindo as palmeiras, de $-1,7$ anos. 
O Anexo 6 traz uma compilação dos valores das taxas de crescimento, recrutamento e mortalidade obtidos em alguns trabalhos realizados em diferentes regiões do mundo, em parcelas permanentes instaladas em Florestas Tropicais.

$\mathrm{Na}$ revisão dos estudos realizados em parcelas permanentes, Gomes (1998) apresentou uma tabela semelhante contendo as taxas de recrutamento e de mortalidade, recalculadas pela forma algébrica, e os tempos de meia-vida e para dobrar, calculados em anos.

O dados registrados no Anexo 6 são apresentados da maneira como os autores citaram na literatura, ou seja, sem a realização de cálculos adicionais. Notas de rodapé foram feitas, quando pertinentes.

\section{Discussão}

$\mathrm{Na}$ análise em que Gomes (1998) quantificou os dados das parcelas permanentes utilizadas nos estudos demográficos em Florestas Tropicais, a maioria das parcelas situaram-se abaixo dos 500m de altitude, com temperaturas médias anuais entre 22 e $26^{\circ} \mathrm{C}$ e média dos totais pluviométricos anuais situados entre 2.000 e $3.500 \mathrm{~mm}$. A parcela utilizada na presente pesquisa apresenta características físicas semelhantes a da maioria das parcelas analisadas, pois: situa-se entre 100250m.s.m.; sob temperatura média anual de $21,2^{\circ} \mathrm{C}$ e chegando a alcançar índices de precipitação anual de mais de $3.000 \mathrm{~mm}$. Das características amostrais, o critério de inclusão de árvores adotado, com DAP $\geq 9,9 \mathrm{~cm}$ (aproximadamente 10,0cm), foi o mais utilizado na maioria dos estudos. Os tamanhos de parcela utilizados no presente estudo enquadram-se dentre os mais freqüentes em diversos trabalhos: 0,25ha, aqui adotado para o estudo do sub-bosque, e, em especial, 1ha, para o do componente dominante. O intervalo entre levantamentos (6,8 anos) aproximou-se de valores em que se enquadra o maior número de estudos analisados. 


\section{Estrutura da floresta}

Considerando-se as parcelas quantificadas por Gomes (1998), que utilizaram como critério de inclusão DAP $\geq 10 \mathrm{~cm}$, a densidade variou entre 280 e 935 indivíduos por hectare, com mediana de 583,5 ind./ha. A da parcela permanente do presente trabalho foi de 727 árvores vivas/ha consideradas para o estudo da estrutura da floresta, no primeiro levantamento, valor distante da mediana dos valores levantados. Na análise daquelas parcelas, foram registradas de 60 a 283 espécies, com mediana de 165 espécies. No presente estudo, registraram-se 108 espécies no primeiro levantamento, valor situado abaixo da mediana dos valores das parcelas quantificados por Gomes (1998). A distribuição dos valores de área basal apresentou moda entre 25,01 e $35,00 \mathrm{~m}^{2} / \mathrm{ha}$, com mediana de $30,60 \mathrm{~m}^{2} /$ ha. A área total encontrada no presente trabalho foi de $43,48 \mathrm{~m}^{2} / \mathrm{ha}$, no primeiro levantamento. Este valor é considerado alto e se aproxima daqueles obtidos nas parcelas permanentes que adotaram o citado critério de inclusão na Austrália, no sudeste asiático e em duas parcelas do continente americano.

De maneira geral, a estrutura e a composição de espécies do trecho de floresta estudado mudou pouco durante o período de 6,8 anos. Esta situação ocorreu àdespeito da mortalidade e do recrutamento registrados para as espécies. Como pode ser observado na Tabela 6, houve, no entanto, um aumento relativamente pequeno no número absoluto dos indivíduos do componente dominante e uma diminuição no dos indivíduos do sub-bosque. Ocorreu o aumento de 1 espécie para o componente dominante e a redução de 4, no sub-bosque. Concomitantemente a esta mudança, houve aumento maior na área total dos caules do componente dominante e pouca redução na do sub-bosque. Estas mudanças pequenas parecem indicar que, estruturalmente, o trecho de floresta estudado encontra-se em eqüilíbrio dinâmico.

Após a ocupação da llha do Cardoso por uma civilização anterior à dos índios, que mantinha hábitos sedentários e cuja alimentação se baseava na pesca e na coleta de crustáceos, seguiu-se uma outra fase, com a formação dos primeiros núcleos de colonização européia, no início do século XVI. A partir daí, os habitantes 
utilizavam, em geral, as encostas dos morros para o plantio de culturas de subsistência, evitando apenas as partes mais elevadas (Barros et al., 1991).

Mais recentemente, com a transformação da Ilha do Cardoso em Parque Estadual, em 1962, permaneceram umas poucas propriedades particulares, até hoje não desapropriadas pelo Estado, porém a prática do cultivo agrícola intensivo foi abandonada. Têm-se registros da invasão das florestas da llha do Cardoso por caçadores e palmiteiros, que agem de maneira ilegal e clandestina. Pouco tempo antes do período em que se realizou o segundo levantamento, foram registrados, na parcela permanente da presente pesquisa, os cortes de 24 indivíduos adultos de Euterpe edulis, espécie fornecedora de excelente palmito, principalmente nas regiões Sul e Sudeste do Brasil. Além da interferência antrópica, alguns trechos de florestas vêm sofrendo a ação de fatores naturais, tais como deslizamentos das encostas dos morros e queda de árvores após as chuvas torrenciais, acompanhadas de ventos fortes, bastante comuns na região.

Deve-se ressaltar a dificuldade em interpretar os dados obtidos no presente estudo pelas incertezas sobre os eventos ocorridos durante os anos que se sucederam após o primeiro levantamento, provavelmente tempestades ou interferência antrópica, que provocaram a morte de $13,3 \%$ do total de árvores consideradas para análise demográfica. Contudo, pode-se depreender que a Floresta Pluvial Tropical Atlântica na Ilha do Cardoso possui uma dinâmica própria, estando sujeita æ̀ perturbações de origem natural, que ocorrem de maneira esporádica e com um impacto de certa forma moderado.

\section{Dinâmica da floresta}

\section{Crescimento}

A taxa média de crescimento absoluta do diâmetro do caule ( $T_{C A}$ ) no local do presente estudo, considerando o componente dominante constituído de indivíduos com $\mathrm{DAP} \geq 10 \mathrm{~cm}$, foi de $1,9 \mathrm{~mm} /$ ano. Comparando este valor com aqueles obtidos 
em alguns estudos realizados (Anexo 6, do presente trabalho; Tabela 1, Gomes, 1998), pode-se observar que: é inferior àqueles obtidos por Crow \& Weaver (1977) em Luquillo Mountains, Porto Rico - 3,76 a 4,19mm/ano; por Okali \& Ola-Adams (1987) na Reserva Florestal de Omo, Nigéria, África - 2,7mm/ano; por Korning \& Balslev (1994b) em Añangu, Equador - 2,7mm/ano; por Herwitz \& Young (1994), em Bellenden-Ker, Queensland, Austrália - 2,7mm/ano; por Felfili (1995) em floresta de galeria do rio Gama, em Brasília, DF, Brasil - 2,5mm/ano; por Gomes (1998) em floresta de planalto na capital do Estado de São Paulo, Brasil - 2,3mm/ano; é superior aos registrados por Jordan \& Murphy in Uhl (1982) em San Carlos de Rio Negro, Venezuela - 1,3mm/ano; por Primack et al. (1985) em Sarawak, Costa Noroeste da Ilha de Bornéo, Leste da Malásia - 0,04 a 0,3mm/ano; por Swaine et al. (1987) em Kade, Ghana, África - 0,45mm/ano; por Swaine et al. (1990) em Shai Hills, Ghana, África - 0,6 a 1,6mm/ano; por Clark \& Clark (1992) em La Selva, Costa Rica - 0,25 a 0,63mm/ano; e é muito próximo ao obtido por Silva et al. (1995) na Floresta Nacional do Tapajós, Santarém, PA, Brasil - 2,0mm/ano.

Os valores das taxas de crescimento (Tc) podem variar tanto em relação ao regime de perturbação local durante o período de estudo, quanto ao critério de inclusão adotado, que incluirá ou não indivíduos do sub-bosque. Quanto maior a perturbação local, maiores serão as aberturas do dossel e quanto maior a entrada de luz no interior da floresta, mais as espécies dos estádios iniciais da sucessão ecológica serão favorecidas. À medida que o dossel se torne mais fechado, as espécies tolerantes à sombra passam a ser as favorecidas. As espécies dos estádios iniciais, por apresentarem Tc mais elevadas, contribuirão para o aumento da Tc média para todo o trecho estudado e as dos estádios tardios, com Tc de valores menores, contribuirão para a diminuição da Tc média (Gomes, 1998).

No presente estudo, tanto no sub-bosque quanto no componente dominante, as medianas das taxas de crescimento absolutas das espécies consideradas iniciais foram maiores do que a das tardias (Figura 18). Em geral, as espécies do dossel, demandantes de luz, tendem a ter taxas de crescimento mais altas e os incrementos médios tendem a ser mais altos para classes de DAP maiores (Felfili, 1995).

O padrão de distribuição das classes de taxas de crescimento, tanto absolutas quanto relativas, por número de indivíduos foi o de $\mathrm{J}$ invertido (Figura 15 e 
20), nos dois componentes da floresta, sub-bosque e componente dominante. Padrão idêntico foi encontrado em estudos realizados por Gentry \& Terborgh (1990), Korning \& Balslev (1994a, b), Clark \& Clark (1996) e Gomes (1998), e distinto daquele encontrado por Felfili (1995). O padrão observado no presente trabalho deveu-se à existência de numerosos indivíduos sob o dossel fechado da floresta estudada, pertencentes a espécies típicas do sub-bosque que não alcançam o dossel, ou espécies do dossel ou emergentes, representadas por árvores jovens. As taxas de crescimento maiores corresponderam à classes de DAP maiores, 0 mesmo encontrado por Connell et al. (1984), Swaine et al. (1987), Gentry \& Terborgh (1990), Milton et al. (1994), Felfili (1995) e Gomes (1998).

Comportamentos diferentes foram encontrados em outros estudos e estes resultados contraditórios podem ser explicados pela amplitude das classes de tamanho em cada local. Os tamanhos mínimos de DAP dependem do critério de inclusão adotado no censo e o máximo, do tipo de floresta estudada (Gomes, 1998).

Para o componente dominante, das 14 espécies consideradas abundantes, duas foram responsáveis pela diferença significativa de taxas de crescimento absolutas entre as classes de tamanho: Cryptocarya moschata e Virola oleifera. São espécies do dossel e tardias no processo sucessional, com alguns indivíduos emergentes. As taxas médias anuais de crescimento absolutas $\left(T_{C A}\right)$ tiveram os maiores registros para as populações do componente dominante que apresentaram os maiores DAP, podendo-se citar Hyeronima alchorneoides $(2,0463 \mathrm{~cm} / \mathrm{ano})$, Pseudopiptadenia warmingii (dois indivíduos com 2,0263 e 2,1580cm/ano) e Ficus organensis $(2,2736 \mathrm{~cm} / a n o)$, espécies que ocupam posições tardias na sucessão e são emergentes na área.

A interpretação dos dados sobre incremento diamétrico é problemática, mesmo quando os dados são cuidadosamente registrados, por causa da variação inerente ao crescimento em muitas populações arbóreas tropicais. A maioria das árvores numa população terá taxas de crescimento abaixo da taxa média de crescimento, enquanto poucas árvores têm taxas altas (Primack et al., 1985).

Analisando as taxas de crescimento absolutas calculadas para cada população, pode-se observar que houve um incremento substancial para o conjunto de árvores das populações abundantes do componente dominante, em relação 
àquelas do sub-bosque. As $\mathrm{T}_{\mathrm{CA}}$ para o conjunto das populações raras foi superior à demais, em especial no componente dominante. Como já referido por Gomes (1998), as populações raras, em geral, não apresentam qualquer característica que as distingam das demais, pois não se observa um estrato preferencial para as raras, podendo ser encontradas tanto sob o dossel como nos estratos superiores e possuir os mais diferentes tamanhos de DAP. Em uma floresta se ocorrer uma perturbação espera-se que espécies dos estádios tardios tornem-se raras e as heliófitas, dos estádios iniciais, mais comuns.

Podem-se citar como exemplos de espécies raras heliófitas, que ocupam os estratos superiores do trecho de floresta estudado, dossel superior e como emergentes: Acacia polyphylla, Cedrela odorata, Ficus organensis e Vochysia bifalcata, com alturas que variaram de 27,0 a 29,0m, estimadas no primeiro levantamento; Cariniana estrellensis e Machaerium nictitans, ambas emergentes com alturas de cerca de $32,0 \mathrm{~m}$.

Os resultados da distribuição das taxas de crescimento pelas síndromes de dispersão apresentadas pelas espécies amostrados no presente trabalho, não puderam ser comparados com outros estudos, pela ausência desta abordagem. No sub-bosque era de se esperar que as taxas das espécies zoocóricas fossem menores, pois as espécies típicas deste componente apresentam taxas, em geral, menores. No componente dominante, as anemocóricas apresentaram taxas maiores, resultado também esperado, pois são espécies com representantes, principalmente, nas classes maiores de tamanho de DAP, podendo-se citar Pseudopiptadenia warmingii, espécie presente na área com indivíduos emergentes e Machaerium nictitans, fazendo parte do dossel da floresta.

Pela análise dos dados de crescimento, existem indícios de que o trecho de Floresta Pluvial Tropical Atlântica estudado encontra-se num estádio climácico.

\section{Recrutamento e Mortalidade}

Considerando os estudos de demografia de árvores que adotaram o critério de inclusão de indivíduos com DAP $\geq 10 \mathrm{~cm}$, o valor médio de recrutamento para 68 
locais dos 110 quantificados por Gomes (1998), foi de 1,6\%/ano. Os valores estiveram entre 0,40 a 3,41\%/ano. Para 50\% das parcelas permanentes quantificadas, os valores situaram-se entre 1,06 a 1,95\%/ano, inferiores ao valor obtido no presente estudo, considerando todas as espécies para o componente dominante (2,43\%/ano). Na literatura, valores altos de taxas de recrutamento foram registrados após períodos de perturbação aguda, crônica, como um ano mais seco e/ou sítios secundários (Gomes, 1998).

Nos estudos de demografia de árvores com $D A P \geq 10 \mathrm{~cm}$, o valor médio de mortalidade para 79 locais dos 110 quantificados por Gomes (1998), foi de $1,48 \%$ /ano. Os valores estiveram entre 0,43 a 3,44\%/ano. Para 50\% das parcelas permanentes quantificadas, os valores situaram-se entre 1,13 a 2,10\%/ano, faixa de variação na qual enquadra-se o valor obtido no presente estudo, considerando todas as espécies para o componente dominante (2,05\%/ano).

A morte na floresta geralmente vem em pulsos localizados. As árvores em algumas partes da floresta parecem ser mais vulneráveis ao dano e à morte por causa de fatores diversos, tais como encostas íngremes e solos rasos, porém as condições do sítio e sua composição em espécies parecem ter um papel também importante. Não parece que a floresta inteira se desenvolva e se degenere de maneira coordenada, porém em áreas de um ou poucos hectares, períodos curtos de alta mortalidade parecem ser seguidos por longos e relativamente tranqüilos, períodos de recuperação (Putz \& Milton, 1982).

Os valores das taxas de mortalidade variaram muito entre as espécies, sendo nulos para quatro e, particularmente, altos para duas espécies abundantes no subbosque, Malouetia arborea (3,48\%/ano) e Euterpe edulis (3,42\%/ano). Dentre as espécies abundantes no componente dominante, Malouetia arborea e Psychotria nuda, tiveram as mais altas taxas de mortalidade, 4,64 e 4,03\%/ano, respectivamente, seguidas por Euterpe edulis (3,57\%/ano), três espécies típicas de sub-bosque, representadas no componente dominante por indivíduos de grande porte.

Existem na literatura registros de maior dinamismo entre as espécies raras (Manokaran \& Kochummenn, 1987; Okali \& Ola-Adams, 1987; Hubbell \& Foster, 1990a; Swaine et al., 1987; Welden et al., 1991; Condit et al., 1995 e Rolim, 1997). 
As taxas médias anuais de mortalidade e recrutamento para o conjunto de espécies raras, tanto no sub-bosque quanto no componente dominante, foram altas, comparativamente com as das demais, especialmente as de sub-bosque (Tabela 8). Esta ocorrência foi devida, em parte, æ̀s espécies associadas æ̀s clareiras, como observado por Gomes (1998) em sua pesquisa. Registraram-se recrutamento de Leandra mosenii e Miconia pyrifolia, no sub-bosque e de Cecropia glazioui e Shizolobium parahyba, no componente dominante; e mortalidade de Miconia rigidiuscula, no sub-bosque e Machaerium nictitans e Casearia sylvestris, no componente dominante, todas espécies dos estádios iniciais de sucessão. Por outro lado, o registro de taxas elevadas de mortalidade, em especial no componente dominante, deveu-se àmorte de indivíduos de grande porte, encontrados caídos.

Há registros de mortalidade mais acentuada nas classes de DAP menores em estudos sobre demografia de árvores em Florestas Tropicais, podendo-se citar: Uhl et al. (1988), em San Carlos de Río Negro, Venezuela; Swaine et al. (1990)), em Shai Hills, Gana, África; e Milton et al. (1994), na Ilha do Barro Colorado, Panamá. Provavelmente, a competição entre as árvores jovens, que participaram da cicatrização de clareiras formadas pela queda de árvores de porte grande ou a exposição de árvores do sub-bosque a níveis maiores de luminosidade, poderiam ser as explicações para esta ocorrência, como ressaltado por Felfili (1995) e por Gomes (1998). Uma outra causa seria a queda de algumas árvores de porte maior, que arrastariam consigo as de porte médio a pequeno. Podem-se realizar estas observações a partir de dados de pesquisas onde o critério de inclusão foi o de amostrar indivíduos arbóreos com diâmetros pequenos. Naqueles estudos onde 0 critério de inclusão foi o de diâmetros maiores, as árvores típicas do sub-bosque e as jovens, de tamanhos pequenos, ficam fora da análise.

Existem, no entanto, na literatura, estudos onde não se registraram diferenças significativas dos valores das taxas de mortalidade entre as classes de DAP, como os de Gentry \& Terborgh (1990), em Cocha Cashu, rio Manu, Peru; Rankin-deMerona et al. (1990, 1992), no Distrito Agropecuário da SUFRAMA, Amazonas, Brasil; Korning \& Balslev (1994a, b), em Añangu, Equador; Carey et al. (1994), em Merida, Venezuela e Rolim (1997), na Reserva Florestal de Linhares, Espírito Santo, Brasil. 


\section{Distribuição espacial das árvores mortas}

Os resultados obtidos estão sob a influência do tamanho e da forma das unidades amostrais utilizadas no estudo, principalmente se o padrão é agregado. A heterogeneidade, assim como o padrão de distribuição, é uma função da escala abordada (Ludwig \& Reynolds, 1988). O valor do índice de dispersão (variância/média) do número de árvores mortas amostradas por parcela pode dar uma idéia da heterogeneidade da distribuição no espaço horizontal para cada maneira como as árvores mortas foram encontradas (Ludwig \& Reynolds, 1988) e (Krebs, 1989).

Pela análise da Tabela 9, observou-se que o padrão de distribuição agregado foi detectado para o conjunto de árvores, amostradas no componente dominante, encontradas cortadas no segundo levantamento, quando se consideraram, individualmente, as 40 unidades amostrais, numa primeira escala de abordagem. Numa segunda escala, quando se agruparam as 40 subparcelas em 4 blocos de 10 , o mesmo padrão foi detectado, tendo-se agora a oportunidade de saber em qual área da parcela permanente do estudo, ocorreu maior número de árvores cortadas, ou seja, no bloco composto das 10 últimas unidades amostrais, de números 31 a 40 (Figura 2).

O resultado da análise de correlação entre as árvores vivas e as árvores mortas encontradas nas subparcelas utilizadas na amostragem dos dois componentes, revelou que houve correlação negativa ou inversa, significativa, entre as árvores vivas e as árvores cortadas, para o componente dominante.

Uma interpretação destes resultado poderia ser feita da seguinte maneira: os palmiteiros escolheram esta área por ser a mais distante da trilha que conduz à barragem para a captação d'água e por onde transitam os funcionários do Parque Estadual da Ilha do Cardoso; é um trecho de floresta mais fechada, sombreada portanto, diferentemente dos trechos que margeiam a trilha e os rios que cortam a área de amostragem (Figura 10); a densidade das árvores é menor e os indivíduos de Euterpe edulis, pela condição de baixa luminosidade local tiveram maiores crescimentos tanto em altura quanto em diâmetro. Foram justamente estes, os 
indivíduos escolhidos pelos palmiteiros para sua extração, por possuírem o tamanho ideal para comercialização.

\section{Relação entre o recrutamento e a mortalidade}

No sub-bosque, o número de árvores recrutadas foi $111 \%$ superior ao de mortas, e no componente dominante, foi $135 \%$. É possível afirmar que o trecho de floresta estudado não se encontra em estado de eqüilíbrio. No entanto, os valores altos das taxas de recrutamento para as espécies abundantes do sub-bosque e, em especial, do componente dominante, tenderam a compensar a mortalidade nestes componentes, mantendo, deste modo, o número razoavelmente elevado de indivíduos. Há que se fazer restrição na análise da mortalidade registrada para o componente dominante, pelo corte seletivo de 24 indivíduos de Euterpe edulis, feito por palmiteiros clandestinos que invadiram a área da parcela permanente, como já referido anteriormente.

A compensação entre o recrutamento e a mortalidade de árvores é comum em estudos em outras Florestas Tropicais. Segundo Felfili (1995), estes resultados são devidos, provavelmente, à natureza dos processos de mortalidade ocorrendo num primeiro instante, dando espaço para que haja recrutamento no instante seguinte, criando, deste modo, num curto intervalo de tempo, um deseqüilíbrio na floresta. Como na maioria das Florestas Pluviais Tropicais, uma das principais causas da mortalidade é a ocorrência de chuvas torrenciais, acompanhadas de ventos fortes.

No trecho de floresta estudado, observaram-se aumentos do número de indivíduos, da área total dos troncos das árvores, do número de recrutamentos registrados e do número de espécies amostradas, decorrentes de uma dinâmica interna da Floresta Pluvial Tropical Atlântica. Estas mudanças podem ser atribuídas a causas naturais, independentes de fatores intrínsecos à vegetação, tais como chuvas torrenciais acompanhadas de ventos fortes, comuns na região, que provocam a queda de árvores, que arrastam consigo várias árvores de pequeno a médio portes. 
$\mathrm{Na}$ literatura as áreas que apresentaram valores mais elevados de dinâmica local, isto é, onde ocorreram recrutamento e mortalidade a taxas mais altas, possivelmente o fator declividade, dentre as variáveis analisadas, influenciou os resultados (Gomes, 1998). A parcela permanente utilizada para a presente pesquisa foi instalada numa porção da média encosta, com suas 40 subparcelas dispostas de forma que seus lados maiores se dispusessem numa mesma cota de altitude (Melo \& Mantovani, 1994). De maneira geral, as unidades amostrais foram instaladas num trecho da floresta sem registro de relevo acidentado. Portanto, o fator relevo não foi o responsável pelas variações encontradas.

Analisando-se os valores das taxas de recrutamento e mortalidade, disponíveis na literatura (Tabela 1, Gomes, 1998; Anexo 6, do presente trabalho), é possível observar-se que valores altos encontraram-se em áreas em fase de recuperação (Gomes, 1998, em floresta de planalto na capital do Estado de São Paulo, Brasil; Oliveira-Filho et al., 1998, em floresta montana semidecídua no sudeste do Brasil); em áreas sujeitas a perturbações catastróficas (Crow \& Weaver, 1977 e Crow, 1980, em Luquillo Mountains, El Verde, Porto Rico); em áreas situadas æ̀ proximidades de rios (Gentry \& Terborgh, 1990, em Cocha Cashu, rio Manu, Peru; Felfili, 1995, rio Gama, Distrito Federal, Brasil); e em áreas de florestas montanas e de terras baixas na Venezuela (Carey et al., 1994).

Na Ilha do Cardoso, os valores das taxas de recrutamento e de mortalidade estão um pouco abaixo dos valores encontrados nestes lugares, porém acima daqueles lugares mais estáveis, mostrando indícios de que o trecho de Floresta Pluvial Tropical Atlântica estudado encontra-se num estádio climácico.

\section{Lambda $(\lambda)$}

Os valores de lambda não têm sido registrados nos estudos de parcelas permanentes. No entanto, esta abordagem parece ser muito promissora no estudo de demografia das plantas, visto que o valor de lambda pode variar entre populações e, assim, proporcionar uma medida da habilidade das espécies para competir com outros componentes da comunidade ao longo de gradientes 
ambientais. Igualmente, a variação dos valores de lambda calculados para uma espécie está intimamente relacionada com a estratégia de seu ciclo de vida (Córdova-Casillas, 1985).

Os valores obtidos no presente estudo revelaram estabilidade numérica (lambda $=1)$ para as populações abundantes de Calyptranthes lanceolata, no subbosque, e de Calyptranthes lucida, Cryptocaria moschata, Sorocea bonplandii e Virola oleifera, no componente dominante (Tabela 7). O número de indivíduos amostrados no primeiro e no segundo levantamentos foram iguais, porém isto não quer dizer que não houve morte ou recrutamento de indivíduos, no intervalo de tempo. Podem-se citar, como exemplos: C. lucida e C. lanceolata, amostradas, respectivamente, no componente dominante e no sub-bosque, que perderam um indivíduo e ganharam um recrutado, no intervalo de tempo.

Valores de lambda > 1 indicaram que as populações recrutaram mais indivíduos no intervalo de tempo e valores < 1, que as populações perderam indivíduos, no intervalo de tempo, situações que revelam ao mesmo tempo uma certa instabilidade numérica das populações e suas estratégias de ocupação da área.

\section{Tempo de meia vida e Tempo para dobrar}

Considerando os dados obtidos em estudos de demografia de árvores com DAP $\geq 10 \mathrm{~cm}$, o valor médio do tempo de meia-vida para 79 locais dos 110 quantificados por Gomes (1998) foi de 47,7 anos. Para 50\% das parcelas permanentes quantificadas, os valores situaram-se entre 33,4 e 61,0 anos, faixa de variação na qual situa-se o valor obtido no presente estudo, considerando todas as espécies para o componente dominante (33,4 anos).

Tanto para o sub-bosque quanto para o componente dominante, na presente pesquisa, Euterpe edulis, a espécie típica de sub-bosque, a mais importante na composição estrutural da floresta, e Malouetia arborea, espécie típica de subbosque, presente também no componente dominante, necessitariam de períodos de tempos menores (de 14,6 a 19,9 anos) para reduzir àmetade os tamanhos de suas 
populações iniciais, isto porque apresentaram as mais altas taxas de mortalidade, nos dois componentes. No componente dominante, Psychotria nuda e Rudgea jasminoides, espécies típicas de sub-bosque, e Myrcia pubipetala, foram as que apresentaram os menores tempos para redução de tamanho de suas populações, de 16,9 a 23,1 anos. As demais espécies abundantes dos dois componentes necessitariam de períodos de tempos maiores para reduzir à metade suas populações iniciais, com os máximos registrados para Eugenia cuprea (64,5 anos), no sub-bosque, e Cryptocharia moschata (89,2 anos), no componente dominante.

Quantificando os dados obtidos em estudos de demografia de árvores com DAP $\geq 10 \mathrm{~cm}$, Gomes (1998) encontrou o valor médio do tempo para dobrar a população inicial igual a 43,7 anos, para 68 locais dos 110 examinados. Para 50\% das parcelas permanentes quantificadas, os valores situaram-se entre 35,7 e 63,8 anos, bem acima do obtido no presente estudo, considerando todas as espécies para o componente dominante (28,9 anos).

Os valores médios do tempo para dobrar a população inicial de Euterpe edulis (13,4 anos), foi o mais baixo para o sub-bosque. Para o componente dominante, Psychotria nuda, Tetrastilydium grandifolium, Garcinia gardneriana, Rudgea jasminoides e a própria $E$. edulis apresentaram os menores valores, igualmente porque foram as espécies que apresentaram as mais altas taxas de recrutamento, nos dois componentes. Com exceção de T. grandifolium, as demais espécies são típicas do sub-bosque, que tiveram alguns indivíduos que apresentaram incremento diamétrico e conseguiram migrar para o componente dominante, como recrutados. As outras espécies abundantes dos dois componentes necessitariam de períodos de tempos maiores para dobrar suas populações iniciais, com os máximos registrados para Calyptranthes lanceolata (58,9 anos) e $P$. nuda (57,8 anos), no sub-bosque, e Cryptocharia moschata (93,8 anos), no componente dominante.

Os valores de tempo médio e tempo para dobrar são indicadores da dinâmica de uma floresta. Os valores obtidos para a Floresta Pluvial Tropical na llha do Cardoso indicam que a área não está sujeita àperturbações de grande impacto, que é uma floresta climácica, em eqüilíbrio dinâmico. 


\section{Dinâmica e Estabilidade}

Vários são os fatores apontados por diversos autores que influenciariam o aumento da dinâmica de uma floresta: o efeito estufa na atmosfera provocado pelo aumento dos gases; problemas metodológicos, como menor intervalo de tempo entre censos e implantação das unidades amostrais; maior riqueza em espécies da floresta; inclinação dos terrenos, que estaria favorecendo a morte das árvores por queda, por exemplos: Phillips \& Gentry (1994), Phillips et al. (1994), Sheil (1995), Sheil \& May (1996); Phillips (1996) e Gomes (1998).

Uma das dificuldades apontadas por Gomes (1998) em sua revisão de estudos em parcelas permanentes, no que diz respeito à dinâmica, foi a falta de padronização nos intervalos entre censos, que podem fornecer resultados muito distintos quando calculados pelo período médio, devido ao caráter agregado da maioria das populações, na escala de um hectare, e à dependência da taxa ao período entre censos.

Por tudo o que foi exposto nos itens anteriores, pode-se observar que o trecho de floresta estudado apresentou taxas médias anuais altas de crescimento, recrutamento e mortalidade, podendo-se considerar, com base nos resultados obtidos, que a Floresta Pluvial Tropical Atlântica na llha do Cardoso é bem dinâmica.

\section{Conclusões}

- De maneira geral, a estrutura e a composição de espécies do trecho de floresta estudado mudou pouco durante o período de 6,8 anos. Esta situação ocorreu à despeito da mortalidade e do recrutamento registrados para as espécies. Houve um aumento relativamente pequeno no número absoluto dos indivíduos do componente dominante e uma diminuição no dos indivíduos do sub-bosque. Houve aumento maior na área total dos caules do componente dominante e pouca redução na do sub-bosque. Estas mudanças parecem indicar que, estruturalmente, o trecho de floresta estudado encontra-se em eqüilíbrio instável, com alterações, de pequena escala, em sua estrutura e composição. 
- O padrão de distribuição das classes de taxas de crescimento, tanto absolutas quanto relativas, por número de indivíduos foi o de $\mathrm{J}$ invertido, no sub-bosque e no componente dominante.

- As taxas médias anuais de crescimento, absolutas e relativas, foram maiores nas classes maiores de diâmetros dos caules.

- No presente estudo, tanto no sub-bosque quanto no componente dominante, as medianas das taxas de crescimento absolutas das espécies consideradas iniciais foram maiores do que as das tardias.

- No sub-bosque era de se esperar que as taxas de crescimento absolutas das fossem menores, pois as espécies típicas deste ambiente de pouca luz, em geral, apresentam taxas de crescimento menores. No componente dominante, as espécies anemocóricas apresentaram taxas maiores, sendo que nem todas são secundárias.

- As taxas de crescimento absolutas ( $\left.T_{C A}\right)$ foram maiores para o conjunto de árvores das populações abundantes do componente dominante, em relação àquelas do sub-bosque. As $T_{C A}$ para o conjunto das populações raras foi superior às demais, em especial, no componente dominante

- Os valores das taxas de mortalidade variaram muito entre as espécies, sendo nulos para quatro e, particularmente, altos para duas espécies abundantes no subbosque, Malouetia arborea e Euterpe edulis. Dentre as populações abundantes no componente dominante, $M$. arborea, Psychotria nuda e E. edulis tiveram as mais altas taxas de mortalidade.

- A mortalidade foi mais acentuada nas classes de DAP menores, tanto no subbosque quanto no componente dominante.

- As taxas médias anuais de mortalidade e de recrutamento para o conjunto de espécies raras, tanto no sub-bosque quanto no componente dominante, foram altas, comparativamente com as das demais, especialmente de sub-bosque.

- Os padrões predominantes de distribuição espacial das árvores mortas do subbosque foram: aleatório, para as árvores encontradas mortas em pé e cortadas; agregado para as árvores caídas e para todas as mortas. Para o componente dominante, obtiveram-se padrões agregado para as árvores cortadas e caídas e aleatório para as mortas em pé e para o conjunto de todas as mortas. 
- Houve correlação negativa ou inversa, significativa, entre as árvores vivas e as árvores mortas cortadas, presentes nas subparcelas utilizadas na amostragem do componente dominante.

- No sub-bosque, o número de árvores recrutadas foi $111 \%$ superior ao de mortas, e no componente dominante, foi $135 \%$. É possível afirmar que o trecho de floresta estudado se encontra em estado dinâmico de eqüilíbrio. Os valores altos das taxas de recrutamento para as espécies abundantes do sub-bosque e, em especial, do componente dominante, tenderam a compensar a mortalidade nestes componentes, mantendo, deste modo, o número razoavelmente elevado de indivíduos.

- Os valores das taxas médias anuais de crescimento, absolutas e relativas, de recrutamento e de mortalidade, relativas, aproximam-se daqueles obtidos em alguns dos trabalhos desenvolvidos em trechos de Florestas Pluviais Tropicais.

- Os valores de lambda revelaram estabilidade para determinadas populações abundantes (Calyptranthes lanceolata, no sub-bosque, e de Calyptranthes lucida, Cryptocaria moschata, Sorocea bonplandii e Virola oleifera, no componente dominante), que se pode atribuir à compensação entre a mortalidade e o recrutamento.

- Considerando todas as espécies para o componente dominante, o tempo de meia vida seria de 33,4 anos; o tempo para dobrar seria de 28,9 anos. Excluindo-se as palmeiras, o tempo de meia vida seria de 47,4 anos e o tempo para dobrar seria de 35,9 anos. Os valores obtidos para a Floresta Pluvial Tropical na llha do Cardoso indicam que a área não está sujeita a perturbações de grande impacto e que é uma floresta climácica em eqüilíbrio dinâmico.

- O trecho de floresta estudado apresentou taxas médias anuais altas de crescimento, recrutamento e mortalidade, podendo-se considerar, com base nos resultados obtidos, que a Floresta Pluvial Tropical Atlântica na llha do Cardoso possui uma dinâmica própria, estando sujeita æ̀ perturbações de origem natural, que ocorrem de maneira esporádica e com um impacto de certa forma moderado.

- Na llha do Cardoso, os valores das taxas de recrutamento e de mortalidade estão um pouco abaixo dos valores encontrados em locais sujeitos à perturbações catastróficas ou em fase de recuperação ou situados às proximidades de rios ou ainda nas encostas íngremes, porém acima daqueles lugares mais estáveis, 
mostrando indícios de que o trecho de Floresta Pluvial Tropical Atlântica estudado encontra-se num processo naturalmente dinâmico de alteração.

\section{Referências bibliográficas}

Álvarez-Buylla, E.R. \& Martínez-Ramos, M. 1992. Demography and allometry of Cecropia obtusifolia, a neotropical pioneer tree - an evaluation of climax-pioneer paradigm for tropical rain forests. Journal of Ecology 80(2):275-290.

Amo, R.S. del \& Nieto de Pascual, J. 1985. Crecimiento y edad en arboles tropicales. In A. Gómez-Pompa \& R.S. del Amo (eds.). Investigaciones sobre la regeneración de selvas altas en Veracruz, Mexico. II INIREB, Xalapa, Mexico. p.129-145.

Aragaki, S. 1997. Florística e estrutura de trecho remanescente de floresta no planalto paulistano (SP). Dissertação de Mestrado, Instituto de Biociências, Universidade de São Paulo, São Paulo, 108p.

Ashton, P.S. \& Hall, P. 1992. Comparisons of structure among mixed dipterocarp forests of north-western Borneo. Journal of Ecology 80:459-481.

Barros, F., Melo, M.M.R.F., Chiea, S.A.C., Kirizawa, M., Wanderley, M.G.L., JungMendaçolli, S.L. 1991. In M.M.R.F. Melo, F. Barros, M.G.L. Wanderley, M. Kirizawa, S.L. Jung-Mendaçolli \& S.A.C. Chiea (eds.) Caracterização geral da vegetação e listagem das espécies ocorrentes. Instituto de Botânica, São Paulo. v.1. 184p.

Batista, J.L.F. 1994. Spatial dynamics of trees in a Brazilian tropical forest under natural and managed conditions. DPhil. Thesis, University of Washington, Washington, 327p.

Carey, E.V., Brown, S., Gillespie, A.J.R. \& Lugo, A.E. 1994. Tree mortality in mature lowland tropical moist and tropical lower montane moist forests of Venezuela. Biotropica 26(3):255-265.

Catharino, E.L.M. 1990. Estudos fisionômico-florísticos e fitossociológicos em matas residuais secundárias no município de Piracicaba, SP. Dissertação de Mestrado, Instituto de Biologia, Universidade Estadual de Campinas, Campinas, 181p.

Clark, D.A. \& Clark, D.B. 1987. Análisis de la regeneración de árboles del dosel en bosque muy húmedo tropical: aspectos teóricos y prácticos. Revista de Biologia Tropical 35(1):41-54.

Clark, D.A. \& Clark, D.B. 1992. Life history diversity of canopy and emergent trees in a neotropical rain forest. Ecological Monographs 62(3):315-344.

Clark, D.B. \& Clark, D.A. 1991. The impact of physical damage on canopy tree regeneration in tropical rain forest. Journal of Ecology 79:447-457.

Clark, D.B. \& Clark, D.A. 1996. Abundance, growth and mortality of very large trees in neotropical lowland rain forest. Forest Ecology and Management 80:235-244.

Condit, R., Hubbell, S.P. \& Foster, R.B. 1992a. Recruitment near conspecific adults and the maintenance of tree and shrub diversity in a neotropical forest. The American Naturalist 140:261-286.

Condit, R., Hubbell, S.P. \& Foster, R.B. 1992b. Short-term dynamics of a neotropical forest. BioScience 42(11):822-828. 
Condit, R., Hubbell, S.P. \& Foster, R.B. 1993. Mortality and growth of a commercial hardwood "el cativo", Prioria copaifera, in Panama. Forest Ecology and Management 62:107-122.

Condit, R., Hubbell, S.P. \& Foster, R.B. 1995. Mortality rates of 205 neotropical tree and shrub species and the impact of a severe drought. Ecological Monographs 65(4):419439.

Connel, J.H., Tracey, J.G. \& Webb, L.J. 1984. Compensatory recruitment, growth, and mortality as factors maintaining rain forest tree diversity. Ecological Monographs 54(2):141-164.

Córdova-Casillas, B. 1985. Demografia de arboles tropicales. In A. Gómez-Pompa \& R.S. del Amo (eds.). Investigaciones sobre la regeneración de selvas altas en Veracruz, Mexico. II INERB, Xalapa, Mexico. p.103-128.

Crow, T.R. \& Weaver P.L. 1977. Tree growth in a moist tropical forest of Puerto Rico. United States Forest Service Research Paper ITF-22:1-17.

Crow, T.R. 1980. A rainforest chronicle: a 30-year record of change in structure and composition at El Verde, Puerto Rico. Biotropica 12(1):42-55.

Elouard, C.; Pascal, J.-P.; Pélissier, R.; Ramesh, B.R.; Houllier, F.; Durand, M.; Aravajy, S.; Moravie, M.-A. \& Carpentier-Gimaret, C. 1997. Monitoring the structure and dynamics of a dense moist evergreen forest in the Western Ghats (Kodagu District, Karnataka, India). Tropical Ecology 38(2):193-214.

Felfili, J.M. 1995. Growth, recruitment and mortality in the Gama gallery forest in central Brazil over a six-year period (1985-1991). Journal of Tropical Ecology 11:67-83.

Felfili, J.M. 1997. Dinamics of the natural regeneration in the Gama gallery forest in central Brazil. Forest Ecology and Management 91:235-245.

Fisch, S.T.V. 1999. Dinâmica de Euterpe edulis na Floresta Ombrófila Densa Atlântica em Pindamonhangaba-SP. Tese de Doutorado, Instituto de Biociências, Universidade de São Paulo, São Paulo, 126p.

Foster, R.B. \& Brokaw, N.V.L. 1982. Structure and history of the vegetation of Barro Colorado Island. In E.G. Leigh Junior, A.S. Rand \& D.M. Windsor (eds.). The ecology of a tropical forest: seasonal rhytms and long-term changes. Smithsonian Institution Press, Washington, D.C., p.67-81.

Gandolfi, S., Leitão Filho, H.F. \& Bezerra, C.L.E. 1995. Levantamento florístico e caráter sucessional das espécies arbustivo-arbóreas de uma floresta mesófila semidecídua no município de Guarulhos, SP. Revista Brasileira de Biologia 55 (4):753-767.

Gentry, A.H. \& Terborgh, J. 1990. Composition and dynamics of the Cocha Cashu "mature" floodplain forest . In A.H. Gentry (ed.) Four neotropical rainforests. Yale University Press, New Haven. p.542-564.

Gilbert, G.S., Hubbell, S.P. \& Foster, R.B. 1994. Density and distance-to-adult effects of a canker disease of trees in a moist tropical forest. Oecologia 98:100-108.

Gomes, E.P.C. 1998. Dinâmica do componente arbóreo de um trecho de mata em São Paulo, SP. Tese de Doutorado, Instituto de Biociências, Universidade de São Paulo, São Paulo, 285p.

Herwitz, S.R. \& Young, S.S. 1994. Mortality, recruitment, and growth rates of montane tropical rain forest canopy trees on Mount Bellenden-Ker, Northeast Queensland, Australia. Biotropica 26(4):350-361. 
Ho, C.C., Newbery, D. McC. \& Poore, M.E. 1987. Forest composition and inferred dynamics in Jengka Forest Reserve, Malaysia. Journal of Tropical Ecology (Special Issue) 3(1):25-56.

Hubbell, S.P. \& Foster, R.B. 1987. La estructura espacial en gran escala de un bosque neotropical. Revista de Biologia Tropical 35(Suplemento 1):7-22.

Hubbell, S.P. \& Foster, R.B. 1990a. Structure, dynamics, and equilibrium status of old-growth forest on Barro Colorado Island. In A.H. Gentry (ed.). Four neotropical forests. Yale University Press, New Haven. p.522-541.

Hubbell, S.P. \& Foster, R.B. 1990b. The fate of juvenile trees in a neotropical forest: implications for the natural maintenance of tropical tree diversity. In K.S. Bawa \& M. Hadley (eds.). Reproductive ecology of tropical forest plants. Man and the Biosphere Series, Vol. 7. UNESCO/IUBS Paris and Parthenon Publishing, Carnforth. p.317-341.

Jardim, F.C.S. 1990. Mortalidade e crescimento na floresta equatorial de terra firme. Boletim do Museu Paraense Emílio Goeldi, Série Botânica 6(2):227-234.

Knight, D.H.1975. A phytosociological analysis of species-rich tropical forest on Barro Colorado Island, Panama. Ecological Monographs 45:259-284.

Knobel, M.G. 1995. Aspectos da regeneração natural do componente arbóreo-arbustivo de trecho da floresta da Reserva Biológica do Instituto de Botânica de São Paulo, SP. Dissertação de Mestrado, Instituto de Biociências, Universidade de São Paulo, São Paulo, 128p.

Kohyama, T. \& Takada, T. 1998. Recruitment rates in forest plots: Gf estimates using growth rates and size distributions. Journal of Ecology 86:633-639.

Korning, J. \& Balslev, H. 1994a. Growth and mortality of trees in Amazonian tropical rain forest in Ecuador. Journal of Vegetation Science 4:77-86.

Korning, J. \& Balslev, H. 1994b. Growth rates and mortality patterns of tropical lowland tree species and the relation to forest structure in Amazonian Ecuador. Journal of Tropical Ecology 10:151-166.

Kozlowski, T.T. \& Winget, C.H. 1964. Diurnal and seasonal variation in radii of tree stems. Ecology 45(1):149-155.

Krebs, C.J. 1989. Ecological metodology. Harper \& Row, New York. 654p.

LaFrankie Junior, J.V. 1994. Population dynamics of some tropical trees that yield non-timber forest products. Economic Botany 48(3):301-309.

Lang, G.E. \& Knight, D.H. 1983. Tree growth, mortality, recruitment, and canopy gap formation during a 10-year period in a Tropical Moist Forest. Ecology 64(5):1075-1080.

Laurance, W.F.; Ferreira, L.V.; Rankin-de-Merona, J.M. \& Laurance, S.G. 1998. Rain forest fragmentation and dynamics of amazonian tree communities. Ecology 79(6):2032-2040.

Leitão Filho, H.F. (org.) 1993. Ecologia da Mata Atlântica em Cubatão. Campinas, Editora UNESP da Fundação para o Desenvolvimento da Universidade Estadual Paulista, Editora da Universidade de Campinas. 184p.

Lieberman, D. \& Lieberman, M. 1987. Forest tree growth and dynamics at La Selva, Costa Rica (1969-1982). Journal of Tropical Ecology (Special Issue) 3:347-358.

Lieberman, D. 1982. Seasonality and phenology in a dry tropical forest in Ghana. Journal of Ecology 70:791-806.

Lieberman, D., Hartshorn, G.S., Lieberman, M. \& Peralta, R. 1990. Forest dynamics at La Selva Biological Station, Costa Rica, 1969-1985. In A.H. Gentry (ed.) Four neotropical rainforests. Yale University Press, New Haven. p.509-521. 
Lieberman, D., Lieberman, M., Hartshorn, G.S. \& Peralta, R. 1985a. Small-scale altitudinal variation in lowland wet tropical forest vegetation. Journal of Ecology 73:505-516.

Lieberman, D., Lieberman, M., Peralta, R. \& Hartshorn, G.S. 1985b. Mortality patterns and stand turnover rates in a wet tropical forest in Costa Rica. Journal of Ecology 73:915924.

Lieberman, M., Lieberman, D. 1994. Patterns of density and dispersion of forest trees. In L.A. McDade, K.S. Bawa, H. Hespenheide \& G.S. Hartshorn (eds.) La Selva: Ecology and natural history of a neotropical rain forest. University of Chicago Press, Illinois. p.106-119.

Lorenzi, H. 1992. Árvores brasileiras: manual de identificação e cultivo de plantas arbóreas nativas do Brasil. Editora Plantarum, Nova Odessa, São Paulo. 352p.

Ludwig, J.A. \& Reynolds, J.F. 1988. Statistical Ecology: a primer on methods and computing. John Wiley \& Sons, New York. 337p.

Manokaran, N. \& Kochumen, K.M. 1987. Recruitment, growth and mortality of tree species in a lowland dipterocarp forest in Peninsular Malaysia. Journal of Tropical Ecology (Special Issue) 3:315-330.

Manokaran, N. \& Kochumen, K.M. 1994. Tree growth in primary lowland and hill dipterocarp forests. Journal of Tropical Forest Science 6(3):332-345.

Mantovani, W. 1993. Estrutura e dinâmica da floresta atlântica na Juréia, Iguape - SP. Tese de Livre Docência, Instituto de Biociências, Universidade de São Paulo, São Paulo, 126p.

Martínez-Ramos, M. \& Álvarez-Buylla, E. 1995. Ecología de poblaciones de plantas en una selva húmeda de México. Boletim Sociedad Botánica de México 56:121-153.

van der Meer, P.J. \& Bongers, F. 1996. Patterns of the tree-fall and branch-fall in a tropical rain forest in French Guiana. Journal of Ecology 84:19-29.

Melo, M.M.R.F. \& Mantovani, W. 1994. Composição florística e estrutura de trecho de Mata Atlântica de encosta, na Ilha do Cardoso (Cananéia, SP, Brasil). Boletim do Instituto de Botânica 9:107-158.

Milton, K., Laca, E.A. \& Demment, M.W. 1994. Successional patterns of mortality and growth of large trees in a Panamanian lowland forest. Journal of Ecology 82(1):79-87.

Nicholson, D.I. 1965. One year's growth of Shorea smithiana in North Borneo. Malayan Forester 21(3):193-196.

Noether, G.E. 1983. Introdução à estatística: uma abordagem não-paramétrica. $2^{\mathrm{a}}$ ed. Guanabara Dois, Rio de Janeiro. 95p.

Okali, D.U.U. \& Ola-Adams, B.A. 1987. Tree population changes in treated rain forest at Omo Forest Reserve, south-western Nigeria. Journal of Tropical Ecology (Special Issue) 3:291-313.

Oliveira Filho, A.T., Mello, J.M. \& Scolforo, J.R.S. 1997. Effects of past disturbance and edges on tree community structure and dynamics within a fragment of tropical semidecidous forest in south-eastern Brazil over a five-year period (1987-1992). Plant Ecology 131:45-66.

Oliveira, R.J. 1999. Dinâmica de plântulas e estrutura da Mata Atlântica Secundária de encosta, Peruíbe, SP. Dissertação de Mestrado, Instituto de Biociências, Universidade de São Paulo, São Paulo, 125p.

Parresol, B.R. 1995. Basal area growth for 15 tropical tree species in Puerto Rico. Forest Ecology and Management 73:211-219. 
Peralta, R., Hartshorn, G.S., Lieberman,D. \& Lieberman, M. 1987. Reseña de estudios a largo plazo sobre composición florística y dinámica del bosque tropical en La Selva, Costa Rica. Revista de Biologia Tropical 35(Supl. 1):23-39.

Pfeifer, R.M. 1981-1982. Levantamento semidetalhado dos solos do Parque Estadual da llha do Cardoso. Revista do Instituto Florestal. 1(1):39-49.

Phillips, O.L. \& Gentry, A.H. 1994. Increasing turnover through time in tropical forests. Science 263:954-958.

Phillips, O.L. 1996. Long-term environmental change in tropical forests: increasing tree turnover. Environmental Conservation 23(3):235-248.

Phillips, O.L., Hall, P., Gentry, A.H., Sawyer, S.A. \& Vázquez, R. 1994. Dynamics and species richness of tropical rain forests. Proceedings of Natural Academy of Science of USA 91:2805-2809.

van der Pijl, P. 1982. Principles of dispersal in higher plants. $3^{\text {nd }}$ ed. Springer-Verlag, Berlim. 213p.

Primack, R.B. \& Hall, P. 1992. Biodiversity and forest change in Malaysian Borneo. Bioscience 42(11):829-837.

Primack, R.B. \& Lee, H.S. 1991. Population dynamics of pioner (Macaranga) trees and understorey (Mallotus) trees (Euphorbiaceae) in primary and selectively logged Bornean rain forests. Journal of Tropical Ecology 7:439-458.

Primack, R.B., Ashton, P.S., Chai, P., Lee, H.S. 1985. Growth rates and population structure of Moraceae trees in Sarawak, East Malaysia. Ecology 66(2):577-588.

Putz, F.E. \& Milton, K. 1982. Tree mortality rates on Barro Colorado Island. In E.G. Leigh Junior, A.S. Rand \& D.M. Windsor (eds.). The ecology of a tropical forest: seasonal rhytms and long-term changes. Oxford University Press, Oxford. p.95-100.

Rankin-de-Merona, J.M., Hutchings, H.R.W. \& Lovejoy, T.E. 1990. Tree mortality and recruitment over a five-year period in undisturbed upland rainforest of the central Amazon. In A.H. Gentry (ed.) Four neotropical rainforests. Yale University Press, New Haven. p.573-584.

Rankin-de-Merona, J.M., Prance, G.T., Hutchings, R.W., Silva, M.F., Rodrigues, W.A. \& Uehling, M.E. 1992. Preliminary results of a large-scale tree inventory of upland rain forest in the Central Amazon. Acta Amazonica 22(4):493-534.

Rogers, S. 1981. Seasonal variation in radial growth and phloem activity of Terminalia ivorensis A. Chev. Annals of Botany 47:603-610.

Roizman, L.G. 1993. Fitossociologia e dinâmica do bnco de sementes de populações arbóreas de floresta secundária em São Paulo. Dissertação de Mestrado, Instituto de Biociências, Universidade de São Paulo, São Paulo, 184p.

Rolim, S.G. 1997. Dinâmica da floresta atlântica em Linhares (ES) - 1980-1995. Dissertação de Mestrado, Escola Superior de Agricultura Luiz de Queiroz, Universidade de São Paulo, Piracicaba, 87p.

Rossi, L. 1994. A flora arbóreo-arbustiva da mata da Reserva da Cidade Universitária "Armando Salles de Oliveira", São Paulo, SP". Boletim do Instituto de Botânica 9:1105.

Sampaio, P.D. 1997. Estrutura e floristica de floresta atlântica secundária - Reserva Biológica Estadual da Praia do Sul, Ilha Grande, RJ. Dissertação de Mestrado, Instituto de Biociências, Universidade de São Paulo, São Paulo, 117p.

Sheil, D. \& May, R.1996. Mortality and recruitment rate evaluations in heterogeneous tropical forests. Journal of Ecology 84:91-100. 
Sheil, D. 1995. Evaluating turnover in tropical forests. Science 268:894.

Sheil, D., Burslem, D.F.R.P. \& Alader, D. 1995. The interpretation and misinterpretation of mortality rate measures. Journal of Ecology 83:331-333.

Silva, J.N.M., Carvalho, J.O.P., Lopes, J.C.A., Almeida, B.F., Costa, D.H.M., Oliveira, L.C., Vanclay, J.K. \& Skovsgaard, J.P. 1995. Growth and yield of a tropical rain forest in the Brazilian Amazon 13 years after logging. Forest Ecology and Management 71:267274.

Sukumar, R., Dattaraja, H.S., Suresh, H.S., Radhakrishnan, J., Vasudeva, R., Nirmala, S. \& Joshi, N.V. 1992. Long-term monitoring of vegetation in a tropical deciduous forest in Mudumalai, Southern Índia. Current Science 62(9):608-616.

Swaine, M.D. \& Whitmore, T.C. 1988. On the definition of ecological species groups in tropical rain forests. Vegetatio 75:81-86.

Swaine, M.D. 1989. Population dynamics of tree species in tropical forests. In L.B. HolmNielsen, I.C. Nielsen \& H. Balslev (eds). Tropical forests: Botanical dynamics, speciation, and diversity. Academic Press, London. p.101-110.

Swaine, M.D., Hall, J.B. \& Alexander, I.J. 1987. Tree populations dynamics at Kade, Ghana (1968-1982). Journal of Tropical Ecology (Special Issue) 3:331-345.

Swaine, M.D., Lieberman, D. \& Hall, J.B. 1990. Structure and dynamics of a tropical dry forest in Ghana. Vegetatio 88:31-51.

Swaine, M.D., Lieberman, D. \& Putz, F.E. 1987. The dynamics of tree populations in tropical forest: a review. Journal of Tropical Ecology (Special Issue) 3:359-369.

Tabarelli, M. 1994. Clareiras naturais e a dinâmica sucessional em um trecho de floresta na Serra da Cantareira, SP. Dissertação de Mestrado, Instituto de Biociências, Universidade de São Paulo, São Paulo, 142p.

Tabarelli, M., Villani, J.P. \& Mantovani, W. 1993. Aspectos da sucessão secundária em trecho da floresta atlântica no Parque Estadual da Serra do Mar, SP. Revista do Instituto Florestal 5(1):99-112.

Terborgh, J., Flores, C.N., Mueller, P. \& Davenport, L. 1997. Estimating the ages of successional stands of tropical trees from growth increments. Journal of Tropical Ecology 14:833-856.

Uhl, C. 1982. Tree dynamics in a species rich Terra Firme forest in Amazonia, Venezuela. Acta Científica Venezolana 33:72-77.

Uhl, C., Clark, K., Dezzeo, N. \& Maquirino, P. 1988. Vegetation dynamics in amazonian treefall gaps. Ecology 69(3):751-763.

Welden C.W., Hewett S.W., Hubbell S.P. \& Foster R.B. 1991. Sapling survival, growth, and recruitment: relationship to canopy height in a neotropical forest. Ecology 72(1):35-50.

Whitmore, T.C. 1984. Tropical rain forests of the Far East. $2^{\text {nd }}$ ed. Claredon Press, Oxford. $352 p$.

Whitmore, T.C. 1989a. Canopy gaps and two major groups of forest trees. Ecology 70(3):536-538.

Whitmore, T.C. 1989b. Changes over twenty-one years in the Kolombangara rain forests. Journal of Ecology 77:469-483. 


\section{Capítulo 5}

\section{CONSIDERAÇÕES FINAIS}

Com base nos resultados da presente pesquisa e, considerando os principais processos ecológicos básicos que regem a Floresta Pluvial Tropical Atlântica, a história pretérita de ocupação da llha do Cardoso, com o uso agricultural das partes baixas dos morros, as perturbações naturais a que estão sujeitas as Florestas Tropicais no mundo todo, conclui-se que: o trecho estudado é de floresta natural com dinâmica própria, que se encontra em eqüilíbrio dinâmico, está sujeita a distúrbios de origem natural, que ocorrem de maneira esporádica e com um impacto de certa forma moderado, podendo ser considerada como uma floresta climácica.

Estudos em parcelas permanentes de grande extensão, realizados durante períodos de longa duração, são essenciais para o desenvolvimento de estudos sobre a biologia de Florestas Tropicais, tais como: ecologia reprodutiva, dinâmica de populações, ecologia de comunidade, produtividade das plantas, genética de populações, silvicultura aplicada, dentre outros. Tais pesquisas poderiam prover com perspectivas futuras boas as bases científicas do manejo sustentável das Florestas Tropicais (Hubbell \& Foster, 1990; Sukumar et al., 1992).

Embora o presente estudo tenha sido realizado em uma área relativamente pequena, considera-se que foi possível obter informações sobre a estrutura e a dinâmica da Floresta Pluvial Tropical Atlântica.

São necessários estudos demográficos completos de determinadas populações de árvores de nossas Florestas Pluviais Tropicais Atlânticas, como aqueles realizados por Knight (1975), Clark \& Clark (1987), Henriques \& Sousa (1989), Martínez-Ramos \& Álvarez-Buylla (1995), dentre outros.

Algumas recomendações específicas no procedimento de obtenção de dados que poderão solucionar, em boa parte, as dificuldades no conhecimento demográfico das espécies arbóreas tropicais, foram dadas por Córdova-Casillas (1985):

- estabelecer áreas permanentes de observação, pois esta é a única maneira de coletar os registros com o detalhe e a periodicidade que os estudos demográficos 
requerem;

- desenhar a amostra para o estudo levando-se em conta que é muito conveniente ter uma representação adequada de todas as classes de tamanho ou idades, se possível, sobretudo se pretende-se elaborar a tabela de vida para uma subseqüente análise demográfica;

- realizar estudos a longo prazo (5 a 10 anos) e assim abranger as variações interanuais de vários eventos; isto é especialmente útil na obtenção dos padrões de floração e frutificação, e igualmente, no recrutamento das plântulas;

- registrar cada indivíduo da amostra escolhida e efetuar a seleção das espécies a estudar, dentro do limite de conhecimento básico da comunidade onde vivem.

Deve-se propor, no Brasil, um projeto a ser desenvolvido numa área permanente de grande extensão, instalada numa região de ocorrência da Floresta Pluvial Tropical Atlântica, que integre as diferentes universidades e instituições, com pesquisadores atuando nas diversas linhas de pesquisa e trabalhando durante um período de longa duração. Somente assim, ao final deste projeto, poder-se-á obter uma visão real e aprofundada da dinâmica destas florestas.

\section{Referências bibliográficas}

Clark, D.A. \& Clark, D.B. 1987. Análisis de la regeneración de árboles del dosel en bosque muy húmedo tropical: aspectos teóricos y prácticos. Revista de Biologia Tropical 35(1):41-54.

Córdova-Casillas, B. 1985. Demografia de arboles tropicales. In A. Gómez-Pompa \& R.S. del Amo (eds.). Investigaciones sobre la regeneración de selvas altas en Veracruz, Mexico. II INERB, Xalapa, Mexico. p.103-128.

Henriques, R.P.B. \& Sousa, E.C.G. 1989. Population structure, dispersion and microhabitat regeneration of Carapa guianensis in northeastern Brazil. Biotropica 21(3):204-209.

Hubbell, S.P. \& Foster, R.B. 1990. Structure, dynamics, and equilibrium status of old-growth forest on Barro Colorado Island. In A.H. Gentry (ed.). Four neotropical forests. Yale University Press, New Haven. p.522-541.

Knight, D.H.1975. A phytosociological analysis of species-rich tropical forest on Barro Colorado Island, Panama. Ecological Monographs 45:259-284.

Martínez-Ramos, M. \& Álvarez-Buylla, E. 1995. Ecología de poblaciones de plantas en una selva húmeda de México. Boletim Sociedad Botánica de México 56:121-153.

Sukumar, R., Dattaraja, H.S., Suresh, H.S., Radhakrishnan, J., Vasudeva, R., Nirmala, S. \& Joshi, N.V. 1992. Long-term monitoring of vegetation in a tropical deciduous forest in 
Mudumalai, Southern Índia. Current Science 62(9):608-616. 


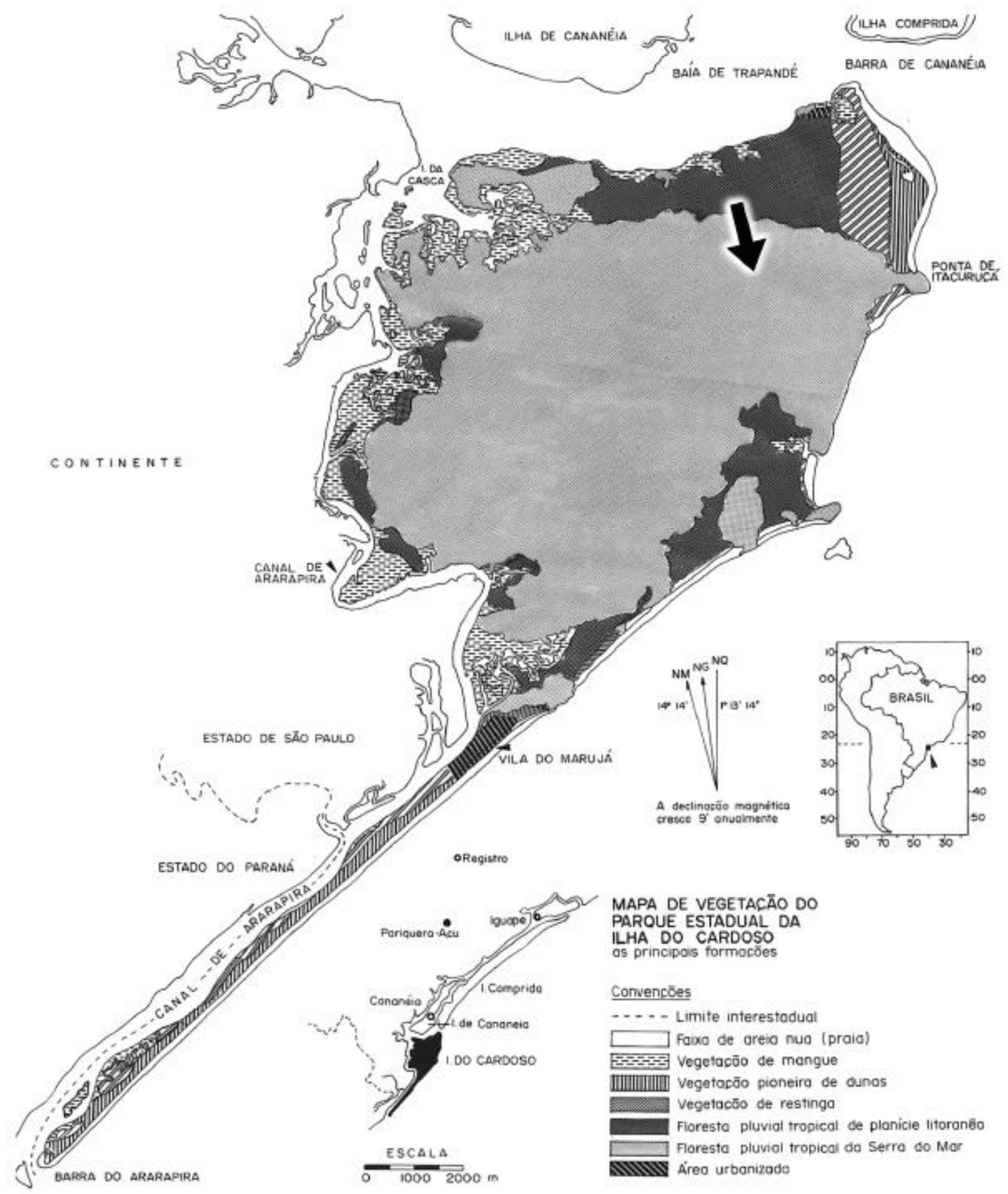

Figura 1: Mapa mostrando a distribuição dos diferentes tipos de vegetação ocorrentes na Ilha do Cardoso. A seta indica a localização aproximada da área de estudo em Floresta Pluvial Tropical Atlântica, Ilha do Cardoso, SP, Brasil. Fonte: Barros et al. (1991). 


\begin{tabular}{|c|c|}
\hline 39 & 40 \\
\hline 38 & 37 \\
\hline 35 & 36 \\
\hline 34 & 33 \\
\hline 31 & 32 \\
\hline 30 & 29 \\
\hline 27 & 28 \\
\hline 26 & 25 \\
\hline 23 & 24 \\
\hline 22 & 21 \\
\hline
\end{tabular}

\begin{tabular}{|c|c|}
\hline 19 & 20 \\
\hline 18 & 17 \\
\hline 15 & 16 \\
\hline 14 & 13 \\
\hline 11 & 12 \\
\hline
\end{tabular}

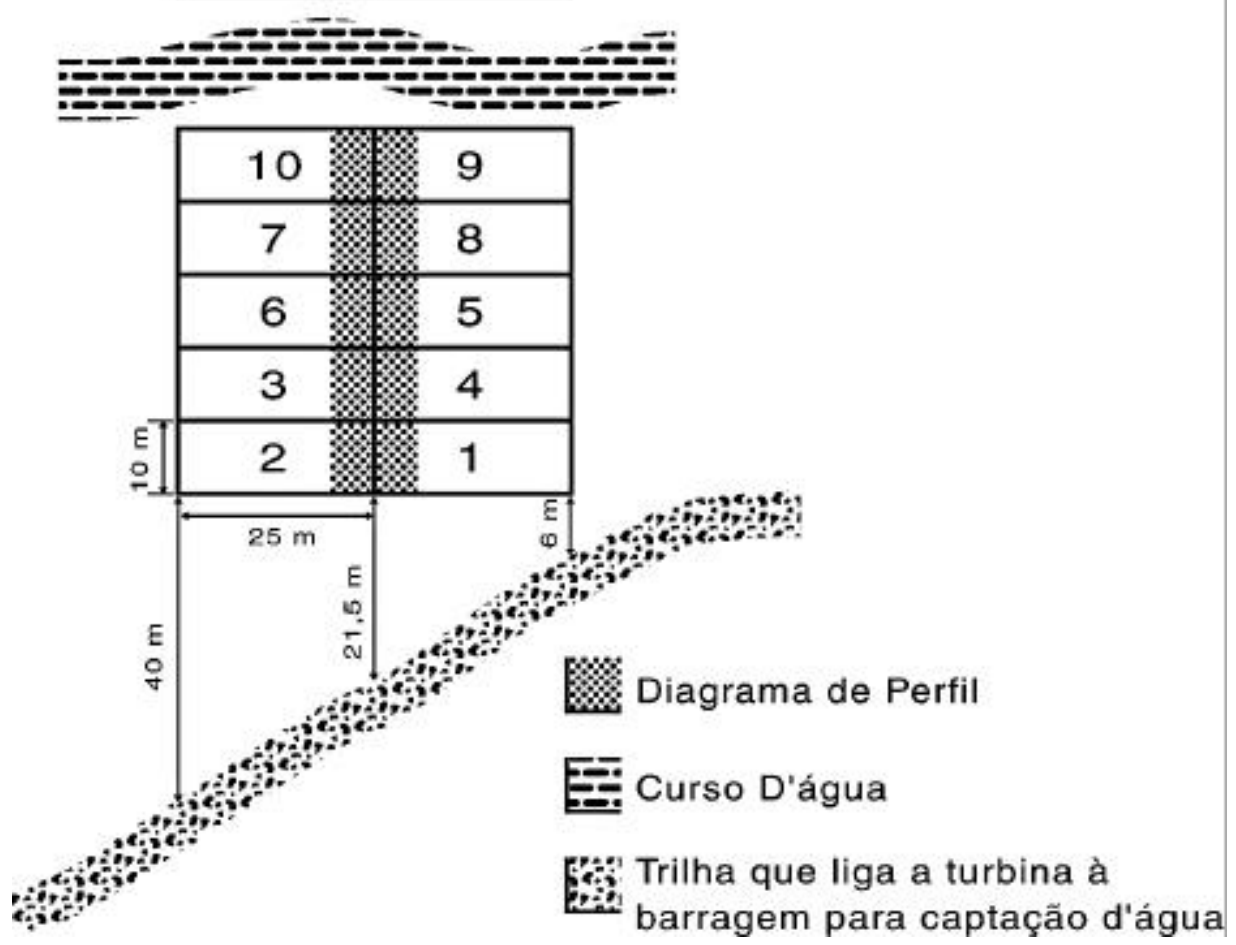

Figura 2: Esquema da distribuição das subparcelas utilizadas na amostragem de trecho de Floresta Pluvial Tropical Atlântica, Ilha do Cardoso, SP, Brasil. Fonte: Melo \& Mantovani (1994). 
a

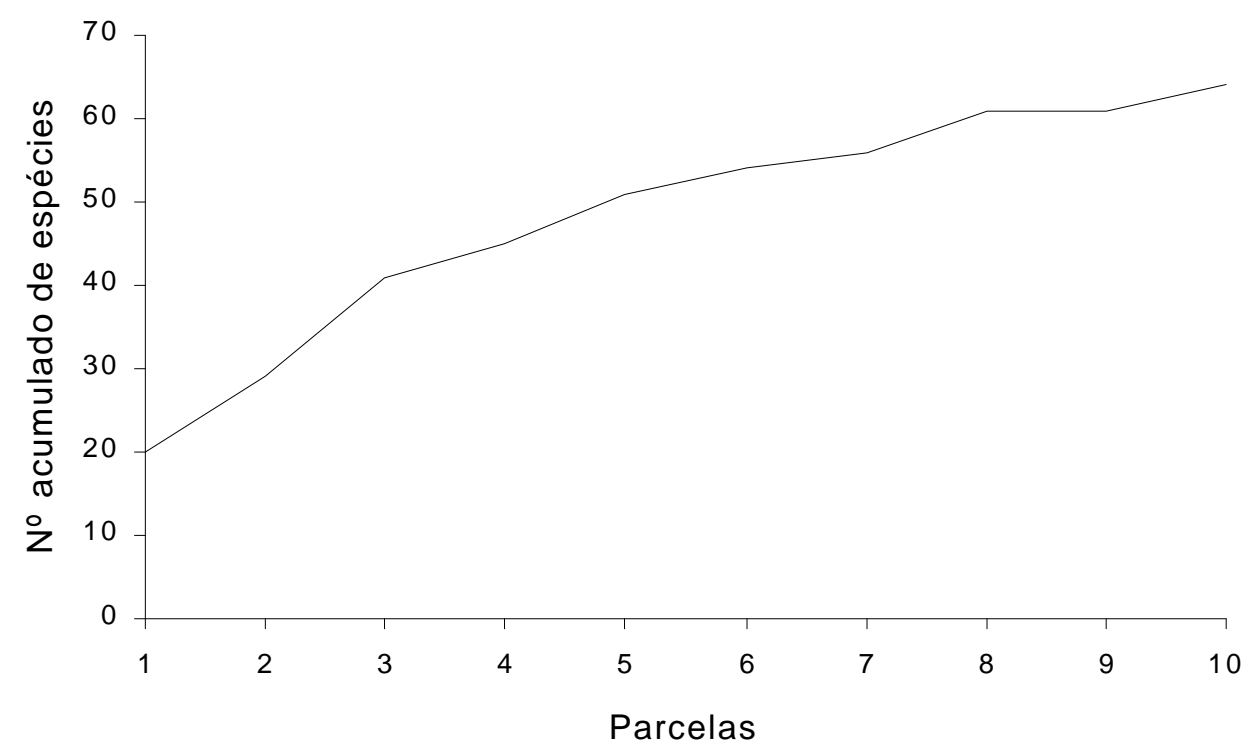

b

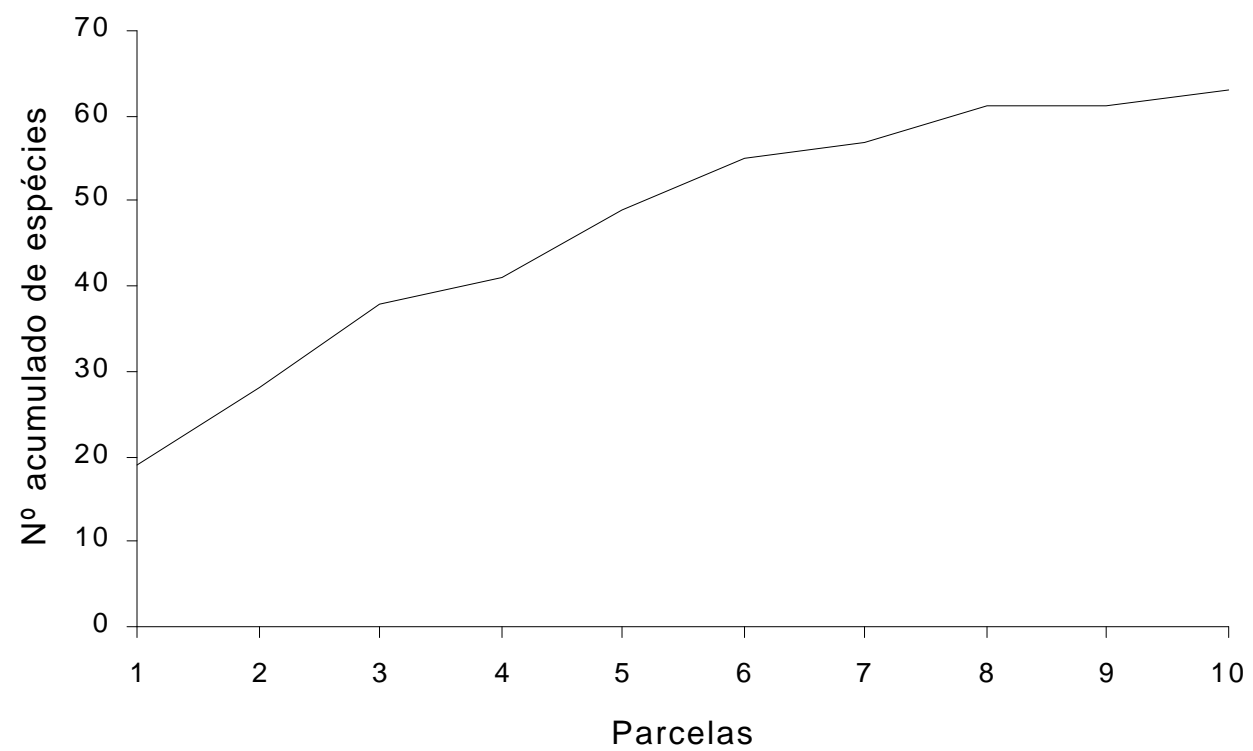

Figura 3: Curvas do número acumulado de espécies $\mathrm{x}$ área amostrada do sub-bosque, em Floresta Pluvial Tropical Atlântica, Ilha do Cardoso, SP, Brasil. a: primeiro levantamento e b: segundo levantamento. Os números das subparcelas deste gráfico, correspondem, seqüencialmente, aos números $4,6,15,16,20,23,25,27$, 32 e 35 dos gráficos da Figura 4. 


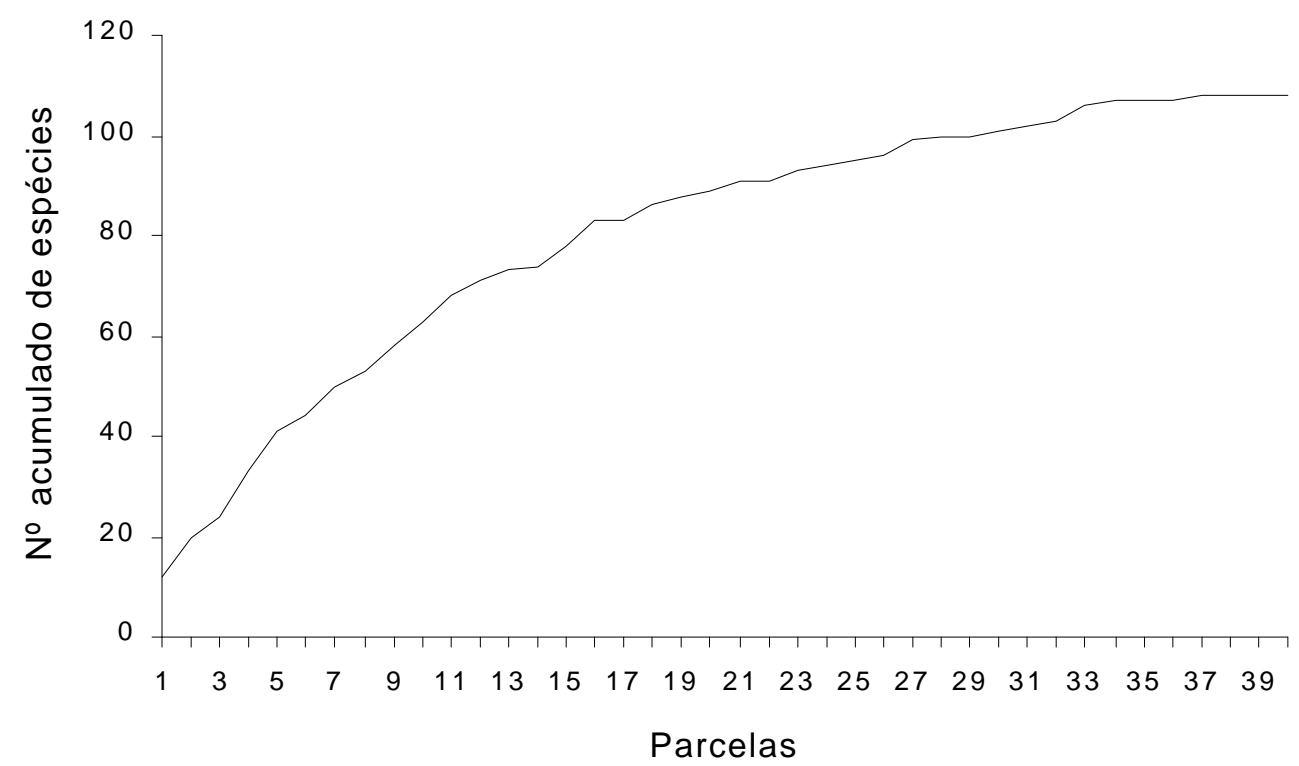

b

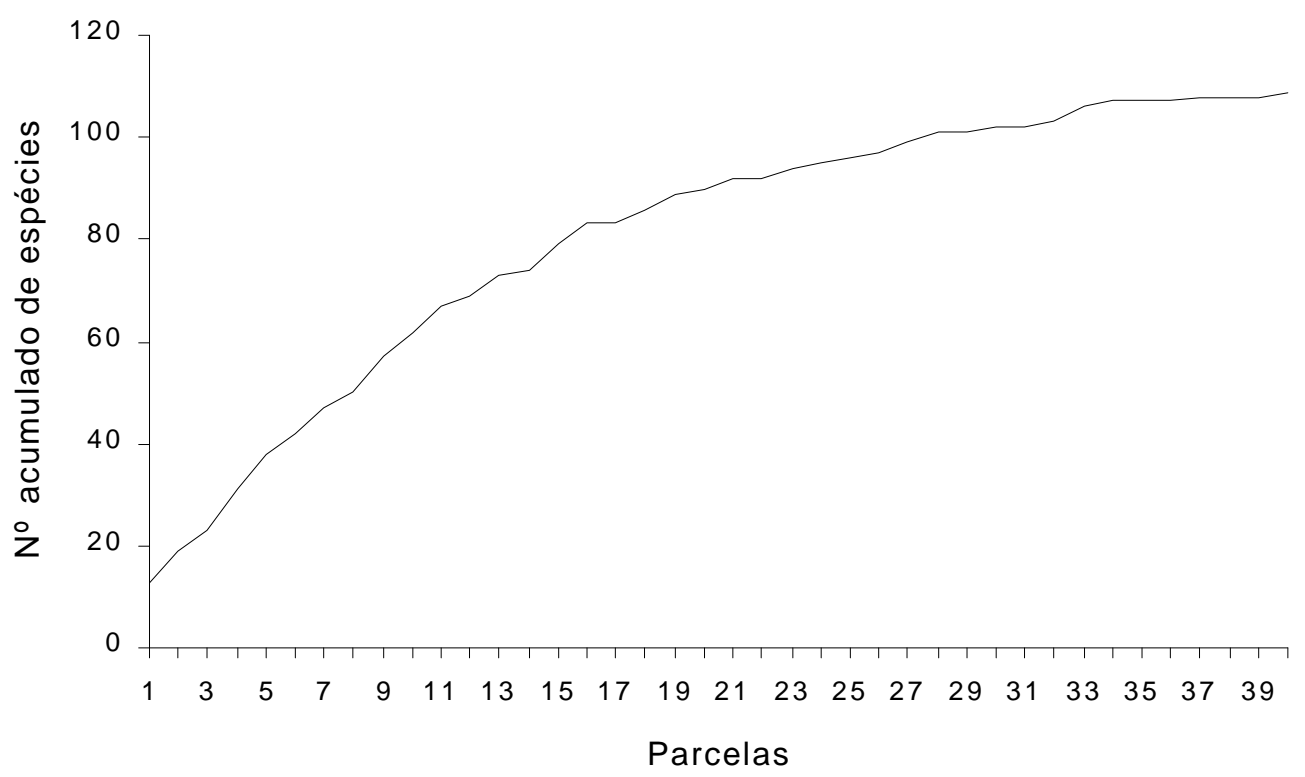

Figura 4: Curvas do número acumulado de espécies $x$ área amostrada do componente dominante, construídas a partir da seqüência original das subparcelas, em Floresta Pluvial Tropical Atlântica, Ilha do Cardoso, SP, Brasil. a: primeiro levantamento e b: segundo levantamento. 


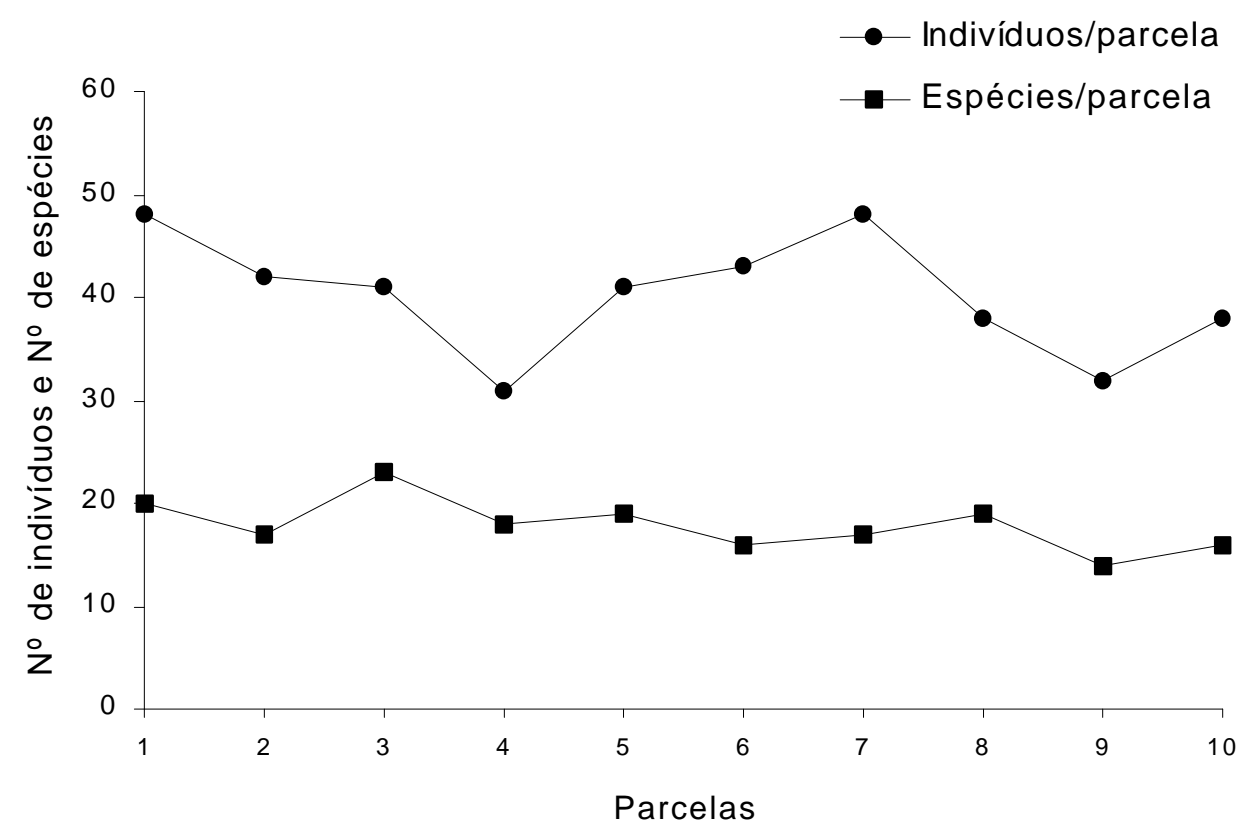

b

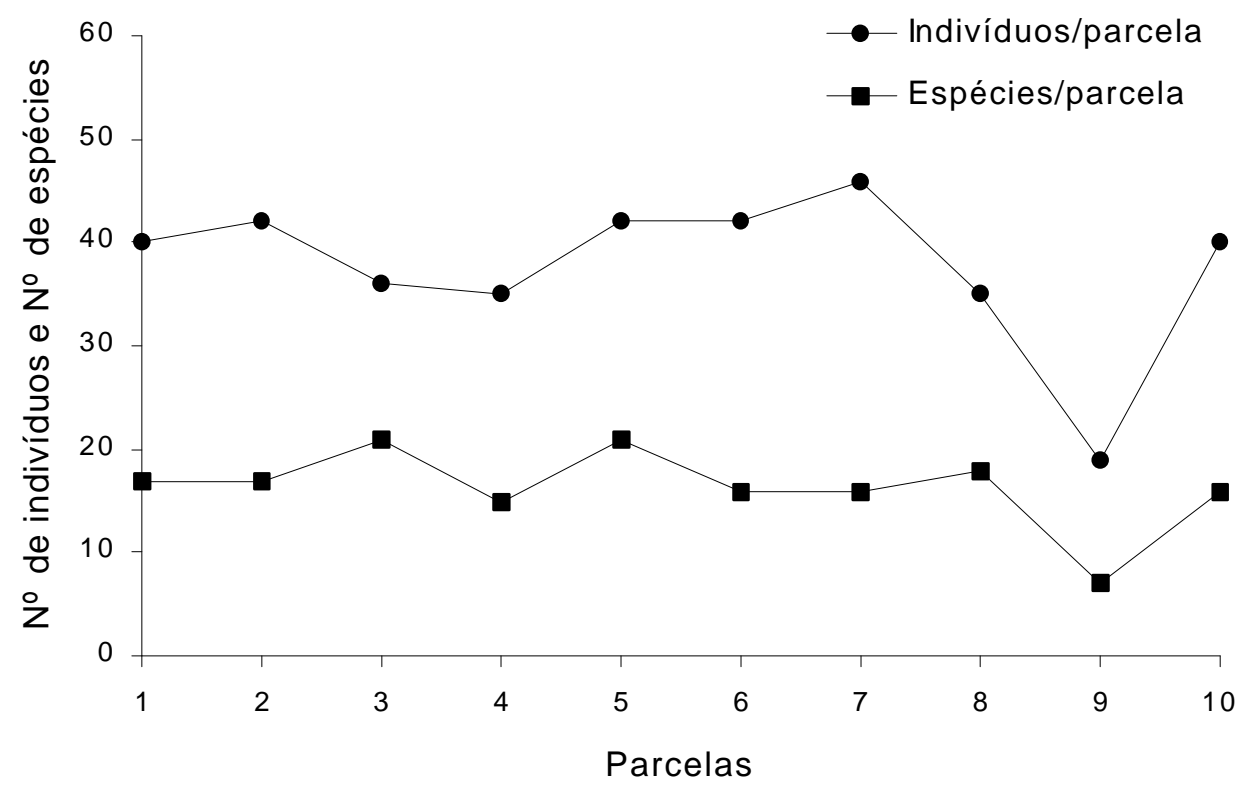

Figura 5: Curvas do número de ocorrência de indivíduos e de espécies $\mathrm{x}$ área amostrada do sub-bosque, em Floresta Pluvial Tropical Atlântica, Ilha do Cardoso, SP, Brasil. a: primeiro levantamento e $\mathrm{b}$ : segundo levantamento. Os números das subparcelas deste gráfico, correspondem, seqüencialmente, aos números 4, 6, 15, 16, 20, 23, 25, 27, 32 e 35 dos gráficos da Figura 6. 


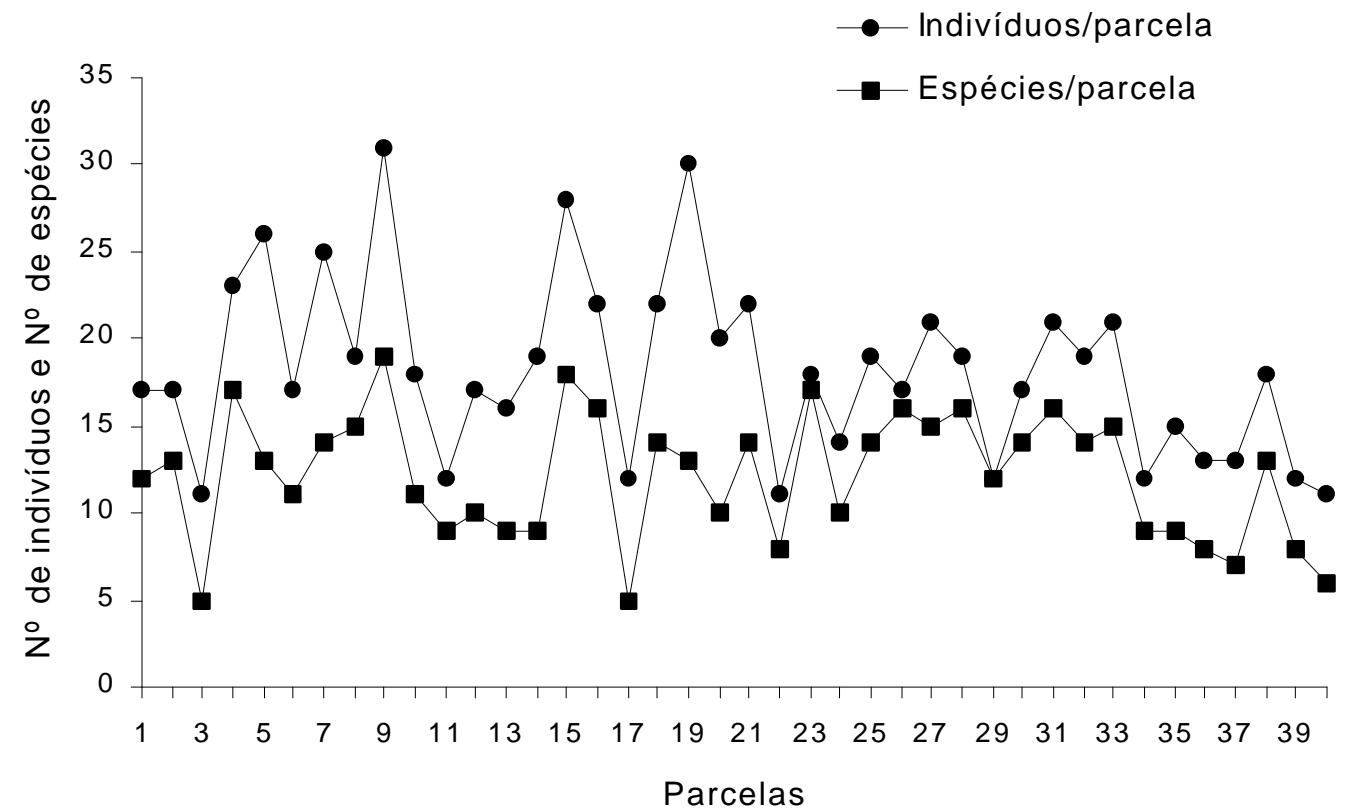

b

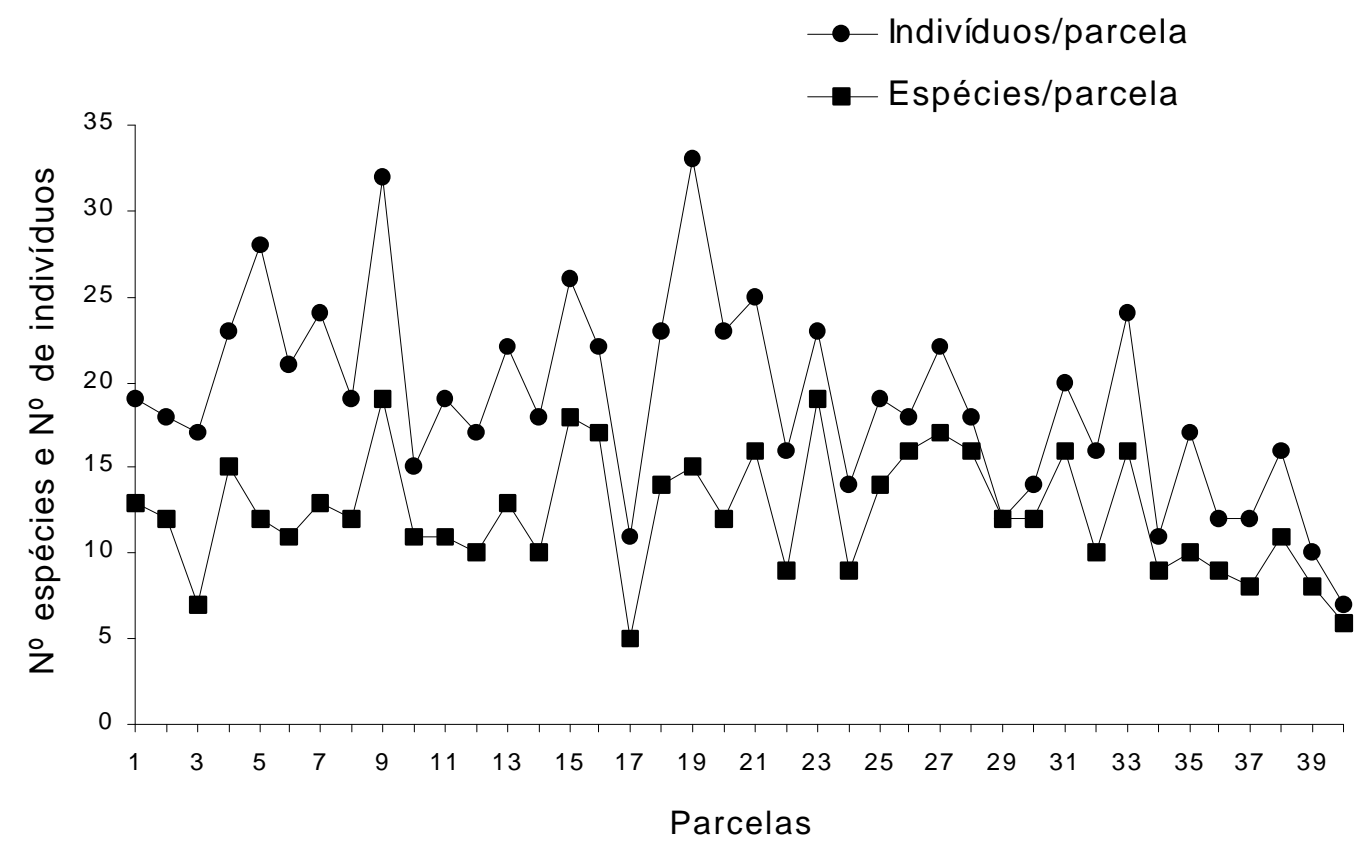

Figura 6: Curvas do número de ocorrência de indivíduos e de espécies $\mathrm{x}$ área amostrada do componente dominante, construídas a partir da seqüência original das subparcelas, em Floresta Pluvial Tropical Atlântica, Ilha do Cardoso, SP, Brasil. a: primeiro levantamento e b: segundo levantamento. 


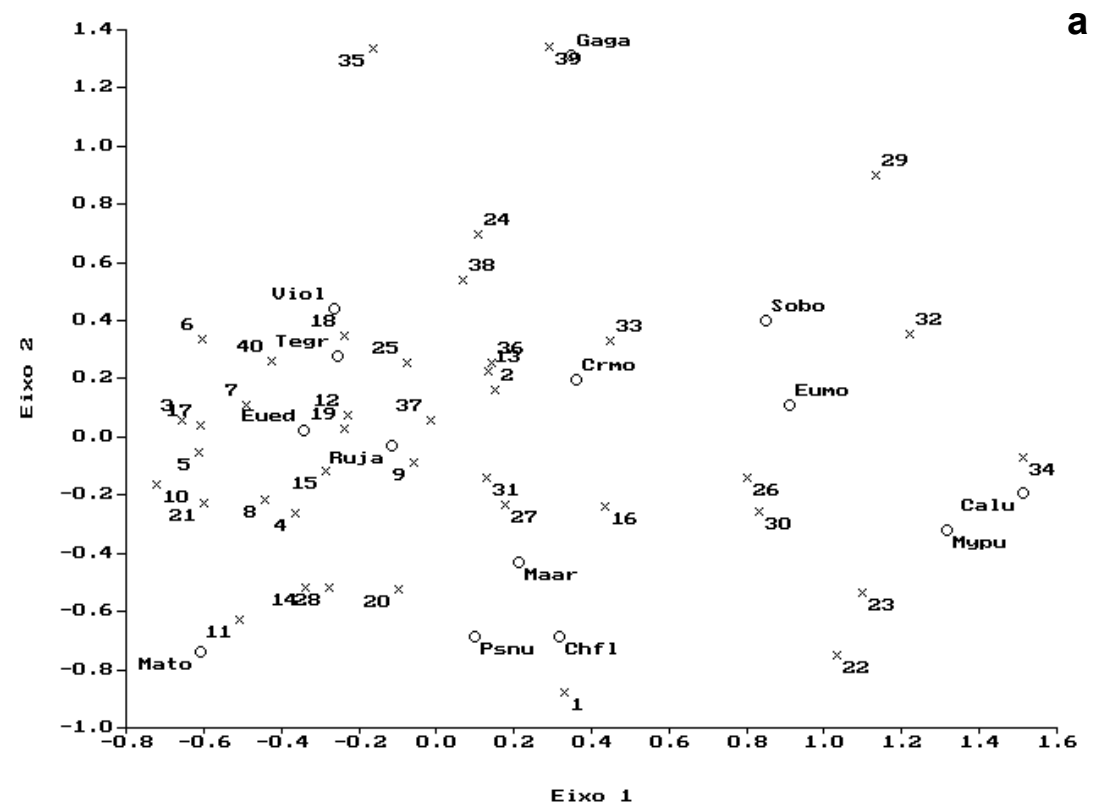

a

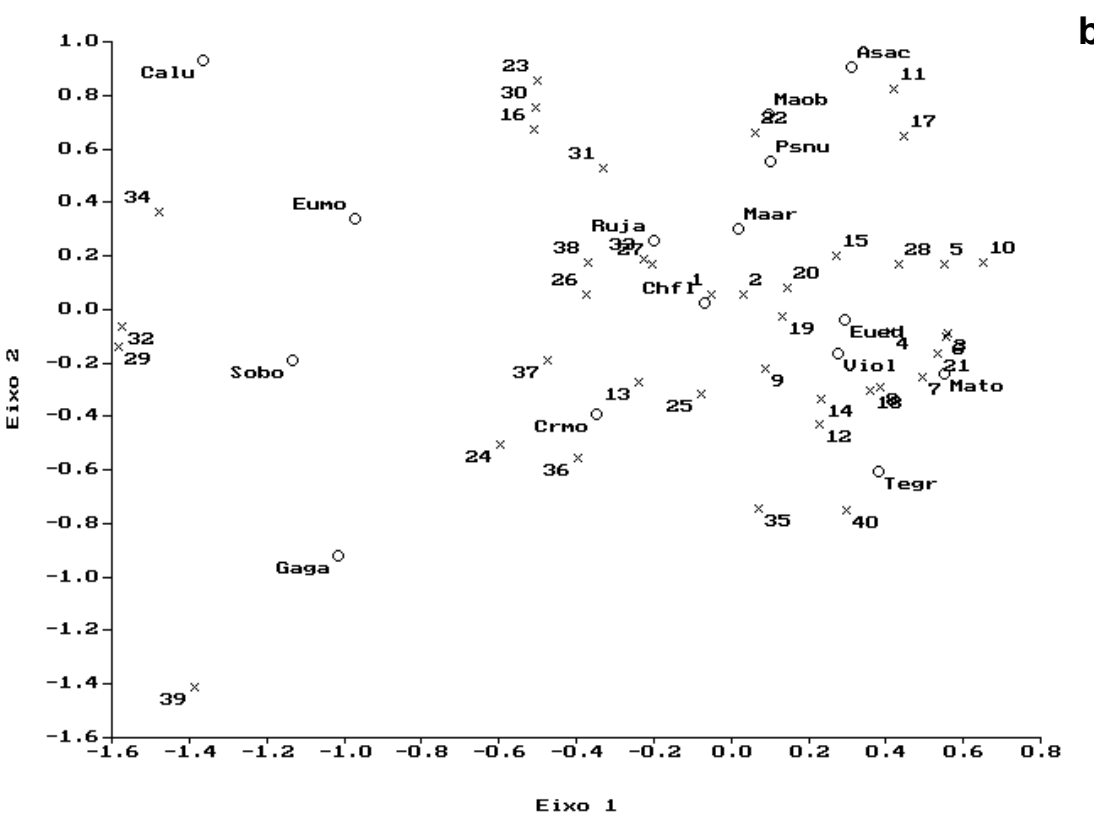

Figura 7: Gráfico Biplot resultante da ordenação pela Análise de Correspondência àmatriz original das 40 unidades amostrais $x$ número de indivíduos das espécies abundantes do componente dominante, em Floresta Pluvial Tropical Atlântica, llha do Cardoso, SP, Brasil. a: primeiro levantamento e b: segundo levantamento. Os códigos correspondem æ̀ 2 letras iniciais do nome genérico e às 2 letras iniciais do epíteto específico. Os nomes completos das espécies encontram-se nos Anexos 4 e 5. 

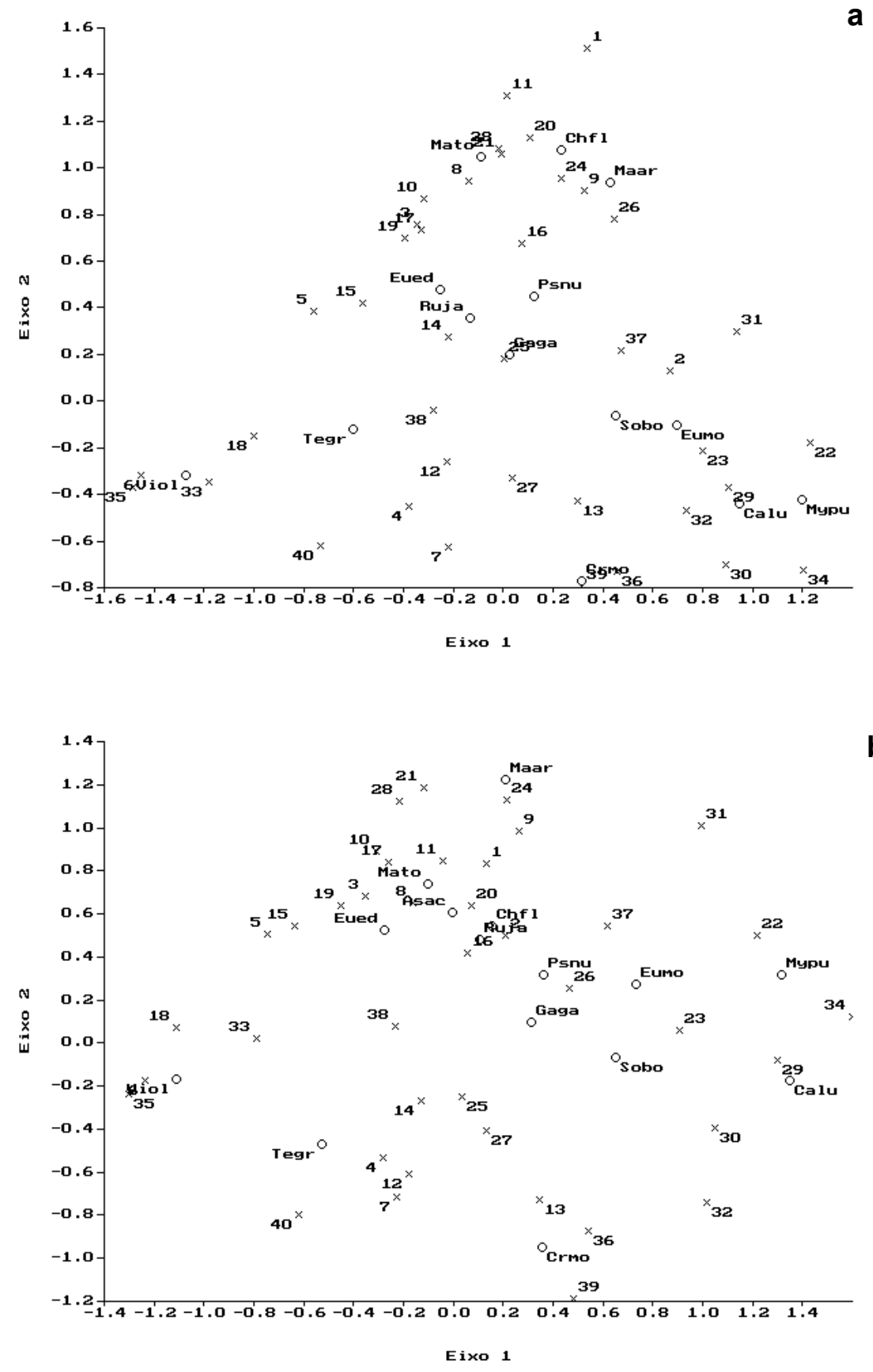

Figura 8: Gráfico Biplot resultante da ordenação pela Análise de Correspondência àmatriz original das 40 unidades amostrais $\mathrm{x}$ área dos troncos das árvores das espécies abundantes do componente dominante, em Floresta Pluvial Tropical Atlântica, llha do Cardoso, SP, Brasil. a: primeiro levantamento e b: segundo levantamento. Os códigos correspondem à 2 letras iniciais do nome genérico e às 2 letras iniciais do epíteto específico. Os nomes completos das espécies encontram-se nos Anexos 4 e 5. 


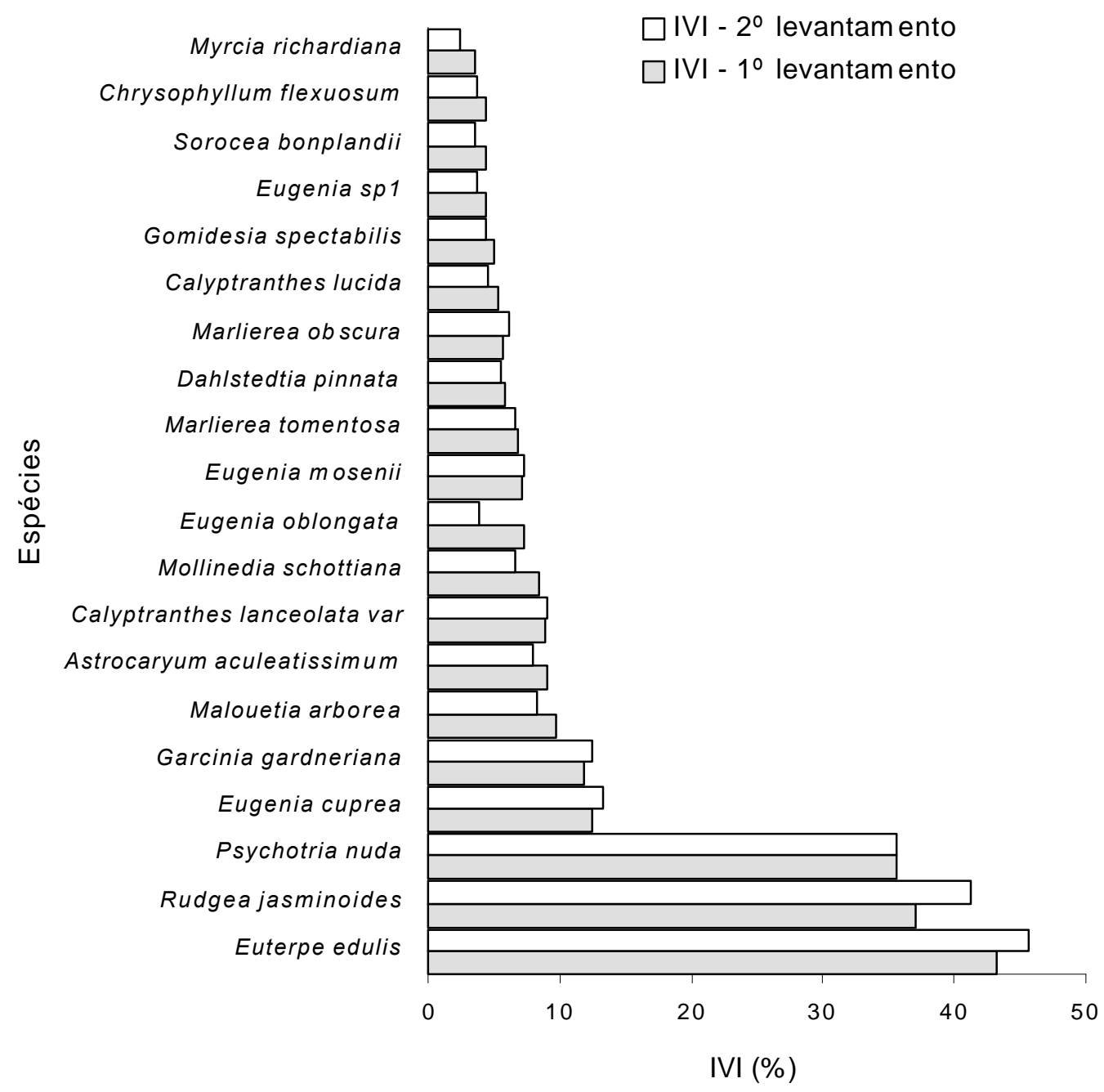

Figura 9: Valores dos índices do valor de importância (IVI) das espécies que ocorreram nos dois levantamento do sub-bosque e do componente dominante, em Floresta Pluvial Tropical Atlântica, Ilha do Cardoso, SP, Brasil. a: sub-bosque e b: componente dominante. 


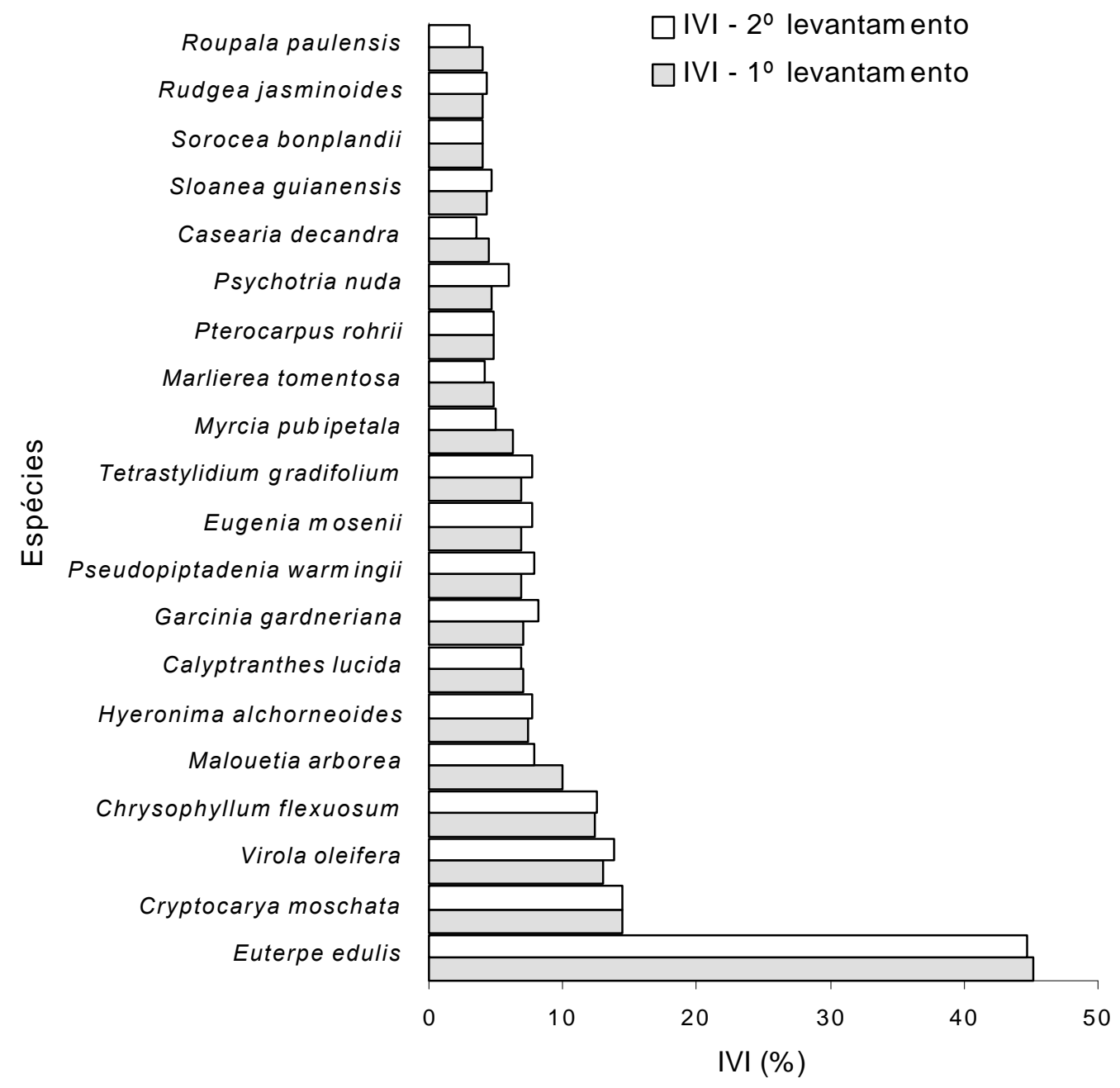

Figura 9: Continuação. 


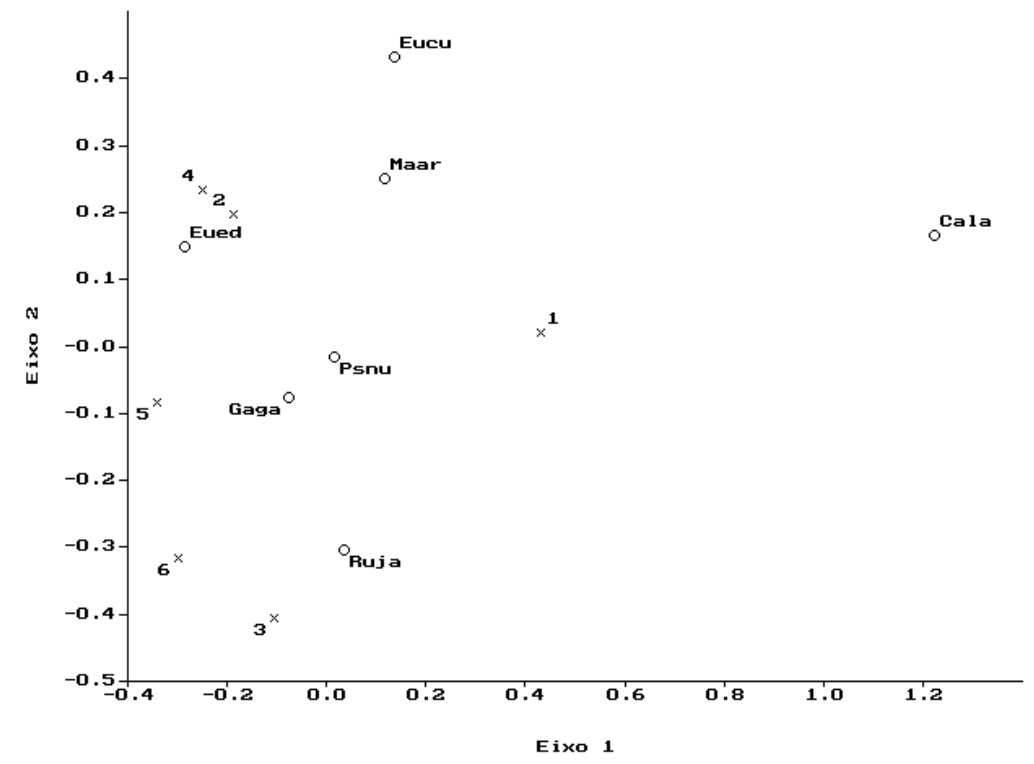

a

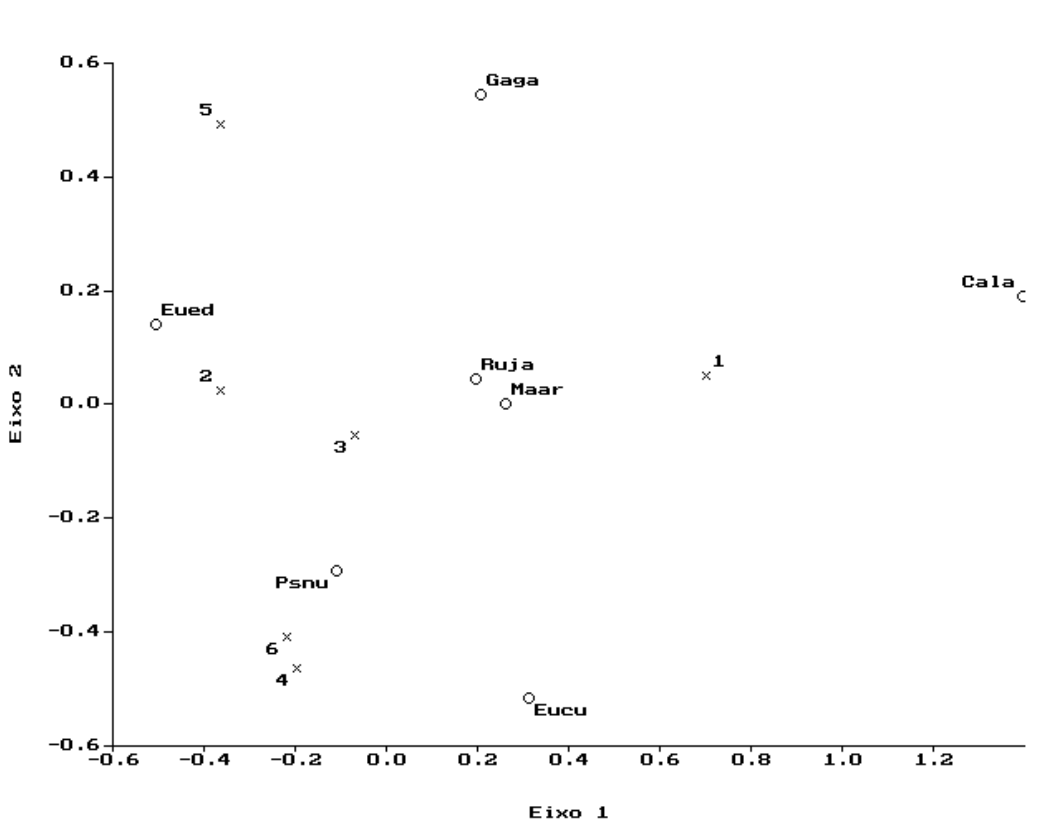

Figura 10: Gráfico Biplot resultante da ordenação pela Análise de Correspondência àmatriz original das 40 unidades amostrais $x$ classes de diâmetro das árvores das espécies amostradas no sub-bosque, em Floresta Pluvial Tropical Atlântica, Ilha do Cardoso, SP, Brasil. a: primeiro levantamento e b: segundo levantamento. Os códigos correspondem æ̀s 2 letras iniciais do nome genérico e æ̀s 2 letras iniciais do epíteto específico. Os nomes completos das espécies encontram-se nos Anexos 4 e 5. 


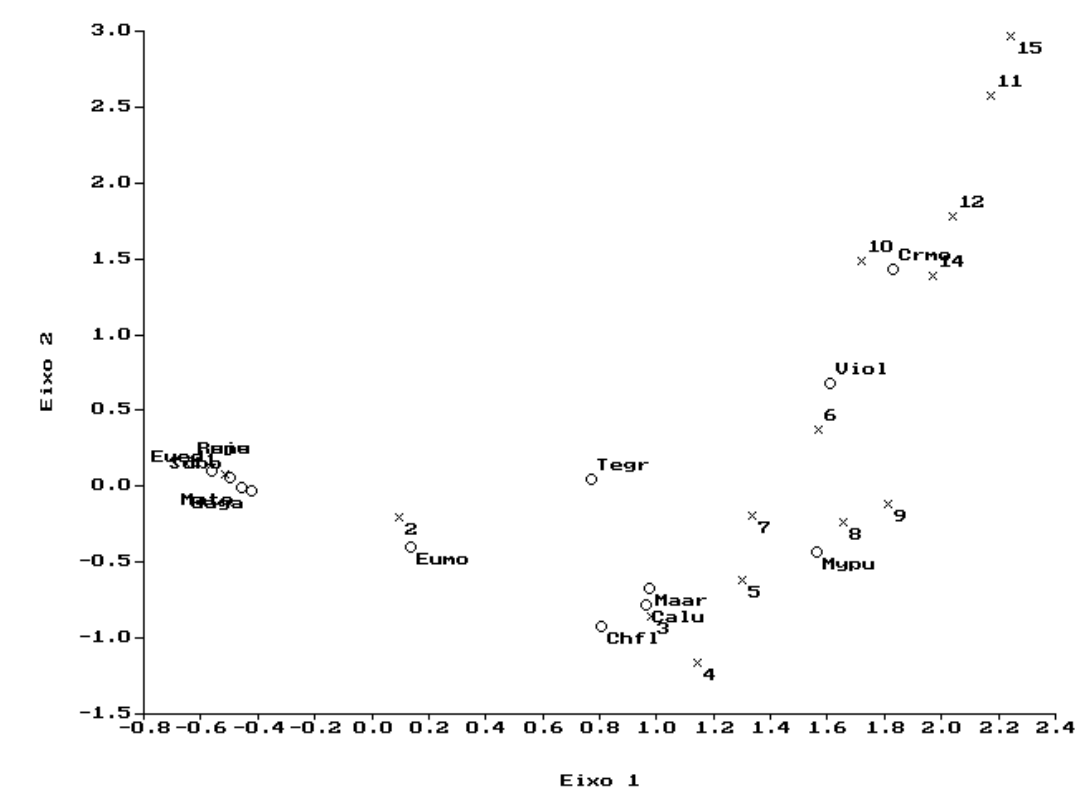

a

b

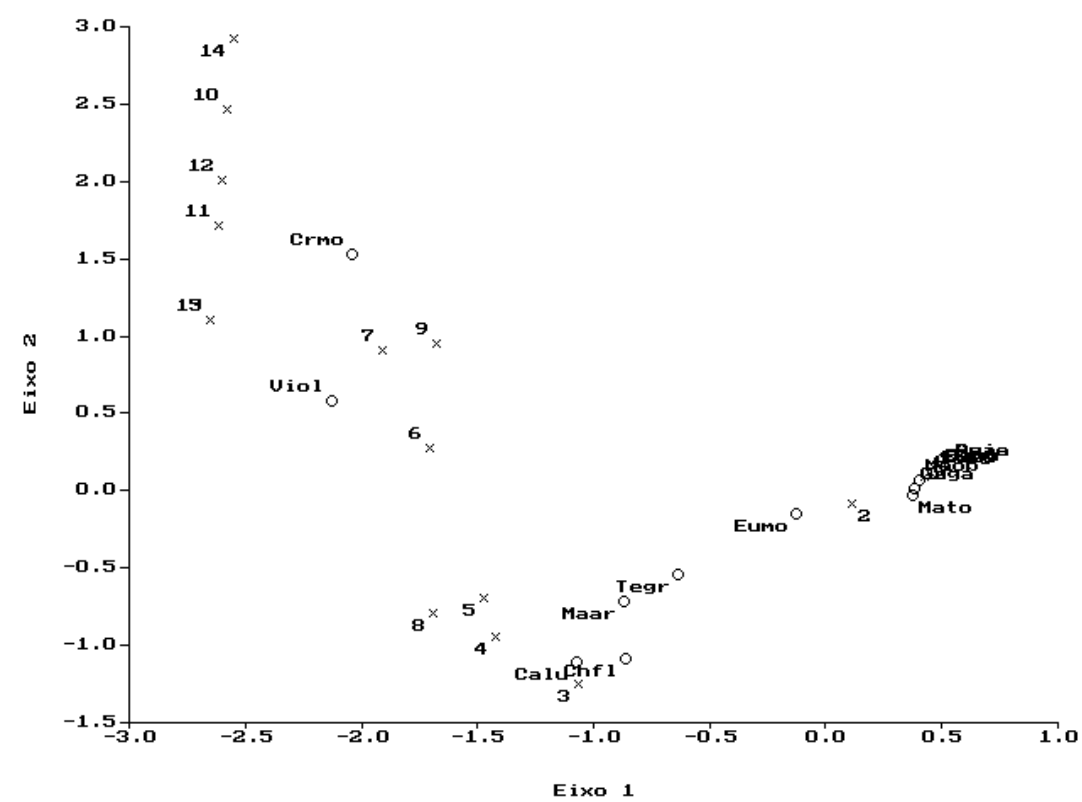

Figura 11: Gráfico Biplot resultante da ordenação pela Análise de Correspondência àmatriz original das 40 unidades amostrais x classes de diâmetro das árvores das espécies amostradas no componente dominante, em Floresta Pluvial Tropical Atlântica, Ilha do Cardoso, SP, Brasil. a: primeiro levantamento e b: segundo levantamento. Os códigos correspondem às 2 letras iniciais do nome genérico e às 2 letras iniciais do epíteto específico. Os nomes completos das espécies encontram-se nos Anexos 4 e 5. 

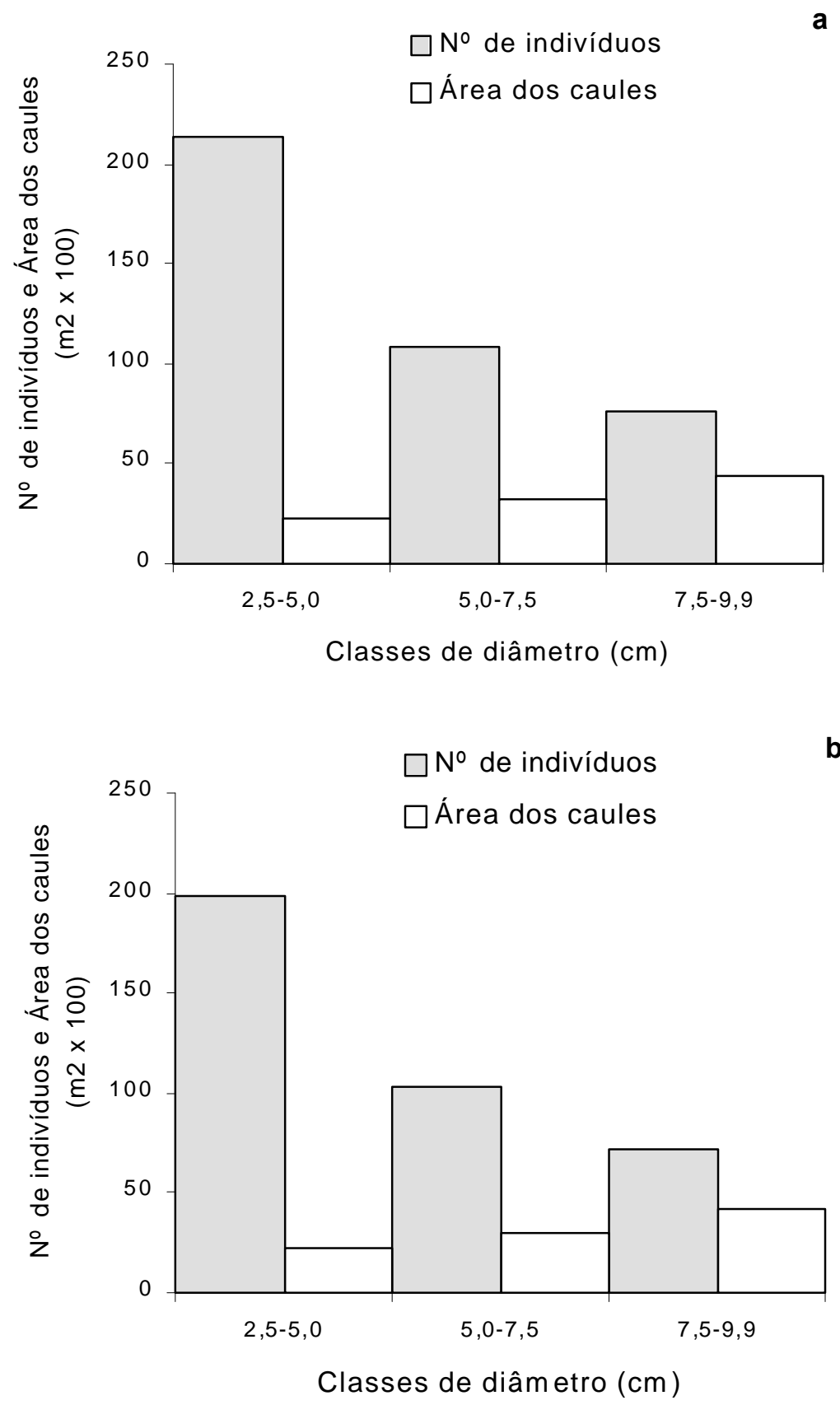

Figura 12: Distribuição de freqüência das classes de diâmetro por número de indivíduos e área dos caules das árvores amostradas no sub-bosque, nos dois levantamentos, em Floresta Pluvial Tropical Atlântica, Ilha do Cardoso, SP, Brasil. a: primeiro levantamento e b: segundo levantamento. 

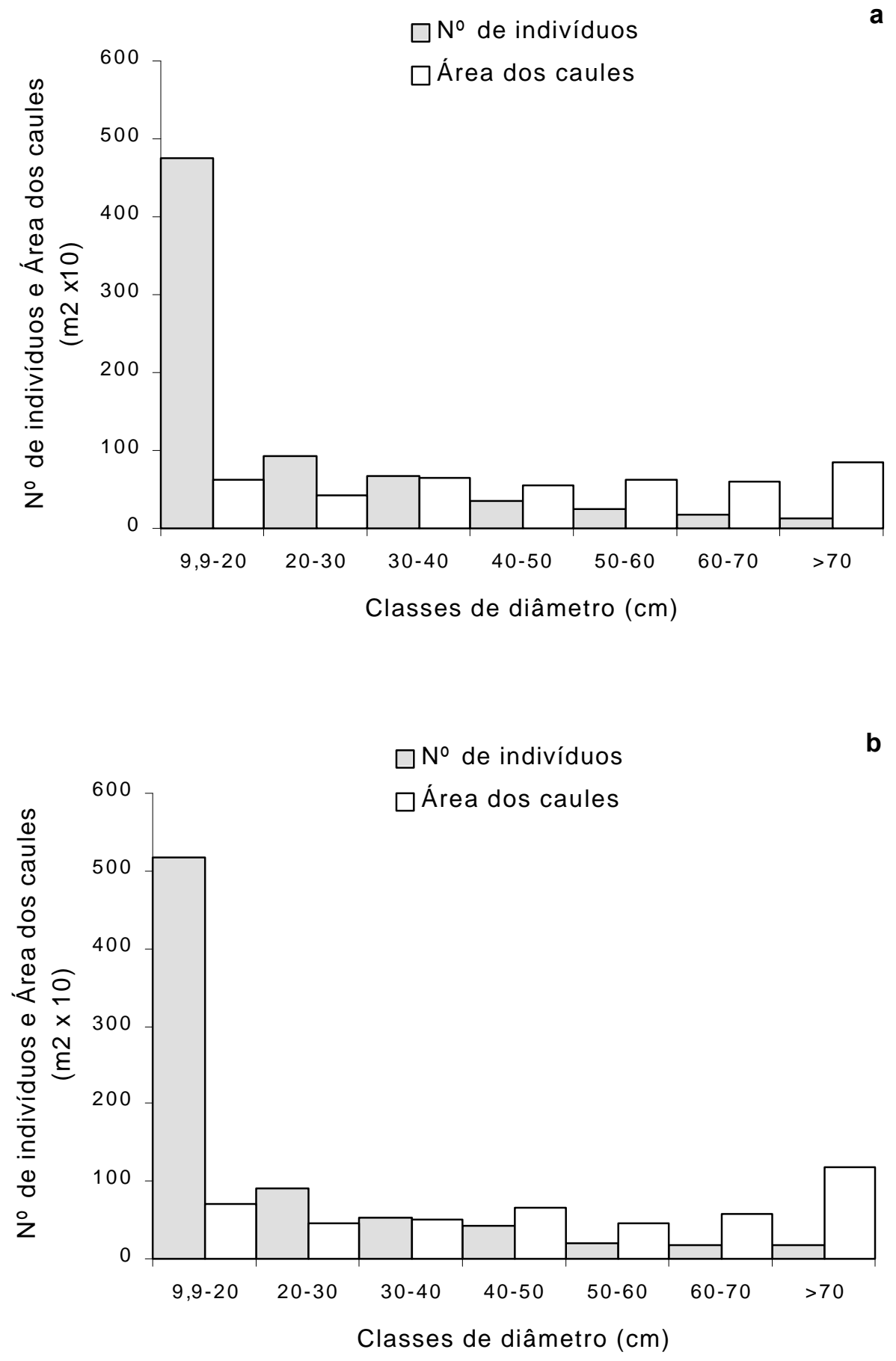

Figura 13: Distribuição de freqüência das classes de diâmetro por número de indivíduos e área dos caules das árvores amostradas no componente dominante, nos dois levantamentos, em Floresta Pluvial Tropical Atlântica, Ilha do Cardoso, SP, Brasil. a: primeiro levantamento e b: segundo levantamento. 
a
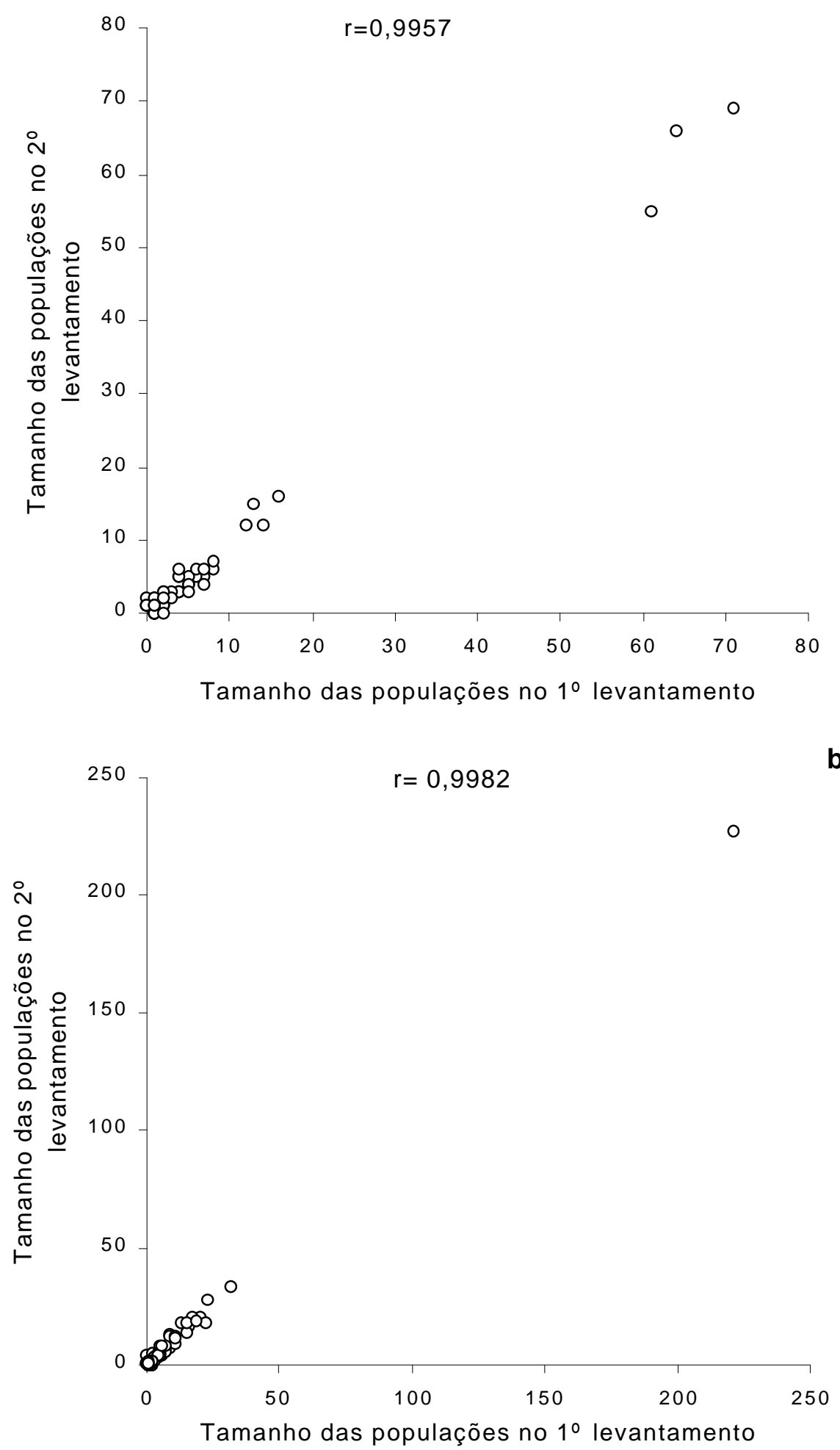

Figura 14: Diagramas de dispersão dos dados de abundância das espécies amostradas no primeiro e segundo levantamentos, no sub-bosque e no componente dominante, em Floresta Pluvial Tropical Atlântica, Ilha do Cardoso, SP, Brasil. a: sub-bosque e b: componente dominante. 

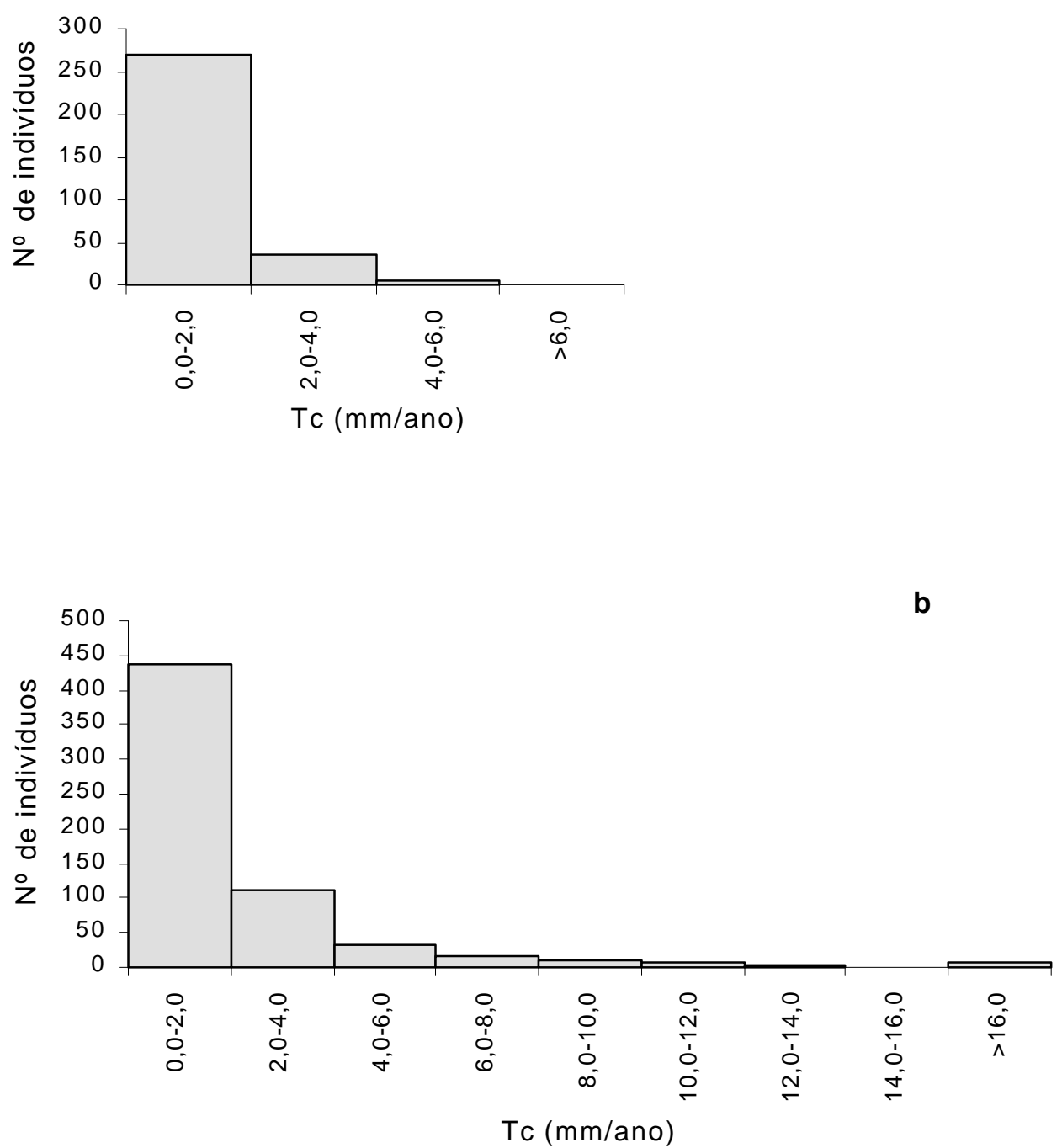

Figura 15: Distribuição de freqüência das classes de taxas de crescimento absolutas por indivíduos amostrados em Floresta Pluvial Tropical Atlântica, Ilha do Cardoso, $\mathrm{SP}$, Brasil. a: sub-bosque e b: componente dominante. 
a

TAXAS DE CRESCIMENTO - ABUNDÂNCIA DAS ESPÉCIES - SUB-BOSQUE

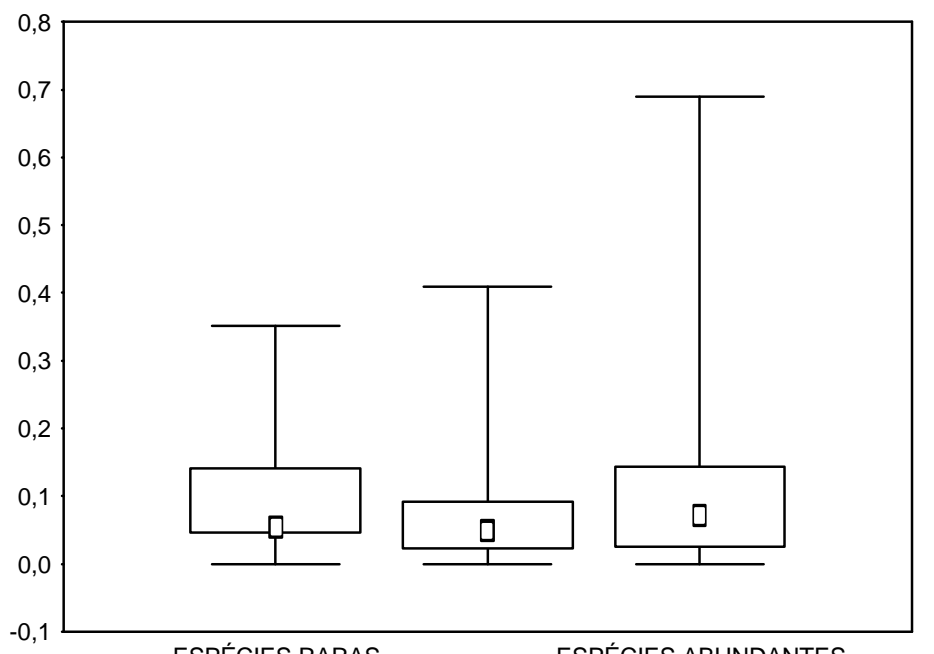
ESPÉCIES OCASIONAIS

I Min-Max 25\%-75\%

(]) Median value

b

TAXAS DE CRESCIMENTO / ABUNDÂNCIA DAS ESPÉCIES - DOMINANTE

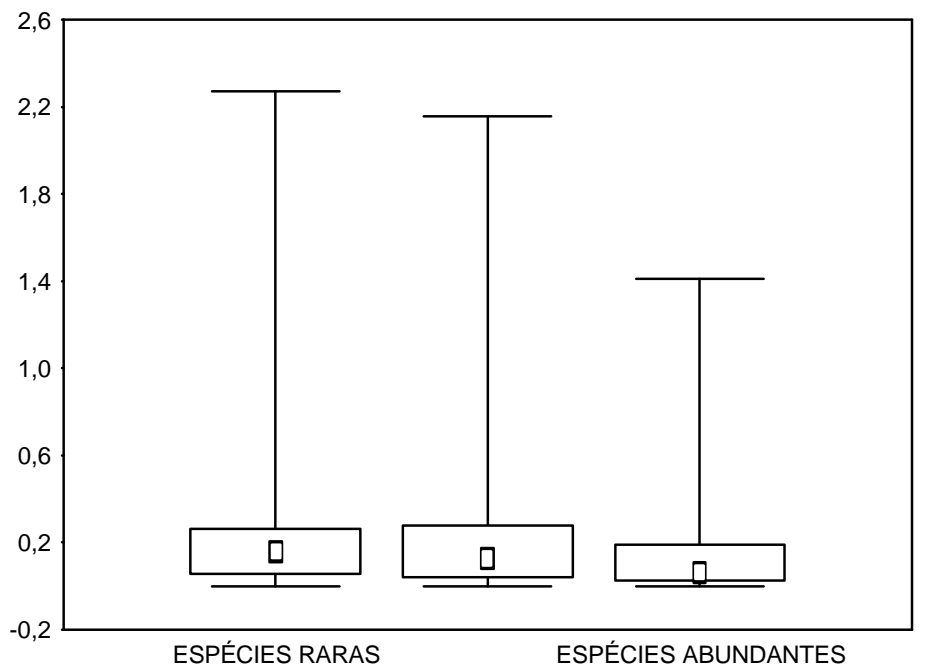

ESPÉCIES OCASIONAIS

Figura 16: Distribuição das taxas de crescimento absolutas por categorias de abundância das espécies amostradas em Floresta Pluvial Tropical Atlântica, Ilha do Cardoso, SP, Brasil. a: sub-bosque e b: componente dominante. 


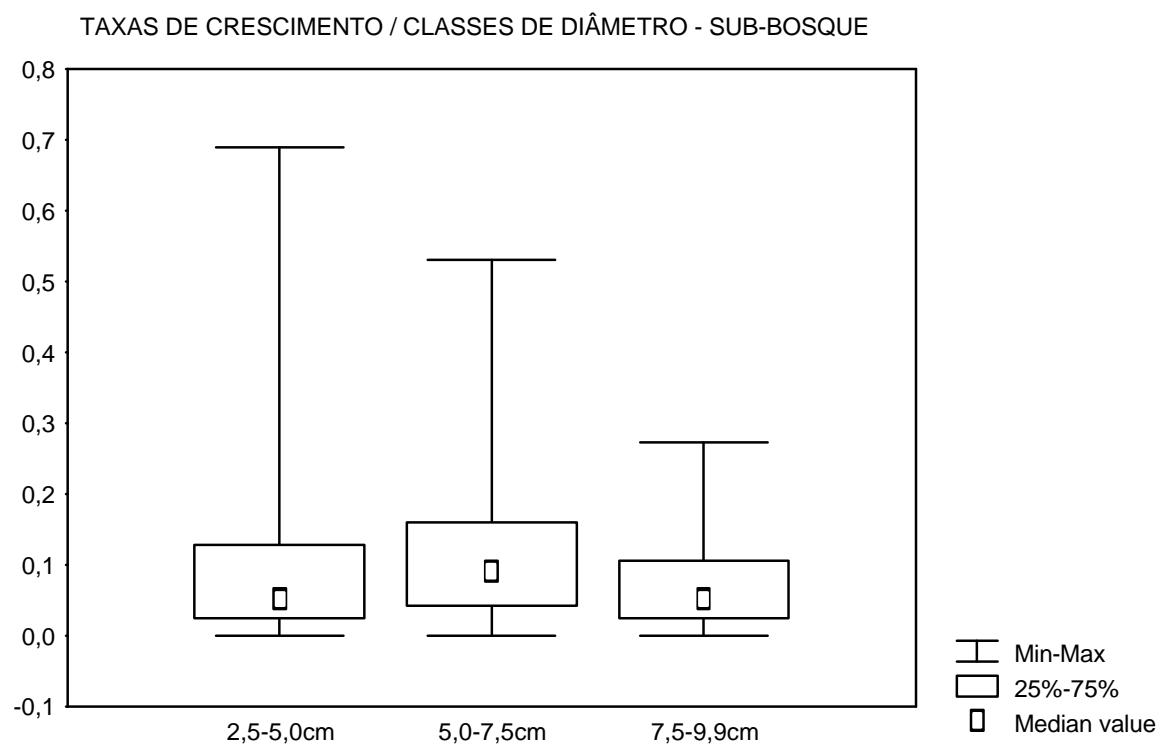

b

TAXAS DE CRESCIMENTO / CLASSES DE DIÂMETRO - DOMINANTE

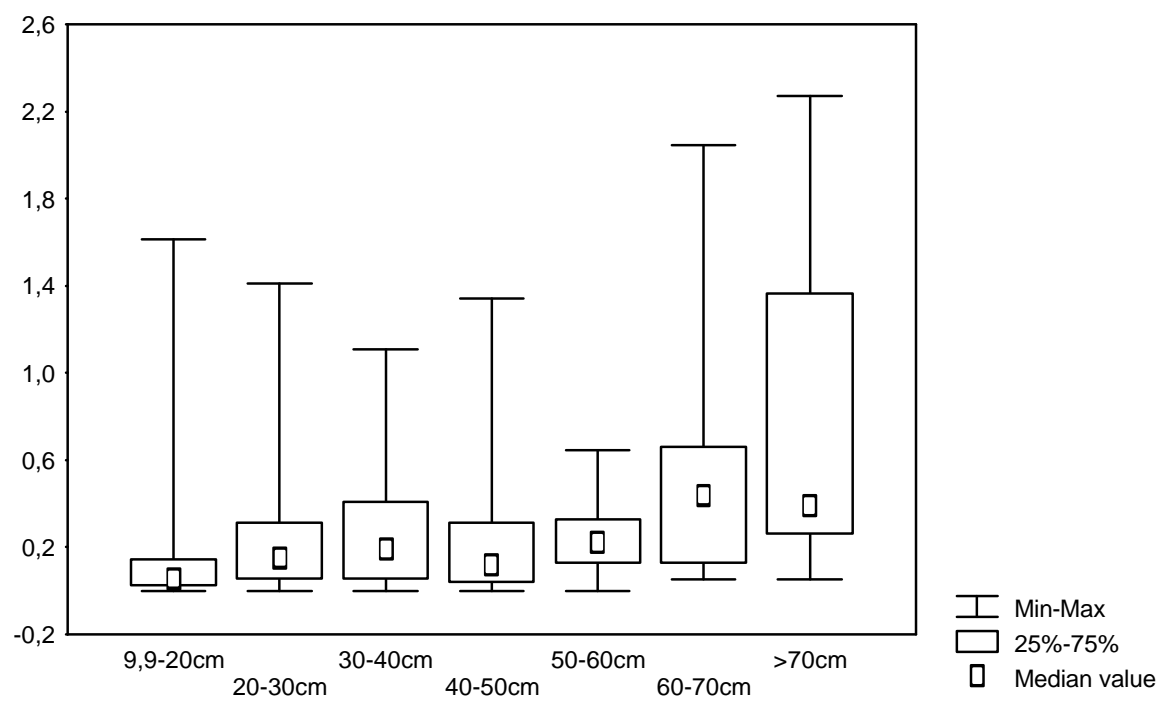

Figura 17: Distribuição de freqüência das classes de diâmetro por taxas de crescimento absolutas das espécies amostradas em Floresta Pluvial Tropical Atlântica, Ilha do Cardoso, SP, Brasil. a: sub-bosque e b: componente dominante. 
TAXAS DE CRESCIMENTO / CARACTERÍSTICAS NA SUCESSÃO - SUB-BOSQUE

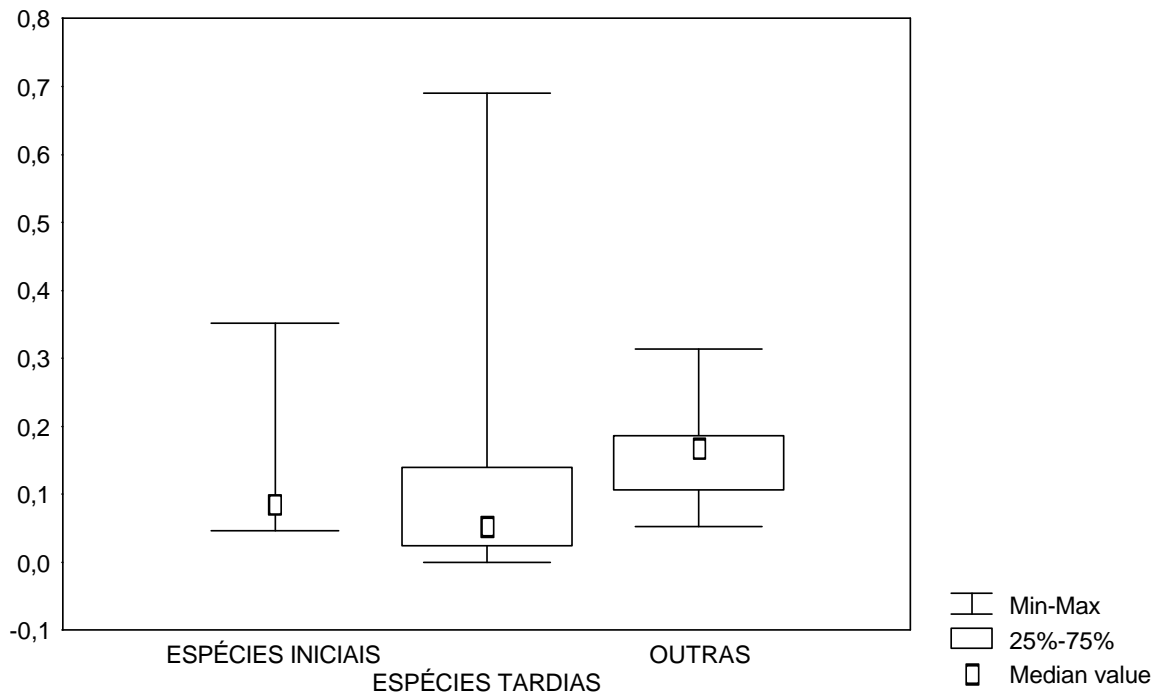

b

TAXAS DE CRESCIMENTO / CARACTARÍSTICAS NA SUCESSÃO - DOMINANTE

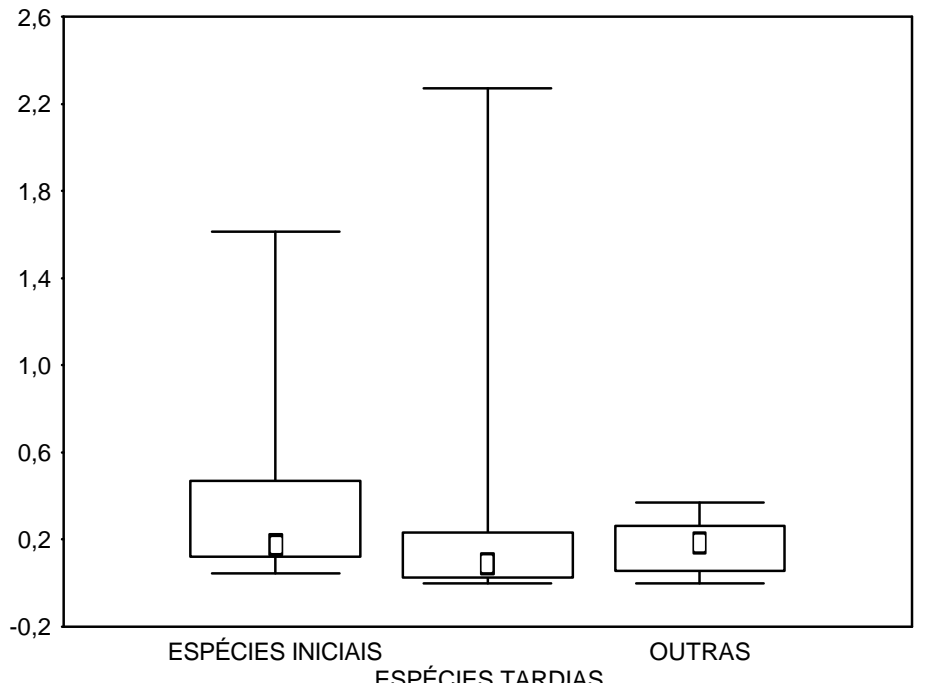

Figura 18: Distribuição das taxas de crescimento absolutas das espécies por características que apresentam no processo sucessional em Floresta Pluvial Tropical Atlântica, Ilha do Cardoso, SP, Brasil. a: sub-bosque e b: componente dominante. 
a

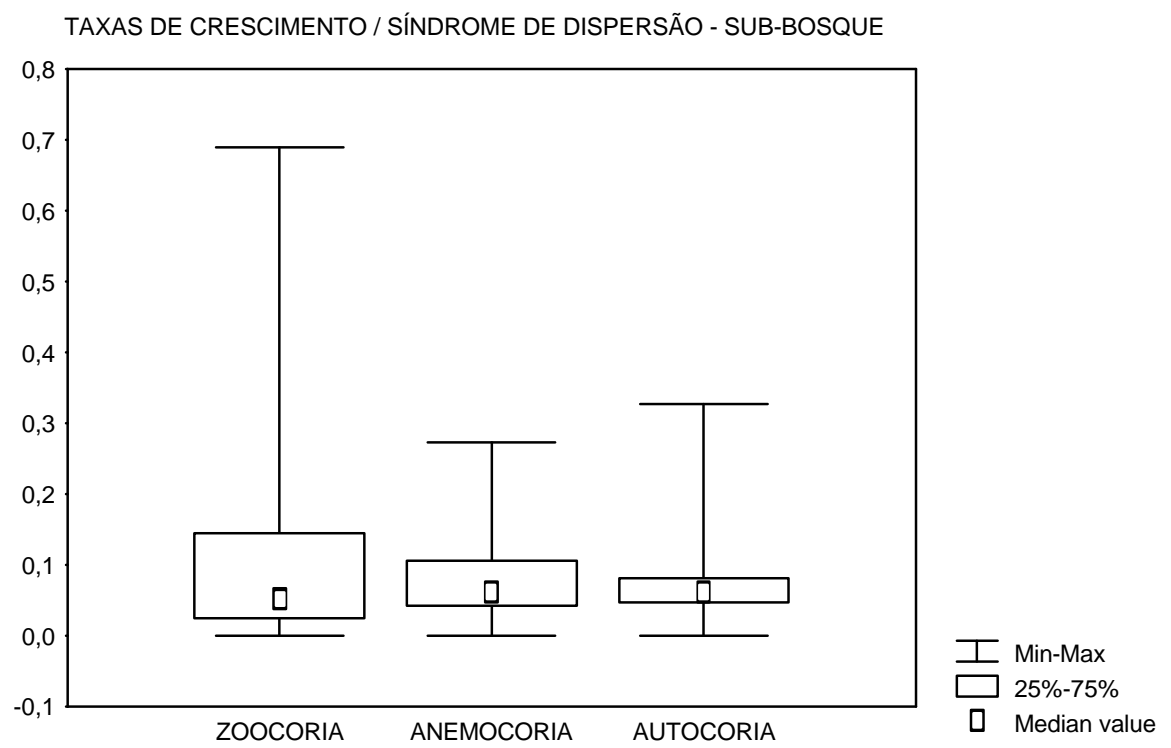

b

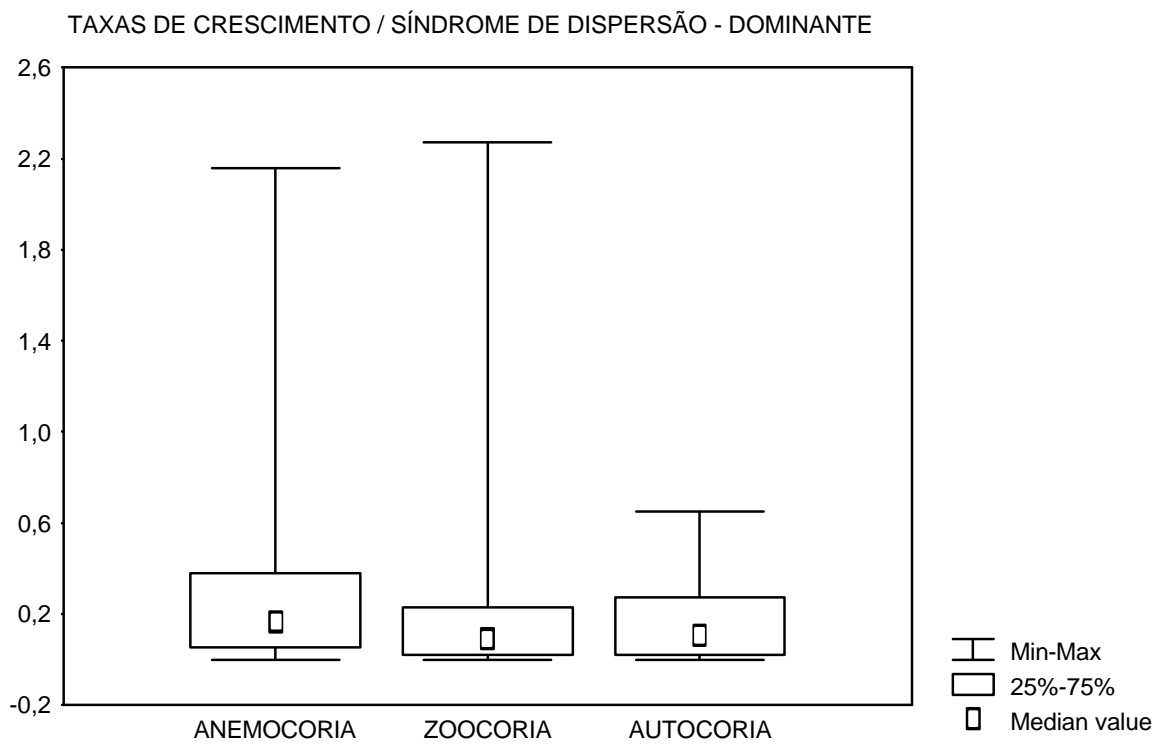

Figura 19: Distribuição das taxas de crescimento absolutas por síndromes de dispersão das espécies amostradas em Floresta Pluvial Tropical Atlântica, Ilha do Cardoso, SP, Brasil. a: sub-bosque e b: componente dominante. 
a

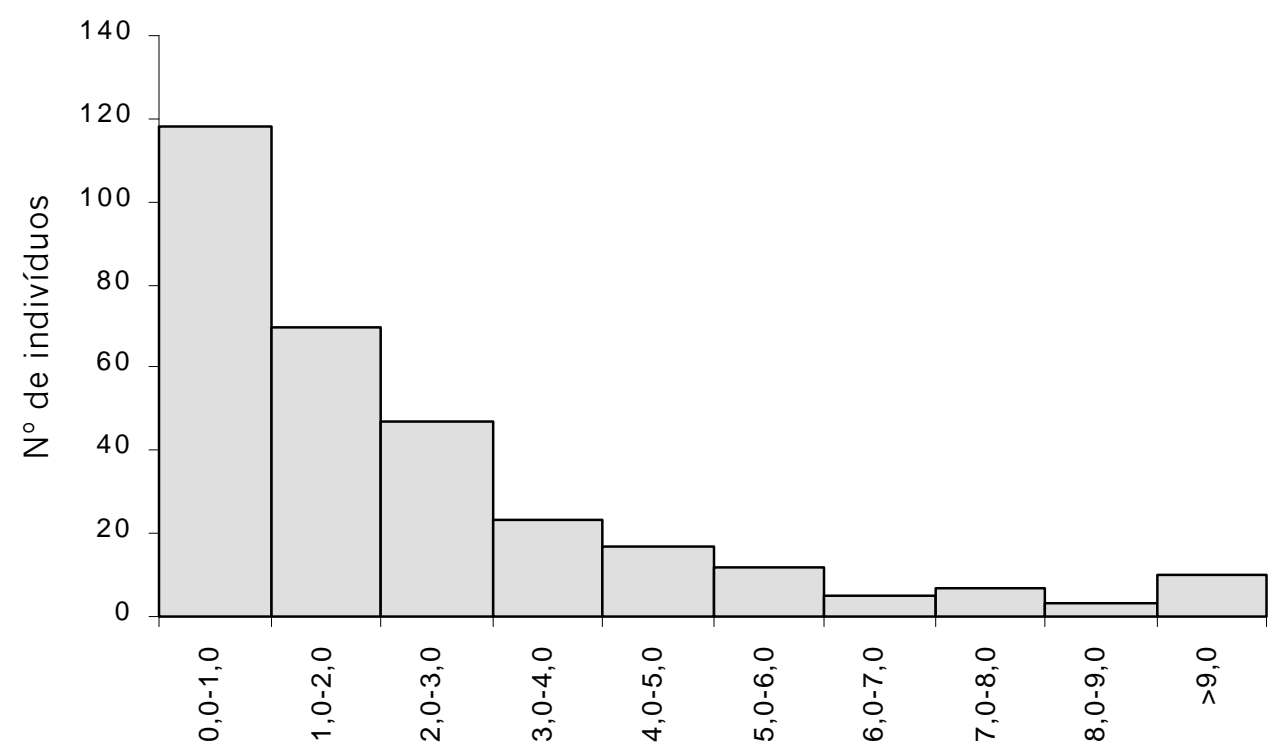

Tc (\%/ano)

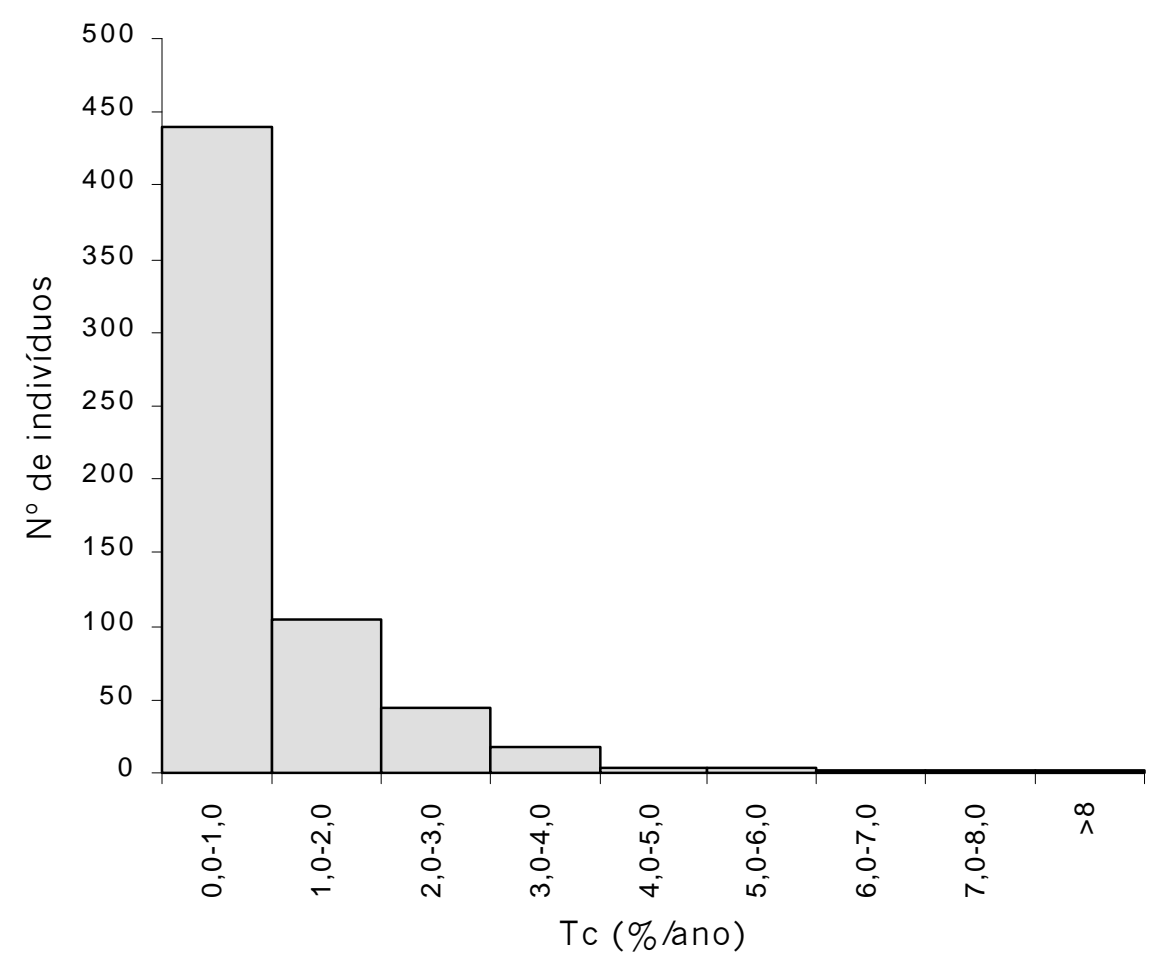

b

Figura 20: Distribuição de freqüência das classes de taxas de crescimento relativas por número de indivíduos amostrados nos dois componentes, em Floresta Pluvial Tropical Atlântica, Ilha do Cardoso, SP, Brasil. a: sub-bosque e b: componente dominante. 


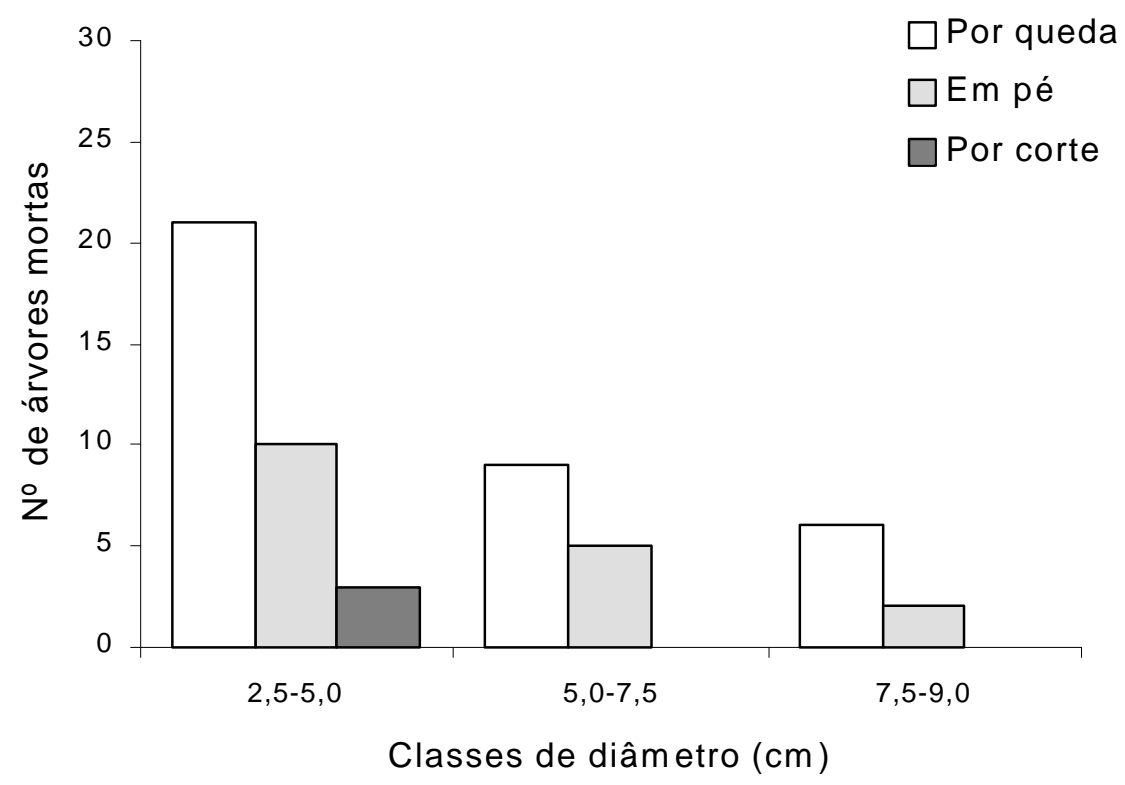

b

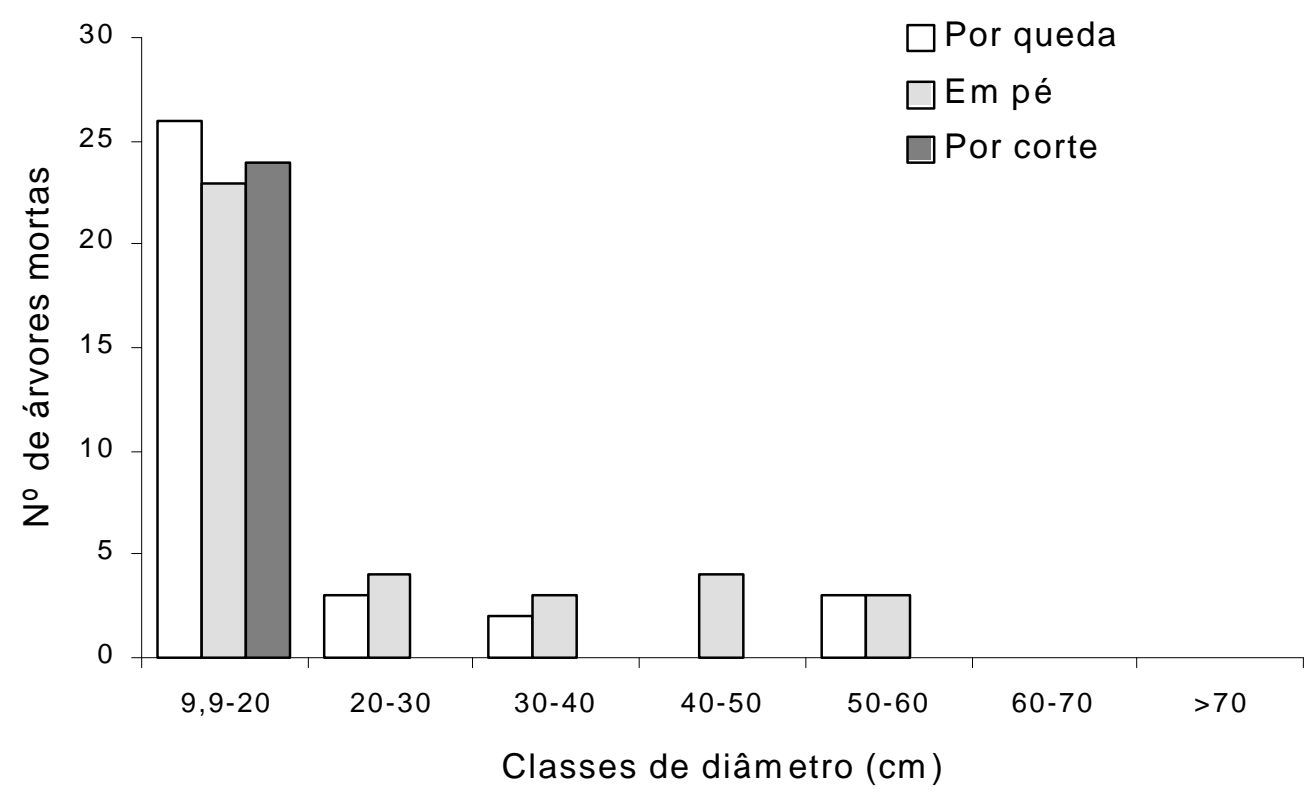

Figura 21: Distribuição de freqüência das classes de diâmetro por árvores mortas registradas no segundo levantamento, em Floresta Pluvial Tropical Atlantica, Ilha do Cardoso, SP, Brasil. a: sub-bosque e b: componente dominante. 
Anexo 1: Listagem das espécies, com respectivas mudanças nas identificações ou correções nomenclaturais, amostradas em trecho de Floresta Pluvial Tropical Atlântica, llha do Cardoso, SP, Brasil.

\begin{tabular}{|c|c|c|}
\hline Melo \& Mantovani (1994) & Presente trabalho $(2000)$ & Famílias \\
\hline Malouetia cestroides (Nees \& Mart.) M. Arg. & Malouetia arborea (Vell.) Miers & Apocynaceae \\
\hline Cinnamodendron aff. dinisii Schwacke & Cinnamodendron dinisii (Schwacke) Occhioni & Canellaceae \\
\hline Couepia cf. bondari Prance & Parinari brasiliensis (Scott.) Hook. f. & Chrysobalanaceae \\
\hline Hirtella hebeclada Moric & Hirtella hebeclada Moric ex A. DC. & Chrysobalanaceae \\
\hline Casearia obliqua Spreng. & Casearia decandra Jacq. & Flacourtiaceae \\
\hline Rheedia gardneriana Planch. \& Triana & Garcinia gardneriana (Planch. \& Triana) Zappi & Guttiferae \\
\hline Lacistema pubescens Mart. & Lacistema lucidum Schnizl. & Lacistemaceae \\
\hline Nectandra leucothyrsus Meisn. & Nectandra membranacea (Sw.) Griseb & Lauraceae \\
\hline Ocotea laxa (Nees) Mez & Ocotea teleiandra (Meisn.) Mez & Lauraceae \\
\hline Cariniana sp. & Cariniana cf. legalis (Mart.) Kuntze & Lecythidaceae \\
\hline Guarea sp. (M.R.F. Melo \& J.A. Correa 735) & $\begin{array}{l}\text { Trichilia lepidota Mart. spp. schumanniana } \\
\text { (Harms) Penn. }\end{array}$ & Meliaceae \\
\hline $\begin{array}{l}\text { Trichilia elegans A. Juss. ssp. richardiana (A. Juss.) } \\
\text { Penn. }\end{array}$ & Trichilia pallens C. DC. & Meliaceae \\
\hline $\begin{array}{l}\text { Rapanea ferruginea (R. \& P.) Mez (M.R.F. Melo \& } \\
\text { A. Lobo 983) }\end{array}$ & Rapanea ferruginea (Ruiz \& Pav.) Mez & Myrsinaceae \\
\hline $\begin{array}{l}\text { Rapanea guyanensis Aubl. (M.R.F. Melo \& A. Lobo } \\
\text { 984) }\end{array}$ & $\begin{array}{l}\text { Rapanea hermogenesii Jung-Mendaçolli \& } \\
\text { Bernacci }\end{array}$ & Myrsinaceae \\
\hline $\begin{array}{l}\text { Rapanea umbellata (Mart.) Mez (M.R.F. Melo \& A. } \\
\text { Penina 985) }\end{array}$ & Rapanea guyanensis Aubl. & Myrsinaceae \\
\hline Calycorectes australis Legr. var. australis & Eugenia sp3 & Myrtaceae \\
\hline Calyptranthes sp. & Eugenia cf. glomerata Spring & Myrtaceae \\
\hline Eugenia cf. flavescens DC. & Eugenia mosenii (Kausel) Sobral & Myrtaceae \\
\hline Eugenia moraviana Berg & Eugenia sp4 & Myrtaceae \\
\hline Eugenia cf. silvestris Berg & Eugenia cf. multicostata D. Legrand & Myrtaceae \\
\hline Eugenia cf. subavenia Berg & Eugenia pruinosa D. Legrand & Myrtaceae \\
\hline Marlierea antonia (Berg) Legr. & Myrcia pubipetala Miq. & Myrtaceae \\
\hline Marlierea cf. polygama Berg & Marlierea reitzii $\mathrm{D}$. Legrand & Myrtaceae \\
\hline Marlierea cf. suaveolens Camb. & Gomidesia tijucensis (Kiaersk.) D. Legrand & Myrtaceae \\
\hline Myrcia sp2 & Myrcia richardiana O. Berg & Myrtaceae \\
\hline Myrcia sp3 & Marlierea cf. bippenis (Berg) Mc Vaugh & Myrtaceae \\
\hline Schoepfia brasiliensis DC. & Tetrastylidium grandifolium (Baill.) Sleumer & Olacaceae \\
\hline $\begin{array}{l}\text { Alibertia myrcifolia (Spruce ex Schumann) } \\
\text { Schumann }\end{array}$ & Alibertia myrciifolia K. Schum. & Rubiaceae \\
\hline Chomelia cf. catharinae (Smith \& Downs) Steyerm. & $\begin{array}{l}\text { Chomelia catharinae (L.B. Sm. \& Downs) } \\
\text { Steyerm. }\end{array}$ & Rubiaceae \\
\hline Coussarea cf. ilheotica M. Arg. & $\begin{array}{l}\text { Coussarea contracta (Walp.) Benth. \& Hook. ex } \\
\text { Müll. Arg. }\end{array}$ & Rubiaceae \\
\hline Ixora cf. burcheliana M. Arg. & Ixora burchelliana Müll. Arg. & Rubiaceae \\
\hline Psychotria aff. pubigera Schlecht & Psychotria pubigera Schltdl. & Rubiaceae \\
\hline
\end{tabular}


Anexo 2: Listagem das espécies arbóreas amostradas nos levantamentos fitossociológicos, com respectivas ocorrências nos componentes sub-bosque e dominante, em trecho de Floresta Pluvial Tropical Atlântica, Ilha do Cardoso, $\mathrm{SP}$, Brasil, classificadas quanto à síndrome de dispersão dos propágulos (ANEMO = anemocórica, AUTO = autocórica, ZOO = zoocórica) e quanto às características que apresentam no processo sucessional (Grupo 1 = espécies pioneiras + secundárias iniciais, neste trabalho denominado Grupo das Espécies Iniciais; Grupo 2 = espécies secundárias tardias e climácicas, denominado Grupo das Espécies Tardias; \# = não classificadas, por falta de identificação ao nível específico, denominadas Grupo das Outras Espécies); * = espécies não amostradas no segundo levantamento, por não se encontrarem nas 10 parcelas sorteadas para amostragem do sub-bosque.

\begin{tabular}{|c|c|c|c|c|}
\hline \multirow[t]{2}{*}{ ESPÉCIES } & \multicolumn{2}{|c|}{$\begin{array}{c}\text { COM PONENTE } \\
\text { ONDE FOI AMOSTRADA }\end{array}$} & \multirow{2}{*}{$\begin{array}{l}\text { Síndrome de } \\
\text { dispersão }\end{array}$} & \multirow[t]{2}{*}{ Grupo Sucessional } \\
\hline & Sub-bosque & Dominante & & \\
\hline Acacia polyphylla & & $x$ & ANEMO & 1 \\
\hline Aegiphilla sellowiana & $\mathrm{X} *$ & & ZOO & 1 \\
\hline Alchornea glandulosa & $\mathrm{X} *$ & $x$ & $\mathrm{ZOO}$ & 2 \\
\hline Alchornea triplinervia & $x$ & & ZOO & 2 \\
\hline Alibertia myrciifolia & & $x$ & $\mathrm{ZOO}$ & 2 \\
\hline Allophylus petiolulatus & $\mathrm{X} *$ & & ZOO & 2 \\
\hline Alseis floribunda & $\mathrm{X} *$ & $x$ & AUTO & 2 \\
\hline Ardisia catharinensis & $\mathrm{X} *$ & & ZOO & 2 \\
\hline Astrocaryum aculeatissimum & $x$ & $x$ & $\mathrm{ZOO}$ & 2 \\
\hline Attalea cf. dubia & $\mathrm{X} *$ & & $\mathrm{ZOO}$ & 1 \\
\hline Bactris setosa & $x$ & & ZOO & 2 \\
\hline Barnebya dispar & & $x$ & ANEMO & 2 \\
\hline Brosimum glazioui & $\mathrm{X} *$ & $x$ & ZOO & 2 \\
\hline Brosimum guianense & $\mathrm{X} *$ & $x$ & ZOO & 2 \\
\hline Cabralea canjerana & & $x$ & ZOO & 2 \\
\hline Calyptranthes lanceolata & $x$ & & $\mathrm{ZOO}$ & 2 \\
\hline Calyptranthes lucida & $x$ & $x$ & $\mathrm{ZOO}$ & 2 \\
\hline Campomanesia guaviroba & & $x$ & ZOO & 1 \\
\hline Cariniana estrellensis & $x$ & $x$ & ANEMO & 2 \\
\hline Cariniana cf. legalis & $x$ & & ANEMO & 2 \\
\hline Casearia decandra & $x$ & $x$ & ZOO & 2 \\
\hline Casearia sylvestris & $x$ & $x$ & $\mathrm{ZOO}$ & 1 \\
\hline Cecropia glazioui & $\mathrm{X} *$ & $x$ & $\mathrm{ZOO}$ & 1 \\
\hline Cedrela odorata & $\mathrm{X} *$ & $x$ & ZOO & 2 \\
\hline Centrolobium robustum & $x$ & $x$ & ANEMO & 2 \\
\hline Chomelia catharinae & $x$ & & ZOO & 2 \\
\hline Chrysophyllum flexuosum & $x$ & $x$ & ZOO & 2 \\
\hline Chrysophyllum inornatum & $\mathrm{X} *$ & $x$ & ZOO & 2 \\
\hline Cinnamodendron dinisii & $x$ & $x$ & $\mathrm{ZOO}$ & 2 \\
\hline Citronella paniculata & $x$ & $x$ & $\mathrm{ZOO}$ & 2 \\
\hline Copaifera trapezifolia & $x$ & $x$ & $\mathrm{ZOO}$ & 2 \\
\hline Cordia sellowiana & $\mathrm{X} *$ & & $\mathrm{ZOO}$ & 1 \\
\hline Coussapoa microcarpa & & $x$ & $\mathrm{ZOO}$ & 2 \\
\hline Coussarea contracta & $\mathrm{X} *$ & $x$ & ZOO & 2 \\
\hline Croton macrobothrys & $\mathrm{X} *$ & $x$ & AUTO & 1 \\
\hline Cryptocarya moschata & $\mathrm{X} *$ & $x$ & ZOO & 2 \\
\hline Cupania oblongifolia & & $x$ & ZOO & 2 \\
\hline Dahlstedtia pinnata & $x$ & $x$ & ANEMO & 2 \\
\hline
\end{tabular}


Anexo 2:Continuação

\begin{tabular}{|c|c|c|c|c|}
\hline \multirow{2}{*}{ ESPÉCIES } & \multicolumn{2}{|c|}{$\begin{array}{c}\text { COM PONENTE } \\
\text { ONDE FOI AMOSTRADA }\end{array}$} & \multirow{2}{*}{$\begin{array}{l}\text { Síndrome de } \\
\text { dispersão }\end{array}$} & \multirow[t]{2}{*}{ Grupo Sucessional } \\
\hline & Sub-bosque & Dominante & & \\
\hline Ecclinusa ramiflora & & $x$ & $\mathrm{ZOO}$ & 2 \\
\hline Endlicheria paniculata & $x$ & & $\mathrm{ZOO}$ & 2 \\
\hline Eugenia beaurepaireana & $\mathrm{X} *$ & & ZOO & 2 \\
\hline Eugenia cuprea & $x$ & $x$ & $\mathrm{ZOO}$ & 2 \\
\hline Eugenia cf. glomerata & $x$ & $x$ & ZOO & 2 \\
\hline Eugenia mosenii & $x$ & $x$ & $\mathrm{ZOO}$ & 2 \\
\hline Eugenia cf. multicostata & $x$ & & ZOO & 2 \\
\hline Eugenia oblongata & $x$ & $x$ & ZOO & 2 \\
\hline Eugenia pruinosa & $x$ & $x$ & $\mathrm{ZOO}$ & 2 \\
\hline Eugenia sp1 & $x$ & $x$ & ZOO & $\#$ \\
\hline Eugenia sp2 & $x$ & $x$ & ZOO & $\#$ \\
\hline Eugenia sp3 & $\mathrm{X} *$ & $x$ & ZOO & $\#$ \\
\hline Eugenia sp4 & $x$ & $x$ & ZOO & $\#$ \\
\hline Euterpe edulis & $x$ & $x$ & ZOO & 2 \\
\hline Ficus insipida & $\mathrm{X} *$ & & ZOO & 2 \\
\hline Ficus organensis & & $x$ & ZOO & 2 \\
\hline Ficus pulchella & & $x$ & ZO० & 2 \\
\hline Garcinia gardneriana & $x$ & $x$ & ZOO & 2 \\
\hline Geonoma gamiova & $x$ & & ZOO & 2 \\
\hline Gomidesia flagellaris & $x$ & $x$ & ZO० & 2 \\
\hline Gomidesia spectabilis & $x$ & $x$ & ZOO & 2 \\
\hline Gomidesia tijucensis & & $x$ & ZOO & 2 \\
\hline Guapira opposita & $x$ & $x$ & ZOO & 2 \\
\hline Guarea macrophylla & $x$ & & ZOO & 2 \\
\hline Heisteria silvianii & $\mathrm{X} *$ & $x$ & ZO० & 2 \\
\hline Hirtella hebeclada & $\mathrm{X} *$ & $x$ & ZOO & 2 \\
\hline Hyeronima alchorneoides & $\mathrm{X} *$ & $x$ & ZO० & 2 \\
\hline Ilex dumosa & $x$ & $x$ & ZOO & 2 \\
\hline Ilex integerrima & $x$ & $x$ & $\mathrm{ZOO}$ & 2 \\
\hline Ilex theezans & & $x$ & ZO० & 2 \\
\hline Inga edulis & $x$ & $x$ & ZO० & 2 \\
\hline Ixora burchelliana & $\mathrm{X} *$ & & $\mathrm{ZOO}$ & 2 \\
\hline Lacistema lucidum & $\mathrm{X} *$ & & ZOO & 2 \\
\hline Leandra mosenii & $x$ & & ZOO & 1 \\
\hline Licaria armeniaca & $\mathrm{X} *$ & & ZOO & 2 \\
\hline Machaerium nictitans & $x$ & $x$ & ANEMO & 1 \\
\hline Machaerium scleroxylon & & $x$ & ANEMO & 2 \\
\hline Malouetia arborea & $\mathrm{X}$ & $x$ & AUTO & 2 \\
\hline Manilkara subsericea & $\mathrm{X} *$ & $x$ & ZOO & 2 \\
\hline Marlierea cf. bippenis & $\mathrm{X} *$ & & ZOO & 2 \\
\hline Marlierea obscura & $\mathrm{X}$ & $x$ & ZOO & 2 \\
\hline Marlierea reitzii & $x$ & & $\mathrm{ZOO}$ & 2 \\
\hline Marlierea tomentosa & $x$ & $x$ & ZOO & 2 \\
\hline Matayba juglandifolia & $\mathrm{X} *$ & & ZOO & 2 \\
\hline Meliosma sellowii & $\mathrm{X} *$ & $x$ & ZOO & 2 \\
\hline Metrodorea nigra & $\mathrm{X} *$ & $x$ & AUTO & 2 \\
\hline Miconia cabucu & $\mathrm{X} *$ & & ZOO & 1 \\
\hline Miconia dodecandra & $\mathrm{X} *$ & $x$ & ZOO & 1 \\
\hline Miconia pyrifolia & $x$ & & ZOO & 1 \\
\hline Miconia rigidiuscula & $x$ & & ZOO & 1 \\
\hline Mollinedia schottiana & $x$ & $x$ & ZOO & 2 \\
\hline
\end{tabular}


Anexo 2:Continuação

\begin{tabular}{|c|c|c|c|c|}
\hline \multirow[t]{2}{*}{ ESPÉCIES } & \multicolumn{2}{|c|}{$\begin{array}{c}\text { COM PONENTE } \\
\text { ONDE FOI AMOSTRADA }\end{array}$} & \multirow{2}{*}{$\begin{array}{l}\text { Síndrome de } \\
\text { dispersão }\end{array}$} & \multirow[t]{2}{*}{ Grupo Sucessional } \\
\hline & Sub-bosque & Dominante & & \\
\hline Mollinedia uleana & $x$ & $x$ & ZOO & 2 \\
\hline Myrceugenia miersiana & $\mathrm{X} *$ & $x$ & ZOO & 2 \\
\hline Myrceugenia myrcioides & $x$ & $x$ & zoo & 2 \\
\hline Myrcia pubipetala & $\mathrm{X} *$ & $x$ & zoo & 2 \\
\hline Myrcia racemosa & $\mathrm{X} *$ & & ZOO & 2 \\
\hline Myrcia richardiana & $x$ & $x$ & ZOO & 2 \\
\hline Myrcia tenuivenosa & $\mathrm{X} *$ & $x$ & ZOO & 2 \\
\hline Myrcia sp. & $x$ & $x$ & ZOO & \# \\
\hline Myrocarpus frondosus & $\mathrm{X} *$ & $x$ & ANEMO & 2 \\
\hline Myroxylon peruiferum & $\mathrm{X} *$ & & ANEMO & 2 \\
\hline Nectandra membranacea & & $x$ & ZOO & 2 \\
\hline Nectandra sp. & & $x$ & ZOO & $\#$ \\
\hline Neomitranthes glomerata & $x$ & $x$ & zOO & 2 \\
\hline Ocotea teleiandra & $x$ & $x$ & zoo & 2 \\
\hline Ormosia arborea & $\mathrm{X} *$ & $x$ & zOO & 2 \\
\hline Ouratea parviflora & $x$ & & zOO & 2 \\
\hline Parinari brasiliensis & $\mathrm{X} *$ & $x$ & ZOO & 2 \\
\hline Parinari excelsa & & $x$ & ZOO & 2 \\
\hline Pausandra morisiana & $x$ & $x$ & AUTO & 2 \\
\hline Piper aduncum & $\mathrm{X} *$ & & ZOO & 2 \\
\hline Platymiscium floribundum & & $x$ & ANEMO & 2 \\
\hline Pourouma guianensis & $x$ & $x$ & ZOO & 1 \\
\hline Pouteria cf. laurifolia & $x$ & & ZOO & 2 \\
\hline Pouteria psammophila & $\mathrm{X} *$ & & ZOO & 2 \\
\hline Pouteria venosa & $\mathrm{X} *$ & $x$ & ZOO & 2 \\
\hline Protium kleinii & $\mathrm{X} *$ & $x$ & ZOO & 2 \\
\hline Pseudopiptadenia warmingii & & $x$ & ANEMO & 2 \\
\hline Psychotria mapoureoides & $\mathrm{X} *$ & $x$ & ZOO & 2 \\
\hline Psychotria nuda & $x$ & $x$ & zoo & 2 \\
\hline Psychotria pubigera & $x$ & & ZOO & 2 \\
\hline Psychotria suterella & $\mathrm{X} *$ & & ZOO & 2 \\
\hline Pterocarpus rohrii & & $x$ & ANEMO & 2 \\
\hline Quiina glaziovii & & $x$ & ZOO & 2 \\
\hline Rapanea cf. ferruginea & $\mathrm{X} *$ & & zOO & 1 \\
\hline Rapanea guyanensis & & $x$ & ZOO & 1 \\
\hline Rapanea hermogenesii & & $x$ & ZOO & 2 \\
\hline Rollinia sericea & $x$ & $x$ & ZOO & 1 \\
\hline Roupala montana & $\mathrm{X} *$ & $x$ & AUTO & 2 \\
\hline Roupala paulensis & & $x$ & AUTO & 2 \\
\hline Rudgea jasminoides & $x$ & $x$ & ZOO & 2 \\
\hline Rudgea recurva & $x$ & & ZOO & 2 \\
\hline Sapium glandulatum & & $x$ & AUTO & 1 \\
\hline Schizolobium parahyba & $\mathrm{X} *$ & $x$ & ANEMO & 1 \\
\hline Sloanea guianensis & $\mathrm{X} *$ & $x$ & ZOO & 2 \\
\hline Solanum inaequale & $\mathrm{X} *$ & & ZOO & 1 \\
\hline Solanum swartzianum & $\mathrm{X} *$ & & ZOO & 1 \\
\hline Sorocea bonplandii & $x$ & $x$ & ZOO & 2 \\
\hline Sphaeropteris sp. & $\mathrm{X} *$ & & ANEMO & $\#$ \\
\hline Swartzia macrostachya & $\mathrm{X} *$ & $x$ & ZOO & 2 \\
\hline Symplocos mosenii & & $x$ & ZOO & 2 \\
\hline Tabebuia heptaphylla & & $x$ & ANEMO & 2 \\
\hline
\end{tabular}


Anexo 2:Continuação

\begin{tabular}{|c|c|c|c|c|}
\hline \multirow{2}{*}{ ESPÉCIES } & \multicolumn{2}{|c|}{$\begin{array}{c}\text { COM PONENTE } \\
\text { ONDE FOI AMOSTRADA }\end{array}$} & \multirow{2}{*}{$\begin{array}{l}\text { Síndrome de } \\
\text { dispersão }\end{array}$} & \multirow[t]{2}{*}{ Grupo Sucessional } \\
\hline & Sub-bosque & Dominante & & \\
\hline Tabebuia serratifolia & $\mathrm{X} *$ & $x$ & ANEMO & 2 \\
\hline Talauma ovata & $\mathrm{X} *$ & $x$ & ZOO & 2 \\
\hline Tetrastylidium grandifolium & $\mathrm{X} *$ & $x$ & ZOO & 2 \\
\hline Tetrorchidium rubrivenium & $x$ & $x$ & AUTO & 2 \\
\hline Trema micrantha & $\mathrm{X} *$ & & $\mathrm{ZOO}$ & 1 \\
\hline Trichilia lepidota & $x$ & $x$ & ZOO & 2 \\
\hline Trichilia pallens & $x$ & & ZOO & 2 \\
\hline Trichilia silvatica & $x$ & $x$ & ZOO & 2 \\
\hline Urera nitida & $\mathrm{X} *$ & & ZOO & 1 \\
\hline Vantanea compacta & & $x$ & ZOO & 2 \\
\hline Virola gardneri & $\mathrm{X} *$ & $x$ & ZOO & 2 \\
\hline Virola oleifera & & $x$ & $\mathrm{ZOO}$ & 2 \\
\hline Vochysia bifalcata & $\mathrm{X} *$ & $x$ & ZO० & 2 \\
\hline Xylopia langsdorffiana & $\mathrm{X} *$ & $x$ & ZOO & 2 \\
\hline Zanthoxyllum rhoifolium & $\mathrm{X} *$ & & ZOO & 1 \\
\hline Zollernia ilicifolia & $\mathrm{X} *$ & & ZOO & 2 \\
\hline
\end{tabular}


Anexo 3: Dados sobre o número de espécies, a densidade e a área total dos caules das árvores, obtidos em parcelas permanentes instaladas em Florestas Tropicais. LATI. = latitude; LONGI. = longitude; ALTI. = altitude; TMA = temperatura média anual; PPA = precipitação pluviométrica média anual; DAP = diâmetro do caule a $1,30 \mathrm{~m}$ de altura do solo; ÁREA = tamanho da área estudada; TEMPO = intervalo de tempo entre censos; $\mathrm{N}$ esp. = número total de espécies amostradas, em cada inventário; Dens. = número de indivíduos amostrados / ha, em cada inventário; AT = área total dos caules das árvores, em cada inventário.

\begin{tabular}{|c|c|c|c|c|c|c|c|c|c|c|c|}
\hline FONTE & LOCAL & LATI. I LONGI. & $\begin{array}{l}\text { ALTI. } \\
(\mathrm{m})\end{array}$ & $\begin{array}{l}\text { TMA } \\
\left({ }^{\circ} \mathrm{C}\right)\end{array}$ & $\begin{array}{l}\text { PPA } \\
(\mathrm{mm})\end{array}$ & $\begin{array}{l}\text { DAP } \\
(\mathrm{cm})\end{array}$ & $\begin{array}{l}\text { ÁREA } \\
\text { (ha) }\end{array}$ & $\begin{array}{l}\text { TEMPO } \\
\text { (anos) }\end{array}$ & N esp. & Dens. & $\begin{array}{c}\text { AT } \\
\left(\mathrm{m}^{2} / \mathrm{ha}\right)\end{array}$ \\
\hline $\begin{array}{l}\text { MELO (sub-bosque, } \\
\text { presente estudo) }\end{array}$ & $\begin{array}{l}\text { Ilha do Cardoso, } \\
\text { São Paulo, Brasil }\end{array}$ & $25^{\circ} 03^{\prime} \mathrm{S}, 47^{\circ} 53^{\prime} \mathrm{W}$ & $\begin{array}{c}100- \\
150\end{array}$ & 21,2 & 1.948 & 2,5 & 0,25 & $\begin{array}{c}1987-95 \\
(6,8)\end{array}$ & 64 e 60 & $\begin{array}{c}402 \text { e } \\
377\end{array}$ & $\begin{array}{c}1,03 a \\
0,97\end{array}$ \\
\hline $\begin{array}{c}\text { MELO (componente } \\
\text { dominante, presente estudo) }\end{array}$ & $\begin{array}{l}\text { Ilha do Cardoso, } \\
\text { São Paulo, Brasil }\end{array}$ & $25^{\circ} 03^{\prime} \mathrm{S}, 47^{\circ} 53^{\prime} \mathrm{W}$ & $\begin{array}{c}100- \\
150\end{array}$ & 21,2 & 1.948 & 9,9 & 1 & $\begin{array}{l}1987-95 \\
(6,8)\end{array}$ & $\begin{array}{c}108 \mathrm{e} \\
109\end{array}$ & $\begin{array}{l}727 \text { e } \\
756\end{array}$ & $\begin{array}{c}43,48 \text { e } \\
45,57\end{array}$ \\
\hline GOMES (1998) & $\begin{array}{l}\text { São Paulo, São } \\
\text { Paulo, Brasil }\end{array}$ & $23^{\circ} 40^{\prime} \mathrm{S}, 46^{\circ} 37^{\prime} \mathrm{W}$ & 790 & 19 & 1.477 & 8 & 1 & $\begin{array}{c}1989-95 \\
(5,6)\end{array}$ & 91 e 97 & $\begin{array}{l}759 \text { e } \\
872\end{array}$ & $\begin{array}{c}17,03 \text { e } \\
19,55\end{array}$ \\
\hline $\begin{array}{l}\text { OLIVEIRA-FILHO et al. } \\
(1997)\end{array}$ & $\begin{array}{c}\text { Reserva Florestal } \\
\text { da UFLA, MG, } \\
\text { Brasil }\end{array}$ & $21^{\circ} 13^{\prime} \mathrm{S}, 44^{\circ} 57^{\prime} \mathrm{W}$ & 935 & 19,4 & $1.529,7$ & 5 & 5,04 & $\begin{array}{l}1987-92 \\
(5)\end{array}$ & $\begin{array}{l}137 \mathrm{e} \\
135\end{array}$ & $\begin{array}{c}1.295,2 \\
e \\
1.343,3\end{array}$ & $\begin{array}{c}18,83 \text { e } \\
21,53\end{array}$ \\
\hline FELFILI (1994) & $\begin{array}{l}\text { Rio Gama, Distrito } \\
\text { Federal, Brasil }\end{array}$ & $15^{\circ} 56^{\prime} \mathrm{S}, 4^{\circ}{ }^{\circ} 55^{\prime} \mathrm{W}$ & 1.100 & 19,5 & 1.600 & 10 & 3,02 & $\begin{array}{l}1985-88- \\
91(6)\end{array}$ & $\begin{array}{l}93,97 \text { e } \\
97 \text { (b) }\end{array}$ & $\begin{array}{c}649,67 \\
663,58 \mathrm{e} \\
657,24\end{array}$ & $\begin{array}{c}30,42 \\
30,95 \mathrm{e} \\
30,30\end{array}$ \\
\hline $\begin{array}{c}\text { MANOKARAN \& } \\
\text { KOCHUMMEN (1987) }\end{array}$ & $\begin{array}{l}\text { Sungei Menyala, } \\
\text { Malásia }\end{array}$ & $2^{\circ} 28^{\prime} \mathrm{N}, 101^{\circ} 55^{\prime} \mathrm{E}$ & 30 & 28 & 2.376 & 10 & 2 & $\begin{array}{l}1947-81 \\
(34)\end{array}$ & $\begin{array}{l}243- \\
244\end{array}$ & $\begin{array}{c}537,5 \text { e } \\
484,0\end{array}$ & $\begin{array}{c}33,09 \mathrm{e} \\
32,64\end{array}$ \\
\hline $\begin{array}{c}\text { OKALI \& OLA-ADAMS } \\
(1987)\end{array}$ & $\begin{array}{l}\text { Omo Forest, } \\
\text { Nigeria, África }\end{array}$ & $6^{\circ} 35^{\prime} \mathrm{N}, 4^{\circ} 19^{\prime} \mathrm{E}$ & 150 & 25,8 & 1.577 & 10 & 4,05 & $\begin{array}{l}1952-81 \\
(28)\end{array}$ & 50 & $\begin{array}{l}4.468 \mathrm{e} \\
1097(\mathrm{~b})\end{array}$ & $\begin{array}{l}35,3 \text { e } \\
68,2(b)\end{array}$ \\
\hline $\begin{array}{l}\text { HUBBELL \& FOSTER } \\
(1990,1992)\end{array}$ & $\begin{array}{l}\text { Barro Colorado } \\
\text { Island, Panama }\end{array}$ & $9^{\circ} 9^{\prime} \mathrm{N}, 79^{\circ} 51^{\prime} \mathrm{W}$ & 150 & 27 & 2.600 & 1 & 50 & $\begin{array}{l}1982-85 \\
(3)\end{array}$ & (c) & $\begin{array}{c}235.895 \\
\mathrm{e} \\
242.218\end{array}$ & --- \\
\hline PERALTA et al. (1987) & $\begin{array}{l}\text { La Selva, Costa } \\
\text { Rica }\end{array}$ & $10^{\circ} 26^{\prime} \mathrm{N}, 83^{\circ} 59^{\prime} \mathrm{W}$ & $32-71$ & 25,4 & 4.015 & 10 & 12,4 & $\begin{array}{c}1969-83 \\
(13)\end{array}$ & 269 & $\begin{array}{l}5.623 \mathrm{e} \\
5.530\end{array}$ & --- \\
\hline
\end{tabular}

a) Incluindo as árvores mortas como uma única população.

b) O primeiro censo, em 1952, foram amostrados 4,05ha e, no segundo, em 1981, apenas 0,75ha. 
c) O número de espécies nos dois censos é incerto. Hubbell \& Foster (1990) informaram ser 306 e, em 1992, afirmaram ser 303 no primeiro censo. Condit et al. (1992) indicam 301 para o censo de 1982 e 303 para o de 1985 
Anexo 4: Parâmetros fitossociológicos das espécies amostradas no sub-bosque, no primeiro e segundo levantamentos, em trecho de Floresta Pluvial Tropical Atlântica, Ilha do Cardoso, SP, Brasil. Ni = número de árvores amostradas; No = número de parcelas em que a espécie ocorreu; $\mathrm{DoA}=$ dominância absoluta; $\mathrm{DR}=$ densidade relativa (\%); FR = freqüência relativa (\%); DoR = dominância relativa (\%); IVI = índice do valor de importância (DR+FR+DoR).

\begin{tabular}{|c|c|c|c|c|c|c|c|c|c|c|c|c|c|c|}
\hline \multirow{2}{*}{ Espécies } & \multicolumn{7}{|c|}{ Primeiro Levantamento } & \multicolumn{7}{|c|}{ Segundo Levantamento } \\
\hline & $\mathrm{Ni}$ & No & DoA & DR & FR & DoR & IVI & $\mathbf{N i}$ & No & DoA & DR & $\mathbf{F R}$ & DoR & IVI \\
\hline Euterpe edulis & 71 & 10 & 0,82 & 17,66 & 5,59 & 19,91 & 43,16 & 69 & 10 & 0,82 & 18,30 & 6,10 & 21,21 & 45,61 \\
\hline Rudgea jasminoides & 64 & 10 & 0,64 & 15,92 & 5,59 & 15,63 & 37,13 & 66 & 10 & 0,68 & 17,51 & 6,10 & 17,62 & 41,23 \\
\hline Psychotria nuda & 62 & 8 & 0,65 & 15,42 & 4,47 & 15,78 & 35,67 & 56 & 8 & 0,61 & 14,85 & 4,88 & 15,85 & 35,58 \\
\hline Eugenia cuprea & 14 & 10 & 0,14 & 3,48 & 5,59 & 3,34 & 12,41 & 15 & 9 & 0,15 & 3,98 & 5,49 & 3,80 & 13,27 \\
\hline Garcinia gardneriana & 16 & 7 & 0,16 & 3,98 & 3,91 & 3,99 & 11,88 & 16 & 7 & 0,16 & 4,24 & 4,27 & 4,01 & 12,52 \\
\hline Malouetia arborea & 14 & 7 & 0,10 & 3,48 & 3,91 & 2,32 & 9,72 & 12 & 5 & 0,08 & 3,18 & 3,05 & 2,09 & 8,32 \\
\hline Astrocaryum aculeatissimum & 8 & 5 & 0,18 & 1,99 & 2,79 & 4,33 & 9,12 & 6 & 4 & 0,15 & 1,59 & 2,44 & 3,88 & 7,91 \\
\hline Calyptranthes lanceolata & 12 & 9 & 0,04 & 2,99 & 5,03 & 0,89 & 8,91 & 12 & 8 & 0,04 & 3,18 & 4,88 & 1,02 & 9,09 \\
\hline Mollinedia schottiana & 8 & 5 & 0,15 & 1,99 & 2,79 & 3,57 & 8,35 & 6 & 5 & 0,08 & 1,59 & 3,05 & 1,94 & 6,59 \\
\hline Eugenia oblongata & 7 & 6 & 0,09 & 1,74 & 3,35 & 2,26 & 7,36 & 4 & 3 & 0,04 & 1,06 & 1,83 & 1,07 & 3,96 \\
\hline Eugenia mosenii & 6 & 5 & 0,12 & 1,49 & 2,79 & 2,90 & 7,18 & 5 & 5 & 0,11 & 1,33 & 3,05 & 2,88 & 7,26 \\
\hline Marlierea tomentosa & 8 & 5 & 0,09 & 1,99 & 2,79 & 2,08 & 6,87 & 7 & 5 & 0,07 & 1,86 & 3,05 & 1,75 & 6,65 \\
\hline Dahlstedtia pinnata & 6 & 5 & 0,06 & 1,49 & 2,79 & 1,48 & 5,76 & 5 & 4 & 0,07 & 1,33 & 2,44 & 1,74 & 5,51 \\
\hline Marlierea obscura & 6 & 4 & 0,08 & 1,49 & 2,23 & 1,93 & 5,65 & 6 & 5 & 0,06 & 1,59 & 3,05 & 1,52 & 6,16 \\
\hline Calyptranthes lucida & 7 & 5 & 0,03 & 1,74 & 2,79 & 0,76 & 5,30 & 5 & 4 & 0,03 & 1,33 & 2,44 & 0,80 & 4,57 \\
\hline Gomidesia spectabilis & 5 & 4 & 0,06 & 1,24 & 2,23 & 1,48 & 4,96 & 4 & 3 & 0,06 & 1,06 & 1,83 & 1,54 & 4,43 \\
\hline Eugenia sp1 & 4 & 4 & 0,05 & 1,00 & 2,23 & 1,19 & 4,42 & 3 & 3 & 0,05 & 0,80 & 1,83 & 1,17 & 3,80 \\
\hline Sorocea bonplandii & 5 & 4 & 0,04 & 1,24 & 2,23 & 0,93 & 4,40 & 3 & 3 & 0,04 & 0,80 & 1,83 & 0,91 & 3,54 \\
\hline Chrysophyllum flexuosum & 4 & 4 & 0,05 & 1,00 & 2,23 & 1,10 & 4,33 & 3 & 3 & 0,05 & 0,80 & 1,83 & 1,17 & 3,80 \\
\hline Myrcia richardiana & 4 & 3 & 0,04 & 1,00 & 1,68 & 0,97 & 3,64 & 3 & 2 & 0,01 & 0,80 & 1,22 & 0,35 & 2,36 \\
\hline Pausandra morisiana & 4 & 3 & 0,04 & 1,00 & 1,68 & 0,87 & 3,54 & 6 & 3 & 0,05 & 1,59 & 1,83 & 1,35 & 4,77 \\
\hline Marlierea reitzii & 3 & 3 & 0,05 & 0,75 & 1,68 & 1,10 & 3,52 & 4 & 4 & 0,06 & 1,06 & 2,44 & 1,53 & 5,03 \\
\hline Guapira opposita & 4 & 3 & 0,02 & 1,00 & 1,68 & 0,47 & 3,14 & 5 & 4 & 0,03 & 1,33 & 2,44 & 0,82 & 4,59 \\
\hline Gomidesia flagellaris & 5 & 2 & 0,03 & 1,24 & 1,12 & 0,70 & 3,06 & 5 & 2 & 0,04 & 1,33 & 1,22 & 1,07 & 3,62 \\
\hline Geonoma gamiova & 4 & 3 & 0,01 & 1,00 & 1,68 & 0,21 & 2,88 & 5 & 3 & 0,01 & 1,33 & 1,83 & 0,30 & 3,45 \\
\hline Tetrastylidium gradifolium & 2 & 1 & 0,06 & 0,50 & 0,56 & 1,35 & 2,40 & - & - & - & - & - & - & - \\
\hline Pourouma guianensis & 3 & 2 & 0,01 & 0,75 & 1,12 & 0,33 & 2,20 & 2 & 2 & 0,01 & 0,53 & 1,22 & 0,21 & 1,96 \\
\hline
\end{tabular}


Anexo 4: Continuação

\begin{tabular}{|c|c|c|c|c|c|c|c|c|c|c|c|c|c|c|}
\hline \multirow{2}{*}{ Espécies } & \multicolumn{7}{|c|}{ Primeiro Levantamento } & \multicolumn{7}{|c|}{ Segundo Levantamento } \\
\hline & $\mathbf{N i}$ & No & DoA & DR & FR & DoR & IVI & $\mathbf{N i}$ & No & DoA & DR & $\mathbf{F R}$ & DoR & IVI \\
\hline Neomitranthes glomerata & 3 & 2 & 0,01 & 0,75 & 1,12 & 0,30 & 2,16 & 3 & 2 & 0,01 & 0,80 & 1,22 & 0,34 & 2,36 \\
\hline Guarea macrophylla & 2 & 2 & 0,02 & 0,50 & 1,12 & 0,47 & 2,08 & 2 & 2 & 0,03 & 0,53 & 1,22 & 0,70 & 2,45 \\
\hline Leandra mosenii & - & - & - & - & - & - & - & 2 & 2 & 0,01 & 0,53 & 1,22 & 0,19 & 1,94 \\
\hline Cariniana estrellensis & 2 & 2 & 0,01 & 0,50 & 1,12 & 0,19 & 1,80 & 1 & 1 & 0,00 & 0,27 & 0,61 & 0,10 & 0,97 \\
\hline Endlicheria paniculata & 2 & 2 & 0,01 & 0,50 & 1,12 & 0,16 & 1,77 & 1 & 1 & 0,00 & 0,27 & 0,61 & 0,08 & 0,96 \\
\hline Bactris setosa & 2 & 2 & 0,00 & 0,50 & 1,12 & 0,11 & 1,73 & 1 & 1 & 0,00 & 0,27 & 0,61 & 0,08 & 0,96 \\
\hline Tetrorchidium rubrivenium & 2 & 1 & 0,02 & 0,50 & 0,56 & 0,45 & 1,50 & 3 & 2 & 0,03 & 0,80 & 1,22 & 0,84 & 2,86 \\
\hline Cryptocarya moschata & 1 & 1 & 0,03 & 0,25 & 0,56 & 0,65 & 1,46 & - & - & - & - & - & - & - \\
\hline Protium kleinii & 1 & 1 & 0,02 & 0,25 & 0,56 & 0,61 & 1,41 & - & - & - & - & - & - & - \\
\hline Sloanea guianensis & 1 & 1 & 0,02 & 0,25 & 0,56 & 0,61 & 1,41 & - & - & - & - & - & - & - \\
\hline Trichilia lepidota & 2 & 1 & 0,01 & 0,50 & 0,56 & 0,30 & 1,36 & 2 & 1 & 0,01 & 0,53 & 0,61 & 0,34 & 1,48 \\
\hline Ouratea parviflora & 2 & 1 & 0,01 & 0,50 & 0,56 & 0,24 & 1,29 & 2 & 1 & 0,01 & 0,53 & 0,61 & 0,24 & 1,38 \\
\hline Cinnamodendron aff. dinisii & 1 & 1 & 0,02 & 0,25 & 0,56 & 0,39 & 1,20 & 1 & 1 & 0,03 & 0,27 & 0,61 & 0,72 & 1,59 \\
\hline Myrcia sp1 & 1 & 1 & 0,01 & 0,25 & 0,56 & 0,34 & 1,15 & 1 & 1 & 0,02 & 0,27 & 0,61 & 0,62 & 1,50 \\
\hline Cariniana cf. legalis & 1 & 1 & 0,01 & 0,25 & 0,56 & 0,34 & 1,15 & 1 & 1 & 0,02 & 0,27 & 0,61 & 0,60 & 1,47 \\
\hline Rollinia sericea & 1 & 1 & 0,01 & 0,25 & 0,56 & 0,31 & 1,12 & - & - & - & - & - & - & - \\
\hline Citronella paniculata & 1 & 1 & 0,01 & 0,25 & 0,56 & 0,28 & 1,09 & - & - & - & - & - & - & - \\
\hline Ocotea teleiandra & 1 & 1 & 0,01 & 0,25 & 0,56 & 0,28 & 1,09 & 1 & 1 & 0,02 & 0,27 & 0,61 & 0,40 & 1,27 \\
\hline Copaifera trapezifolia & 1 & 1 & 0,01 & 0,25 & 0,56 & 0,25 & 1,06 & 1 & 1 & 0,01 & 0,27 & 0,61 & 0,30 & 1,17 \\
\hline Trichilia silvatica & 1 & 1 & 0,01 & 0,25 & 0,56 & 0,20 & 1,00 & 1 & 1 & 0,01 & 0,27 & 0,61 & 0,24 & 1,11 \\
\hline Mollinedia uleana & 1 & 1 & 0,01 & 0,25 & 0,56 & 0,17 & 0,98 & 2 & 2 & 0,01 & 0,53 & 1,22 & 0,30 & 2,05 \\
\hline Casearia decandra & 1 & 1 & 0,01 & 0,25 & 0,56 & 0,15 & 0,96 & 1 & 1 & 0,01 & 0,27 & 0,61 & 0,18 & 1,06 \\
\hline Inga edulis & 1 & 1 & 0,01 & 0,25 & 0,56 & 0,13 & 0,94 & - & - & - & - & - & - & - \\
\hline Casearia sylvestris & 1 & 1 & 0,00 & 0,25 & 0,56 & 0,11 & 0,92 & 1 & 1 & 0,01 & 0,27 & 0,61 & 0,35 & 1,22 \\
\hline Eugenia sp2 & 1 & 1 & 0,00 & 0,25 & 0,56 & 0,11 & 0,92 & 1 & 1 & 0,01 & 0,27 & 0,61 & 0,16 & 1,04 \\
\hline Myrceugenia myrcioides & 1 & 1 & 0,00 & 0,25 & 0,56 & 0,11 & 0,91 & 1 & 1 & 0,00 & 0,27 & 0,61 & 0,12 & 0,99 \\
\hline Ilex dumosa & 1 & 1 & 0,00 & 0,25 & 0,56 & 0,09 & 0,90 & 1 & 1 & 0,01 & 0,27 & 0,61 & 0,21 & 1,09 \\
\hline Psychotria pubigera & 1 & 1 & 0,00 & 0,25 & 0,56 & 0,09 & 0,90 & 1 & 1 & 0,01 & 0,27 & 0,61 & 0,14 & 1,01 \\
\hline Eugenia cf. glomerata & 1 & 1 & 0,00 & 0,25 & 0,56 & 0,09 & 0,90 & 1 & 1 & 0,00 & 0,27 & 0,61 & 0,12 & 0,99 \\
\hline Miconia rigidiuscula & 1 & 1 & 0,00 & 0,25 & 0,56 & 0,08 & 0,89 & - & - & - & - & - & - & - \\
\hline Ilex integerrima & 1 & 1 & 0,00 & 0,25 & 0,56 & 0,09 & 0,89 & 1 & 1 & 0,00 & 0,27 & 0,61 & 0,11 & 0,98 \\
\hline
\end{tabular}


Anexo 4: Continuação

\begin{tabular}{|c|c|c|c|c|c|c|c|c|c|c|c|c|c|c|}
\hline \multirow{2}{*}{ Espécies } & \multicolumn{7}{|c|}{ Primeiro Levantamento } & \multicolumn{7}{|c|}{ Segundo Levantamento } \\
\hline & $\mathrm{Ni}$ & No & DoA & DR & FR & DoR & IVI & $\mathbf{N i}$ & No & DoA & DR & FR & DoR & IVI \\
\hline Eugenia pruinosa & 1 & 1 & 0,00 & 0,25 & 0,56 & 0,08 & 0,88 & 1 & 1 & 0,01 & 0,27 & 0,61 & 0,14 & 1,01 \\
\hline Machaerium nictitans & 1 & 1 & 0,00 & 0,25 & 0,56 & 0,08 & 0,88 & 1 & 1 & 0,00 & 0,27 & 0,61 & 0,12 & 0,99 \\
\hline Trichilia pallens & 1 & 1 & 0,00 & 0,25 & 0,56 & 0,08 & 0,88 & 1 & 1 & 0,00 & 0,27 & 0,61 & 0,09 & 0,97 \\
\hline Pouteria cf. laurifolia & 1 & 1 & 0,00 & 0,25 & 0,56 & 0,06 & 0,86 & - & - & - & - & - & - & - \\
\hline Eugenia cf. multicostata & 1 & 1 & 0,00 & 0,25 & 0,56 & 0,05 & 0,86 & 2 & 2 & 0,00 & 0,53 & 1,22 & 0,13 & 1,88 \\
\hline Alchornea triplinervia & - & - & - & - & - & - & - & 1 & 1 & 0,00 & 0,27 & 0,61 & 0,12 & 0,99 \\
\hline Centrolobium robustum & 1 & 1 & 0,00 & 0,25 & 0,56 & 0,05 & 0,86 & 1 & 1 & 0,00 & 0,27 & 0,61 & 0,07 & 0,95 \\
\hline Chomelia cf. catharinae & 1 & 1 & 0,00 & 0,25 & 0,56 & 0,05 & 0,86 & 1 & 1 & 0,00 & 0,27 & 0,61 & 0,07 & 0,94 \\
\hline Miconia pyrifolia & - & - & - & - & - & - & - & 1 & 1 & 0,00 & 0,27 & 0,61 & 0,07 & 0,94 \\
\hline Rudgea recurva & - & - & - & - & - & - & - & 1 & 1 & 0,00 & 0,27 & 0,61 & 0,05 & 0,93 \\
\hline Eugenia sp4 & - & - & - & - & - & - & - & 1 & 1 & 0,00 & 0,27 & 0,61 & 0,05 & 0,93 \\
\hline
\end{tabular}


Anexo 5: Parâmetros fitossociológicos das espécies amostradas no componente dominante, no primeiro e segundo levantamentos, em trecho de Floresta Pluvial Tropical Atlântica, llha do Cardoso, SP, Brasil. Ni = número de árvores amostradas; No = número de parcelas em que a espécie ocorreu; DoA = dominância absoluta; $\mathrm{DR}=$ densidade relativa $(\%) ; \mathrm{FR}=$ freqüência relativa $(\%)$; DoR = dominância relativa $(\%)$; IVI = índice do valor de importância (DR+FR+DoR).

\begin{tabular}{|c|c|c|c|c|c|c|c|c|c|c|c|c|c|c|}
\hline \multirow{2}{*}{ Espécies } & \multicolumn{7}{|c|}{ Primeiro Levantamento } & \multicolumn{7}{|c|}{ Segundo Levantamento } \\
\hline & $\mathbf{N i}$ & No & DoA & DR & FR & DoR & IVI & $\mathbf{N i}$ & No & DoA & DR & FR & DoR & IVI \\
\hline Euterpe edulis & 221 & 40 & 2,82 & 30,40 & 8,30 & 6,49 & 45,19 & 227 & 40 & 2,99 & 30,03 & 8,11 & 6,56 & 44,70 \\
\hline Cryptocarya moschata & 20 & 17 & 3,59 & 2,75 & 3,53 & 8,26 & 14,54 & 20 & 17 & 3,82 & 2,65 & 3,45 & 8,38 & 14,48 \\
\hline Virola oleifera & 19 & 16 & 3,10 & 2,61 & 3,32 & 7,13 & 13,07 & 19 & 16 & 3,69 & 2,51 & 3,25 & 8,10 & 13,85 \\
\hline Chrysophyllum flexuosum & 32 & 21 & 1,60 & 4,40 & 4,36 & 3,67 & 12,43 & 33 & 22 & 1,72 & 4,37 & 4,46 & 3,78 & 12,61 \\
\hline Malouetia arborea & 22 & 16 & 1,58 & 3,03 & 3,32 & 3,64 & 9,98 & 18 & 14 & 1,23 & 2,38 & 2,84 & 2,70 & 7,92 \\
\hline Hyeronima alchorneoides & 8 & 7 & 2,11 & 1,10 & 1,45 & 4,85 & 7,40 & 8 & 7 & 2,38 & 1,06 & 1,42 & 5,22 & 7,69 \\
\hline Calyptranthes lucida & 16 & 12 & 1,04 & 2,20 & 2,49 & 2,40 & 7,09 & 16 & 12 & 1,07 & 2,12 & 2,43 & 2,35 & 6,90 \\
\hline Garcinia gardneriana & 23 & 15 & 0,34 & 3,16 & 3,11 & 0,78 & 7,05 & 28 & 18 & 0,42 & 3,70 & 3,65 & 0,92 & 8,27 \\
\hline Pseudopiptadenia warmingii & 5 & 4 & 2,37 & 0,69 & 0,83 & 5,44 & 6,96 & 5 & 4 & 2,90 & 0,66 & 0,81 & 6,37 & 7,85 \\
\hline Eugenia mosenii & 17 & 15 & 0,64 & 2,34 & 3,11 & 1,48 & 6,93 & 20 & 17 & 0,72 & 2,65 & 3,45 & 1,59 & 7,68 \\
\hline Tetrastylidium gradifolium & 15 & 13 & 0,91 & 2,06 & 2,70 & 2,10 & 6,86 & 18 & 15 & 1,03 & 2,38 & 3,04 & 2,27 & 7,69 \\
\hline Myrcia pubipetala & 11 & 9 & 1,28 & 1,51 & 1,87 & 2,95 & 6,33 & 9 & 8 & 1,00 & 1,19 & 1,62 & 2,20 & 5,02 \\
\hline Marlierea tomentosa & 15 & 11 & 0,20 & 2,06 & 2,28 & 0,47 & 4,82 & 14 & 9 & 0,21 & 1,85 & 1,83 & 0,45 & 4,13 \\
\hline Pterocarpus rohrii & 4 & 4 & 1,48 & 0,55 & 0,83 & 3,41 & 4,79 & 4 & 4 & 1,56 & 0,53 & 0,81 & 3,42 & 4,77 \\
\hline Psychotria nuda & 13 & 12 & 0,14 & 1,79 & 2,49 & 0,33 & 4,60 & 18 & 15 & 0,20 & 2,38 & 3,04 & 0,44 & 5,87 \\
\hline Casearia decandra & 7 & 7 & 0,88 & 0,96 & 1,45 & 2,02 & 4,44 & 6 & 6 & 0,71 & 0,79 & 1,22 & 1,55 & 3,56 \\
\hline Sloanea guianensis & 7 & 6 & 0,93 & 0,96 & 1,24 & 2,13 & 4,34 & 8 & 7 & 1,02 & 1,06 & 1,42 & 2,24 & 4,71 \\
\hline Sorocea bonplandii & 11 & 11 & 0,13 & 1,51 & 2,28 & 0,29 & 4,09 & 11 & 11 & 0,13 & 1,46 & 2,23 & 0,29 & 3,98 \\
\hline Rudgea jasminoides & 11 & 11 & 0,10 & 1,51 & 2,28 & 0,23 & 4,03 & 12 & 12 & 0,12 & 1,59 & 2,43 & 0,27 & 4,29 \\
\hline Roupala paulensis & 5 & 5 & 0,96 & 0,69 & 1,04 & 2,22 & 3,94 & 4 & 4 & 0,79 & 0,53 & 0,81 & 1,73 & 3,07 \\
\hline Chrysophyllum inornatum & 8 & 6 & 0,66 & 1,10 & 1,24 & 1,51 & 3,85 & 8 & 6 & 0,71 & 1,06 & 1,22 & 1,56 & 3,83 \\
\hline Mollinedia uleana & 9 & 8 & 0,32 & 1,24 & 1,66 & 0,75 & 3,64 & 7 & 6 & 0,25 & 0,93 & 1,22 & 0,54 & 2,69 \\
\hline Marlierea obscura & 9 & 9 & 0,20 & 1,24 & 1,87 & 0,46 & 3,57 & 12 & 12 & 0,19 & 1,59 & 2,43 & 0,41 & 4,43 \\
\hline Protium kleinii & 4 & 4 & 0,94 & 0,55 & 0,83 & 2,17 & 3,55 & 5 & 5 & 1,06 & 0,66 & 1,01 & 2,33 & 4,01 \\
\hline Talauma ovata & 6 & 6 & 0,55 & 0,83 & 1,24 & 1,27 & 3,34 & 8 & 8 & 0,60 & 1,06 & 1,62 & 1,33 & 4,01 \\
\hline Astrocaryum aculeatissimum & 9 & 8 & 0,08 & 1,24 & 1,66 & 0,19 & 3,08 & 13 & 9 & 0,13 & 1,72 & 1,83 & 0,28 & 3,82 \\
\hline Ilex theezans & 4 & 4 & 0,73 & 0,55 & 0,83 & 1,67 & 3,05 & 4 & 4 & 0,73 & 0,53 & 0,81 & 1,61 & 2,95 \\
\hline
\end{tabular}


Anexo 5: Continuação

\begin{tabular}{|c|c|c|c|c|c|c|c|c|c|c|c|c|c|c|}
\hline \multirow{2}{*}{ Espécies } & \multicolumn{7}{|c|}{ Primeiro Levantamento } & \multicolumn{7}{|c|}{ Segundo Levantamento } \\
\hline & $\mathbf{N i}$ & No & DoA & DR & FR & DoR & IVI & $\mathbf{N i}$ & No & DoA & DR & FR & DoR & IVI \\
\hline Cariniana estrellensis & 2 & 2 & 1,01 & 0,28 & 0,41 & 2,32 & 3,01 & 2 & 2 & 1,05 & 0,26 & 0,41 & 2,29 & 2,96 \\
\hline Myrcia sp1 & 7 & 5 & 0,37 & 0,96 & 1,04 & 0,85 & 2,85 & 6 & 4 & 0,24 & 0,79 & 0,81 & 0,54 & 2,14 \\
\hline Hirtella hebeclada & 6 & 6 & 0,33 & 0,83 & 1,24 & 0,76 & 2,84 & 6 & 6 & 0,34 & 0,79 & 1,22 & 0,75 & 2,76 \\
\hline Ficus organensis & 1 & 1 & 0,97 & 0,14 & 0,21 & 2,24 & 2,59 & 1 & 1 & 1,31 & 0,13 & 0,20 & 2,86 & 3,20 \\
\hline Myrceugenia myrcioides & 7 & 6 & 0,09 & 0,96 & 1,24 & 0,22 & 2,43 & 7 & 6 & 0,09 & 0,93 & 1,22 & 0,20 & 2,34 \\
\hline Pouteria venosa & 4 & 3 & 0,52 & 0,55 & 0,62 & 1,20 & 2,38 & 4 & 3 & 0,58 & 0,53 & 0,61 & 1,28 & 2,41 \\
\hline Citronella paniculata & 6 & 5 & 0,20 & 0,83 & 1,04 & 0,45 & 2,31 & 5 & 4 & 0,16 & 0,66 & 0,81 & 0,35 & 1,82 \\
\hline Gomidesia spectabilis & 6 & 6 & 0,10 & 0,83 & 1,24 & 0,23 & 2,30 & 4 & 4 & 0,05 & 0,53 & 0,81 & 0,12 & 1,46 \\
\hline Campomanesia guaviroba & 5 & 5 & 0,24 & 0,69 & 1,04 & 0,56 & 2,28 & 5 & 5 & 0,28 & 0,66 & 1,01 & 0,62 & 2,29 \\
\hline Cupania oblongifolia & 3 & 3 & 0,54 & 0,41 & 0,62 & 1,23 & 2,27 & 3 & 3 & 0,56 & 0,40 & 0,61 & 1,22 & 2,23 \\
\hline Platymiscium floribundum & 4 & 4 & 0,38 & 0,55 & 0,83 & 0,87 & 2,25 & 3 & 3 & 0,13 & 0,40 & 0,61 & 0,29 & 1,30 \\
\hline Coussapoa microcarpa & 5 & 4 & 0,28 & 0,69 & 0,83 & 0,64 & 2,16 & 5 & 4 & 0,36 & 0,66 & 0,81 & 0,80 & 2,27 \\
\hline Rollinia sericea & 5 & 4 & 0,22 & 0,69 & 0,83 & 0,51 & 2,03 & 8 & 5 & 0,29 & 1,06 & 1,01 & 0,64 & 2,72 \\
\hline Eugenia sp3 & 5 & 5 & 0,12 & 0,69 & 1,04 & 0,27 & 2,00 & 5 & 5 & 0,14 & 0,66 & 1,01 & 0,31 & 1,99 \\
\hline Manilkara subsericea & 1 & 1 & 0,72 & 0,14 & 0,21 & 1,65 & 1,99 & 1 & 1 & 0,76 & 0,13 & 0,20 & 1,66 & 2,00 \\
\hline Cabralea canjerana & 3 & 3 & 0,41 & 0,41 & 0,62 & 0,95 & 1,98 & 3 & 3 & 0,45 & 0,40 & 0,61 & 0,99 & 2,00 \\
\hline Neomitranthes glomerata & 5 & 5 & 0,11 & 0,69 & 1,04 & 0,25 & 1,97 & 5 & 5 & 0,12 & 0,66 & 1,01 & 0,25 & 1,93 \\
\hline Eugenia sp4 & 5 & 5 & 0,10 & 0,69 & 1,04 & 0,24 & 1,96 & 4 & 4 & 0,10 & 0,53 & 0,81 & 0,22 & 1,56 \\
\hline Tetrorchidium rubrivenium & 2 & 2 & 0,53 & 0,28 & 0,41 & 1,21 & 1,90 & 2 & 2 & 0,55 & 0,26 & 0,41 & 1,21 & 1,88 \\
\hline Mollinedia schottiana & 5 & 5 & 0,05 & 0,69 & 1,04 & 0,11 & 1,83 & 5 & 5 & 0,05 & 0,66 & 1,01 & 0,11 & 1,79 \\
\hline Symplocos mosenii & 4 & 4 & 0,19 & 0,55 & 0,83 & 0,44 & 1,82 & 4 & 4 & 0,21 & 0,53 & 0,81 & 0,47 & 1,81 \\
\hline Metrodorea nigra & 5 & 4 & 0,13 & 0,69 & 0,83 & 0,30 & 1,81 & 4 & 4 & 0,04 & 0,53 & 0,81 & 0,10 & 1,44 \\
\hline Myrocarpus frondosus & 3 & 3 & 0,25 & 0,41 & 0,62 & 0,57 & 1,61 & 3 & 3 & 0,28 & 0,40 & 0,61 & 0,61 & 1,61 \\
\hline Rapanea guyanensis & 2 & 2 & 0,39 & 0,28 & 0,41 & 0,91 & 1,60 & 2 & 2 & 0,42 & 0,26 & 0,41 & 0,93 & 1,60 \\
\hline Eugenia pruinosa & 4 & 4 & 0,09 & 0,55 & 0,83 & 0,20 & 1,58 & 4 & 4 & 0,10 & 0,53 & 0,81 & 0,21 & 1,55 \\
\hline Myrcia tenuivenosa & 3 & 3 & 0,24 & 0,41 & 0,62 & 0,54 & 1,58 & 3 & 3 & 0,25 & 0,40 & 0,61 & 0,54 & 1,55 \\
\hline Vochysia bifalcata & 1 & 1 & 0,52 & 0,14 & 0,21 & 1,19 & 1,54 & 2 & 2 & 0,56 & 0,26 & 0,41 & 1,22 & 1,89 \\
\hline Eugenia cf glomerata & 4 & 4 & 0,05 & 0,55 & 0,83 & 0,11 & 1,49 & 4 & 4 & 0,06 & 0,53 & 0,81 & 0,12 & 1,46 \\
\hline Eugenia cuprea & 4 & 4 & 0,04 & 0,55 & 0,83 & 0,10 & 1,48 & 4 & 4 & 0,05 & 0,53 & 0,81 & 0,10 & 1,44 \\
\hline Alchornea glandulosa & 2 & 2 & 0,35 & 0,28 & 0,41 & 0,79 & 1,48 & 2 & 2 & 0,35 & 0,26 & 0,41 & 0,76 & 1,43 \\
\hline Meliosma sellowii & 3 & 3 & 0,16 & 0,41 & 0,62 & 0,37 & 1,41 & 4 & 4 & 0,18 & 0,53 & 0,81 & 0,40 & 1,74 \\
\hline
\end{tabular}


Anexo 5: Continuação

\begin{tabular}{|c|c|c|c|c|c|c|c|c|c|c|c|c|c|c|}
\hline \multirow{2}{*}{ Espécies } & \multicolumn{7}{|c|}{ Primeiro Levantamento } & \multicolumn{7}{|c|}{ Segundo Levantamento } \\
\hline & $\mathrm{Ni}$ & No & DoA & DR & FR & DoR & IVI & $\mathbf{N i}$ & No & DoA & DR & FR & DoR & IVI \\
\hline Parinari excelsa & 2 & 2 & 0,31 & 0,28 & 0,41 & 0,72 & 1,41 & 2 & 2 & 0,37 & 0,26 & 0,41 & 0,81 & 1,48 \\
\hline Brosimum guianense & 3 & 3 & 0,14 & 0,41 & 0,62 & 0,32 & 1,36 & 3 & 3 & 0,15 & 0,40 & 0,61 & 0,34 & 1,34 \\
\hline Eugenia oblongata & 4 & 3 & 0,05 & 0,55 & 0,62 & 0,11 & 1,28 & 5 & 4 & 0,06 & 0,66 & 0,81 & 0,14 & 1,61 \\
\hline Acacia polyphylla & 1 & 1 & 0,37 & 0,14 & 0,21 & 0,86 & 1,21 & 1 & 1 & 0,38 & 0,13 & 0,20 & 0,83 & 1,17 \\
\hline Pourouma guianensis & 3 & 3 & 0,07 & 0,41 & 0,62 & 0,16 & 1,19 & 2 & 2 & 0,04 & 0,26 & 0,41 & 0,09 & 0,76 \\
\hline Casearia sylvestris & 2 & 2 & 0,21 & 0,28 & 0,41 & 0,49 & 1,18 & 1 & 1 & 0,12 & 0,13 & 0,20 & 0,26 & 0,59 \\
\hline Psychotria mapoureoides & 3 & 3 & 0,06 & 0,41 & 0,62 & 0,14 & 1,17 & 3 & 3 & 0,07 & 0,40 & 0,61 & 0,15 & 1,15 \\
\hline Guapira opposita & 2 & 2 & 0,21 & 0,28 & 0,41 & 0,48 & 1,17 & - & - & - & - & - & - & - \\
\hline Trichilia lepidota & 2 & 2 & 0,20 & 0,28 & 0,41 & 0,46 & 1,15 & 2 & 2 & 0,22 & 0,26 & 0,41 & 0,47 & 1,14 \\
\hline Cedrela odorata & 1 & 1 & 0,30 & 0,14 & 0,21 & 0,70 & 1,04 & 1 & 1 & 0,40 & 0,13 & 0,20 & 0,88 & 1,22 \\
\hline Nectandra membranacea & 1 & 1 & 0,26 & 0,14 & 0,21 & 0,59 & 0,94 & - & - & - & - & - & - & - \\
\hline Parinari brasiliensis & 2 & 2 & 0,10 & 0,28 & 0,41 & 0,24 & 0,93 & 2 & 2 & 0,11 & 0,26 & 0,41 & 0,24 & 0,91 \\
\hline Machaerium nictitans & 2 & 2 & 0,09 & 0,28 & 0,41 & 0,21 & 0,90 & 1 & 1 & 0,11 & 0,13 & 0,20 & 0,25 & 0,58 \\
\hline Ficus pulchella & 2 & 2 & 0,09 & 0,28 & 0,41 & 0,20 & 0,89 & 2 & 2 & 0,10 & 0,26 & 0,41 & 0,22 & 0,89 \\
\hline Centrolobium robustum & 1 & 1 & 0,24 & 0,14 & 0,21 & 0,54 & 0,89 & 1 & 1 & 0,24 & 0,13 & 0,20 & 0,53 & 0,87 \\
\hline Copaifera trapezifolia & 2 & 2 & 0,07 & 0,28 & 0,41 & 0,15 & 0,84 & 1 & 1 & 0,05 & 0,13 & 0,20 & 0,12 & 0,45 \\
\hline Trichilia silvatica & 2 & 2 & 0,05 & 0,28 & 0,41 & 0,12 & 0,81 & 2 & 2 & 0,05 & 0,26 & 0,41 & 0,12 & 0,79 \\
\hline Myrceugenia miersiana & 2 & 2 & 0,04 & 0,28 & 0,41 & 0,09 & 0,78 & 2 & 2 & 0,04 & 0,26 & 0,41 & 0,09 & 0,76 \\
\hline Pausandra morisiana & 2 & 2 & 0,04 & 0,28 & 0,41 & 0,08 & 0,77 & 2 & 2 & 0,04 & 0,26 & 0,41 & 0,08 & 0,75 \\
\hline Rapanea hermogenesii & 2 & 2 & 0,03 & 0,28 & 0,41 & 0,08 & 0,77 & 2 & 2 & 0,04 & 0,26 & 0,41 & 0,08 & 0,75 \\
\hline Cinnamodendron & 2 & 2 & 0,02 & 0,28 & 0,41 & 0,04 & 0,73 & 3 & 3 & 0,03 & 0,40 & 0,61 & 0,07 & 1,08 \\
\hline Machaerium scleroxylon & 1 & 1 & 0,16 & 0,14 & 0,21 & 0,37 & 0,72 & 1 & 1 & 0,17 & 0,13 & 0,20 & 0,38 & 0,71 \\
\hline Cecropia glazioui & 2 & 1 & 0,05 & 0,28 & 0,21 & 0,12 & 0,61 & 5 & 2 & 0,18 & 0,66 & 0,41 & 0,39 & 1,46 \\
\hline Myrcia richardiana & 2 & 1 & 0,05 & 0,28 & 0,21 & 0,11 & 0,60 & 5 & 4 & 0,09 & 0,66 & 0,81 & 0,20 & 1,67 \\
\hline Quiina glaziovii & 1 & 1 & 0,09 & 0,14 & 0,21 & 0,20 & 0,55 & 1 & 1 & 0,09 & 0,13 & 0,20 & 0,20 & 0,53 \\
\hline Ecclinusa ramiflora & 1 & 1 & 0,08 & 0,14 & 0,21 & 0,19 & 0,53 & 1 & 1 & 0,10 & 0,13 & 0,20 & 0,22 & 0,56 \\
\hline Vantanea compacta & 1 & 1 & 0,08 & 0,14 & 0,21 & 0,18 & 0,53 & 1 & 1 & 0,09 & 0,13 & 0,20 & 0,20 & 0,54 \\
\hline Brosimum glazioui & 1 & 1 & 0,07 & 0,14 & 0,21 & 0,17 & 0,52 & 1 & 1 & 0,04 & 0,13 & 0,20 & 0,09 & 0,42 \\
\hline Barnebya dispar & 1 & 1 & 0,06 & 0,14 & 0,21 & 0,14 & 0,49 & 1 & 1 & 0,06 & 0,13 & 0,20 & 0,14 & 0,48 \\
\hline Alseis floribunda & 1 & 1 & 0,06 & 0,14 & 0,21 & 0,13 & 0,48 & 1 & 1 & 0,06 & 0,13 & 0,20 & 0,13 & 0,46 \\
\hline Eugenia sp2 & 1 & 1 & 0,06 & 0,14 & 0,21 & 0,13 & 0,47 & 1 & 1 & 0,06 & 0,13 & 0,20 & 0,14 & 0,47 \\
\hline
\end{tabular}


Anexo 5: Continuação

\begin{tabular}{|c|c|c|c|c|c|c|c|c|c|c|c|c|c|c|}
\hline \multirow{2}{*}{ Espécies } & \multicolumn{7}{|c|}{ Primeiro Levantamento } & \multicolumn{7}{|c|}{ Segundo Levantamento } \\
\hline & $\mathrm{Ni}$ & No & DoA & DR & $\mathbf{F R}$ & DoR & IVI & $\mathbf{N i}$ & No & DoA & DR & FR & DoR & IVI \\
\hline Gomidesia tijucensis & 1 & 1 & 0,05 & 0,14 & 0,21 & 0,12 & 0,47 & 1 & 1 & 0,06 & 0,13 & 0,20 & 0,13 & 0,46 \\
\hline Heisteria silvianii & 1 & 1 & 0,04 & 0,14 & 0,21 & 0,10 & 0,45 & 1 & 1 & 0,05 & 0,13 & 0,20 & 0,12 & 0,45 \\
\hline Roupala montana & 1 & 1 & 0,04 & 0,14 & 0,21 & 0,10 & 0,44 & 1 & 1 & 0,04 & 0,13 & 0,20 & 0,10 & 0,43 \\
\hline Miconia dodecandra & - & - & - & - & - & - & - & 4 & 2 & 0,05 & 0,53 & 0,41 & 0,10 & 1,04 \\
\hline Ilex dumosa & 1 & 1 & 0,04 & 0,14 & 0,21 & 0,08 & 0,43 & - & - & - & - & - & - & - \\
\hline Sapium glandulatum & 1 & 1 & 0,03 & 0,14 & 0,21 & 0,08 & 0,42 & 1 & 1 & 0,04 & 0,13 & 0,20 & 0,08 & 0,42 \\
\hline Swartzia macrostachya & 1 & 1 & 0,03 & 0,14 & 0,21 & 0,07 & 0,41 & 1 & 1 & 0,03 & 0,13 & 0,20 & 0,07 & 0,40 \\
\hline Virola gardneri & 1 & 1 & 0,02 & 0,14 & 0,21 & 0,05 & 0,39 & 1 & 1 & 0,02 & 0,13 & 0,20 & 0,05 & 0,39 \\
\hline Schizolobium parahyba & - & - & - & - & - & - & - & 1 & 1 & 0,03 & 0,13 & 0,20 & 0,05 & 0,39 \\
\hline Croton macrobothrys & - & - & - & - & - & - & - & 1 & 1 & 0,03 & 0,13 & 0,20 & 0,05 & 0,39 \\
\hline Tabebuia heptaphylla & 1 & 1 & 0,01 & 0,14 & 0,21 & 0,03 & 0,38 & 1 & 1 & 0,01 & 0,13 & 0,20 & 0,03 & 0,37 \\
\hline Nectandra sp & 1 & 1 & 0,01 & 0,14 & 0,21 & 0,03 & 0,38 & 1 & 1 & 0,01 & 0,13 & 0,20 & 0,03 & 0,36 \\
\hline Tabebuia serratifolia & 1 & 1 & 0,01 & 0,14 & 0,21 & 0,03 & 0,37 & 1 & 1 & 0,01 & 0,13 & 0,20 & 0,03 & 0,36 \\
\hline Inga edulis & 1 & 1 & 0,01 & 0,14 & 0,21 & 0,03 & 0,37 & 1 & 1 & 0,01 & 0,13 & 0,20 & 0,03 & 0,36 \\
\hline Coussarea cf ilheotica & 1 & 1 & 0,01 & 0,14 & 0,21 & 0,03 & 0,37 & 1 & 1 & 0,01 & 0,13 & 0,20 & 0,02 & 0,36 \\
\hline Gomidesia flagellaris & 1 & 1 & 0,01 & 0,14 & 0,21 & 0,02 & 0,37 & 1 & 1 & 0,01 & 0,13 & 0,20 & 0,03 & 0,36 \\
\hline Alibertia myrcifolia & 1 & 1 & 0,01 & 0,14 & 0,21 & 0,02 & 0,37 & 1 & 1 & 0,01 & 0,13 & 0,20 & 0,02 & 0,36 \\
\hline Ilex integerrima & 1 & 1 & 0,01 & 0,14 & 0,21 & 0,02 & 0,37 & 1 & 1 & 0,01 & 0,13 & 0,20 & 0,03 & 0,36 \\
\hline Xylopia langsdorffiana & 1 & 1 & 0,01 & 0,14 & 0,21 & 0,02 & 0,37 & 1 & 1 & 0,01 & 0,13 & 0,20 & 0,03 & 0,36 \\
\hline Eugenia sp1 & 1 & 1 & 0,01 & 0,14 & 0,21 & 0,02 & 0,37 & 1 & 1 & 0,01 & 0,13 & 0,20 & 0,02 & 0,36 \\
\hline Dahlstedtia pinnata & 1 & 1 & 0,01 & 0,14 & 0,21 & 0,02 & 0,36 & 1 & 1 & 0,01 & 0,13 & 0,20 & 0,02 & 0,35 \\
\hline Ocotea teleiandra & 1 & 1 & 0,01 & 0,14 & 0,21 & 0,02 & 0,36 & 1 & 1 & 0,01 & 0,13 & 0,20 & 0,02 & 0,36 \\
\hline Ormosia arborea & - & - & - & - & - & - & - & 1 & 1 & 0,01 & 0,13 & 0,20 & 0,02 & 0,35 \\
\hline
\end{tabular}


Anexo 6: Dados sobre crescimento, recrutamento e mortalidade de árvores, obtidos em parcelas permanentes instaladas em Florestas Tropicais. LATI. = latitude Norte ou Sul; LONGI. = longitude Oeste ou Leste; ALTI. = altitude; TMA = temperatura média anual; PPA = precipitação pluviométrica média anual; $\mathrm{DAP}=$ diâmetro do caule a $1,30 \mathrm{~m}$ de altura do solo; ÁREA = tamanho da área estudada; TEMPO = intervalo de tempo entre censos; $\mathrm{N}$ esp. $=$ número de total de espécies amostradas; $T_{C}=$ taxa média anual de crescimento, em $\mathrm{cm} /$ ano; $T_{R}=$ taxa média anual de recrutamento. Os valores das $T_{R}$ estão citados da maneira como os autores publicaram, constando no rodapé da tabela algumas informações pertinentes. $\mathrm{O}$ sinal de $\%$ significa que a $\mathrm{T}_{\mathrm{R}}$ foi calculada pela forma algébrica; $\mathrm{T}_{\mathrm{M}}=$ taxa anual média de mortalidade, em \%/ano.

\begin{tabular}{ccccccccccc}
\hline \hline FONTE & LOCAL & LATI. / LONGI. & $\begin{array}{c}\text { ALTI. } \\
(\mathrm{m})\end{array}$ & $\begin{array}{c}\text { TMA } \\
\left({ }^{\circ} \mathrm{C}\right)\end{array}$ & $\begin{array}{c}\text { PPA } \\
(\mathrm{mm})\end{array}$ & $\begin{array}{c}\text { DAP } \\
(\mathrm{cm})\end{array}$ & $\begin{array}{c}\text { ÁREA } \\
(\mathrm{ha})\end{array}$ & $\begin{array}{c}\text { TEMPO } \\
(\mathrm{anos})\end{array}$ & $\begin{array}{c}\mathrm{N} \text { esp. } \\
(\mathrm{cm} / \mathrm{a})\end{array}$ & $\begin{array}{c}\mathrm{T}_{\mathrm{R}} \\
(\%)\end{array}$ \\
\hline
\end{tabular}

\section{BRASIL}

\begin{tabular}{|c|c|c|c|c|c|c|c|c|c|c|c|c|}
\hline $\begin{array}{l}\text { Melo (sub-bosque, presente } \\
\text { estudo) }\end{array}$ & $\begin{array}{l}\text { Ilha do Cardoso, } \\
\text { São Paulo, Brasil }\end{array}$ & $25^{\circ} 03^{\prime} \mathrm{S}, 47^{\circ} 53^{\prime} \mathrm{W}$ & $\begin{array}{c}100- \\
150\end{array}$ & 21,2 & 1.948 & 2,5 & 0,25 & $\begin{array}{c}1987-95 \\
(6,8)\end{array}$ & 55 & $\begin{array}{c}0,10 \text { e } \\
0,08(\mathrm{~A})\end{array}$ & $\begin{array}{c}2,30 \mathrm{e} \\
1,68 \% \\
(\mathrm{~A})\end{array}$ & $\begin{array}{l}2,38 \text { e } \\
2,08 \\
(\mathrm{~A})\end{array}$ \\
\hline $\begin{array}{l}\text { Melo (componente dominante, } \\
\text { presente estudo) }\end{array}$ & $\begin{array}{l}\text { Ilha do Cardoso, } \\
\text { São Paulo, Brasil }\end{array}$ & 250' $03^{\prime}$, $47^{\circ} 53^{\prime} \mathrm{W}$ & $\begin{array}{c}100- \\
150\end{array}$ & 21,2 & 1.948 & 9,9 & 1 & $\begin{array}{c}1987-95 \\
(6,8)\end{array}$ & 104 & $\begin{array}{c}0,19 e \\
0,23(\mathrm{~A})\end{array}$ & $\begin{array}{c}2,43 \mathrm{e} \\
1,95 \% \\
(\mathrm{~A})\end{array}$ & $\begin{array}{l}2,05 \mathrm{e} \\
1,45 \\
\text { (A) }\end{array}$ \\
\hline Gomes (1998) & $\begin{array}{l}\text { São Paulo, São } \\
\text { Paulo, Brasil }\end{array}$ & $23^{\circ} 40^{\prime} \mathrm{S}, 46^{\circ} 37^{\prime} \mathrm{W}$ & 790 & 19 & 1.477 & 8 & 1 & $\begin{array}{c}1989-95 \\
(5,6)\end{array}$ & 87 & 0,23 & $\begin{array}{l}3,96 \% \\
(B)\end{array}$ & $\begin{array}{l}1,71 \\
(\mathrm{~B})\end{array}$ \\
\hline Oliveira-Filho et al. (1997) & $\begin{array}{l}\text { Lavras, Minas } \\
\text { Gerais, Brasil }\end{array}$ & $21^{\circ} 13^{\prime} \mathrm{S}, 44^{\circ} 57^{\prime} \mathrm{W}$ & $\begin{array}{l}920- \\
935\end{array}$ & 19,4 & $1.529,7$ & 5 & 5,04 & $\begin{array}{l}1987-92 \\
(5)\end{array}$ & 137 & 1,43 & $3,0 \%$ & 2,6 \\
\hline Rolim (1997) & $\begin{array}{c}\text { Linhares, } \\
\text { Espírito Santo, } \\
\text { Brasil }\end{array}$ & $19^{\circ} 06^{\prime} \mathrm{S}, 39^{\circ} 45^{\prime} \mathrm{W}$ & $28-65$ & 23 & 1.230 & 10 & 2,5 & $\begin{array}{l}1980-95 \\
(15)\end{array}$ & 266 & --- & (C) & 1,52 \\
\hline Felfili (1995) & $\begin{array}{c}\text { Rio Gama, } \\
\text { Distrito Federal, } \\
\text { Brasil }\end{array}$ & $15^{\circ} 56^{\prime} \mathrm{S}, 47^{\circ} 55^{\prime} \mathrm{W}$ & 1.100 & 19,5 & 1.600 & 10 & 3,02 & $\begin{array}{l}1985-91 \\
(6)\end{array}$ & 93 & 0,25 & $2,7 \%$ & 3,5 \\
\hline
\end{tabular}




\begin{tabular}{|c|c|c|c|c|c|c|c|c|c|c|c|c|}
\hline FONTE & LOCAL & LATI. / LONGI. & $\begin{array}{l}\text { ALTI. } \\
(\mathrm{m})\end{array}$ & $\begin{array}{l}\text { TMA } \\
\left({ }^{\circ} \mathrm{C}\right)\end{array}$ & $\begin{array}{c}\text { PPA } \\
(\mathrm{mm})\end{array}$ & $\begin{array}{l}\text { DAP } \\
(\mathrm{cm})\end{array}$ & $\begin{array}{l}\text { ÁREA } \\
\text { (ha) }\end{array}$ & $\begin{array}{l}\text { TEMPO } \\
\text { (anos) }\end{array}$ & N esp. & $\begin{array}{c}\mathrm{T}_{\mathrm{c}} \\
(\mathrm{cm} / \mathrm{a})\end{array}$ & $\mathbf{T}_{\mathbf{R}}$ & $\begin{array}{c}T_{M} \\
(\%)\end{array}$ \\
\hline Silva et al. (1995) & $\begin{array}{c}\text { Floresta } \\
\text { Nacional do } \\
\text { Tapajós, Pará, } \\
\text { Brasil }\end{array}$ & $2^{\circ} 45^{\prime} \mathrm{S}, 55^{\circ} 00^{\prime} \mathrm{W}$ & --- & $24-26$ & 1.900 & 5 & 9 & $\begin{array}{l}1981-92 \\
(11)\end{array}$ & 195 & 0,2 & $3,1 \%$ & 2,2 \\
\hline Jardim (1990) & $\begin{array}{c}\text { Distrito } \\
\text { Agropecuário da } \\
\text { SUFRAMA, } \\
\text { Amazonas, Brasil }\end{array}$ & $2^{\circ} 38^{\prime} \mathrm{S}, 60^{\circ} 11^{\prime} \mathrm{W}$ & --- & --- & --- & 25 & 12 & $\begin{array}{c}1980-85 \\
\text { (5) }\end{array}$ & --- & $\begin{array}{l}0,04 \\
\text { (D) }\end{array}$ & --- & (D) \\
\hline $\begin{array}{c}\text { Rankin-de-Merona et al. (1990, } \\
\text { 1992) }\end{array}$ & $\begin{array}{c}\text { Distrito } \\
\text { Agropecuário da } \\
\text { SUFRAMA, } \\
\text { Amazonas, Brasil }\end{array}$ & $2^{\circ} 30^{\prime} S, 60^{\circ} \mathrm{W}$ & $\begin{array}{l}100- \\
150\end{array}$ & 26,7 & $\begin{array}{l}1.900- \\
2.500\end{array}$ & 10 & 5 & $\begin{array}{l}1981-86 \\
(6)\end{array}$ & --- & --- & $(E)$ & $(E)$ \\
\hline Laurance et al. (1998) & $\begin{array}{c}\text { Distrito } \\
\text { Agropecuário da } \\
\text { SUFRAMA, } \\
\text { Amazonas, Brasil }\end{array}$ & $2^{\circ} 30^{\prime} S, 60^{\circ} \mathrm{W}$ & $\begin{array}{c}100- \\
150\end{array}$ & 26,7 & $\begin{array}{l}1.900- \\
2.500\end{array}$ & 10 & 66 & $\begin{array}{l}1980-86 \\
(6)\end{array}$ & 250/ha & --- & --- & $(\mathrm{F})$ \\
\hline \multicolumn{13}{|l|}{ VENEZUELA } \\
\hline Carey et al. (1994) & $\begin{array}{c}\text { Merida, Delta } \\
\text { Amacuro, Bolívar } \\
\text { e Merida, } \\
\text { Venezuela }\end{array}$ & $6,5^{\circ} \mathrm{N}, 71,8^{\circ} \mathrm{W}$ & $\begin{array}{l}180- \\
2.450\end{array}$ & --- & $\begin{array}{c}1.400- \\
3.200\end{array}$ & 10 & 4,25 & $\begin{array}{l}(10-29) \\
(G)\end{array}$ & --- & --- & $(G)$ & $(\mathrm{G})$ \\
\hline Uhl (1982) & $\begin{array}{l}\text { San Carlos de } \\
\text { Río Negro, } \\
\text { Venezuela }\end{array}$ & $1^{\circ}-56^{\prime} \mathrm{N}, 67^{\circ} 03^{\prime} \mathrm{W}$ & 119 & 26 & 3.500 & 10 & 1 & $\begin{array}{l}1975-80 \\
(5)\end{array}$ & ca 80 & $\begin{array}{c}0,04 \mathrm{e} \\
0,13(\mathrm{H})\end{array}$ & $(\mathrm{H})$ & $(\mathrm{H})$ \\
\hline Uhl et al. (1988) & $\begin{array}{l}\text { San Carlos de } \\
\text { Río Negro, } \\
\text { Venezuela }\end{array}$ & $1^{\circ} 56^{\prime} \mathrm{N}, 67^{\circ} 03^{\prime} \mathrm{W}$ & 119 & 26 & 3.500 & 10 & 1 & $\begin{array}{l}1975-86 \\
(10)\end{array}$ & ca 80 & $0,01(\mathrm{I})$ & --- & $1,2(\mathrm{I})$ \\
\hline
\end{tabular}




\begin{tabular}{ccccccccccc}
\hline \hline FONTE & LOCAL & LATI. / LONGI. & $\begin{array}{c}\text { ALTI. } \\
(\mathrm{m})\end{array}$ & $\begin{array}{c}\text { TMA } \\
\left({ }^{\circ} \mathrm{C}\right)\end{array}$ & $\begin{array}{c}\text { PPA } \\
(\mathrm{mm})\end{array}$ & $\begin{array}{c}\text { DAP } \\
(\mathrm{cm})\end{array}$ & $\begin{array}{c}\text { AREA } \\
(\mathrm{ha})\end{array}$ & $\begin{array}{c}\text { TEMPO } \\
(\mathrm{anos})\end{array}$ & $\begin{array}{c}\mathrm{N} \text { esp. } \\
(\mathrm{cm} / \mathrm{a})\end{array}$ & $\begin{array}{c}\mathrm{T}_{\mathrm{R}} \\
(\%)\end{array}$ \\
\hline
\end{tabular}

\section{EQUADOR}

\begin{tabular}{|c|c|c|c|c|c|c|c|c|c|c|c|c|}
\hline Korning \& Balslev (1994a, b) & $\begin{array}{l}\text { Añangu, Equador } \\
\text { Transect } 1\end{array}$ & 0 0 $32 ' S, 76^{\circ} 26^{\prime} \mathrm{W}$ & $\begin{array}{c}250- \\
370\end{array}$ & 25 & 3.244 & 10 & 1,1 & $\begin{array}{c}1982-90 \\
(8,5)\end{array}$ & 22 & $9,3(\mathrm{~J})$ & --- & $\begin{array}{c}1,87 \\
(\mathrm{~J})\end{array}$ \\
\hline Korning \& Balslev (1994a, b) & $\begin{array}{l}\text { Añangu, Equador } \\
\text { Transect } 2\end{array}$ & $0^{\circ} 32 ' S, 76^{\circ} 26^{\prime} \mathrm{W}$ & 250 & 25 & 3.244 & 10 & 1 & $\begin{array}{c}1982-90 \\
(8,5)\end{array}$ & 22 & $23,4(J)$ & --- & $\begin{array}{c}3,01 \\
(\mathrm{~J})\end{array}$ \\
\hline Korning \& Balslev (1994a, b) & $\begin{array}{c}\text { Cuyabeno, } \\
\text { Equador-Plot } 1\end{array}$ & $0^{\circ} 00^{\prime} \mathrm{S}, 76^{\circ} 12^{\prime} \mathrm{W}$ & 265 & 25 & 3.244 & 10 & 1 & $\begin{array}{c}1988-90 \\
(2,5)\end{array}$ & 22 & $13,6(J)$ & $\begin{array}{c}3,09 \\
(\mathrm{~J})\end{array}$ & $\begin{array}{c}1,04 \\
(\mathrm{~J})\end{array}$ \\
\hline Korning \& Balslev (1994a, b) & $\begin{array}{c}\text { Añangu, } \\
\text { Equador-Plot } 2\end{array}$ & $0^{\circ} 32 ' \mathrm{~S}, 76^{\circ} 26^{\prime} \mathrm{W}$ & 370 & 25 & 3.244 & 10 & 1 & $\begin{array}{c}1986-90 \\
(4,9)\end{array}$ & 22 & $9,6(J)$ & $\begin{array}{c}1,78 \\
(\mathrm{~J})\end{array}$ & $\begin{array}{c}1,88 \\
(\mathrm{~J})\end{array}$ \\
\hline
\end{tabular}

\section{PERU}

Gentry \& Terborgh (1990); Phillips Cocha Cashu, \& Gentry (1994); Phillips et al.

$$
\text { (1994) }
$$

Manu River, Peru

$$
\text { - Plot } 1
$$

$11^{\circ} 45^{\prime} \mathrm{S}, 71^{\circ} 30^{\prime} \mathrm{W} \quad 400$

$24 \quad 2.028$

10

0,94

1974-90

$(15,5)$

189

$---\quad 1,81 \%$

2,29

Gentry \& Terborgh (1990); Phillips

Cocha Cashu,

$$
\text { (1994) }
$$

Manu River, Peru

$11^{\circ} 45^{\prime} \mathrm{S}, 71^{\circ} 30^{\prime} \mathrm{W} \quad 400$

24

2.028

10

1974-89

- Plot 2

(15)

200

$\begin{array}{lll}--- & 2,32 \% & 2,79\end{array}$

\section{MÉXICO}

Álvarez-Buyla \& Martínez-Ramos

$$
\text { (1992) }
$$

Los Tuxtlas, Veracruz, México $18^{\circ} 35^{\prime} \mathrm{N}, 95^{\circ} 07^{\prime} \mathrm{W} \quad 150$ -

530
27

4.900

0
1983-84

(1)

1 


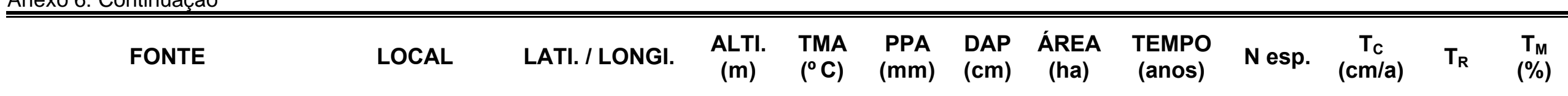

\section{PORTO RICO}

\begin{tabular}{|c|c|c|c|c|c|c|c|c|c|c|c|c|}
\hline Crow \& Weaver (1977) & $\begin{array}{c}\text { Luquillo } \\
\text { Mountains, Porto } \\
\text { Rico - Sabana } 8\end{array}$ & $18^{\circ} \mathrm{N}, 66^{\circ} \mathrm{W}$ & $\begin{array}{c}180- \\
360\end{array}$ & 23 & 2.290 & 1,5 & 8 & $\begin{array}{c}1957-75 \\
(18)\end{array}$ & 18 & 0,39 & --- & --- \\
\hline Crow \& Weaver (1977) & $\begin{array}{c}\text { Luquillo } \\
\text { Mountains, Porto } \\
\text { Rico - Río } \\
\text { Grande }\end{array}$ & $18^{\circ} \mathrm{N}, 66^{\circ} \mathrm{W}$ & $\begin{array}{c}420- \\
600\end{array}$ & 22 & 3.300 & 1,5 & 3,2 & $\begin{array}{c}1957-75 \\
(18)\end{array}$ & 18 & 0,42 & --- & --- \\
\hline Crow \& Weaver (1977) & $\begin{array}{c}\text { Luquillo } \\
\text { Mountains, Porto } \\
\text { Rico - Sabana } 4\end{array}$ & $18^{\circ} \mathrm{N}, 66^{\circ} \mathrm{W}$ & $\begin{array}{c}210- \\
600\end{array}$ & 22 & 3.560 & 1,5 & 3,2 & $\begin{array}{c}1957-75 \\
(18)\end{array}$ & 18 & 0,37 & --- & --- \\
\hline Crow \& Weaver (1977) & $\begin{array}{c}\text { Caribbean } \\
\text { National Forest, } \\
\text { Porto Rico }\end{array}$ & $18^{\circ} 16^{\prime} \mathrm{N}, 65^{\circ} 45^{\prime} \mathrm{W}$ & $\begin{array}{c}300- \\
550\end{array}$ & 19,5 & 2.000 & 9 & 1,6 & $\begin{array}{c}1959-75 \\
(16)\end{array}$ & 9 & 0,37 & --- & --- \\
\hline Crow (1980) & $\begin{array}{l}\text { Luquillo } \\
\text { Mountains, El } \\
\text { Verde, Porto } \\
\text { Rico }\end{array}$ & $18^{\circ} 16^{\prime} \mathrm{N}, 65^{\circ} 45^{\prime} \mathrm{W}$ & 500 & 22,3 & 3.760 & 4 & 0,72 & $\begin{array}{c}1943-76 \\
(33)\end{array}$ & 71 & (M) & --- & --- \\
\hline Parresol (1995) & $\begin{array}{l}\text { Luquillo } \\
\text { Experimental } \\
\text { Forest, Porto } \\
\text { Rico }\end{array}$ & $18 \mathrm{~N}, 66^{\circ} \mathrm{W}$ & $\begin{array}{c}200- \\
640\end{array}$ & \pm 22 & $\begin{array}{c}2.500 \mathrm{a} \\
4.500\end{array}$ & 4 & 0,72 & $\begin{array}{c}1943-82 \\
(39)\end{array}$ & 15 & $(\mathrm{~N})$ & --- & --- \\
\hline
\end{tabular}




\begin{tabular}{|c|c|c|c|c|c|c|c|c|c|c|c|c|}
\hline FONTE & LOCAL & LATI. / LONGI. & $\begin{array}{c}\text { ALTI. } \\
\text { (m) }\end{array}$ & $\begin{array}{l}\text { TMA } \\
\left({ }^{\circ} \mathrm{C}\right)\end{array}$ & $\begin{array}{c}\text { PPA } \\
(\mathrm{mm})\end{array}$ & $\begin{array}{l}\text { DAP } \\
(\mathrm{cm})\end{array}$ & $\begin{array}{c}\text { ÁREA } \\
\text { (ha) }\end{array}$ & $\begin{array}{c}\text { TEMPO } \\
\text { (anos) }\end{array}$ & N esp. & $\begin{array}{c}\mathrm{T}_{\mathrm{c}} \\
(\mathrm{cm} / \mathrm{a})\end{array}$ & $\mathbf{T}_{\mathrm{R}}$ & $\begin{array}{l}T_{M} \\
(\%)\end{array}$ \\
\hline
\end{tabular}

\section{COSTA RICA}

Lieberman et al. (1985b, 1990) Peralta et al. (1987) Lieberman \& Lieberman (1987)

Lieberman et al. (1985b, 1990) Peralta et al. (1987) Lieberman \& Lieberman (1987)

Clark \& Clark (1987)

Clark \& Clark $(1991,1992)$

Clark \& Clark (1996)

\section{PANAMÁ}

Putz \& Milton (1982)

Putz \& Milton (1982)
La Selva, Costa Rica - Plot 1

$10^{\circ} 26^{\prime} \mathrm{N}, 83^{\circ} 59^{\prime} \mathrm{W}$

$34-48$

24

4.000

10

La Selva, Costa Rica - Plot 3

$10^{\circ} 26^{\prime} \mathrm{N}, 83^{\circ} \div 9^{\prime} \mathrm{W}$

33-71

24

4.000

10

$10^{\circ} 26^{\prime} \mathrm{N}, 83^{\circ}{ }^{5} 9^{\prime} \mathrm{W}$

Selva, Costa

Rica

La Selva, Costa Rica

La Selva, Costa Rica $10^{\circ} 26^{\prime} \mathrm{N}, 83^{\circ}{ }^{\circ} 9^{\prime} \mathrm{W}$

$10^{\circ} 26^{\prime} \mathrm{N}, 83^{\circ} \div 9^{\prime} \mathrm{W}$
Barro Colorado, Island, Panamá (floresta jovem)

99N, 795ำ $\mathrm{W}$

150

Barro Colorado, Island, Panamá (floresta madura)
9ㅇำ, 795ำ $\mathrm{W}$

150

27
2.600

60

5

1975-80

(5)

2.600

60
969-82 (13)

$1982-85(2)$

172

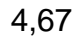

80,7

1,8

1969-82 (13)

1982-85 (2)

165

$4,49 \quad 139,3 \quad 2,2$

1983-85

(2)

1983-89

(6)

1986-93

(7) 


\begin{tabular}{|c|c|c|c|c|c|c|c|c|c|c|c|c|}
\hline FONTE & LOCAL & LATI. / LONGI. & $\begin{array}{l}\text { ALTI. } \\
(\mathrm{m})\end{array}$ & $\begin{array}{l}\text { TMA } \\
\left({ }^{\circ} \mathrm{C}\right)\end{array}$ & $\begin{array}{l}\text { PPA } \\
(\mathrm{mm})\end{array}$ & $\begin{array}{l}\text { DAP } \\
(\mathrm{cm})\end{array}$ & $\begin{array}{c}\text { ÁREA } \\
\text { (ha) }\end{array}$ & $\begin{array}{l}\text { TEMPO } \\
\text { (anos) }\end{array}$ & N esp. & $\begin{array}{c}T_{c} \\
(\mathrm{~cm} / \mathrm{a})\end{array}$ & $\mathbf{T}_{\mathrm{R}}$ & $\begin{array}{l}T_{M} \\
(\%)\end{array}$ \\
\hline Hubbell \& Foster $(1990 a, b)$ & $\begin{array}{l}\text { Barro Colorado } \\
\text { Island, Panamá }\end{array}$ & $9^{\circ} 9^{\prime} \mathrm{N}, 79^{\circ} 51^{\prime} \mathrm{W}$ & 150 & 27 & 2.600 & $>1 \leq 3,9$ & 50 & $\begin{array}{l}1982-85 \\
(3)\end{array}$ & 306 & $(\mathrm{~V})$ & $(\mathrm{V})$ & $(\mathrm{V})$ \\
\hline Condit et al. (1993) & $\begin{array}{l}\text { Barro Colorado, } \\
\text { Island, Panamá }\end{array}$ & $9^{\circ} 9^{\prime} \mathrm{N}, 79^{\circ} 51^{\prime} \mathrm{W}$ & 150 & 27 & 2.600 & 1 & 50 & $\begin{array}{l}1982-85(3) \\
1985-90(5)\end{array}$ & $1(\mathrm{~W})$ & $\begin{array}{c}2,96 \mathrm{e} \\
1,99\end{array}$ & $\begin{array}{l}0,47 \mathrm{e} \\
0,23 \%\end{array}$ & $\begin{array}{c}0,45 \mathrm{e} \\
0,57\end{array}$ \\
\hline Condit et al. (1992b) & $\begin{array}{l}\text { Barro Colorado, } \\
\text { Island, Panamá }\end{array}$ & $9^{\circ} 9^{\prime} \mathrm{N}, 79^{\circ} 51^{\prime} \mathrm{W}$ & 150 & 27 & 2.600 & 30 & 50 & $\begin{array}{l}1982-85(3) \\
1985-90(5)\end{array}$ & $\begin{array}{l}300,303 \\
\text { e } 300(X)\end{array}$ & --- & $\begin{array}{l}3,6 \mathrm{e} \\
2,1 \%\end{array}$ & $\begin{array}{c}3,3 \mathrm{e} \\
2,5\end{array}$ \\
\hline Milton et al. (1994) & $\begin{array}{l}\text { Barro Colorado, } \\
\text { Island, Panamá }\end{array}$ & $9^{\circ} 9^{\prime} \mathrm{N}, 79^{\circ} 51^{\prime} \mathrm{W}$ & 150 & 27 & 2.600 & $\geq 19,1$ & 3 & $\begin{array}{l}1975-80(5) \\
1980-88(8)\end{array}$ & 20 & $\begin{array}{c}2,01 \\
(Y)\end{array}$ & $(\mathrm{Y})$ & $\begin{array}{c}2,24 \\
(\mathrm{Y})\end{array}$ \\
\hline Gilbert et al. (1994) & $\begin{array}{l}\text { Barro Colorado, } \\
\text { Island, Panamá }\end{array}$ & $9^{\circ} 9^{\prime} \mathrm{N}, 79^{\circ} 51^{\prime} \mathrm{W}$ & 150 & 27 & 2.600 & 1 & 20 & $\begin{array}{l}1982-85(3) \\
1985-90(5)\end{array}$ & 1 & --- & $(\mathrm{Z})$ & $(\mathrm{Z})$ \\
\hline Condit et al. (1995) & $\begin{array}{l}\text { Barro Colorado, } \\
\text { Island, Panamá }\end{array}$ & $9^{\circ} 9^{\prime} \mathrm{N}, 79^{\circ} 51^{\prime} \mathrm{W}$ & 150 & 27 & 2.600 & 1 & 50 & $\begin{array}{l}1982-85(3) \\
1985-90(5)\end{array}$ & 205 & --- & --- & (Aa) \\
\hline
\end{tabular}

\section{ÁFRICA}

\begin{tabular}{|c|c|c|c|c|c|c|c|c|c|c|c|c|}
\hline Swaine et al. (1987) & $\begin{array}{l}\text { Kade, Ghana, } \\
\text { África - Plot } 1\end{array}$ & $6^{\circ} 09^{\prime} \mathrm{N}, 0^{\circ} 55^{\prime} \mathrm{W}$ & 137 & 26 & 1.640 & 10 & 1 & $\begin{array}{c}1968-82 \\
(14)\end{array}$ & $\begin{array}{c}86 \\
(1982)\end{array}$ & --- & (Bb) & 1,44 \\
\hline Swaine et al. (1987) & $\begin{array}{l}\text { Kade, Ghana, } \\
\text { África - Plot } 2\end{array}$ & $6^{\circ} 09^{\prime} \mathrm{N}, 0^{\circ} 55^{\prime} \mathrm{W}$ & 137 & 26 & 1.640 & 10 & 1 & $\begin{array}{c}1968-82 \\
(14)\end{array}$ & $\begin{array}{c}92 \\
(1982)\end{array}$ & --- & (Bb) & 2,1 \\
\hline Swaine et al. (1990) & $\begin{array}{l}\text { Shai Hills, } \\
\text { Ghana, África }\end{array}$ & $6 \circ \mathrm{N}, 0^{\circ} \mathrm{W}$ & 745 & $25-28$ & 290 & 3,2 & 0,28 & $\begin{array}{c}1979-87 \\
(8)\end{array}$ & --- & $\begin{array}{c}0,06- \\
0,16\end{array}$ & $1,5 \%$ & $2,3 \%$ \\
\hline
\end{tabular}


Okali \& Ola-Adams (1987)

Omo Forest

Reserve, Nigéria,

África

$6^{\circ} 35^{\prime} \mathrm{N}, 4^{\circ} 19^{\prime} \mathrm{E}$

150

$25,8 \quad 1.577$

10

0,75

1953-81

(28)

53

0,27

Anexo 6: Continuação

\begin{tabular}{|c|c|c|c|c|c|c|c|c|c|c|c|c|}
\hline FONTE & LOCAL & LATI. / LONGI. & $\begin{array}{c}\text { ALTI. } \\
\text { (m) }\end{array}$ & $\begin{array}{l}\text { TMA } \\
\left({ }^{\circ} \mathrm{C}\right)\end{array}$ & $\begin{array}{c}\text { PPA } \\
(\mathrm{mm})\end{array}$ & $\begin{array}{l}\text { DAP } \\
(\mathrm{cm})\end{array}$ & $\begin{array}{c}\text { ÁREA } \\
\text { (ha) }\end{array}$ & $\begin{array}{c}\text { TEMPO } \\
\text { (anos) }\end{array}$ & N esp. & $\begin{array}{c}\mathrm{T}_{\mathrm{c}} \\
(\mathrm{cm} / \mathrm{a})\end{array}$ & $\mathbf{T}_{\mathrm{R}}$ & $\begin{array}{c}T_{M} \\
(\%)\end{array}$ \\
\hline
\end{tabular}

\section{MALÁSIA}

Manokaran \& Kochummen (1987)
Manokaran \& Kochummen (1994)
LaFrankie (1994)

Nicholson (1965) apud Ho et al. (1987)

Wyatt-Smith (1966) apud Ho et al. (1987); Whitmore (1984)

Sungei Menyala, Malásia

Sungei Menyala Bukit Lagong e Pasoh, Malásia

Pasoh Forest Reserve, Malásia

Sepilok Forest

Reserve, Sabah, Malásia

Sungei Menyala, Península da Malásia

Sarawak, Costa Noroeste da Ilha de Bornéo, Leste da Malásia

\begin{tabular}{|c|c|c|c|c|c|c|}
\hline $2^{\circ} 28^{\prime} \mathrm{N}, 101^{\circ} 55^{\prime} \mathrm{E}$ & 30 & 28 & 2.376 & 10 & 2 & $\begin{array}{l}1947-57(10,3) \\
1971-81(10,4)\end{array}$ \\
\hline $2^{\circ} 28^{\prime} \mathrm{N}, 101^{\circ} 55^{\prime} \mathrm{E}$ & 30 & 28 & 2.376 & 10 & $\begin{array}{l}2 \\
2 \\
8\end{array}$ & $\begin{array}{l}1947-85(38) \\
1949-85(36) \\
1971-84(13)\end{array}$ \\
\hline
\end{tabular}

(Cc) $\begin{array}{r}1,78 \\ 2,16\end{array}$

$2^{\circ} 59^{\prime} \mathrm{N}$

2ำ, $115^{\circ} \mathrm{E}$

$2^{\circ} \mathrm{N}, 115^{\circ} \mathrm{E}$

---

$2^{\circ} \mathrm{N}, 115^{\circ} \mathrm{E}$

Primack et al. (1985) 
Bako, Lambir

Hills e Bukit

Mersing - Brunei,

Sarawak,

2N, $115^{\circ} \mathrm{E}$

$1-900$

$--$

9,7

7,8

(20)

$---$

(Ff)

(Gg)

(Hh)

Anexo 6: Continuação

\begin{tabular}{|c|c|c|c|c|c|c|c|c|c|c|c|c|}
\hline FONTE & LOCAL & LATI. / LONGI. & $\begin{array}{l}\text { ALTI. } \\
(\mathrm{m})\end{array}$ & $\begin{array}{l}\text { TMA } \\
\left({ }^{\circ} \mathrm{C}\right)\end{array}$ & $\begin{array}{c}\text { PPA } \\
(\mathrm{mm})\end{array}$ & $\begin{array}{l}\text { DAP } \\
(\mathrm{cm})\end{array}$ & $\begin{array}{c}\text { ÁREA } \\
\text { (ha) }\end{array}$ & $\begin{array}{c}\text { TEMPO } \\
\text { (anos) }\end{array}$ & N esp. & $\begin{array}{c}\mathrm{T}_{\mathrm{c}} \\
(\mathrm{cm} / \mathrm{a})\end{array}$ & $\mathbf{T}_{\mathrm{R}}$ & $\begin{array}{c}T_{M} \\
(\%)\end{array}$ \\
\hline
\end{tabular}

ÍNDIA

Sukumar et al. (1992)

Elouard et al. (1997)

Elouard et al. (1997)
Mudulamai Game Reserva,

Tamil Nadu, Índia

Western Ghats,

$$
\text { Dodagu, }
$$

Karnataka, Índia

- once-logged A

Western Ghats,

$$
\text { Dodagu, }
$$

Karnataka, Índia

$12^{\circ} 30^{\prime} \mathrm{N}, 75^{\circ} 39^{\prime} \mathrm{E}$

- unlogged B $11^{\circ} 35^{\prime} \mathrm{N}, 76^{\circ} 32^{\prime} \mathrm{E}$

1.250

1.800

1

50

1988-89(1)

1989-90(1)

71

$---$

$--$

(li)

$12^{\circ} 30^{\prime} \mathrm{N}, 75^{\circ} 39^{\prime} \mathrm{E}$

400

27

5.200

10

0,6

1986-93

(7)

$400-$

600

27

5.200

10

3,12

1990-93

(3)

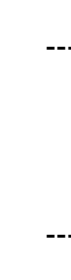

0,86

(Jj)

10,5

5,0

GUIANA FRANCESA

van der Meer \& Bongers (1996)

Nouragues,

Guiana Francesa $4^{\circ}{ }^{\circ} 05^{\prime} \mathrm{N}, 52^{\circ} 40^{\prime} \mathrm{W}$
90 -

110 $\quad 3.000$

10

12

1992-93

(1)

\section{AUSTRÁLIA}


(A) Incluindo todas as espécies e excluindo as espécies de Palmae, respectivamente. $T_{R}$ e $T_{M}$ calculadas pela forma algébrica.

(B) Excluindo as espécies de Palmae. $T_{R}$ e $T_{M}$ calculadas pela forma algébrica.

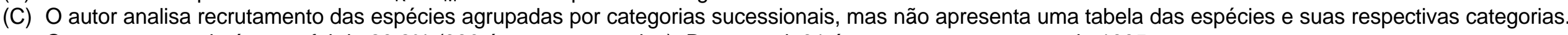
O recrutamento de árvores foi de 29,2\% (380 árvores recrutadas). Deste total, 31 árvores morreram antes de 1995.

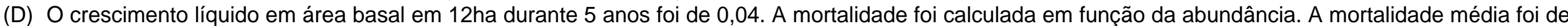
2,4 indivíduos por hectare por ano, representando uma redução de área basal de $1,6686 \mathrm{~m}^{2} /$ ha, o que foi compensado por um incremento periódico de $1,6719 \mathrm{~m}^{2} / \mathrm{ha}$.

(E) Mortalidade: 7,04 árvores mortas/ha/ano ou 1,13\% por ano das árvores inventariadas, inicialmente, nos 5 hectares. Recrutamento: 5,52 árvores recrutadas/ha/ano.

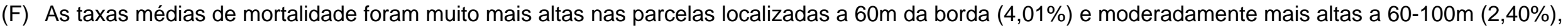
do que nas do interior da floresta $(1,27 \%)$.

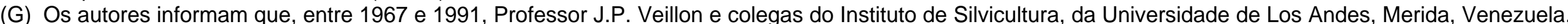
estabeleceram mais de 50 parcelas permanentes ao longo de várias zonas de vida florestal da Venezuela. Os autores usaram 17 destas parcelas, de 0,25 ha (50 x 50m) de área, localizadas em duas zonas de vida da Venezuela, daí a variação de longitude, latitude, precipitação e intervalo de tempo entre os censos. A taxa de mortalidade baseada na densidade das árvores variou entre 0,5 a 3,3\% entre as parcelas estudadas e a taxa baseada na biomassa variou de 0,1 a $3,9 \%$.

(H) Comunicação pessoal de Jordan \& Murphy (1982) in Uhl, C. (1982) sobre Crescimento médio anual em DAP: 0,038cm para árvores com DAP 1-5cm e 0,13 para DAP $\geq 10 \mathrm{~cm}$. Mortalidade, segundo Uhl (1982): 7,8 árvores/ha/ano com DAP $\geq 10 \mathrm{~cm}$. Recrutamento, segundo Uhl (1982): compensou a mortalidade - 154 árvores com DAP $<1 \mathrm{~cm}$ foram recrutados para a classe de $1-5 \mathrm{~cm}$ DAP (143 desta classe de DAP, morreram); 17 árvores foram recrutadas para a classe de $\geq$ $20 \mathrm{~cm}$ DAP (29 árvores da classe de 10-20cm DAP, morreram).

(I) Mortalidade média anual (modelo logarítmico) e crescimento médio para árvores com DAP $\geq 10 \mathrm{~cm}$, num intervalo de tempo de 2 anos.

(J) Valores das taxas de crescimento e mortalidade foram calculadas para as 22 espécies com 12 ou mais indivíduos sobreviventes. Crescimento foi calculado para área basal, portanto leia-se em $\mathrm{cm}^{2}$. Korning \& Balslev (1994a) apresentam a taxa média de crescimento igual a 2,7mm/ano.

(K) Valor máximo para os estádios juvenis (DAP 0,3-4cm) e pré-reprodutivos (DAP 4,1-10cm) de Cecropia obtusifolia. A taxa média de crescimento anual diminuiu a menos de 1,0cm/ano, com o aumento dos diâmetros do estádio maduro (DAP 10,1-50cm).

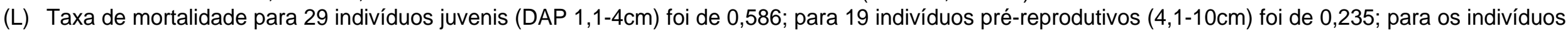
maduros a maior taxa 0,200 , foi registrada na classe DAP $40,1-50 \mathrm{~cm}$.

(M) Área basal no período de 1943-51 aumentou em média 1,18m²/ano e de 1951-76 aumentou somente $0,04 \mathrm{~m}^{2} / \mathrm{ano}$.

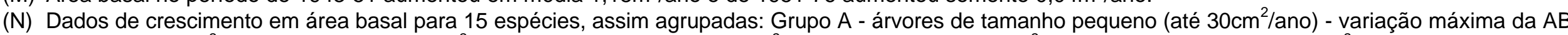
foi de 14 a $31 \mathrm{~cm}^{2} /$ ano; B - médio (até $40 \mathrm{~m}^{2} / \mathrm{ano}$ ) - AB variou de 16 a $42 \mathrm{~cm}^{2} / \mathrm{ano}$; C - grande (até $80 \mathrm{~m}^{2} / \mathrm{ano}$ ) - $\mathrm{AB}$ variou de 29 a $87 \mathrm{~cm}^{2} / \mathrm{ano}$; D - muito grande (até $\left.120 \mathrm{~m}^{2} / \mathrm{ano}\right)$ - $\mathrm{AB}$ variou de 37 a $122 \mathrm{~cm}^{2} / \mathrm{ano}$

(O) Incremento da área basal em $\mathrm{m}^{2} /$ ha (1969-82).

(P) Taxa de recrutamento expressa em termos de densidade de árvores, para o período de 1969 a 1982. 
(Q As 173 árvores, com 2-30cm de DAP sobreviveram do primeiro para o segundo inventário.

(R) As 6 espécies mostraram taxas médias de crescimento anual entre 2,5 a 6,3mm, na faixa de diâmetros entre $>10-30 \mathrm{~cm}$.

(S) Taxa de mortalidade para as 6 espécies combinadas foi altamente baixa. A taxa de mortalidade foi baixa (0,12\%) na classe de $10-30 \mathrm{~cm}$ DAP

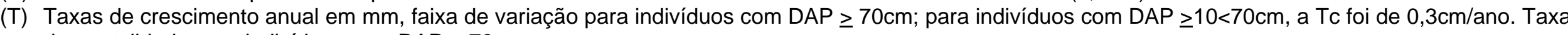
de mortalidade para indivíduos com DAP $\geq 70 \mathrm{~cm}$.

(U) Taxa de crescimento calculada para árvores com 30-50 cm de diâmetro. Recrutamento: o equivalente a $9 \%$ do tamanho da população inicial. Mortalidade: $20 \%$ do total de 934 árvores, presentes em 1968, morreram.

(V) Espécies do dossel, com DAP $>1<3,9 \mathrm{~cm}$, crescendo sob árvores $>20 \mathrm{~cm}$ DAP, da mesma espécie $(0,065 \mathrm{~cm} /$ ano $)$ e de espécies diferentes $(0,085 \mathrm{~cm} /$ ano). Do total de 242.218 árvores com $D A P \geq 1 \mathrm{~cm}, 8,78 \%$ morreram (20.705 árvores) e 14,04\% foram recrutadas (22.126 árvores).

(W) Prioria copaifera (Leguminosae - Caesalpinioideae).

(X) Das 301, 303 e 300 espécies, amostradas em 1982, 85 e 90, calcularam as taxas de recrutamento e mortalidade para árvores com DAP $\geq 30$ cm.

(Y) Demografia de Ocotea whitei (Lauraceae). No período de 1982-85, morreram 227 de um total de 843 vivas e foram recrutadas 77 árvores. No período de 1985-90, morreram 195 de um total de 693 e foram recrutadas 51 árvores. No período de 190-91, morreram 107 do total de 549 árvores vivas e não houve registro de árvores recrutadas.

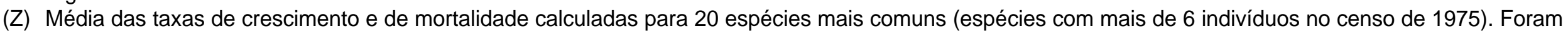
recrutadas 46 árvores no período; no mesmo período 123, das 519 iniciais, morreram.

(Aa) Taxa de mortalidade para 194 espécies para a classe de tamanho DAP>1<10cm - 2,66\% (1982-85) e 2,26\% (1985-90); 128 espécies para a classe DAP $\geq 10 \mathrm{~cm}-2,75 \%(1982-85)$ e 1,98\% (1985-90). Espécies amostradas com $\geq 20$ árvores na parcela de $50 \mathrm{ha}$ em 1982 e 1985.

(Bb) Taxa de recrutamento, calculada por Gomes (1998), pela forma algébrica: Plot 1=1,59\% e Plot $2=1,92 \%$.

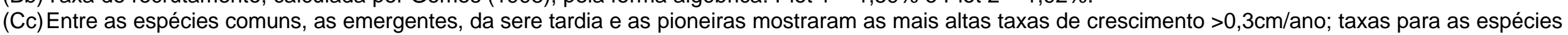
do dossel principal foram entre $0,15-0,25 \mathrm{~cm} / a n o ;$ espécies do sub-bosque foram $<0,2 \mathrm{~cm} /$ ano. O recrutamento foi registrado para dois períodos, com base no número de árvores registradas por ano - Período de 1947-63 (16,4 anos) = 11,8 árvores/ano. Período de 1971-81 (10,4 anos) = 20,9 árvores/ano.

(Dd)O crescimento foi lento nas árvores com $\geq 10 \mathrm{~cm}$ de DAP, enumeradas nas parcelas de Sungei Menyala (2ha) e Bukit Lagong (2ha), com 64\% das árvores crescendo a taxas em torno de $0,1 \mathrm{~cm} / \mathrm{ano}$. Nas parcelas de Pasoh (8ha), somente para árvores com DAP iniciais $\leq 20 \mathrm{~cm}$ com taxa de crescimento alta, $0,7 \mathrm{~cm} / \mathrm{ano}$ ou mais.

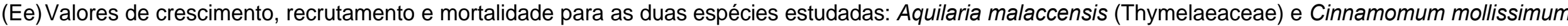
(Lauraceae).

(Ff) Crescimento médio para as 15 espécies mais abundantes: Bako - 0,04 - 0,47cm/ano; Lambir Hills - 0,12 - 0,21cm/ano; Bukit Mersing - 0,20 - 0,40cm/ano.

(Gg) Recrutamento nos três locais: Bako - 1,10\%; Bukit Mersing - 1,77\% e Lambir Hills - 1,00\%.

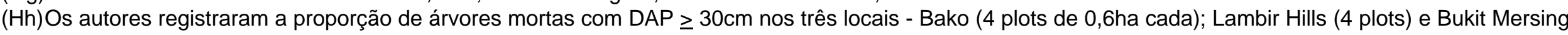
(5 plots). A proporção foi comparada usando análise log-linear.

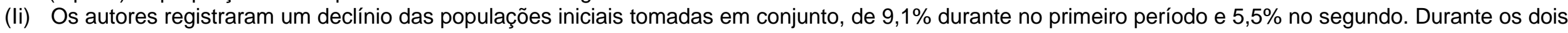
anos a população inicial mostrou uma redução total de $14 \%$.

(Jj) Mortalidade e recrutamento foram calculados pelo número de árvores / hectare / ano. O crescimento foi calculado para área basal ( $\mathrm{m}^{2}$ ).

(Kk) Das 6.314 árvores presentes no início do estudo, 1,5\% caíram e 1,3\% perderam o tronco principal. Houve uma perda de 4,9\% da área basal inicial.

(LI) A mortalidade e o recrutamento são apresentados pelo número total de indivíduos. Os autores apresentam número de mortos ou recrutados por classes de tamanho de DAP (30-40cm a 110-120cm). Das 112 árvores amostradas em 1982, 19 morreram. Em 1992 foram registradas 11 recrutadas. 


\section{TÍTULO: Demografia de árvores em Floresta Pluvial Tropical Atlântica, Ilha do Cardoso, SP, Brasil.}

AUTOR: Maria Margarida da Rocha Fiuza de Melo

ERRATA

\begin{tabular}{|c|c|c|c|c|}
\hline Página & Parágrafo & Linha & Onde se lê: & Leia-se: \\
\hline 23 & $2^{\circ}$ & 10 & São Paulo, Brasil. & São Paulo, Brasil (Anexo 3) \\
\hline 40 & $3^{\circ}$ & 6 & $\begin{array}{l}\text { As numerosas espécies amostradas } \\
\text { com } 1 \text { e } 2 \text { indivíduos contribuíram } \\
\text { de maneira decisiva para todos os } \\
\text { valores acima. }\end{array}$ & $\begin{array}{l}\text { A presença de espécies representadas } \\
\text { na área com muitos indivíduos } \\
\text { contribuiu para esta ocorrência. }\end{array}$ \\
\hline 44 & 4 & 3 & $\begin{array}{l}\text { bosque, com um aumento do } \\
\text { número de indivíduos }\end{array}$ & $\begin{array}{l}\text { bosque, com uma diminuição do } \\
\text { número de indivíduos }\end{array}$ \\
\hline 44 & 4 & 5 & $\begin{array}{l}\text { bosque, porém com uma } \\
\text { diminuição }\end{array}$ & $\begin{array}{l}\text { bosque, também com uma } \\
\text { diminuição }\end{array}$ \\
\hline 91 & 1 & 3 & $\begin{array}{l}\text { e Gomes (1998), e distinto daquele } \\
\text { encontrado por Felfili (1995). }\end{array}$ & e Gomes (1998). \\
\hline 96 & $1^{\mathrm{o}}$ & 3 & $\begin{array}{l}\text { floresta estudado não se encontra } \\
\text { em estado de equilíbrio. }\end{array}$ & $\begin{array}{l}\text { floresta estudado se encontra em } \\
\text { estado de eqüilíbrio dinâmico. }\end{array}$ \\
\hline 100 & 4 & 8 & $\begin{array}{l}\text { floresta estudado encontra-se em } \\
\text { equilíbrio instável, }\end{array}$ & $\begin{array}{l}\text { floresta estudado se encontra em } \\
\text { eqüilíbrio dinâmico, }\end{array}$ \\
\hline 121 & $\begin{array}{l}\text { Único da } \\
\text { legenda }\end{array}$ & 2 & $\begin{array}{l}\text { original das } 40 \text { unidades amostrais } \\
\text { x classes de diâmetro das árvores } \\
\text { das espécies amostradas no sub- } \\
\text { bosque }\end{array}$ & $\begin{array}{l}\text { original das classes de diâmetro das } \\
\text { árvores x número de indivíduos das } \\
\text { espécies abundantes amostradas no } \\
\text { sub-bosque }\end{array}$ \\
\hline 122 & $\begin{array}{l}\text { Único da } \\
\text { legenda }\end{array}$ & 2 & $\begin{array}{l}\text { original das } 40 \text { unidades amostrais } \\
\text { x classes de diâmetro das árvores } \\
\text { das espécies amostradas no } \\
\text { componente dominante }\end{array}$ & $\begin{array}{l}\text { original das classes de diâmetro das } \\
\text { árvores x número de indivíduos das } \\
\text { espécies abundantes amostradas no } \\
\text { componente dominante }\end{array}$ \\
\hline $\begin{array}{l}123, \\
124, \\
126, \\
131 \mathrm{e} \\
132\end{array}$ & $\begin{array}{l}\text { Únicos da } \\
\text { legenda }\end{array}$ & 1 & $\begin{array}{l}\text { Distribuição de freqüência das } \\
\text { classes }\end{array}$ & Distribuição das classes \\
\hline 128 & $\begin{array}{l}\text { Único da } \\
\text { legenda }\end{array}$ & 1 & $\begin{array}{l}\text { Distribuição de frequiência das } \\
\text { classes de diâmetro por taxas de } \\
\text { crescimento absolutas das espécies }\end{array}$ & $\begin{array}{l}\text { Distribuição das taxas de } \\
\text { crescimento absolutas pelas classes } \\
\text { de diâmetro das árvores das espécies }\end{array}$ \\
\hline $\begin{array}{l}139 \text { e } \\
142\end{array}$ & $\begin{array}{l}\text { Único do } \\
\text { cabeçalho }\end{array}$ & 3 & DoA = dominância absoluta; & DoA = dominância absoluta ( $\left.\mathrm{m}^{2} / \mathrm{ha}\right)$; \\
\hline
\end{tabular}

